\title{
BUILDING PEOPLE UP: LEADERSHIP AND EMPLOYEE RESILIENCE
}

\author{
by \\ Esmé Huia Franken
}

\begin{abstract}
A THESIS
SUBMITTED TO THE VICTORIA UNIVERSITY OF WELLINGTON IN FULFILMENT OF THE REQUIREMENTS FOR THE DEGREE OF DOCTOR OF PHILOSOPHY
\end{abstract}

Victoria University Of Wellington

2019 



\begin{abstract}
This mixed method research, in the area of HR and leadership, explores leadership behaviours that foster employee resilience. Resilience is a key capacity in contexts where job demands and challenges are often dynamic and complex, such as in the public sector. This research uses a contemporary definition of resilience, one that views employee resilience as a set of behaviours that help people grow and develop in their jobs, even in the face of challenges. Two questions guide this research: 1. What leadership behaviours enable employee resilience in the public sector?, and 2. How do these behaviours enable employee resilience? This study is situated in the public sector context.

The research consists of five phases. The first phase was a cross-sectional survey of public servants' views on whether paradoxical leadership behaviours, mediated by perceptions of organisational support, might foster resilience. These connections reflect the correspondence between paradoxical leadership and the dilemmas and paradoxes that arise in public sector work. Phases two and three concerned a series of qualitative studies which identified further leadership behaviours, as well as possible mechanisms and outcomes, and generated an explanatory framework to illustrate how managers can enable employee resilience. This led to the development of the construct resilience-enabling leadership. Phase four gathered feedback on the construct's validity so that it could be tested quantitatively in a scale. The fifth and final phase tested the resilience-enabling leadership scale (RELS) as a predictor of resilience. It also tested psychometric properties of the scale, including factor structure, and discriminant and convergent validity.

Findings show that a unique combination of leadership behaviours that foster growth, trust and collaboration in employees, is likely to play a pivotal role in developing employee resilience. The RELS is an innovative contribution to organisational scholarship. It represents a leadership model that recognises the changing nature of leadership and responds to the development needs of employees.
\end{abstract}




\section{ACKNOWLEDGEMENTS}

I have many people to thank for their help, guidance, and support throughout the course of this research.

First, I would like to thank my supervisors, Dr Geoff Plimmer, A/Prof Sanna Malinen and A/Prof Jane Bryson. You have all provided me with tremendous support.

Geoff, thank you for encouraging me to make the most out of this experience and always pushing me to extend myself. I would not have achieved so much in my $\mathrm{PhD}$ experience without your confidence in my abilities. Your feedback has greatly enhanced my thinking, writing, and confidence.

Sanna, thank you for your dedicated involvement in my research from day one. The statistics were made possible with your consistent patience and help. You always encouraged more rigour and pushed me to further clarify my ideas.

Thank you also to my third supervisor, Jane. You've given me great oversight and useful perspectives I would not have otherwise considered.

I want to thank my family, and in particular my mother, Margaret, for supporting me unconditionally on this journey. You have shaped me academically and I would not have achieved this without you. John, Jacob, Leo, Lucy, and Archie, thank you for being there too.

My friends have also been amazing. Maddy, Kate, Lauren, Tommy and Nigel, I am very grateful for your ongoing support, advice, and staying power. Rebecca Downes, you have been the best office mate I could ask for - you have offered many great pieces of advice and I will miss our daily conversations. Megan Key, your guidance and organisation has not gone unnoticed either - thank you very much.

I would finally like to thank Alison Furniss, my previous manager, who not only introduced me to HR, but also helped me understand the value of effort and persistence. You believed in my ability to do a good job, and you trusted and supported me. I think this has contributed to my own resilience. Thank you. 


\section{CONTENTS}

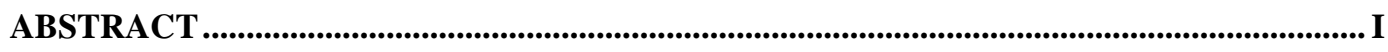

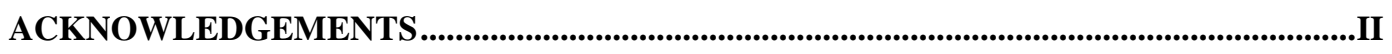

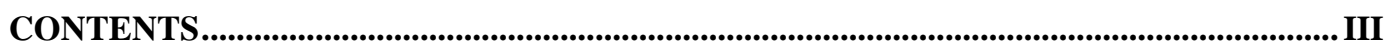

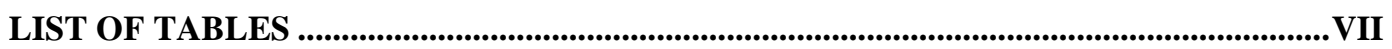

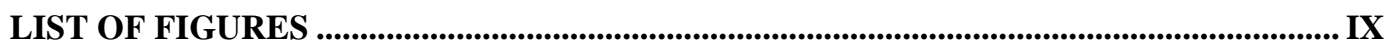

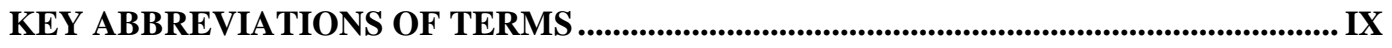

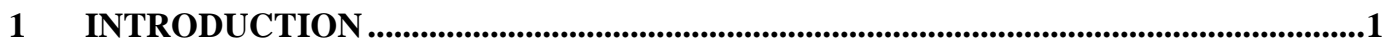

1.1 RESILIENCE, LEADERSHIP, AND THIS RESEARCH ….................................................

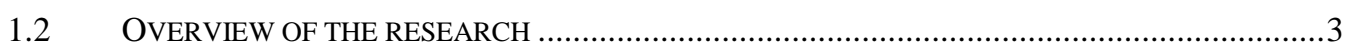

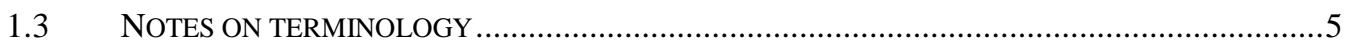

1.4 DEVELOPED OUTPUTS OF THIS RESEARCH...................................................................

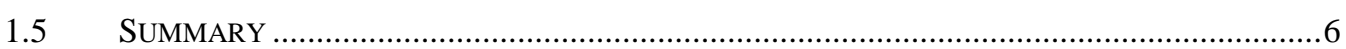

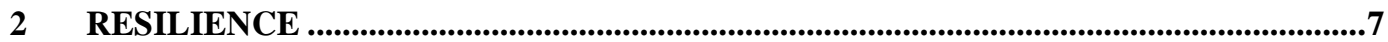

2.1 RESILIENCE AND ITS CONCEPTUAL ORIGINS ...........................................................

2.2 RESILIENCE AS A DEVELOPABLE CAPACITY ............................................................ 10

2.3 RESILIENCE AS A MULTI-LEVELLED CONSTRUCT ........................................................13

2.4 A CONTEXTUAL VIEW OF RESILIENCE ........................................................................ 16

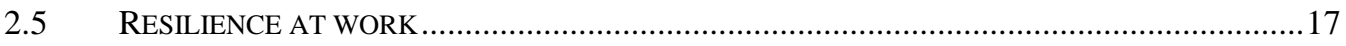

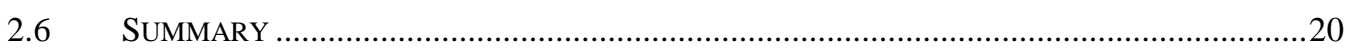

3 THE PUBLIC SECTOR CONTEXT AND LEADERSHIP .........................................21

P.1 PUBLIC SECTOR DEMANDS ON RESILIENCE.............................................................21

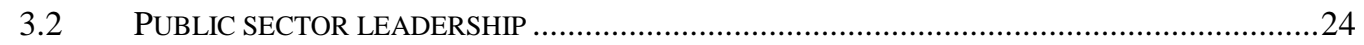

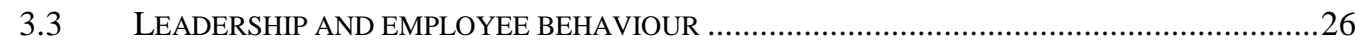

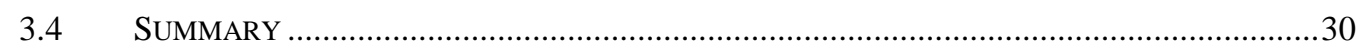

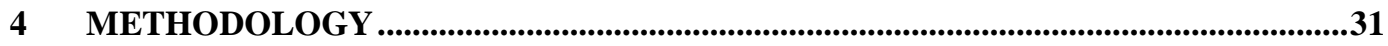

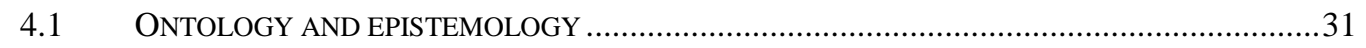

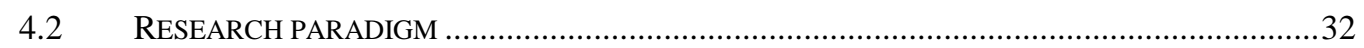

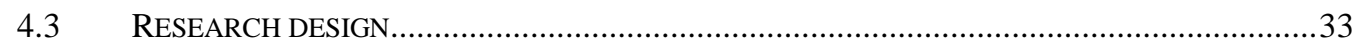

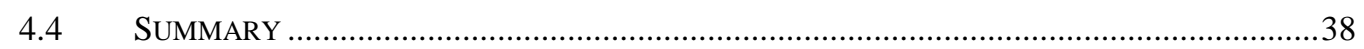

5 PARADOXICAL LEADERSHIP, PERCEIVED ORGANISATIONAL SUPPORT,

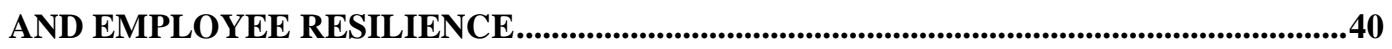

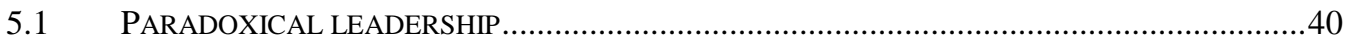


6 PHASE 1: SURVEY ON PARADOXICAL LEADERSHIP AND EMPLOYEE

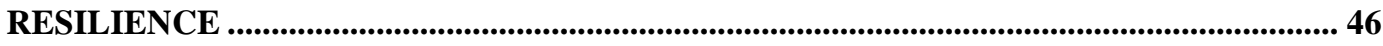

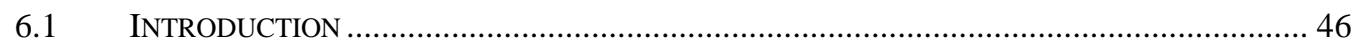

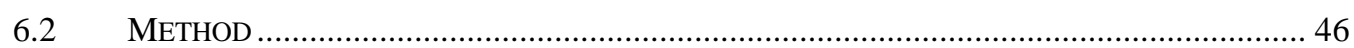

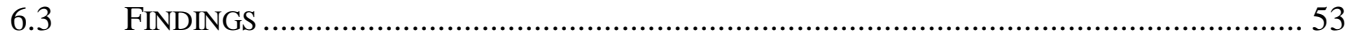

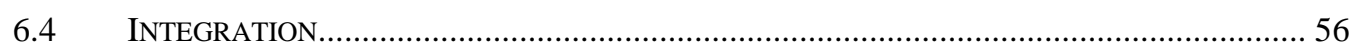

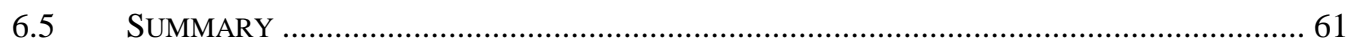

7 PHASE 2 - IDENTIFYING LEADERSHIP BEHAVIOURS......................................... 62

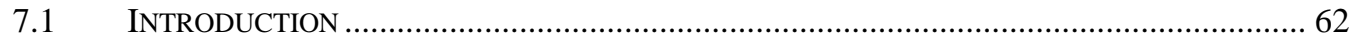

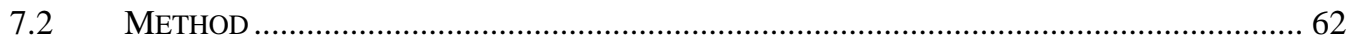

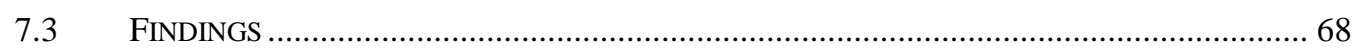

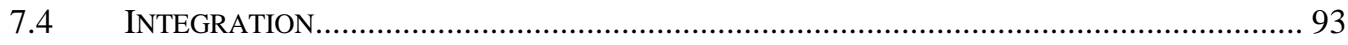

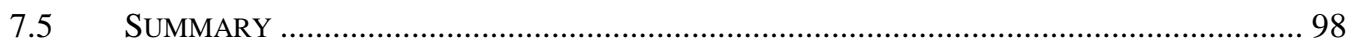

8 PHASE 3 - EXPLAINING LEADERSHIP BEHAVIOURS .................................... 100

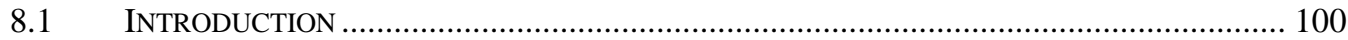

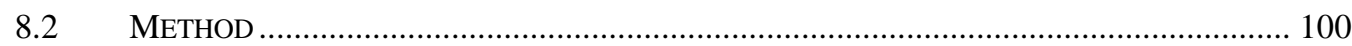

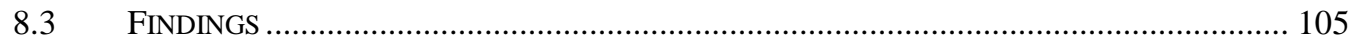

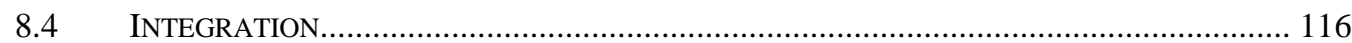

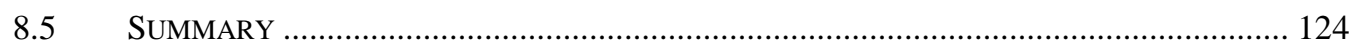

9 PHASE 4 - SCALE DEVELOPMENT AND CONTENT VALIDITY ........................ 125

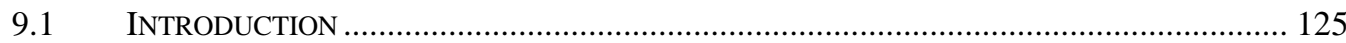

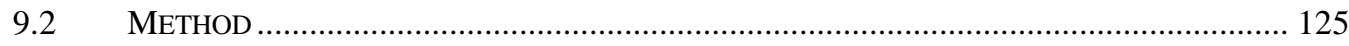

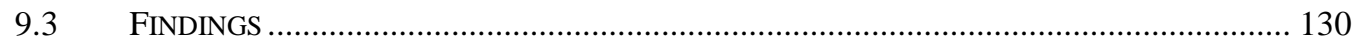

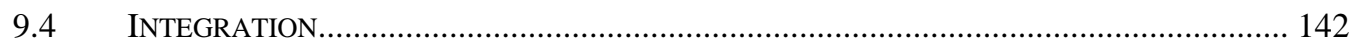

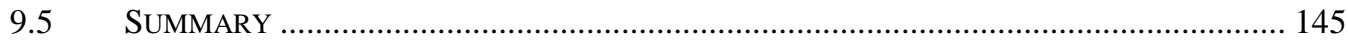

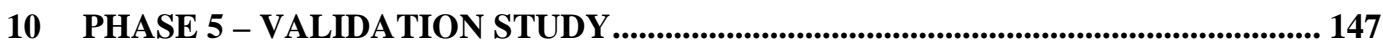

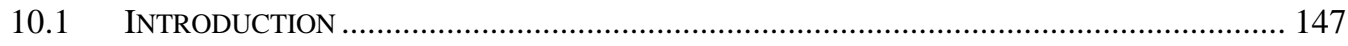

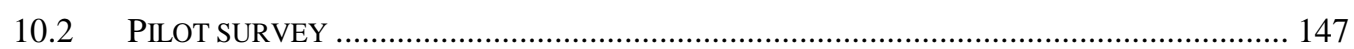

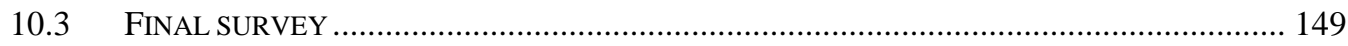

10.4 THE RESILIENCE-ENABLING LEADERSHIP SCALE ....................................................... 156

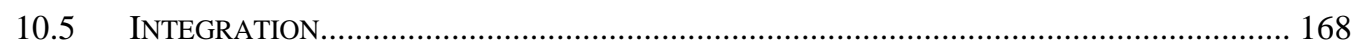

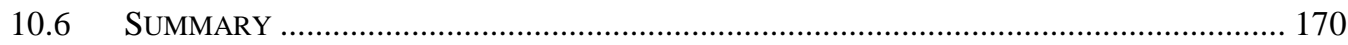

11 GENERAL DISCUSSION AND CONCLUSIONS .................................................... 171

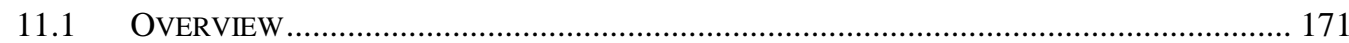

11.2 CONCEPTUAL AND THEORETICAL CONTRIBUTIONS …................................................ 172 
11.3 THE RELEVANCE OF MIXED-METHOD, MULTI-PHASE RESEARCH …..............................185

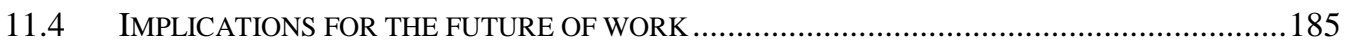

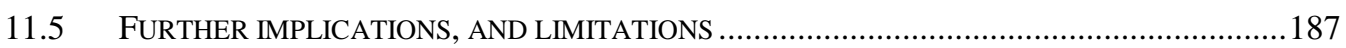

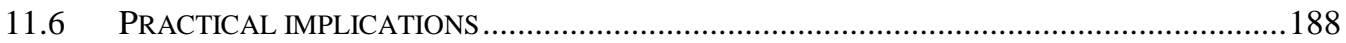

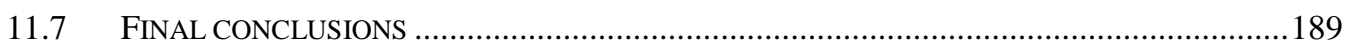

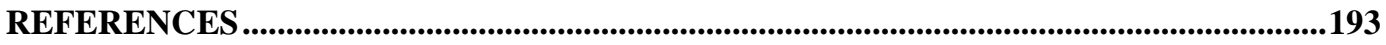

APPENDIX A: FIELDS, LEVELS, AND DEFINITIONS OF RESILIENCE........................2227

APPENDIX B: ETHICS DOCUMENTS (PHASES 1, 2 \& 3) ................................................2230

APPENDIX C: FACTOR LOADINGS FOR PARADOXICAL LEADERSHIP ...................235

APPENDIX D: INTERVIEW GUIDES (PHASES 2 \& 3) ...................................................2236

APPENDIX E: ETHICS DOCUMENTS (PHASE 4) ............................................................238

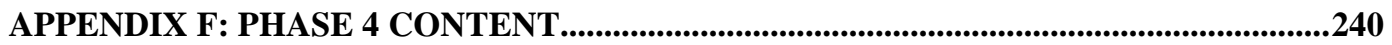

APPENDIX G:ETHICS DOCUMENTS AND CONTENT (PHASE 5) ..............................245

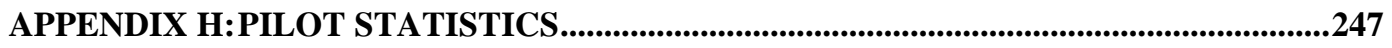

APPENDIX I: MODIFICATION INDICES, CFA MODEL COMPARISON ......................248 



\section{LIST OF TABLES}

TABLE 1: FIELDS, LEVELS, AND DEFINITIONS OF RESILIENCE ................................................... 14

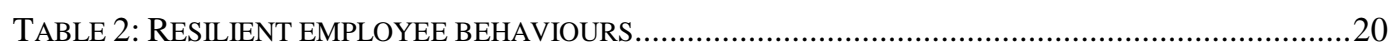

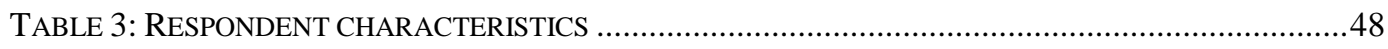

TABLE 4: DESCRIPTIVE STATISTICS OF PHASE 1 STUDY VARIABLES ................................................54

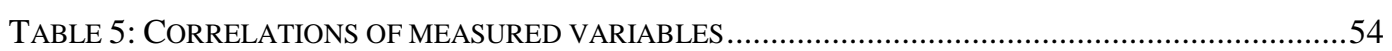

TABLE 6: TOTAL, DIRECT AND INDIRECT EFFECTS ON EMPLOYEE RESILIENCE, MEDIATED BY

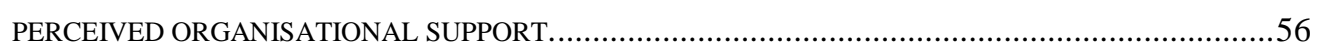

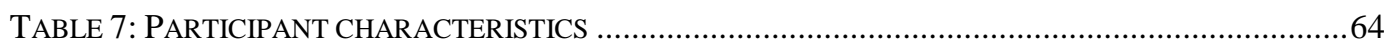

TABLE 8: CODING FRAME FOR THE PUBLIC SECTOR CONTEXT …...............................................71

TABLE 9: INITIAL CATEGORIES OF LEADER BEHAVIOURS WITH EXAMPLES......................................78

TABLE 10: RESILIENT BEHAVIOURS AND CATEGORIES IDENTIFIED THROUGH ANALYSIS ..................80

TABLE 11: CODING FRAME FOR RESILIENCE-ENABLING LEADERSHIP .............................................81

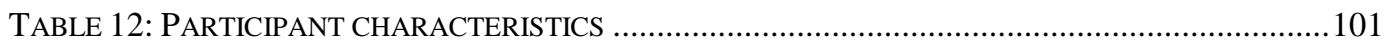

TABLE 13: DISTRIBUTION OF ANSWERS TO PRIMARY QUESTION....................................................103

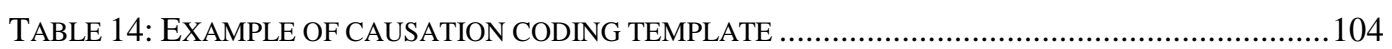

TABLE 15: RESILIENCE-ENABLING LEADERSHIP MODEL FOR VALIDITY TESTING............................122

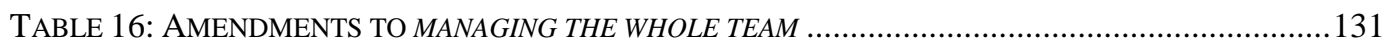

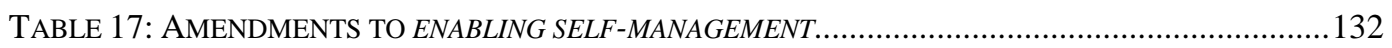

TABLE 18: AMENDMENTS TO SUPPORTING PERSONAL GROWTH AND WELLBEING ..........................134

TABLE 19: AMENDMENTS TO RECOGNISING INDIVIDUAL NEEDS AND CONTRIBUTIONS .......................135

TABLE 20: CHANGES TO SCALE POST-FOCUS GROUPS AND INTERVIEWS. ......................................136

TABLE 21: GLOBAL COMMENTARY ON RESILIENCE ENABLING LEADERSHIP ................................137

TABLE 22: LOCAL COMMENTARY ON RESILIENCE ENABLING LEADERSHIP ...................................140

TABLE 23: REVISED RELS FOR QUANTITATIVE TESTING ….......................................................143

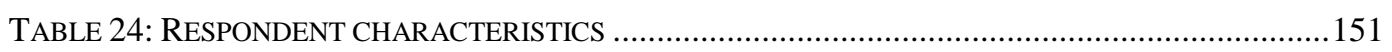

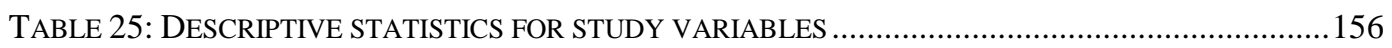

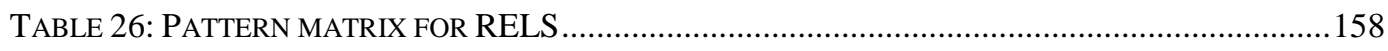

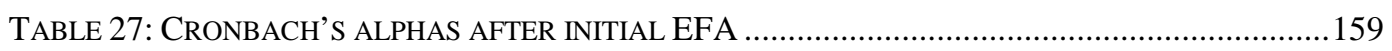

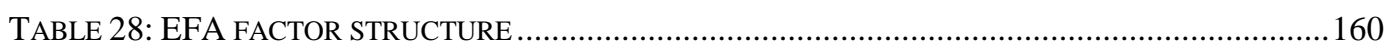

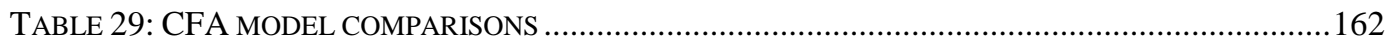

TABLE 30: REGRESSION TABLE FOR CONTROLS, LMX, AND RESILIENCE-ENABLING LEADERSHIP..167

TABLE 31: KEY STEPS IN THE DEVELOPMENT OF THE RELS ......................................................169

TABLE 32: FINAL SCALE FOR MEASURING RESILIENCE-ENABLING LEADERSHIP ...........................190

TABLE A: FIELDS, LEVELS, AND DEFINITIONS OF RESILIENCE ...................................................22

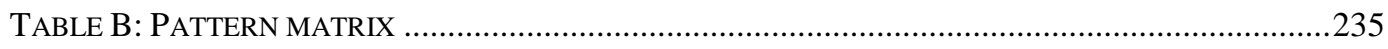

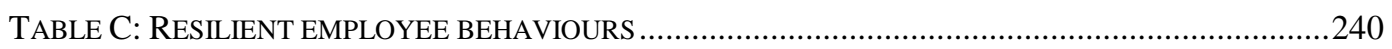


TABLE D: RESILIENCE-ENABLING SUPERVISORY BEHAVIOURS IDENTIFIED THROUGH INITIAL SURVEY

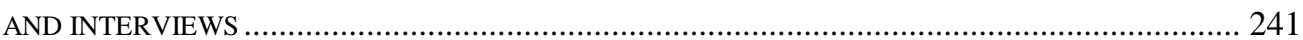

TABLE E: DESCRIPTIVE STATISTICS FOR RESILIENCE-ENABLING LEADERSHIP ............................... 247

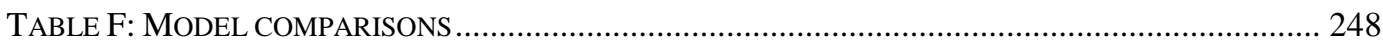




\title{
LIST OF FIGURES
}

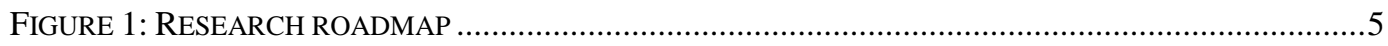

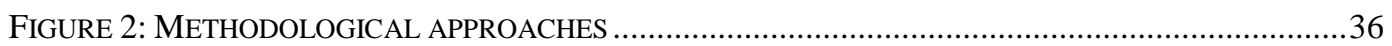

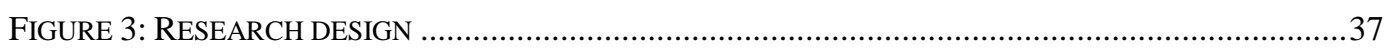

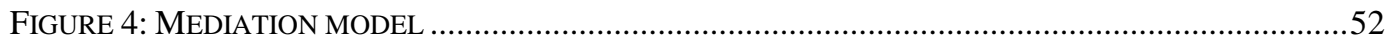

FIGURE 5: THE RESILIENCE-ENABLING LEADERSHIP EXPLANATORY FRAMEWORK........................120

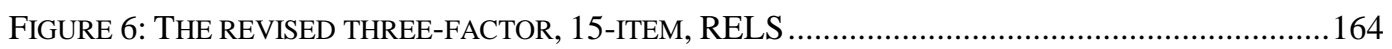

FIGURE 7: RESPONDENT EXPERIENCES OF RESILIENCE-ENABLING LEADERSHIP ............................184

\section{KEY ABBREVIATIONS OF TERMS}

\author{
AMOS Analysis of Moment Structures \\ CFA Confirmatory factor analysis \\ CMB Common-method bias \\ EFA Exploratory factor analysis \\ LMX Leader-member exchange \\ NZ New Zealand \\ POS Perceived organisational support \\ RELS Resilience enabling leadership scale \\ SPSS Statistical Package for Social Sciences \\ SSC State Services Commission
}





\section{INTRODUCTION}

Developing human capabilities has economic, social and psychological benefits for individuals, organisations, and societies (Denhardt, Denhardt, \& Aristigueta, 2012; Hitt, Bierman, Shimizu, \& Kochhar, 2001). Resilience is the capacity of individuals to "utilise resources to continually adapt and flourish..., even when faced with challenging circumstances” (Kuntz et al., 2016, p. 460). This capacity brings about effectiveness at multiple levels - for individuals, groups, organisations and systems (Kozlowski \& Klein, 2000). It enables people, organisations, and systems to engage in ongoing learning and development in order to improve their responses to challenging stimuli. At all these levels, resilience is about adapting, learning, and growing in the face of complexity and change (Lengnick-Hall, Beck, \& Lengnick-Hall, 2011; Ungar, 2012). In organisations, managers play a primary role in shaping and developing resilience in employees.

This research is a mixed method investigation of employee resilience and its development by managers. It expands understandings surrounding the construct of employee resilience - an important capacity for individuals and organisations - by identifying leadership behaviours which enable it. The research focuses on the leadership behaviours that line managers engage in on a daily basis. In short, resilience-enabling leadership is set of line manager behaviours that work to enable the resilient employee behaviours of network leveraging, learning, and adaptability in employees.

\subsection{Resilience, leadership, and this research}

Resilience itself is dynamic. It changes in response to environments, and people can get better at it (Luthans, 2002a). There are particular capabilities that can be developed to allow individuals and systems to use change to improve and thrive in new environments (Hodliffe, 2014). For organisations wanting to be resilient, having resilient employees is a building block in their readiness and ability to adapt during times of change and uncertainty.

Leaders within organisations can enable and develop resilience in employees, and the collective actions of resilient employees can help organisations be more resilient (Horne \& Orr, 1997; Lengnick-Hall et al., 2011). Resilient performance is characterised by the effective use of collective resources that enable employees and organisations to not only cope under, but thrive, following setbacks or periods of adversity (Lengnick-Hall et al., 2011). Although all organisations require resilience, these requirements are likely to be 
unique to particular industries, sectors, and individual businesses. In other words, resilience, and the need for it, is situational and shaped by the context, rather than trait-like. Inquiry into what enables resilience in different contexts is necessary if we are to enhance our understandings of this important phenomenon.

This research is situated in the New Zealand public sector context. It focuses on employee resilience, a behavioural capacity comprised of network leveraging, learning and adaptability (Kuntz, Malinen, \& Näswall, 2017). Resilient behaviours are likely to help knowledge workers, including public servants, deal effectively with the demanding, complex and often contradictory realities of their working environments. There are many tensions needing to be balanced or resolved in such a context. For example, the shift from centralised decision authority by default to more inter-agency, networked collaboration and governance increases engagement with different actors, while contributing to enhanced unpredictability and complexity (Christensen, 2014; Denhardt \& Denhardt, 2007). Contemporary and dynamic demands are placed on public agencies by citizens, as well as other organisations and institutions. This requires organisations and their employees to be adaptive, responsive, and adept at problem solving. The layering of institutional logics from multiple public sector reforms over the past century have also led to diverse, and often contradictory forms of pursuing public value. Such values have been described as "numerous, often contested, and indeed . . . in conflict or even contradictory” (Bryson, Crosby, \& Bloomberg, 2015, p. 14). Public organisations clearly exist in dynamic, often contradictory, environments that demand flexible and mindful responses to constant challenge and shock (Lewis, Andriopoulos, \& Smith, 2014).

To be resilient, employees need a supportive environment to engage in resilient behaviours (Näswall, Kuntz, Hodliffe, \& Malinen, 2015). The development of employee resilience comes from engaging with enabling personal, social and contextual resources. In the workplace, support for resilience may be found in enabling cultures and climates (Khan et al., 2017; Lengnick-Hall et al., 2011), but managers are particularly salient supporters of resilience at a relational level (Nguyen, Kuntz, Näswall, \& Malinen, 2016; Valero, Jung, \& Andrew, 2015). As key organisational agents (Tepper \& Taylor, 2003), their leadership can both help and harm resilience in employees.

The public sector context calls for effective, resilience-enabling leadership and a consideration of what makes a resilient workforce, since both are necessary in building adaptive organisations that can effectively integrate tensions and solve contemporary problems (Howell \& Avolio, 1993; Lengnick-Hall et al., 2011). How line managers in public organisations can enable employee resilience is not yet known. The aim of this 
research is to better understand how employee resilience is enabled, and then developed, through the leadership behaviours of public sector managers. The following research questions guide this research:

1. What leadership behaviours enable employee resilience in the public sector?

2. How do these behaviours enable employee resilience?

\subsection{Overview of the research}

This mixed methods study seeks to identify leadership behaviours that enable resilience, and to explore the mechanisms through which they do so. The identification process involves deductive quantitative testing of theorised resilience-enabling leadership behaviours. Qualitative inquiry then works to expand and enrich understandings of the nature of these behaviours and also identifies new ones. The study also draws on qualitative research to investigate the explanatory mechanisms through which the identified leadership behaviours impact employee resilience (Saldaña, 2015). A framework of new resilienceenabling leadership behaviours is then tested in a final quantitative survey. This study reflects a multi-phase integrated research design, whereby both quantitative and qualitative phases are integrated at different stages throughout the research process to reflect on new findings to meaningfully inform subsequent phases. The phases of this study are described in more detail below.

This research is informed by pragmatism, a philosophy that sees ideas as dependent on humans and their interactions with the environment (Menand, 2001). Our ideas are "provisional responses to particular and unreproducible circumstances" and "their survival depends not on their immutability but on their adaptability” (Menand, 2001, p. xii). Ways of building understanding must be shaped by, and adaptable to, what it is we seek to know about the world. In other words, our methods should be 'fit for purpose' (Rescher, 1977). This research uses mixed methods because they serve both the what and the how of the research questions. Combined, they offer an adaptive, unique, and holistic perspective for understanding human behaviours, such as resilience, and their mechanisms (Dixon-Woods et al., 2014). Pragmatism also corresponds to research aimed at addressing real world problems and adapting to new information as it emerges (Bazeley, 2018; Bogard \& Wertz, 2006).

\subsubsection{Research phases}

Phase 1 consisted of a quantitative survey administered in a large public sector organisation in New Zealand. This phase sought to test the relationships between paradoxical leadership 
behaviours and employee resilience. Paradoxical leadership was included here because it reflects many paradoxes present in public administration, such as those between accountability and flexibility, and consistency and the recognition of individuality (Lipsky, 2010; Wällstedt \& Almqvist, 2015). The behavioural dimensions of paradoxical leadership include "combining self- and other-centeredness, allowing uniformity and individualisation, maintaining distance and closeness, enforcing work requirements while allowing flexibility, and maintaining decision control while allowing autonomy” (Zhang, Waldman, Han, \& Li, 2015, p. 538). Results showed, in general, that the relationships between paradoxical leadership behaviours and employee resilience were mediated by perceptions of organisational support. However, this deductive model did not sufficiently explain the wider phenomenon of resilience-enabling leadership. As will be discussed, it also did not adequately suit the New Zealand public sector context. Thus, further qualitative inquiry was used to refine, modify, and explain this concept of resilience-enabling leadership so that it could be more accurately applied and tested.

Phase 2 involved 10 interviews with both employees and managers from the same public sector organisation. The purpose was to further explore the nature of resilience-enabling leadership behaviours in the public sector context. Informed by both Phase 1 findings and emergent responses from Phase 2 participants, a set of resilience-enabling leadership behaviours were identified. These behaviours consisted of leading for: collaboration, selfmanagement, career and growth, learning, support, and individual differences. Aspects of these behaviours showed correspondence to paradoxical leadership (Zhang et al., 2015) but also extended beyond this concept in various ways. These findings prompted further exploration of the mechanisms behind these behaviours, and in what ways they appeared to impact resilient employee behaviours. Resilience-harming behaviours also emerged in the interviews, and are presented as well. Findings related to the nature of resilience, and aspects of the public sector context, are also presented.

In Phase 3, 10 more interviews were carried out, with employees only. This phase sought to gain further insight into the identified leadership behaviours from the point of view of employees. Perceptions regarding how they experienced such behaviours, if they did indeed experience them, were of particular interest, as well as perceptions of the outcomes these behaviours had on their own resilience. An outcome of this phase was an explanatory framework of resilience-enabling leadership.

Phase 4 was comprised of two focus groups and six individual interviews $(n=13)$ with population experts and consultations with content experts $(n=4)$. Its primary aim was to confirm, modify, and validate the explanatory framework for scale development. Content 
experts were consulted on the clarity, readability and relevance of the items in the explanatory framework. This phase resulted in a four-dimensional scale for measuring resilience-enabling leadership.

The final phase of this study - Phase 5 - consisted of a quantitative survey $(n=893)$ to test the reliability and validity of the resilience-enabling leadership scale (RELS). Exploratory and confirmatory factor analyses were conducted, resulting in a reliable three-dimensions, 15-item, model measuring resilience-enabling leadership. Resilience-enabling leadership was also found to predict employee resilience, after control variables and the comparative predictor, leader-member exchange (LMX), were accounted for.

The research roadmap on the following page outlines all five phases and what they each broadly entailed.

\begin{tabular}{|c|c|c|c|c|}
\hline Phase 1 & Phase 2 & Phase 3 & Phase 4 & Phase 5 \\
\hline $\begin{array}{l}\text { Initial } \\
\text { Survey } \\
\text { Quant } \\
(n=222)\end{array}$ & $\begin{array}{l}\text { Interviews } \\
\text { Qual } \\
(\mathrm{n}=10)\end{array}$ & $\begin{array}{l}\text { Interviews } \\
\text { Qual } \\
(\mathrm{n}=10)\end{array}$ & $\begin{array}{l}\text { Focus groups, } \\
\text { interviews, } \\
\text { consultations } \\
\text { Qual } \\
(\mathrm{n}=13)\end{array}$ & $\begin{array}{l}\text { Final } \\
\text { survey } \\
\text { Quant } \\
(n=893)\end{array}$ \\
\hline $\begin{array}{l}\text { Mediation } \\
\text { analysis } \\
\text { uncovering the } \\
\text { relationship } \\
\text { between } \\
\text { paradoxical } \\
\text { leadership, } \\
\text { perceived } \\
\text { organisational } \\
\text { support, and } \\
\text { employee } \\
\text { resilience }\end{array}$ & $\begin{array}{l}\text { Exploratory } \\
\text { study identifying } \\
\text { six key } \\
\text { behavioural } \\
\text { dimensions of } \\
\text { resilience- } \\
\text { enabling } \\
\text { leadership }\end{array}$ & $\begin{array}{l}\text { Identifying } \\
\text { and } \\
\text { understanding } \\
\text { the } \\
\text { mechanisms } \\
\text { and outcomes } \\
\text { underlying } \\
\text { resilience- } \\
\text { enabling } \\
\text { leadership }\end{array}$ & $\begin{array}{l}\text { Gathering expert } \\
\text { feedback to } \\
\text { inform the } \\
\text { development of } \\
\text { scale for } \\
\text { measuring } \\
\text { resilience- } \\
\text { enabling } \\
\text { leadership }\end{array}$ & $\begin{array}{l}\text { Reliability } \\
\text { and validity } \\
\text { testing of the } \\
\text { RELS }\end{array}$ \\
\hline
\end{tabular}

Note: Quant = Quantitative study; Qual = Qualitative study

\section{Figure 1: Research roadmap}

\subsection{Notes on terminology}

\subsubsection{Leader and manager}

This research uses the terms leader and manager interchangeably because leadership can, and should, be an important aspect of managerial work (Yukl, 1989). Consistent with this view, the study focuses on the leadership behaviours of public managers. 


\subsubsection{Follower, subordinate, and employee}

The related terms of follower and subordinate, are also used interchangeably (as in Mittal \& Elias, 2016). However, the more clearly defined term of employee (Andersen, 2014) is preferred when referring to individuals in relation to their leaders/managers, and is thus used most often.

\subsection{Developed outputs of this research}

Parts of this research have been developed into published articles. Theory and results pertaining to Phase 1 have been published in Australian Journal of Public Administration (Franken, Plimmer \& Malinen, 2019). Findings on resilience-harming leadership have been expanded and further developed in a special issue for International Journal of Public Leadership (Franken \& Plimmer, 2019).

\subsection{Summary}

This chapter has introduced the concept of resilience, and the need for it in organisations. It has also given an overview of the research. The next three chapters present relevant literature on resilience, the public sector context, and leadership. Following this is a methodology chapter, which presents the philosophical assumptions and design of the research. The methods and findings for each phase are then presented according to the roadmap above. After each phase, there is a brief discussion, or integration, section to reflect on findings and discuss how they might influence the subsequent phases. This research will conclude with a general discussion of the study as a whole. 


\section{RESILIENCE}

This chapter reviews the concept of resilience. It covers its traditional underpinnings, its related concepts, and its relevance to organisational, and public sector, contexts.

\subsection{Resilience and its conceptual origins}

Resilience is a well-established and widely recognised concept across contexts and disciplines (Beltman, Mansfield, \& Harris, 2015; H. B. Kaplan, 2005; Luthans, 2002b; Masten et al., 1988). It is generally understood as "patterns of positive adaptation during or following significant adversity or risk” (Masten, Cutuli, Herbers, \& Reed, 2009, p. 118). Although there is agreement on the general idea of resilience, definitions have become more complex and less reductionist over time. For instance, the early psychology studies by Block (1950; 1951) define resilience as a rare personality trait, consisting of naturally low levels of anxiety, and the ability to adapt to situational contingencies. Such people effectively control impulses, and have the "psychological viability" for resilience (Block \& Kremen, 1996, p. 50). Some more recent scholarship mirrors this, positing that resilient individuals share three key characteristics: "an acceptance of reality, a strong belief that life is meaningful, and the ability to improvise” (Bhamra, Dani, \& Burnard, 2011, p. 5379). Resilience has been studied in many ways, at many levels. Fields in which resilience has been studied substantially include psychology, biology, ecology, sociology (Bowes \& Jaffee, 2013; Bronfenbrenner, 2005; Holling, 1973), and, as in this research, organisational studies (Kachali et al., 2012; Lengnick-Hall et al., 2011). Resilience also exists at different levels, ranging from micro-organisms to ecological systems (Adger, 2000; Allison \& Martiny, 2008). It sits next to a number of similar constructs, and has a complicated aetiology.

\subsubsection{Related constructs}

There are several related, but distinct, constructs that exist alongside resilience. Reviewing these constructs further enhances the understanding of resilience developed in this research. Thus, hardiness, grit, and coping will be reviewed below in relation to resilience, before discussing resilience specifically.

The dispositional conception of resilience, as outlined earlier (Block 1950; 1951), is shared in definitions of hardiness - described as a personality trait closely associated with resilience (Bartone, 2007). Like resilience, it too is underpinned by an ability to deal 
effectively with challenging and stressful situations (Kobasa, 1979). In this way, it has been a relevant and popular concept, not only in psychology (Maddi et al., 2006), but also in studies of the military, education, and sport (Kelly, Matthews, \& Bartone, 2014; Meyer, Markgraf, \& Gnacinski, 2017; Ray \& Brown, 2015). More specifically, hardy individuals are understood to possess "the belief that they can control or influence the events they experience . . . and the anticipation of change as an exciting challenge to further development” (Kobasa, 1979, p. 3). Unlike more contemporary conceptions of resilience however, hardiness appears to discount the notion that adaptive orientations toward the world and its complexities can exist and be influenced by elements beyond personality traits, types, or styles. Even though personality traits can influence the way in which an individual responds to a crisis or challenge, it should be noted that such experiences can also shape aspects of personality and the context plays a significant role in whether one's personality plays an adaptive or maladaptive role in the face of adversity (Masten, 2013).

Grit is another related construct and, like hardiness, has been explored extensively in sport and education literatures (Martin, Byrd, Watts, \& Dent, 2015; Wolters \& Hussain, 2015). It is also commonly viewed as a personality trait (Credé, Tynan, \& Harms, 2017), and is understood as long term perseverance and commitment to achieve goals, as well as staying strong in the face of failure (Duckworth, Peterson, Matthews, \& Kelly, 2007). Grit is made up of two core facets: perseverance and consistency (Credé et al., 2017). Resilience, on the other hand, encompasses a wider range of behaviours, such as learning and adaptability, which help individuals respond effectively to challenges and crises, and learn as a result (Kuntz et al., 2017; Yeager \& Dweck, 2012). Resilience and its behaviours, are also not trait-like, but dynamic and developable (Yost, 2016).

Coping is similar to the construct of resilience in various ways. Resilience has often been described as something that aids one’s ability to "cope” effectively (Edward \& Warelow, 2005; Iwasaki, MacTavish, \& MacKay, 2005; Kitano \& Lewis, 2005), as well as an outcome of effective coping or adaptation (Zautra \& Reich, 2011). Coping is also a component of resilience, according to some (Masten, 2001). Thus, the conceptions of coping, and of its relationship to resilience, vary. To add to this confusion, coping itself has seen a variety of conceptualisations. The early work of Lazarus (1966) sparked inquiry into research on coping. In this text, coping was used to describe the strategies individuals use for dealing with threat. Situations that require coping are ones which represent a threat, such as a crisis or an accident (Lazarus, 1966). Coping is therefore viewed as a response to threat; upon an individual's appraisal of a threatening situation, “coping activity is mobilised . . . by virtue of the cognition that "My life, health, wealth, or cherished social relationships are in danger”” (Lazarus, 1966, p. 153). 
For most of the $20^{\text {th }}$ century, coping was described as having two main forms: emotionand problem-focused coping. The first is used to regulate one's distress in relation to a problem, while the second is concerned with understanding and managing the problem itself (Lazarus \& Folkman, 1984). More recently, meaning-focused coping has emerged in the works of influential coping scholars (Folkman, 2008, 2013; Folkman \& Moskowitz, 2007; Gottlieb \& Gignac, 1996). Meaning-focused coping involves evaluating the meaning behind a particular event, which consists of asking why the event happened, how it changed things as a result, and how the event was meaningful on a personal level (Guo, Gan, \& Tong, 2013). The proclaimed existence of problem-, emotion- and meaning-focused coping reflects the notion that both positive and negative emotions can occur during stress and coping (Folkman, 2008). Likewise, the aftermath of coping can bring with it both positive and negative outcomes. For example, coping may result in increased social and personal resources, heightened empathy and maturity, and new, more effective coping skills (Park \& Folkman, 1997; Schaefer \& Moos, 1992). Alternatively, a more common focus has been on the negative outcomes of the stress process (Folkman \& Moskowitz, 2000a), which are purported to include withdrawal, depression, anxiety, ill health, and even death (Day \& Livingstone, 2001; Folkman \& Moskowitz, 2000b).

A large body of research relies on the idea of an appraisal process to explain coping (Lazarus, 1966; Lazarus \& Folkman, 1984). In this sense, coping is processual and transactional in nature (Lazarus, 1990) and involves "continuous appraisals and reappraisals of the shifting person-environment relationship” (Lazarus \& Folkman, 1984, p. 142). There is first a primary appraisal of the situation, where the individual perceives and attempts to understand the nature of the stressor or threat, and this is followed by secondary appraisal, where the individual considers what the possible responses are within the situation (Lazarus \& Folkman, 1984). The ways in which individuals actually respond to the threat are heavily dependent on the resources available to them. These resources can include factors like health, energy, belief systems, problem-solving, social skills, and support (Lazarus \& Folkman, 1984). We can ascertain from Lazarus' seminal groundwork on coping that it requires a degree of effort, and active mobilisation. In other words, coping is not seen as an automatic response process, whereas resilient behaviours, although also processual in their development, eventually become more automatic and habitual (Yost, 2016).

\subsubsection{Resilience and its foundations}

Many messages can be taken from the extensive research history on coping and applied to this study's understanding of resilience. There is no doubt that coping and resilience 
overlap in the literature, and resilience has been referred to as both a result of, and an enabler for, adaptive coping (Leipold \& Greve, 2009; Steinhardt \& Dolbier, 2008; Tugade \& Fredrickson, 2004). Resilience has also been viewed as the higher-level concept for one's ability to cope (Leipold \& Greve, 2009; B. W. Smith et al., 2008). Like the coping process, resilience involves a constant interaction between an individual and their environment and is therefore dynamic and contextual (Armstrong et al., 2005; Masten et al., 1988). Despite the existence of efforts to confound these two related phenomena, resilience in this research goes far beyond the ability to cope with crises - it is a sustained capacity that is developed, and enacted, on a daily basis (Kuntz et al., 2017; Yost, 2016).

The foundations for understanding resilience in the context of this research can be established by exploring Murphy’s (1965) concept of mastery in children. Resilience involves a constant interaction between an individual and their environment and from these ongoing interactions, much like a child's mastery of the world, an individual "develops a certain know-how, patterned way of dealing with newness itself” (L. B. Murphy, 1965, p. 2). Influenced by Murphy's approach to child development, child resilience scholars Masten and Reed describe the process of resilience in individuals as "patterns of positive adaptation” (2002, p. 118). This notion of individual development as a patterned process reflects the idea that frequent, day-to-day experiences and behaviours build individual capabilities and that patterns of interactions between factors within one's environment are what shape the course of resilience development (Masten, 2013). These interactions do not need to invoke stress or represent a threat to individuals such as with coping; they can also be relatively minor learning experiences that occur daily through responding to the surrounding world. Resilience and its development are thus part of a complex system involving many different forms of individual-environment co-action.

\subsection{Resilience as a developable capacity}

Resilience is changeable and developable. It is viewed in this research as a "contextually and culturally embedded construct” that is influenced by the wider system in which both enabling or disabling factors can be present (Ungar, 2012, p. 3). Under this view, resilience is a dynamic process and one that is dependent on the system that surrounds it, where influencing factors are continuously interacting and developing (Masten, 2013). This system consists of positive and negative forces that shape the course of human development (Bronfenbrenner, 2005). For resilience development, these forces might relate to social support, relationship quality (at home, work, and education), provision of resources, and past experiences (Armstrong et al., 2005; D. L. Brown, 2008; Nguyen et al., 2016). From 
birth, individuals develop through perceiving, experiencing and interpreting their environment.

Bronfenbrenner (2005) proposes two properties of human development that are particularly relevant to this research. First, for adaptive development, the effectiveness of positive forces, such as an enabling parent in child development, often depends on a third party to support and legitimise them. Another supportive parent would be an important legitimiser. Second, negative behaviours from immediate influencers (i.e. neglect, abuse, or domination by a parent) help to actualise maladaptive behaviours which disrupt and complicate development. Obviously, the systems surrounding resilience development are not limited to person-to-person interactions; other aspects of context matter too, such as culture, home, education and work quality, and material resources (Cooke, Cooper, Bartram, Wang, \& Mei, 2016; Rutter, 1987; Ungar, 2012). Nevertheless, the way in which we relate and respond to others is a large part of what makes us human, and is thus a crucial component of understanding human development (Bronfenbrenner, 2005).

Resilience scholar Luthans (2002a) also views resilience as dynamic and open to development. He proceeds to define it as "the developable capacity to rebound or bounce back from adversity, conflict, failure or even positive events, progress, and increased responsibility” (p.702). The rationale behind resilience as a developable capacity is underpinned by the idea that there are particular capabilities that can be developed to "allow individuals to capitalise on change and thrive in new environments” (Hodliffe, 2014, p. 6). Under this conceptualisation, there exists the understanding that in addition to adversity, resilience is important for positive events that individuals might face on a day-to-day basis (Kuntz et al., 2016). In taking this view, the focus on negative events and adversity is lessened by an increased emphasis on its positive contributions.

\subsubsection{Resilience and the environment}

Resilience is shaped by the environment. Attention to the role of systemic, external factors in invoking and influencing resilience is not new and gained traction through clinical psychology research in the 1970s, becoming well-established by the 1990s (Garmezy,

1971; Rutter, 1979). These studies were largely focused on the resilience of children facing adversity. Luthar and Zigler (1991) for instance, recognise and highlight the role of family factors in determining children's resilience levels. Family contexts where parental support is strong and values are shared have been associated with resilience in children (Luthar \& Zigler, 1991; Masten et al., 1988). In support of this connection, a relationship between good quality parenting (e.g. "a combination of warmth, expectations, and structure” 
(Masten et al., 1999, p. 146)) and a child's ability to cope effectively with adversity and challenge has also been established (Masten \& Coatsworth, 1998).

\subsubsection{The role of positive psychology}

Although classic resilience studies have provided a productive theoretical foundation upon which to develop the field further, the overwhelming focus on children and men (Kobasa, 1979; Masten, 2013; Masten \& Reed, 2002) as the primary subjects in resilience research has been a severe empirical limitation. The exclusion of more representative demographics, in terms of gender, age, ethnicity, as well as context, has arguably prevented the field from making valuable progress on the wide-reaching implications of resilience, its development, and its relationship to the environment. Positive psychology changed the shape of resilience scholarship by extending the focus from children and men only, and emphasising the role of protective factors in the environment that can influence resilience and its development. It was not until the peak of this movement in the 2000s that resilience was consistently described as being relevant to individuals generally (instead of specifically to children and men). The movement was primarily concerned with shifting the study of "psychology from a preoccupation only with repairing the worst things in life to also building the best qualities in life” (Snyder \& Lopez, 2009, p. 3). Child psychologist, Murphy, who argued that the negative focus employed in psychological studies of children limited the progression of human development and advancement, was an influential scholar for the positive psychologists in manifesting the adaptive and developmental arguments propelling the movement into popularity (Masten, 2001; L. B. Murphy, 1965).

A common view of resilience in the positive psychology literature is that although it is state-like and a result of factors and traits within an individual, external factors play a role in protecting individuals from adversity (Luthans, Vogelgesang, \& Lester, 2006). Positive psychology scholars emphasise the special role of protective factors in ensuring resilience when adversity or risk is high (Masten, Cutuli, Herbers, \& Reed, 2009). These protective factors exist within the individual (skills and dispositions), in the individual's immediate environment (family and friends), and in the communities and organisations they operate in (educational institutions and workplaces) (Masten et al., 2009). The notion of protective factors has since been shared by scholars of resilience outside of psychology-related fields. Such factors vary depending on context, and have been stressed as important for resilience in sport, workplaces, and schools (Hernandez, 1993; Sarkar \& Fletcher, 2014; van Breda, 2011). 
An issue with having a protective orientation to understanding resilience is that it assumes resilience is about "defending” against adversity. Scholars in the early 2000s, viewed adversity and risk as important elements in understanding resilience, and as the required stimuli preceding a resilient response (Rutter, 2006; Steinhardt \& Dolbier, 2008). Resilience in this research is instead viewed as a proactive behavioural capacity that can be demonstrated daily and that does not require an adverse event in order for it to be triggered. Also, resilience is, as understood in this research, not only a defensive state during crises, but rather it is an important capacity in both low-adversity situations i.e. daily hassles or stressors (Diehl, Hay, \& Chui, 2012), enabling personal learning and growth, and post-adversity circumstances i.e. after a large crisis (Nikalant et al., 2016), where resilience capacity can help individuals to reflect on a crisis or challenge and subsequently improve (Kuntz et al., 2016). Thus, the developable capacity of resilience consists of and contributes to a continuous learning process that shapes personal development (Yost, 2016).

\subsection{Resilience as a multi-levelled construct}

Table 1 shows the multi-levelled and contextual nature of resilience across fields of inquiry. Some understandings of resilience, for example, emphasise the importance of adversity in triggering resilience (Bonanno, 2004), while others recognise that resilience is a continuous, ongoing capacity that is important for day-to-day activities as well as large shocks (Kuntz et al., 2017). The psychology literature emphasises adversity and crisis through a mix of emotional, cognitive and environmental features. 
Table 1: Fields, levels, and definitions of resilience

\begin{tabular}{|c|c|c|}
\hline Field & $\begin{array}{l}\text { Level/ } \\
\text { unit of } \\
\text { analysis }\end{array}$ & Definition \\
\hline \multirow[t]{3}{*}{ Psychology } & Child & $\begin{array}{l}\text { A class of phenomena "characterised by good outcomes in } \\
\text { spite of serious threats to [a child's] adaptation or } \\
\text { development" (Masten, 2001, p. 228) }\end{array}$ \\
\hline & Adult & $\begin{array}{l}\text { "The ability of adults in otherwise normal circumstances who } \\
\text { are exposed to an isolated and potentially highly disruptive } \\
\text { event, such as the death of a close relation or a violent or life- } \\
\text { threatening situation, to maintain relatively stable, healthy } \\
\text { levels of psychological and physical functioning" (Bonanno, } \\
\text { 2004, p. 20) }\end{array}$ \\
\hline & Family & $\begin{array}{l}\text { "The processes by which families are able to adapt and } \\
\text { function competently following exposure to significant } \\
\text { adversity or crises" (Patterson, 2002, p. 351) }\end{array}$ \\
\hline Ecology & Ecosystem & $\begin{array}{l}\text { No precise definition, but described as "the buffer capacity or } \\
\text { the ability of a system to absorb perturbations, or the } \\
\text { magnitude of disturbance that can be absorbed before a system } \\
\text { changes its structure by changing the variables and processes } \\
\text { that control behaviour" (Adger, 2000, p. 349) }\end{array}$ \\
\hline \multirow[t]{3}{*}{ Education } & Student & $\begin{array}{l}\text { "The heightened likelihood of success in school and other life } \\
\text { accomplishments despite environmental adversities brought } \\
\text { about by early traits, conditions, and experiences" (M. Wang, } \\
\text { Haertel \& Walberg, 1994) }\end{array}$ \\
\hline & Teacher & $\begin{array}{l}\text { A capacity which “enables teachers to persist in the face of } \\
\text { challenges" (Beltman et al., 2015, p. 185) }\end{array}$ \\
\hline & School & $\begin{array}{l}\text { "The ability of an individual, team or school to adapt to } \\
\text { changing demands, to recover, and to remain vigorous after } \\
\text { the changes have occurred" (Schelvis, Zwetsloot, Bos, \& } \\
\text { Wiezer, 2014) }\end{array}$ \\
\hline \multirow[t]{3}{*}{ Management } & Employee & $\begin{array}{l}\text { “The capacity of employees to utilise resources to } \\
\text { continually adapt and flourish at work, even when faced } \\
\text { with challenging circumstances" (Kuntz, Näswall, \& } \\
\text { Malinen, 2016, p. 460) }\end{array}$ \\
\hline & Organisation & $\begin{array}{l}\text { An organisation's ability "to withstand systematic } \\
\text { discontinuities as well as the capability to adapt to new risk } \\
\text { environments" (Burnard \& Bhamra, 2011, p. 5583) }\end{array}$ \\
\hline & Workplace & $\begin{array}{l}\text { "The characteristics, dimensions, and properties of } \\
\text { workplaces that help workplaces to be resistant to disruption } \\
\text { in the face of change and adaptive in the face of crisis } \\
\text { situations" (van Breda, 2011, p. 35) }\end{array}$ \\
\hline
\end{tabular}


The ecology literature notes the contextual, dynamic, and interdependent nature of resilience, while the education material highlights the valuable role of resilient capacities and competencies. The management literature, which will be emphasised later, focuses largely on behavioural capacities like those described in education. An expanded table showing the specific components of resilience in each of these disciplines is presented in Appendix A.

In terms of resilience at the level of the employee, there is some consensus on its role as an “adaptive behavioural capacity to gather, integrate and utilize organizational resources” (Kuntz et al., 2016; 2017; Näswall et al., 2019, p. 354; Lengnick-Hall et al., 2011). This study agrees, and more specifically takes the view of employee resilience as a developable capacity, consisting of three core behavioural dimensions: network leveraging, learning and adaptability (Kuntz et al., 2017). This understanding enables us to observe the key behaviours through which resilience elicits positive personal and organisational outcomes (Näswall et al., 2019). In other words, a behavioural understanding establishes how employees can make change and influence the organisation and themselves through their behaviours. This focus on interactions with the environment, in particular the workplace, is consistent with other HRM theories such as person-job fit, selection, organisational culture, and climate (Paauwe \& Farndale, 2017). The ways in which these behaviours have impact in their organisational contexts are discussed shortly.

Recognising the multi-levelled nature of resilience is also important here because it means that different levels of resilience might mutually and contextually reinforce one another (Giustiniano, Clegg, e Cunha, \& Rego, 2018). In other words, we can view resilience capacity and its development as systemic in nature. For instance, employee resilience, the topic of focus in this research, is a form of resilience that exists at the employee level, as well as within the wider system of workplace resilience, comprised of a variety of different forms and levels of resilience (van Breda, 2011). Resilience development occurs when employees engage with resilience-enabling resources at any of these levels. The resilienceenabling resources focused on in this research are the leadership behaviours performed by managers. This development process occurs between the employee and the manager. 


\subsection{A contextual view of resilience}

When viewing resilience as a multi-levelled, developable capacity, individual-environment co-action is key. Resilience requires an individual to engage with personal, social and contextual resources for development. The nature of resilience is therefore at least partially reflective of the context in which it exists in. Thus, resilience is manifested in various ways, and is externalised, such as through particular behaviours, depending on the characteristics and demands that exist in a particular context (Harney, 2007). Of course, there are many studies on resilience among psychology scholarship (Armstrong et al., 2005; Kitano \& Lewis, 2005; Masten, 2013; M. Stewart, Reid, \& Mangham, 1997), but resilience has also been explored in the contexts of parenthood (Horton \& Wallander, 2001), war (Froehlich, 2013; D. W. King, King, Foy, Keane, \& Fairbank, 1999), natural disasters (Cutter et al., 2008; Nikalant et al., 2016; Stevenson, 2014), education (Beltman et al., 2015; Yeager \& Dweck, 2012) and organisations (Kuntz et al., 2016; Lengnick-Hall \& Beck, 2003; Vogus \& Sutcliffe, 2007).

Resilience takes different meanings and forms across contexts, and is important for different reasons. For example, in the context of war, or post-war, resilience is described as a capacity necessary for coping and recovering under severe adversity (D. W. King et al., 1999; MacDermid Wadsworth, 2010). Here, resilience is seen as relevant in adverse, crisis situations. On the other hand, recent views on the resilience of employees in organisations argue that resilience is not just triggered (and developed) by adverse events and crises. In fact, day-to-day, business as usual activities containing within them minor challenges and learning experiences, are significant in helping to develop resilient capabilities in employees (Kuntz et al., 2016). This study shares the view that day-to-day activities and interactions are central in shaping resilience development in the organisational context, which is why the influence of leaders, and their daily behaviours, are deemed critical factors in the continuous development of employee resilience.

A contextual view of resilience also carries the understanding that within a given context, “particular processes cultivate resilience for particular people” (Harney, 2007, p. 77). This means that enabling and disabling factors for resilience may differ across contexts and many may even be unique and distinct in that they are only ever effective in a particular context. The role of parental support, for instance, is viewed as crucial for resilience development in children (Armstrong et al., 2005). Alternatively, in the workplace, enabling processes for resilience in employees may include inclusive job design, information sharing, or certain forms of leadership (Khan et al., 2017; Nguyen et al., 2016). 
Resilience can thus be expressed in many ways, and what builds it depends on the context. Instead of being trait-like and determined by personal resources, such as disposition and personality, resilience requires an individual to engage with environmental factors for development. This study focuses on resilience in the context of the workplace, and within this, at the employee-level. The next section will contextualise resilience as a workplace phenomenon by reviewing relevant literature in and around the fields of management and organisational psychology.

\subsection{Resilience at work}

A resilient workplace is defined as one that achieves "desirable outcomes amid adversity, strain, and significant barriers to adaptation or development” (Sutcliffe \& Vogus, 2003, p. 94). Growing attention to resilience as an important phenomenon across all contexts has led to a recontextualised view of the concept in the workplace and the subsequent development of employee resilience (Kuntz et al., 2017). Despite this recent development, studies on organisational resilience remain more prevalent than those on employee resilience. These organisational resilience studies help to provide the concept of employee resilience with a contextual and conceptual backdrop, and are therefore summarised below. This study adopts the definition of organisational resilience as "a firm's ability to effectively absorb, develop situation-specific responses to, and ultimately engage in transformative activities to capitalise on disruptive surprises that potentially threaten organisation survival” (Lengnick-Hall et al., 2011, p. 244). These responses and activities need not be invoked by stress or adversity, they can be built into daily practices to better prepare organisations for disruptions and crises when they do occur.

Studies on the phenomenon of organisational resilience are abundant (Barasa, Mbau, \& Gilson, 2018; Gittell, Cameron, Lim, \& Rivas, 2006; Kantur \& İşeri-Say, 2015; Ortiz-deMandojana \& Bansal, 2015; Verrynne, Ho \& Linnenluecke, 2018) and have identified antecedent factors such as leadership capacity (Barasa et al., 2018; Samba, Vera, Kong, \& Maldonado, 2017), organisational culture (Sawalha, 2015), and human and social capital (Ager et al., 2015; Andrew, Arlikatti, Siebeneck, Pongponrat, \& Jaikampan, 2016) as influential in its development.

Recent attention to resilience development in organisations has also involved discussion of the terms adaptive and inherent resilience (Nikalant et al., 2016). These are viewed as the building blocks of a resilient organisation. Adaptive resilience recognises that resilience in the face of adversity is important (Nikalant et al., 2016). It relates to the "effective 
responsiveness to instances of significant adversity” (Kuntz et al., 2016, p. 458). Inherent resilience is developed in contexts of low to moderate adversity (Kuntz et al., 2016). It is constant and stable regardless of the severity of the situation. This is similar to the idea of strategic agility defined by Välikangas (2016), which is the continuous pursuit of opportunities in competitive environments, which contribute to an “organisation's capability to adapt to change without requiring, or resulting in, a . . crisis” (p. 1). Adaptive and inherent resilience are complementary and necessary components of an organisation's overall resilience, such that "inherent resilience prior to exposure to a significant adverse event is associated with adaptive resilience” (Kuntz et al., 2016, p. 458).

People play a significant role in making an organisation resilient. In a healthy, resilient organisation, people effectively prepare for, survive, and thrive in challenging environments (Lee et al., 2013; Vogus \& Sutcliffe, 2007). Resilient organisations are comprised of individuals who are collectively aware of what is currently happening in their environment, are capable of managing vulnerabilities, and are able to display adaptive and responsive behaviours (Lee, Vargo, \& Seville, 2013; Mallak, 1998). Building inherent resilience is most possible during stable periods on a day-to-day basis, and is near impossible in crisis situations, and so this form of resilience may work to build the foundation needed to effectively activate adaptive resilience. Developing employee resilience on a daily basis is one way in which organisations can build inherent resilience in these more stable periods.

\subsubsection{Employee resilience}

The development of resilience in employees involves a constant interaction between an individual and their work context (Mansfield, Beltman, \& Price, 2014). At this level, resilience is generally understood as "the capacity of employees to utilise resources to continually adapt and flourish at work, even when faced with challenging circumstances” (Kuntz et al., 2016, p. 460). As well as being developable by context, employee resilience is a behavioural construct evidenced through a set of workplace behaviours, centred around network leveraging behaviours, learning, and adaptability (Kuntz et al., 2017). These behaviours are separate from, but precede, attitudes such as job satisfaction, motivation, and wellbeing (Brennan, 2017; Youssef \& Luthans, 2007). As a set of capacity-enhancing behaviours, they are likely to contribute to engagement, and its dimensions such as vigour, which are measured more as attitudes, or as a "state of mind" (Schaufeli, Bakker, \& Salanova, 2006, p. 702).

This conceptualisation of resilience, as a developable set of behaviours shaped by the environment, means that workplace actors and contexts can promote or hinder resilience 
(Stokes et al., 2018; M. Vera, Rodríguez-Sánchez, \& Salanova, 2017). Rather than being discrete facets, these behaviours work together, and interact with contextual factors, to support the protection and acquisition of further job and personal resources to deal with work challenges. These resources include skills, relationships, and social and professional support (Hobfoll, 2011).

Network-leveraging behaviours consist of effective collaboration between colleagues, sharing knowledge and information and cooperating across teams, networks and functions (Lengnick-Hall et al., 2011; Uzzi, 1997). These behaviours facilitate access to and exchange of resources which bolster one's ability to deal with challenge and crises competently, without a high stress burden (Mitchell, O’Leary, \& Gerard, 2015). Networkleveraging behaviours may in turn foster other resilient behaviours such as problem-solving and seeking feedback. Further to this, collaborative teams facilitate use of collective competencies to resolve shared issues and challenges (Hardy, Lawrence, \& Grant, 2005). In the public sector, the varied demands from diverse stakeholders place pressures on collective skills and capacity, making interpersonal collaboration particularly relevant and important (O'Leary \& Bingham, 2009).

Learning, another key behavioural component of employee resilience, supports innovation in stable contexts, and helps develop the competencies that are necessary in overcoming and learning from crises (Kuntz et al., 2017). Like collaboration, this skill is particularly salient in the public sector, where under-resourcing and complex demands are prevalent (Cameron, 1998; Christensen \& Lægreid, 2011a). Having goals that are learning-centered, rather than rigid and performance-oriented, helps to foster wellbeing and growth as well as performance, supporting deep and sustained learning that ultimately builds capacity (Winters \& Latham, 1996).

The third key behavioural component of resilience is adaptability. It occurs when employees use their resources (both personal and job-related) to respond swiftly to changes and uncertainties. Adaptability helps individuals use experiences involving change or challenge in order to grow and develop personally and professionally (Kuntz et al., 2017). It also means that employees can effectively adapt to changing demands and stressors that arise and develop in a particular context. In doing to, they use learning to improve and modify their adaptive responses over time.

These behaviours are all closely interlinked and mutually reinforcing. They are not discrete. For instance, collaboration enables learning, and requires adaptability. Adaptability is easier with help from others (collaboration) and often stems from, and creates, learning (Folke et al., 2010). A person who has resilience-enabling support would 
be one who collaborates well with others, learns from them, and likely contributes to individual and organisational learning. They would adapt to changing circumstances easily in the job, and acquire and use personal and social resources well. In contrast, a person who lacks resilience-enabling support may find collaboration difficult; and not learn easily. They may also struggle with change. Leadership that does not match the changing demands on public services, and their employees, may be a factor in this. In contrast, a resilience-enabling leader is one who understands the complexities of context, and develops employees to demonstrate these behaviours and subsequently build resilience capacity. A summary of how, and through what specific behaviours, employee resilience is enacted in workplaces is illustrated in Table 2 below.

Table 2: Resilient employee behaviours

\begin{tabular}{|c|c|}
\hline Resilient behaviour & Behavioural examples \\
\hline \multirow[t]{5}{*}{$\begin{array}{l}\text { Network leveraging } \\
\text { ability }\end{array}$} & $\begin{array}{l}\text { Collaborating internally with peers, managers and } \\
\text { teams }\end{array}$ \\
\hline & $\begin{array}{l}\text { Collaborating with people and teams in other } \\
\text { organisations }\end{array}$ \\
\hline & Seeking support from managers when required \\
\hline & Exchanging resources with peers and managers \\
\hline & Seeking resources from peers \\
\hline \multirow[t]{3}{*}{ Learning } & Using mistakes as learning opportunities \\
\hline & $\begin{array}{l}\text { Re-evaluating performance on a continuous basis to } \\
\text { improve own work }\end{array}$ \\
\hline & $\begin{array}{l}\text { Using feedback, including negative feedback, for } \\
\text { learning and improvement of own work }\end{array}$ \\
\hline \multirow[t]{3}{*}{ Adaptability } & $\begin{array}{l}\text { Managing resources effectively in order to cope with } \\
\text { high workloads when needed }\end{array}$ \\
\hline & Engaging in crisis management effectively \\
\hline & Using change as an opportunity for growth \\
\hline
\end{tabular}

Note: Adapted from Näswall, Kuntz, Hodliffe, \& Malinen (2015) and Kuntz et al. (2017).

\subsection{Summary}

This section has provided a detailed overview of the construct of resilience, including its conceptual underpinnings, its relationship to the environment and context, and its role in the workplace - particularly at the level of the employee. Given that this study is guided by a model of resilience that exists beyond the fixed states of an individual, i.e. it is developable, it is necessary to next describe the broader context - that of the public sector. The next chapter also discusses the subsequent demands that this context places on resilience. 


\section{THE PUBLIC SECTOR CONTEXT AND LEADERSHIP}

This chapter introduces and describes the public sector context, its demands on resilience, and its implications for leadership. It then discusses the idea of leadership more generally, including the ways in which it can influence employee behaviour, and subsequently, resilience.

\subsection{Public sector demands on resilience}

The public sector context has particular implications for employee resilience, and its development. In this research, the public sector context is an important contextual issue, but not a core concept. The public sector is well suited to study employee resilience due to the complex demands and challenges it is often faced with. Relevant contextual characteristics of the public sector, particularly those applicable to the New Zealand context, are discussed below.

Literature points to an emerging public sector aimed at addressing the limitations of both Traditional Public Administration (TPA) and New Public Management (NPM); one that highlights the failure of over-reliance on both big government and the market (Bryson, Crosby, \& Bloomberg, 2014). This emerging context consists of many unique tensions and challenges, many of which require a resilient response.

Although contested in public administration scholarship (Alford \& O'Flynn, 2009; Osborne, 2010), the emerging context appears to prioritise public value and representative service delivery over past priorities emphasised under TPA and NPM, such as bureaucratic or contractual compliance. Warner (2008) argues that what is now needed is a "new balanced position which combines the use of markets, democracy, and planning to reach decisions which may be both efficient and more socially optimal” (p. 171). This balanced position is likely to be associated with complex and unique demands, some of which may be in tension with each other.

The new expansion and dispersion of public services has forced governments to take a more networked approach to decision-making and organisational structures (Stoker, 2006). “Wicked problems”, for example, might be more effectively tackled through collaborative, networked processes both within and between public organisations, and with external (i.e. private) organisations and stakeholders. Public administration scholars call for public organisations to exercise discretion to allow for things like effective collaboration and innovation, whilst remaining constrained by and accountable to democratic laws and values 
(Bryson et al., 2014). From a leadership perspective, a response to this shift might be about designing leadership that reflects the demands of the context, rather than retaining traditional prescribed leadership models that are at risk of losing relevance in today's dynamic public environments (Ospina, 2016; Van Wart, 2014; Zeier, Plimmer, \& Franken, 2018).

With stakeholder relationships and inter-agency communication increasing, government organisations are functioning in turbulent and trying conditions. Lengnick-Hall et al. (2011) argue that in dynamic environments like this, "only flexible, agile, and relentlessly dynamic organisations will thrive” (p. 243). Governments require resilient workforces that not only survive, but prosper in the face of challenge and adversity (Lengnick-Hall et al., 2011) to meet and exceed public sector demands.

Despite these changes, and the subsequent demands for resilience, tenets of TPA and NPM are still an inevitable part of public sector reality. Christensen (2014) argues “[p]ost-NPM reforms did not replace NPM-reforms, but instead partly merged with them and partly modified them in what can be described as a layering process” (p. 161). This is understandable, as the philosophical principles of these reforms, although in conflict ideologically, have both been driven by a desire to deal effectively with changing demands. This hybridisation of past and present ideologies influences the public sector work environment, mainly by increasing role complexity, demands and tensions (Wällstedt \& Almqvist, 2015). The review to follow will explain the current nature of public service work, and the associated managerial implications, in more depth. It will also explain why it is necessary to have a resilient workforce in the public sector, and why effective, public sector leadership is essential in ensuring this.

\subsubsection{Public sector work and the implications for managers}

In a study of organisational responses to public sector reform, Fossestøl, Breit, Andreassen, and Klemsdal (2015) refer to managing the associated complexities and tensions effectively as positive hybridity. This hybridity idea reflects literature on hybrid organisations, which are those that "combine institutional logics in their efforts to generate innovative solutions to complex problems” (Jay, 2013, p. 137). These institutional logics impose conflicting demands on individuals and organisations, including pressures to collaborate across networks, while needing to retain centralised accountability and decision making (Fossestøl et al., 2015; Witesman \& Wise, 2009). Although balancing conflicting demands is seen as achievable (March, 1991), it is challenging. 
At the individual level, public servants may find it difficult to perform consistently with the evolved-NPM logic of being accountable to serving the democratic interests of citizens (Denhardt \& Denhardt, 2007), while also experiencing the residual NPM pressure to ensure efficient implementation of decisions (Christensen \& Lægreid, 2011b). Hendrikx and van Gestel's (2016) research provides insight into the impact of public sector reform post-NPM on public servants' work experiences. The authors argue that most attention has been placed on the shifting managerial roles post-reform, rather than on the impact that postNPM reforms have had on professional and front-line staff, whose experiences are arguably more representative of public sector realities. They give an example from healthcare, where public servants "are expected to collaborate with peers in a local network context to ensure continuity, as well as to be competitive, guided by financial incentives and performance measurement set by central government” (Hendrikx \& van Gestel, 2016, p. 12). This is a strong example of how institutional logics and reforms shape behaviour at the employee level (Noblet \& Rodwell, 2009; Yang \& Pandey, 2008).

Leadership is also affected by political and administrative reforms. Balancing tensions like those inherent in NPM, and those which are even more prominent in post-NPM environments, may be particularly challenging if leadership does not support employees to balance such tensions, and if there are high demands and work pressures. New Zealand's PSA (Public Service Association) survey, measuring the work experiences of 14,125 public servants, found that many public servants are experiencing poor reward systems, competing demands, and a limited culture for learning (Plimmer et al., 2017). Public sector professionals have long experienced lower job satisfaction, higher turnover intentions and lower commitment than their private counterparts (Aryee, 1992; Zeffane, 1994).

The shift from a centralised, bureaucratic form of public administration to a more decentralised, market-driven method of organising (Bryson et al., 2014) has also intensified work (Cameron, 1998). The customer-oriented demands on public organisations to deliver services at all costs puts pressure on resources, such as labour, that also need use elsewhere (Christensen \& Lægreid, 2011b). Resource shortages exacerbate this pressure, as "many large-scale reforms that have occurred in the public sector have involved a loss of resources, especially in terms of people, time, and budgetary support” (Noblet, Rodwell, \& McWilliams, 2006, p. 338). These challenges further prompt the need for resilience development in public sector workforces. They also place an emphasis on public managers to display leadership that confronts these challenges and helps to develop and support resilience in employees. 


\subsection{Public sector leadership}

Public sector leadership does not always help development. The approach to leadership under NPM has been referred to as "managerialist" (O'Reilly \& Reed, 2011). Managerialism represents a belief that "all aspects of organisational life can and should be managed according to rational structures, procedures and modes of accountability” (Wallace \& Pocklington, 2002, p. 962). The ongoing relevance of this rational-technical approach to managing is increasingly critiqued by today's organisational scholars because it does not deal with institutional and stakeholder complexity. Managerialism is poor at balancing diverse stakeholder needs and fulfilling other ethical obligations (Simmons, 2004). This matters in the public sector, where stakeholder involvement is necessary, creating public value is essential, and maintaining public trust is important.

Managerialism has also been associated with output-based performance management. Although technically "efficient” on resources, an over-reliance on output measurement, with a disregard for strategy and process, can lead to performance management systems that are ambiguous, partial, and misaligned with policy or organisational objectives (Van Thiel \& Leeuw, 2002). If the relationship between the system and the aims and goals of the organisation are unclear and ambiguous, managers will essentially establish "inadequate paths for future growth” (Andrews, Boyne, \& Enticott, 2006, p. 277).

This argument is not new, and was emphasised in the 1970s in Levine's studies on cutback management, which is a form of management concerned with responding to resource scarcity across sectors (Levine, 1979). Levine claimed that management concerned with tight, standardised resource allocation and reversing the sequences of previous organisational activities to save on resources will actually do the opposite of its intention. It will reduce productivity and growth and contribute to organisational decline (Levine, 1978). What is instead necessary in times of tight resource-dependency is management that fosters flexibility, learning and innovation, rather than management that punishes mistakes and experimentation because of the initial burden they may place on valuable organisational resources (Pandey, 2010). Under the conditions of cutback management, "creativity diminishes, innovation and risk-taking decline, and the sense of excitement that comes from doing new things disappears” (Levine, 1979, p. 180). For employees and organisations, the effects of these conditions are antithetical to resilience and its development.

The Better Public Services Advisory Group highlighted a number of leadership challenges facing the New Zealand public sector. For example, decision making and accountability primarily lie centrally with agency chief executives (Better Public Services Advisory 
Group, 2011), which has resulted in centralised single agencies with strong chains of command. But horizontal relationships both within and between organisations are fragmented. Productive horizontal relationships can be difficult to uphold with strict lines of command and control (Schillemans \& Busuioc, 2015). Again, this has potentially stagnating effects for multi-party collaboration and stakeholder engagement, especially in the current context where leaders are required to navigate increasingly complex and diverse challenges (Page, 2016). Other leadership issues identified relate to business over governance priorities, weak people management, and ineffective use of information and resources to drive agency success (Better Public Services Advisory Group, 2011).

Public sector managers are often unable to effectively balance conflicting imperatives, such as the need for both innovation and flexibility as well as control and accountability (Plimmer, Gill, \& Norman, 2011). A reason for this might lie in poor people management by executive leaders. Senior executives often fail to appropriately balance conflicting needs for control and flexibility (Plimmer et al., 2011). Managers are often "unrewarded for innovation and, paradoxically, sometimes lacking in real accountability despite the plethora of control” (Plimmer et al., 2011, p. 296). Senior executives' reluctance to embrace paradoxes and tensions encourages subordinates to follow suit, in a replication process of sorts. This may well cascade down to front-line employees, resulting in risk-averse workforces lacking in innovative and adaptive capabilities, which are just as important as control and accountability in today's public sector. This ultimately renders this approach to conflicting imperatives counterproductive.

The management and leadership issues identified above highlight the need to rethink and redefine the nature of effective public sector leadership. In this study, effective public leadership is viewed as a capacity comprised of leadership behaviours that enable resilience in employees. Such leadership needs to be adaptive, to be effective at leveraging networks, and to foster the ability to learn in changing environments.

Many public administration studies stress the importance of shifting from rational and linear approaches to leadership towards more decentralised, organic, and adaptive approaches (Ospina, 2016; Page, 2016; Zeier et al., 2018). These views address the need to take collective responsibility for solving complex problems (Dunoon, 2002), deal with crises and thrive in post-crisis contexts, and ensure adaptation to dynamic demands and environments. Despite this, traditional models of leadership persist in government (Van Wart, 2014). This may occur because, as indicated earlier, leadership standards are often low (De Waal, 2010; Taylor, 2017). It may also be partly because public demands and accountabilities create a strong demand for control and hierarchy, even if this does not 
match the complexity of the context. Leadership is contextual (Oc, 2018), and public leadership has a unique character that should be, at least partly, informed and reflected by the context itself (Getha-Taylor, Holmes, Jacobson, Morse, \& Sowa, 2011).

So far, only relatively traditional conceptions of leadership have been explored in resilience studies, and a public sector specific approach to studying leadership in this context remains underdeveloped. Valero, Jung, and Andrew (2015) posit that to respond effectively to public sector uncertainties and state emergencies, leaders need to be able to "motivate, communicate, and articulate an organisation's mission” to followers (p. 4). Not surprisingly, the authors go on to associate transformational leadership with organisational resilience (Valero et al., 2015). Harland, Harrison, Jones and Reiter-Palmon (2005) found more generally that particular dimensions of both transactional and transformational leadership can contribute to resilience in subordinates. For example, the transformational and transactional dimensions of intellectual stimulation and contingent reward help subordinates' resilience, while others do not, such as active and passive management by exception (Harland et al., 2005). Developing employee resilience is therefore complex, influenced by context, and likely involves a diverse set of leadership competencies and approaches, some of which may seem paradoxical or in tension with each other. These ideas surrounding leadership will be developed further below, and then throughout this research.

\subsection{Leadership and employee behaviour}

The section above has described the characteristics of the public sector and the state of leadership in this context. Before discussing specific aspects of leadership that may build employee resilience, it is first necessary to highlight, in a more general fashion, some of the key ways, and mechanisms by which, leaders can impact employee behaviour. Relevant theory is applied to discuss these ideas.

\subsubsection{Transformational and transactional models}

Transformational and transactional leadership are two dominant leadership styles that have featured extensively in the leadership literature of the last 35 years (Bass, 1985, 1990; Hater \& Bass, 1988; Judge \& Piccolo, 2004; Podsakoff, MacKenzie, \& Bommer, 1996). These theories, particularly that of transformational leadership, are also well-established in public administration (Bellé, 2014; Caillier, 2014; Jensen et al., 2019; Taylor, 2017; Wright, Moynihan, \& Pandey, 2012). Both forms of leadership are understood to influence and benefit employees through several processes (Hartley \& Allison, 2000). 
Transformational leadership is multi-dimensional, and comprised of charismatic, inspirational, individualised and intellectually stimulating leadership (Judge \& Piccolo, 2004). These dimensions work to motivate and influence individuals to achieve organisational outcomes (Hartley \& Allison, 2000). Scholars indicate that leaders who combine these dimensions are transformational, and can instil in followers a sense of pride, creativity, and a clear vision for the future (Bass, 1990; Mester, Visser, Roodt, \& Kellerman, 2003). The effects of transformational leadership on followers occur "when a leader's end values (internal standards) are adopted by followers thereby producing changes in the attitudes, beliefs, and goals of followers" (Kuhnert \& Lewis, 1987, p. 653).

The charismatic leadership dimension of transformational leadership is also seen as a leadership style on its own, and its influencing processes share much similarity with those underpinning transformational leadership. Originally developed by House (1976), charismatic leadership represents certain personality characteristics (being dominant and confident, and having strong values and a desire to influence) that, when displayed by a leader, have specific effects on followers (Northouse, 1997). Such leaders also demonstrate particular behaviours, such as role modelling, competence, goal articulation, and confidence that work alongside personality characteristics to influence followers (House, 1976). According to the theory, followers subsequently develop trust in their leader, congruent belief systems, acceptance of decisions, obedience, identification, and increased confidence (House, 1976). Although this process seems to work in a top-down manner, followers play a key role in validating a leader’s charisma (Bryman, 1992).

Transactional leadership works via an exchange process between leader and follower (MacKenzie, Podsakoff, \& Rich, 2001). It is comprised of contingent reward and punishment behaviours. Particular construct dimensions include contingent reward or reinforcement, active management by exception, and passive management by exception (Bass \& Avolio, 1997; Hater \& Bass, 1988). These relate strongly to theories of reinforcement (Sims, 1977) and influence employee behaviour via instrumental compliance (MacKenzie et al., 2001), which diverges from the identification process (Kelman, 1958) implied in transformational leadership.

\subsubsection{Leader-member exchange}

A less top-down approach to leadership and its processes is the theory of leader-member exchange (LMX) (Graen \& Uhl-Bien, 1995). Whilst still recognising the role of leader as a source of authority, the theory recognises leadership as a dyadic exchange process between leader and follower. Thus, followers play a primary role in enabling leader effectiveness. The quality of the leader-follower relationship is essential in the LMX 
process, such that "when these relationships are of high quality, the goals of the leader, the followers, and the organisation are all advanced” (Northouse, 1997, p. 116). Goals are advanced because a process of exchange ensues, where followers are motivated to reciprocate effort back to the leader, and the organisation. LMX is strongly related to social exchange theory, the notion that when "one person does another favour, there is an expectation of some future return” (Wayne, Shore, \& Liden, 1997). It is likely that leadership, specifically high-quality leader-follower relationships, can enhance social exchange processes that benefit the wider organisation, such as task and organisational citizenship behaviours (Gottfredson \& Aguinis, 2017; Ladd \& Henry, 2000).

\subsubsection{Destructive leadership}

Whilst the models of leadership mentioned above can make positive contributions to individuals and organisations, it bears mentioning that leadership can also be destructive (Shaw, Erickson, \& Harvey, 2011; Skogstad, Einarsen, Torsheim, Aasland, \& Hetland, 2007). Destructive leadership includes behaviours such as uninformed decision making, bullying, lying, acting in a tyrannical manner, and engaging in inconsistent behaviour (Shaw et al., 2011). These behaviours influence employee wellbeing, productivity and morale (Jóhannsdóttir \& Ólafsson, 2004; Schyns \& Schilling, 2013), as well as organisational performance, which occurs via leaders "undermining and sabotaging . . . the motivation, wellbeing or job satisfaction of subordinates" (Shaw et al., 2011, p. 575).

\subsubsection{Authority in leadership}

These prominent theories of leadership illustrate the underlying role, and strength, of authority in leader-follower relations. Leaders clearly matter. Adopting Heifetz's (1994) view, organisations are systems of dependencies that rely on appropriate authority. These dependencies are between individuals who work vertically, as leader-followers and together, as co-workers. In organisations, Heifetz states, "we construct a network of appropriate dependencies based on a realistic appraisal of what we and others can provide” (1994, p. 70). As established, these dependent networks are essential in the development and maintenance of employee resilience, i.e. horizontally through network-leveraging, but they also feature, in a vertical fashion, in the relationship between leader and employee. The two are dependent on each other, and the leader's use (or misuse) of authority is an important factor in influencing the nature of these dependencies.

Heifetz (1994) distinguishes between adaptive and maladaptive authority/dependency relationships and states that although authority is important for order and control, "habitually seeking solutions from people in authority is maladaptive” (p.73). This is 
particularly true when complex and adaptive solutions to problems are a necessary priority, such as in the public sector (Head \& Alford, 2013). Thus, leaders need to use their authority to mobilise adaptability in employees, and "provoke debate, rethinking, and other processes of social learning” (Heifetz, 1994, p. 87). This corresponds strongly to the role that leadership likely has on an employee's ability to behave resiliently. It also indicates that social learning may be a relevant theory to explore in order to understand this relationship. Social learning theory applies to leadership (M. E. Brown, Treviño, \& Harrison, 2005; Sims Jr \& Manz, 1982). This theory relates to the development of a series of behavioural response patterns that "can be acquired either by direct experience or by observation" (Bandura, 1977, p. 16). Social learning, much like resilience development, implies that behavioural learning occurs through interaction between an individual and their environment (Bandura, 1977; Ungar, 2012). Leaders, as figures of authority in one's environment, can influence employee behaviour via modelling (M. E. Brown et al., 2005). This may be one way in which leadership behaviours can enable resilient behaviours in employees.

\subsubsection{Considerations for this research}

The influence processes of leadership are varied and complex. These dyadic processes involve meaningful exchanges between employees and leaders, and employee responses to leadership can be established through modelling behaviours from leaders. Some theories, like transformational and transactional leadership, and adaptive authority, are inherently paradoxical in that opposing behaviours are being employed in the act of leadership. For example, adaptive authority requires empowering individuals with appropriate autonomy, whilst establishing a clear position of authority (Heifetz, 1994). This research takes these ideas further and later introduces the construct of paradoxical leadership, discussing its potential role in enabling employee resilience. A paradoxical approach to leadership that balances the necessary tensions in the operating environment, might well contribute to resilience development, particularly in the complex public sector context. Other forms and behaviours of leadership are likely to also be discovered throughout the course of this study, that may more adequately match the public context. There may also be certain processes, or mechanisms, by which such leadership influences employee resilience, such as through social learning or exchange. These ideas are developed after the following chapter on methodology. 


\subsection{Summary}

This chapter reviewed the public sector context, its relationship to leadership, and highlighted prominent leadership theory to discuss the ways in which leadership may influence employee behaviour. It also established that enabling resilience in public sector employees is not a straightforward task for managers and traditional models of leadership are unlikely to suffice. This presents particular implications for the research question of: What leadership behaviours enable employee resilience? Perhaps rather complex, contextual, and paradoxical forms may be most appropriate and effective. Many of these ideas hold relevance throughout this research, and are extended in Chapter 5, where the relationship between leadership and employee resilience is hypothesised for Phase 1 exploration. The next chapter discusses the methodological approaches taken in this research, including the ontological and epistemological position of the researcher, as well as the design of the research process. 


\section{METHODOLOGY}

The following chapter outlines the methodological approach taken in this study. This includes the assumptions held about truth and the development of knowledge as well as the research design underpinned by this approach. These issues are important to acknowledge before presenting the more specific details regarding the nature of methods employed for each phase of the study.

\subsection{Ontology and epistemology}

As Jacquette (2002) attests, researchers need to justify their "beliefs about what exists before [they] can venture philosophically to say what particular things and kinds of things actually exist" (p. 13). The term "ontology" relates to premises about the nature of existence and what the world actually is (P. A. Hall, 2003). Individual conceptions regarding the nature of existence can be marked on a continuum from a realist conception of the world to a constructivist one (Morgan, 2013; Neuman, 2013). The former relates to a single reality that exists independently from an individual's personal perceptions of this reality, while the latter recognises multiple realities, determined by the different beliefs and social experiences of different individuals (Morgan, 2013). Inquiry about the world is sometimes perceived from either end of this continuum, reflecting a strict adherence to a singular view of reality and its underlying assumptions. In reality and practice, however, knowledge is ultimately approached from anywhere along the continuum, depending on various personal and contextual factors (Morgan, 2007). There is added value in this more flexible and natural approach to knowing and inquiring. Observing multiple realities and acknowledging the integration between different views can broaden and enrich our understanding of reality, or “truth” (Rorty, 1980).

This research adopts an ontology that is neither exclusively realist nor constructivist, but instead lies in between this dichotomy. This perspective assumes that there is a reality that exists outside of human experience, but that reality is also understood through human experience and interaction with the world (Morgan, 2013). Thus, the nature of reality is both real and socially constructed; and realism and constructivism are mutually relevant. The social construction of reality is both a result of unique individual interpretations of the world and a product of socially shared experiences that have developed throughout history. In this sense, reality is made up of social knowledge of the past and present, and is continuously developing with every new social inquiry. This means that beliefs about reality can also be changed and modified, and even though there are beliefs we currently 
believe to be true, society does not need to "adhere dogmatically should we obtain overruling reasons to believe otherwise” (Munn \& Smith, 2008, p. 8).

In addition to ontology, there is epistemology. This relates to how we define and use knowledge to shape our understandings (Steup, 2005). Consistent with the above perspective on the nature of reality, the epistemological position taken in this study is one that values both the existence of an external reality outside human and social experiences, and yet recognises that seeking to explore the reality defined by human consciousness and co-construction (Robson \& McCartan, 2016) is equally important in knowledge creation and development. Using both objective and subjective realities to create meaning and advance social understandings is a priority in this study.

Pragmatism guides this research. A pragmatic view of the of the world sees that ideas and beliefs are linked to our practical engagement with the environment, not to any defined ‘truth’ (Guyon, Kop, Juhel \& Falissard, 2018). Diverse factors and perspectives exist in our environment and help us to develop robust understandings of the world we live in and interact with. There is no static truth - our interactions shape our understandings of the world and our role in it. Our understandings are both complementary and contradictory: sharing and valuing these differences is what will take us forward to shape new propositions and challenge existing assumptions.

Pragmatism promotes the integration of different perspectives to address real world problems in a rigorous manner (Bogard \& Wertz, 2006; Fishman, 1999). In social research, there is a "need for the combining of quantitative and qualitative methods to answer applied research questions about complex, unknown social realities (Bogard \& Wertz, 2006, p. 396). One unknown reality, explored in this study, is the way in which line managers can foster resilient behaviours in employees. This supports the famous pragmatist, Dewey's (1929) view that mentalities and behaviours result from the "transactions [between] the body [and] its social and biological environment” (Guyon et al., 2018, p. 155).

\subsection{Research paradigm}

This research is underpinned by the belief that reality is infinitely complex and human beings can never fully understand it in its truest form. A pragmatic view sees that there is "no method for knowing when one has reached the truth, or when one is closer to it than before” (Rorty, 1980, p. 726). Since reality, and thus truth, is infinite, it is our behaviours and interactions with our physical world that co-create meaning, and further our understandings. Pragmatists are constantly seeking new insights and knowledge, not to 
reach or define truth itself, but to help us better interact with the world as we know it (A. Kaplan, 1964).

Pragmatism sees that new knowledge is created by approaching multiple perspectives on reality and truth. In the pursuit of new knowledge and understandings, pragmatists value the finite and the infinite, the particular and the universal, and the subjective and objective. To advance this notion, Bazeley (2016) attests that "any phenomenon, whether physical, emotional or cognitive, intrinsically has both qualities and quantities” (p. 190). In life, for instance, people require a certain amount of food and sleep, but to be sustainable for human wellbeing these factors also need to be of adequate quality. Another example, from a more relevant empirical perspective, is the notion that researchers using numbers, or quantity, to investigate a phenomenon need to first develop a qualitative understanding of the relevance of theory to the numbers, and then make meaningful qualitative judgements on those numbers to inform conclusions (Bazeley, 2016; Gorard, 2010).

This research recognises multiple realities and values both subjective and objective knowledge. It acknowledges that by embracing multiple forms of knowledge, new and unexpected insights can emerge, which may not have otherwise been seen under strict adherence to the "rules" stipulated by another existing paradigm, such as pure or naïve realism, idealism or pure constructivism (Morgan, 2007). In valuing diverse perspectives on knowledge and understanding (Kuhn, 1962), the researcher can engage with different forms of data in a balanced way in order to comprehensively and practically address the research questions, and solve research problems (Feilzer, 2010; Tashakkori \& Teddlie, 2010).

\subsection{Research design}

This study used an integrated mixed-methods research design to investigate the research aim of identifying and explaining leadership behaviours that enable or inhibit employee resilience in public sector contexts. By integrating methods, this research values both the objective quantitative and the more subjective qualitative, particularly in respect to how they overlap, or integrate, to provide a strong basis upon which to reflect on findings, and subsequently generate rich insights (Bazeley, 2016). Integrated research designs combine methods so that they are treated as interdependent and mutually reinforcing (Bazeley, 2018). An integrated perspective acknowledges that there are stages throughout the research process that require points of careful reflection, such as recognising complementary or contradictory findings or combining analyses from different phases of 
data collection, and this can help generate useful insights to better inform subsequent phases of the research process.

Integrated designs stand in contrast to conventional processes for undertaking mixed methods research which are promoted by more traditional typologies of mixed-methods research design (Creswell, 1999; Ivankova, Creswell, \& Stick, 2006). These wellestablished designs are helpful in establishing consensus regarding the value of, and complementarity between, both quantitative and qualitative data, but they do tend to assume an independence and isolation of the quantitative and the qualitative. This means they limit a researcher's ability to engage in iterative exchange across and between methods before the final interpretation and discussion of a given study (Bazeley, 2018). This divide also makes an implicit assumption about the incompatibility between paradigms (Feilzer, 2010). This can place constraints on the flexibility and adaptation needed in order to best address research aims and questions, particularly in multi-phase research designs such as this one. Addressing research aims effectively may indeed require temporal shifts in recognising relevant perspectives of prominent paradigms (Morgan, 2007), such as between realism and constructivism mentioned earlier. In reality, empirical inquiry is not linear but an ongoing, iterative, and reflective process (Brannen, 2017) and through an integrated mixed-methods design, this research embraces this principle.

This research employs both quantitative and qualitative research methods. Specifically, two quantitative research phases and three qualitative phases were undertaken. The first quantitative phase aimed to identify the enablers of employee resilience. Qualitative phases were conducted between the initial and final quantitative phases. These qualitative components aimed to enrich and add explanatory insight and depth to inform and explain the quantitative findings (Creswell \& Clark, 2017). The final quantitative phase was aimed at further validating the qualitative findings in a final survey. This supports the overall research objectives of this study as it allows for robust examination of the enablers of resilience, particularly at the leadership level, through identifying them, explaining them, and validating them.

\subsubsection{Research phases}

There were five key phases in this research design, with various stages of integration in between phases: Phase 1 consisted of collecting and analysing data from a quantitative survey ( $n=222)$, Phase 2 and Phase 3 involved two distinct sets of interviews ( $n=20)$, Phase 4 was a combination of focus groups $(n=7)$, interviews $(n=6)$, and written feedback ( $n=14)$, and Phase 5 comprised a final survey $(\mathrm{n}=893)$. 
The quantitative survey in Phase 1 aimed to identify leadership antecedents to employee resilience. In other words, it sought to gain an understanding of what leadership styles or constructs can enable employee resilience. It also sought to test perceived organisational support as a mediator in the relationship between leadership and employee resilience. The leadership style of interest was paradoxical leadership.

Phase 2 and 3 involved two rounds of sequential interviews. The first round, Phase 2, involved further identifying resilience-enabling leadership behaviours through qualitative inquiry with public servants and managers. The second round involved confirming these behaviours with a different sample of only employees, and gathering an understanding of how these behaviours were perceived and experienced by employees, including the perceived impact, if any, they had on resilient employee behaviours. An explanatory framework of resilience-enabling leadership was subsequently developed. As well as having standalone explanatory value, this framework was used as a form of inductive scale development for testing and use in subsequent phases (Hinkin, 1998).

Phase 4's aim was to validate the findings of the explanatory model that was developed in Phase 2 and 3 for scale development purposes. Focus groups, interviews, and written feedback elicited expert feedback on the validity of the resilience-enabling behaviours, and their mechanisms.

Phase 5 constituted a final quantitative survey testing the newly developed RELS for various forms of statistical validity. This included exploratory and confirmatory factor analyses, and assessing is predictive validity in relation to employee resilience.

\subsubsection{Research visualisation}

The methodological approaches (including the ontology, epistemology, and research paradigm) taken are summarised in the figure below. The research design, as shaped by the methodology, is also visualised in Figure 3. 


\section{- Ontology and epistemology}

- Reality is multi-faceted and diverse.

Acknowledges realities that are internal and subjective, as well external and objective.

\section{-Pragmatism}

-Seeks productive insights to better interact with the world as we know it. Diverse perspectives on truth and knowledge are needed.

\section{Figure 2: Methodological approaches}

\section{Integrated mixed-methods design}

-Combining qualitative and quantitative methods enriches insights and understandings. Empirical inquiry is ongoing, iterative and reflective. 


\section{Phase 1 (n=222) Quantitative}

Sought to: quantitatively identify potential enablers of employee resilience (paradoxical leadership and perceived organisation support)

\section{Integration}

Reflected on: what other behaviours can be helpful for employee resilience

\section{Phase 2 (n=10) Qualitative}

Sought to: qualitatively identify leadership behaviours that are helpful for employee resilience

\section{Integration}

Reflected on: how employees experience these behaviours and how they impact their resilience

\section{Phase 3 (n=10) Qualitative}

Sought to: qualitatively identify and explain the mechanisms and outcomes underlying resilience-enabling leadership, in the pursuit of developing a framework for testing

\section{Integration}

Developed: an explanatory framework for resilience-enabling leadership

\section{Phase 4 (n=13; 4) Qualitative}

Sought to: qualitatively gather feedback from experts to inform the development of a resilience-enabling leadership scale for quantitative testing

\section{Integration}

Confirmed: the revised resilience-enabling leadership scale for quantitative testing

\section{Phase 5 (n=893) Quantitative}

Sought to: validate the resilience-enabling leadership scale

\section{Integration}

Presented: the final, validated, resilience-enabling leadership scale

\section{Final integration and discussion}

Discussed: what we now know about employee resilience and resilience-enabling leadership 


\subsection{Summary}

This chapter presented the methodological underpinnings and structure of this research. The research is philosophically informed by pragmatism, and the research design is one that uses mixed methods in an integrated way. The five phases of research were also briefly summarised. The purpose, nature, and findings of each phase will be discussed in more detail in the appropriate method and findings sections that follow. At the end of each findings section there will be an integration section, whereby findings will be discussed with the integration of literature, particularly regarding the way in which they relate to, or inform, preceding and subsequent phases. The following chapter precedes Phase 1 , and discusses the concepts of paradoxical leadership and perceived organisational support, in relation to how they might enable employee resilience. 


\section{PARADOXICAL LEADERSHIP, PERCEIVED ORGANISATIONAL SUPPORT, AND EMPLOYEE RESILIENCE}

The tensions and paradoxes of public sector management (Wällstedt \& Almqvist, 2015; Witesman \& Wise, 2009) mean that more flexible approaches to management are required (Clegg, Cunha, \& Cunha, 2002). A paradoxical approach to public sector leadership might work as it responds to the realities and demands of the context.

\subsection{Paradoxical leadership}

Existing studies on paradoxical leadership state that it offers the flexibility to integrate seemingly conflicting behaviours in order to best address the situation at hand (Zhang et al., 2015). Paradoxical leadership reflects this idea of integration as such leaders "attempt to integrate or harmonise inherent tensions concerning control and empowerment over time” (Zhang et al., 2015, p. 543). Common tensions requiring integration may relate to the presence of both control mechanisms for organisational stability and functioning, and the human element of organisation, which is flexible and unpredictable but essential for innovation, growth and adaptability (Zhang et al., 2015).

Zhang et al. (2015) empirically explored paradoxical leadership and developed a multidimensional view of the construct. This view and measure of paradoxical leadership is comprised of "combining self-centeredness with other-centeredness, maintaining both distance and closeness, treating subordinates uniformly, while allowing individualization, enforcing work requirements, while allowing flexibility, and maintaining decision control, while allowing autonomy” (Zhang et al., 2015, p. 41). The approach allows leaders and followers to address complex organisational tensions in an integrated way.

This research argues that there are two ways in which paradoxical leadership can directly contribute to employee resilience. The first is through social learning, a concept mentioned previously. In leadership terms, social learning is described as an observational form of employee learning, which occurs through the behaviour modelling and training performed by leaders (Bandura, 1977; Decker, 1986). The most relevant form of modelling in this research is that which "occurs in the day-to-day relationships between manager and employees" (Decker, 1986, p. 48). The effect is that followers will learn and respond to modelled norms and attitudes displayed by leaders through learning daily behaviours that match and support those of the leader (Bandura, 1977). 
The second way is by creating what Zhang et al. (2015) call bounded and discretionary work environments. The authors argue that paradoxical leadership creates such an environment, whereby leaders use their locus of influence to establish a hierarchical structure and control mechanisms, whilst also giving them the discretion and individuality to make decisions and work autonomously within this structure (Zhang et al., 2015). This type of environment is associated with employee proficiency, proactivity, and adaptiveness (Zhang et al., 2015). This study posits further that such an environment will also promote resilient behaviours in employees.

\subsubsection{Social learning}

According to Smith and Lewis (2012), “paradoxical leadership requires cognitive complexity to juxtapose seeming contradictions, explore potential synergies, and question oversimplified either/or assumptions” (p. 229). When leaders articulate the unique and necessary interrelationship between tensions in their work context, followers can be more motivated to embrace and manage tensions as well (W. K. Smith \& Lewis, 2012; W. K. Smith \& Tushman, 2005). Managing tensions effectively can in turn give employees more energy to learn new things, adapt to changing environments and ultimately develop a capacity for resilience (W. K. Smith \& Lewis, 2011).

Paradoxically skilled leaders promote decision making that is both flexible and adaptive. They also model and/or articulate the reasoning behind these behaviours to followers (Waldman \& Bowen, 2016). Flexibility and adaptiveness help individuals and organisations embrace the need for high situational awareness and creative problem solving skills, both of which in turn promote resilience (McManus, Seville, Vargo, \& Brunsdon, 2008; Waldman \& Bowen, 2016).

Paradoxical leadership can also contribute to adaptive and proactive behaviours in subordinates (Zhang et al., 2015). Leaders themselves must also be adaptive and proactive if they are to understand their environment, along with its inherent paradoxes, and respond accordingly. Adaptive behaviour in subordinates relates to "handling crises, work stress, uncertainties, and emergencies” (Zhang et al., 2015, p. 545), while proactive behaviour is "the extent to which the individual takes self-directed action to anticipate or initiate change in the work system or work roles” (Griffin, Neal, \& Parker, 2007, p. 329). These behaviours are reflective of resilience capacity in employees. For example, resilient employees handle high workloads effectively, as well as re-evaluate their own performance on a continuous basis (Kuntz et al., 2016). 
An important paradoxical behaviour of leaders is the ability to show humility whilst having a strong sense of self (Waldman \& Bowen, 2016). The former can be shown through using the strengths of others and sharing the limelight with followers and peers. The latter includes a strong sense of self and communication of beliefs and values (Waldman \& Bowen, 2016). Through this, employees may learn the importance of maintaining selfconfidence and self-efficacy whilst eliciting the humility required to critically evaluate their own behaviour and performance, as well as work effectively with others (Kuntz et al., 2017).

Paradoxical leaders can articulate the tensions in their work context, and model how they can be managed. Employees can then observe and learn necessary skills for managing paradoxes and public administration dilemmas. Through social learning, paradoxically competent leaders promote these skills in their team through flexible decision making, and by articulating to employees the reasoning behind their behaviours (Waldman \& Bowen, 2016). Further, their flexibility enables situational awareness and creative problem solving, both of which promote resilience (Waldman \& Bowen, 2016). Paradoxical leadership skills also entail conflict management, as it actively elicits tensions to seek creative solutions (W. K. Smith \& Lewis, 2012).

\subsubsection{Work environments}

Managing paradoxes, such as between structural and relational demands would also foster work environments in which employees know “clearly what to do and how to do it” (Zhang et al. 2015, p. 546). In such circumstances, paradoxical leaders use hierarchies to establish high work requirements, but let employees use personal strengths and capabilities, and have discretion and influence, to achieve job-related and personal goals. When combined with social learning, these work environments would provide the standards, the opportunities, and the means to develop resilience.

Treating followers uniformly whilst also allowing individualisation, one aspect of paradoxical leadership (Zhang et al., 2015), can promote a healthy, team-based context for collaboration, a key component of resilience. Allowing individuals' strengths to shine whilst at the same time fostering an egalitarian structure in teams allows members to contribute (and collaborate) confidently without being overly competitive or individualistic. Leaders can set norms for collaboration in other ways too. Smith and Lewis (2012), for example, argue that paradoxical leadership involves conflict management skills and being able to "actively elicit tensions and use such information to seek creative solutions” (p. 229). 
Through modelling key behaviours and creating a bounded and discretionary work environment, it is expected that a leader who engages in paradoxical leader behaviours is subsequently developing subordinate resilience. Thus, the first hypothesis for quantitative testing in this study is as follows:

H1: Paradoxical leadership will be positively related to employee resilience.

\subsubsection{Perceived organisational support}

Not only is it important to identify enablers of employee resilience, such as leadership in this case, it is also necessary to attempt to understand the mechanisms through which such enablers can influence resilience. These mechanisms might reflect the protective factors that exist as positive resources for resilience (D. L. Brown, 2008; Werner, 2000). There may be many different mechanisms that work to influence resilience, and it may depend on the context. Perceived organisational support (POS) is one potential mechanism.

POS, or employees' perceptions regarding "the extent to which the organisation values their contributions and cares about their wellbeing” (Eisenberger \& Stinglhamber, 2011, p. 26), may well support resilience and help to explain how paradoxical leadership is beneficial in resilience development. POS has been widely understood as a process of social exchange (Eisenberger, Huntington, Hutchison, \& Sowa, 1986; Wayne et al., 1997). Social exchange theory is widely established, and strongly influential, in organisational behaviour studies (Cropanzano \& Mitchell, 2005). The theory is used to refer to "the reciprocal flow of valued behaviour between participants” (Emerson, 1976, p. 347). This might be seen when employees with high POS feel committed and reciprocate positive behaviours back to their employer as a result of experiencing commitment, inclusion and recognition from their leaders (Wayne, Shore, Bommer, \& Tetrick, 2002; Wayne et al., 1997).

Leadership is known to have organisation-wide effects (Igbaekemen, 2014; Lok \& Crawford, 2004). Past studies have identified how perceptions of wider organisational support can stem from line manager behaviours, and how subordinates consequently reciprocate not just to their leader, but also the wider organisation through a range of social capital and task/citizenship behaviours (Ladd \& Henry, 2000). These processes, reflective of social exchange, can be enhanced by effective leadership and high-quality leaderfollower relationships (Gottfredson \& Aguinis, 2017).

POS may increase when leaders recognise an employee's accomplishments, through supervisory actions such as providing promotion and development opportunities, simple 
acknowledgements of good work, and encouraging sustained commitment to the organisation (Wayne et al., 1997). In a context operating under conflicting demands and tensions, a paradoxical, or balanced, approach to leadership might be what is needed to contribute to these forms of recognition. By addressing and explaining the paradoxes inherent in contemporary people management, employees will feel considered and likely to subsequently develop an understanding of what organisational support looks like in the contemporary public context, where job characteristics are not only complex, but often inherently paradoxical. By better matching these job characteristics, employees are likely also to feel more considered and supported. If leadership matches the reality of employees' jobs, they are more likely to have meaningful social exchanges and get the resources needed to support their performance and wellbeing.

POS leads to beneficial outcomes for employees, such as greater commitment, job involvement, and performance (Rhoades \& Eisenberger, 2002). POS also benefits organisations through employees "taking actions to protect the organisation from risk, offering constructive suggestions and gaining knowledge and skills beneficial to the organisation” (Eisenberger \& Stinglhamber, 2011, p. 189). Such consequences are similar to aspects of employee resilience, such as the ability to conceptualise novel solutions, take initiative, and share information and knowledge (Lengnick-Hall et al. 2011). These behaviours matter in response to complex demands and changing public sector environments (Kim, 2004; Morris \& Jones, 1999). Paradoxical leadership, mediated through POS, would therefore motivate followers to face tensions and paradoxes in their jobs, learn new things, adapt to change and ultimately develop their resilience.

This study predicts that paradoxical leadership will promote perceptions of organisational support, thus facilitating reciprocation in resilient social exchange behaviours, such that:

H2: The relationship between paradoxical leadership behaviours and employee resilience will be mediated by perceived organisational support.

\subsection{Summary}

This chapter introduced paradoxical leadership, perceived organisational support, and the subsequent implications for resilience development. The chapter generated empirical questions for inquiry in Phase 1, shown through Hypotheses 1 and 2. The next chapter presents the method, results, and integration for Phase 1. 


\section{PHASE 1: SURVEY ON PARADOXICAL LEADERSHIP AND EMPLOYEE RESILIENCE}

\subsection{Introduction}

Phase 1 constituted an anonymous quantitative survey to identify enablers of employee resilience. In specific, it investigated the relationships between paradoxical leadership behaviours, perceived organisational support, and employee resilience. This survey was sent out to employees and managers in a large public sector organisation in New Zealand. Its purpose was to identify the potential enablers of employee resilience, and therefore address the research question of: What leadership behaviours enable employee resilience? In particular, it sought to test Hypotheses 1 and 2, of Paradoxical leadership is positively related to employee resilience, and The relationship between paradoxical leadership is mediated by perceptions of organisational support, respectively. The findings show support for both hypotheses.

\subsection{Method}

\subsubsection{Sample and design}

The survey was administered in a large public sector organisation (2000+ employees) in New Zealand. This organisation was approached because of its representativeness of the wider public sector. The organisation is diverse in terms of function and roles, with six different functional departments and a well-defined vertical structure. Service and policy are core functions of the ministry, but there are also other areas of the organisation that consist largely of front-line and operational staff (SSC, 2017a). Access to the organisation was gained through email contact and subsequent meetings with senior management. Meetings with the organisation established that there would be mutual benefits gained from the research.

The survey sample consisted of 250 employees and 250 managers from six different functional departments, selected purposively by the organisation. Purposive sampling was chosen to ensure a rich distribution of perspectives (Creswell \& Clark, 2017). The criteria for the purposive sampling was a mix of individuals with and without managerial responsibilities, a distribution of individuals from the organisation's different functional departments, and a relatively even distribution across genders. These criteria were communicated to the organisation, who then generated an Excel spreadsheet with a sample of 500 individuals that matched these requirements, including a gender split. This method 
allowed the researcher to focus on the purpose of the study, and subsequently identify those with characteristics that are relevant to the study (Etikan, Musa, \& Alkassim, 2016).

The survey itself was designed and developed on Qualtrics, an online survey development platform, that can export data for programmes like SPSS and Excel for analysis. It was chosen because of its ability to manage all phases of survey design and administration. It is also free for use at Victoria University of Wellington and commonly used in academic studies (Snow \& Mann, 2013). Before distributing the survey to the sample, a copy was sent to the organisation for checking and feedback. A pilot survey was sent to a small selection of individuals outside of the sample population, asking for any feedback on the survey design and user experience. Since all scales used were already established, the pilot survey did not ask for any feedback regarding the content validity of items and scales. Once the survey design was refined and finalised, an email was distributed anonymously to the sample with a link to the full survey. This email also included information about the survey, specification of voluntary participation and anonymity, and other ethical conditions of the study. The university's ethics committee approval number for this phase is 00000236560. (See Appendix B for other ethics documents.)

The survey remained open for approximately one month, and three anonymous reminders were automatically sent out to non-completers during that time. The survey yielded a $47 \%$ response rate, consistent with the benchmark for organisational research - within one SD of 50\% (Baruch \& Holtom, 2008). The respondent characteristics are presented in Table 3. 
Table 3: Respondent characteristics

\begin{tabular}{|c|c|c|c|}
\hline & & Frequency & Percentage \\
\hline \multirow[t]{2}{*}{ Gender } & Male & 104 & $47.3 \%$ \\
\hline & Female & 116 & $52.7 \%$ \\
\hline \multirow[t]{6}{*}{ Age } & $18-24$ & 6 & $2.7 \%$ \\
\hline & $25-34$ & 52 & $23.7 \%$ \\
\hline & $35-44$ & 57 & $26.0 \%$ \\
\hline & $45-54$ & 57 & $26.0 \%$ \\
\hline & $55-64$ & 41 & $18.7 \%$ \\
\hline & 65 or older & 6 & $2.7 \%$ \\
\hline \multirow[t]{8}{*}{ Ethnicity } & NZ European & 146 & $66.4 \%$ \\
\hline & Māori & 11 & $5 \%$ \\
\hline & Samoan & 1 & $.5 \%$ \\
\hline & Cook Islands Māori & 1 & $.5 \%$ \\
\hline & Tongan & 1 & $.5 \%$ \\
\hline & Chinese & 4 & $1.8 \%$ \\
\hline & Indian & 6 & $2.7 \%$ \\
\hline & Other & 50 & $22.5 \%$ \\
\hline \multirow{3}{*}{$\begin{array}{l}\text { Managerial } \\
\text { responsibility }\end{array}$} & No managerial responsibility & 178 & $80.2 \%$ \\
\hline & Team leader or middle manager & 32 & $14.4 \%$ \\
\hline & Senior-level manager & 12 & $5.4 \%$ \\
\hline \multirow{8}{*}{$\begin{array}{l}\text { Occupational } \\
\text { category }\end{array}$} & Clerical or Administrative Worker & 9 & $4.1 \%$ \\
\hline & Contact or Call Centre Worker & 1 & $.5 \%$ \\
\hline & Inspection or Regulation Worker & 52 & $23.5 \%$ \\
\hline & $\begin{array}{l}\text { Manager (e.g. manager, team } \\
\text { leader) }\end{array}$ & 25 & $11.3 \%$ \\
\hline & $\begin{array}{l}\text { Professional (e.g. legal } \\
\text { professional, policy analyst) }\end{array}$ & 76 & $34.2 \%$ \\
\hline & Scientist & 20 & $9 \%$ \\
\hline & Technician and Trades Worker & 7 & $3.2 \%$ \\
\hline & Other & 32 & $14.4 \%$ \\
\hline
\end{tabular}

Approximately 5\% more females than males took part in the survey. Although this is not a large difference, it does, to some extent, reflect the gender distribution of the New Zealand public sector overall, where women make up $60.5 \%$ of the workforce (SSC, 2017b). The age distribution (primarily 25-64) is also similar to the working population of New Zealand. It does appear to also support the finding that the public sector is ageing, with the proportion of workers over 55 making up $21.4 \%$ of respondents (comparable to $24.1 \%$ of New Zealand's total public sector (SSC, 2017b)). The distribution across ethnicities is notable 
too, in that it reflects statistics on ethnic diversity in the New Zealand public sector overall, although slightly lower rates of Māori and Pasifika peoples took part in this survey compared to the sector average (SSC, 2017b). Eighty point two percent of respondents were employees with no managerial responsibility. Although it is also important to get the perspectives of higher level managers, this was a desired distribution because the survey was primarily focused on perceptions of one's manager, and those with no managerial responsibility seem very likely to have a distinct manager they can reflect on. This is not to say that managers themselves are not also managed to a degree, so their inclusion in the sample is also important and desirable. The occupational categories show that professional and inspection/regulation workers comprised the majority of respondents. These job types are common in public sector work (SSC, 2017a).

\subsubsection{Data screening}

Two hundred and thirty three (233) individuals responded to the survey (47\%). Two hundred and twenty two (222) of these responses were usable after cleaning the data and performing missing values analysis. The 11 cases that were removed had either empty or very nearly empty response categories.

Cleaning the data involved renaming items and variables, computing variables from single items, and inversing reverse scored items. Little's MCAR test was then used to analyse the nature of the missing values in the original dataset. This determined whether missing data was missing in a random, or non-random way, so that the appropriate replacement technique could be employed (Tabachnick \& Fidell, 2007). The test resulted in the following values: $\chi 2$ /df $=2136.06 / 2251.00, p=.96$. The non-significant value meant the null hypothesis that the data was missing at random could be accepted. This finding, coupled with the fact that the missing values accounted for only $4.27 \%$ of the dataset, meant that multiple imputation methods could be used to replace the missing data (Tabachnick \& Fidell, 2007). Multiple imputation with the Expectation-Maximization (EM) algorithm was the technique chosen to impute the missing data due to the relatively low bias found for the technique, as well as its well-established use generally (D. C. Howell, 2008; Lin, 2010). This process was undertaken using Missing Values Analysis in SPSS.

\subsubsection{Measures}

The three key constructs of interest that were measured in this survey were employee resilience, perceived organisational support, and paradoxical leadership behaviours. Demographic variables, such as age, gender, ethnicity and occupational category were also measured. All construct items were measured on 7-point Likert scales (ranging from $1=$ 
strongly disagree to $7=$ strongly agree). Two control variables were used in the testing of this mediation model. These were gender and management level.

\subsubsection{Control variables}

Gender was included because of its common influence in social research (Callanan \& Davis, 2012; LaGrange \& Silverman, 1999). Gender was found to be nonsignificant in terms of its effect on both POS $(\beta=-.06, \mathrm{p}=.36)$ and employee resilience $(\beta=.05, \mathrm{p}=$ .49). Thus, it was excluded from the main mediation analyses.

Managerial level (no managerial responsibility vs. managerial responsibility) was also included as a control, such that those with different managerial responsibilities might experience paradoxical leadership (and its effects through POS) in slightly different ways. Specifically, management level was included to determine whether the relationships between paradoxical leadership, POS, or employee resilience could differ depending on managerial responsibility. Perhaps managers, for instance, who tend to experience more autonomy and control (Dobbin \& Boychuk, 1999), rely less on leadership when judging their perceptions of organisational support. Non-managers, on the other hand, might place primary importance on social exchange relationships with their leaders/managers when assessing the support they receive from their organisation.

\subsubsection{Conceptual measures}

Employee resilience was measured by the 10-item Employee Resilience Scale (EmpRes) developed by Näswall, Kuntz, Hodliffe and Malinen (2015). It measures the degree to which respondents engage in resilient behaviours. They were asked to indicate their level of agreement with the item statements $(1=$ strongly disagree, $7=$ strongly agree). An example item is "I effectively collaborate with others to handle unexpected challenges at work”. The scale’s Cronbach’s alpha for reliability in this study was .80.

Perceived organisational support (POS) was measured using a shortened six-item version of the POS scale developed by Eisenberger and colleagues (1986), with a Cronbach's alpha of .91. This scale was also measured by level of agreement with the item statement (e.g. 1 = strongly disagree, 7 = strongly agree). An example item is "My organisation strongly considers my goals and values”.

Paradoxical leadership behaviours was measured at the individual dimension level due to the distinct factors found by Zhang et al. (2015) in their exploratory factor analyses. The dimensions measured were: treating subordinates uniformly while allowing individualisation ( $\alpha=.96)$; combining self-centredness with other-centeredness $(\alpha=.72)$; 
maintaining decision control while allowing autonomy $(\alpha=.82)$; and maintaining both distance and closeness ( $\alpha=$.79) (Zhang et al., 2015, p. 548). Again, the Likert scale values represented levels of agreement with the item statement. Zhang et al. (2015) proposed a fifth dimension in this scale (enforcing work requirements while allowing flexibility), through which to measure paradoxical leadership, but this was removed during exploratory factor analysis for reasons that will be discussed. Respective example items are: "My manager uses a fair approach to treat all subordinates uniformly, but also treats them as individuals" (uniformity and individualisation); "My manager shows a desire to lead, but allows others to share the leadership role” (self- and other-centredness); "My manager controls important work issues, but allows subordinates to handle details" (decision control and autonomy); and "My manager recognises the distinction between supervisors and subordinates, but does not act superior in the leadership role” (distance and closeness).

\subsubsection{Data analysis}

The survey data was analysed using SPSS. Reliability and factor analyses were conducted first to ensure the robustness of the variables in the conceptual model. Descriptive statistics were then calculated to develop an initial understanding of the nature of the dataset and the relationships between variables. This involved calculating frequencies, central tendencies, and measures of variability in the data. Bivariate correlation analysis was then used as a descriptive measure to ascertain the general relationships between the key variables of interest.

Hayes' PROCESS tool for mediation analysis (Hayes, 2012, 2013) tested the hypotheses for this phase of the research. This tool combines the functions of other mediation and moderation tools in one specialised programme with several models for different statistical procedures (Hayes, 2012). Mediation analyses were run using Model 4 of the PROCESS tool where $\mathrm{X}=$ the four key dimensions of paradoxical leadership, $\mathrm{M}$ = perceived organisational support, and $Y=$ employee resilience (see Figure 4). The analyses were run with 5,000 bootstrapped samples, as per convention (Creedon \& Hayes, 2015). The bootstrapping method has high statistical clarity and replicability, and it helps researchers to make more realistic inferences about the distributions within a sample (Efron \& Tibshirani, 1994; Yu, 2003). In these mediation analyses, the indirect effect of X on Y is the most notable value, in that full mediation, or the "gold standard", is represented by a significant indirect effect with a non-significant direct effect (Baron \& Kenny, 1986; Zhao, Lynch Jr, \& Chen, 2010). 


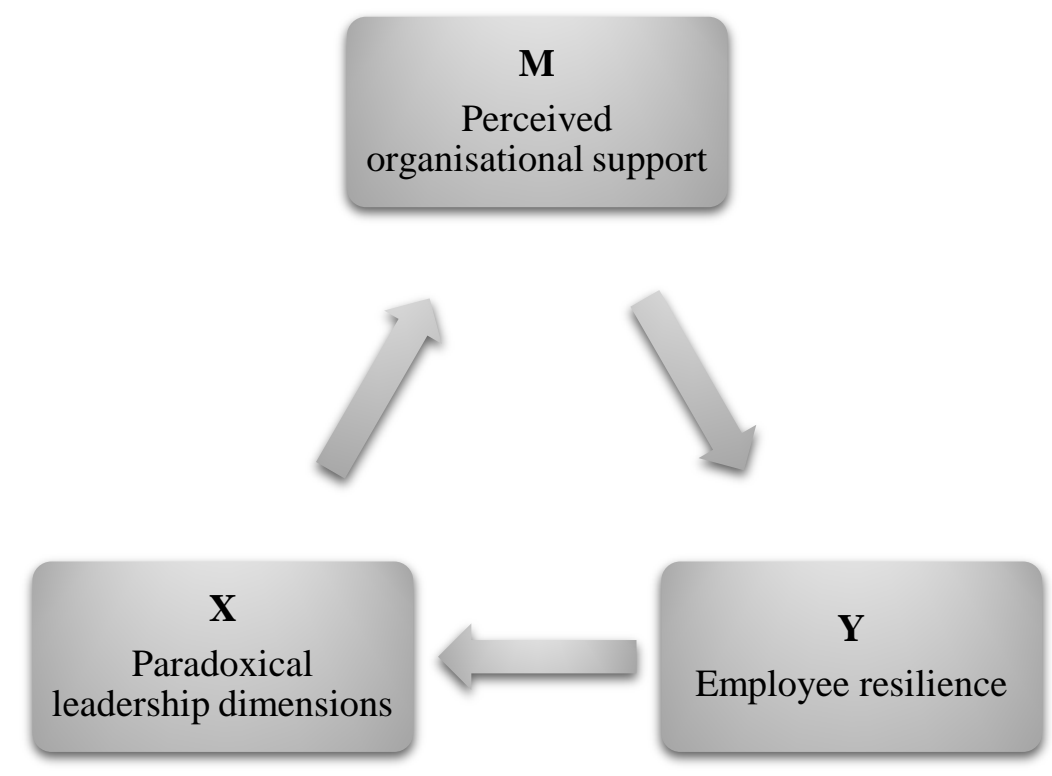

\section{Figure 4: Mediation model}

\subsubsection{Factor analysis}

Exploratory factor analysis was conducted in this phase. Principal Axis Factoring was used for the extraction method and Direct Oblimin was chosen as the rotation method. Principal axis factoring is a well-known and widely used common factoring method (Ford, MacCallum, \& Tait, 1986; Hinkin, 1998). Direct Oblimin is an oblique rotation method which assumes the factors are correlated, as expected in this research (W. P. Vogt, 1993). A combination of item factor loadings $>.40$, single factor loadings for items (no cross loadings above .3) (DeVellis, 2016), Kaiser's criterion (eigenvalues >1), scree plot inspection, and parallel analysis (Hayton, Allen, \& Scarpello, 2004; Kaiser, 1960) were determinants of retention decisions.

Factor analysis was conducted on all multi-item scales in this study, and while perceived organisational support and employee resilience performed as expected as unidimensional measures, further work was needed to achieve a clear factor structure for the paradoxical leadership scale.

The five dimensional (five-factor) 22-item paradoxical leadership scale (Zhang et al., 2015) showed high KMO statistics for the KMO and Bartlett's test (.90, $p=<.001)$. But initial factor analysis yielded results that required further examination. Consistent with Zhang et al.’s (2015) factor analysis, a five-factor solution was expected. However, results showed a poor fit as a five-factor model, with eigenvalues suggesting a four-factor model and the fifth factor explaining only $2.41 \%$ of the variance. Upon inspection of the scree plot 
(Cattell, 1966) it was also clear that there was no point of inflection at component number five.

The result was a 14-item, four-factor model consisting of uniformity and individualisation (5 items), self- and other-centeredness (3 items), control and autonomy (3 items), and distance and closeness (3 items). The factor of requirements and flexibility was removed due to low factor loadings, cross loading of items across factors, and poor content (Schriesheim, Powers, Scandura, Gardiner, \& Lankau, 1993).

The remaining items performed well as part of a four-factor model, with four eigenvalues $>1$ explaining $66 \%$ of the variance. The communalities after extraction were all above .45 (as recommended by Costello \& Osborne, 2005) and the KMO and Bartlett's tests for sphericity were significant $(>.8,<.001)$. There were no cross loadings and factor loadings of $>.4$ were achieved for all items within factors. Factor loadings supported the relationship between item content and the dimensions originally developed by Zhang et al. (2015), except for requirements and flexibility, where the entire dimension was excluded. Parallel analysis was performed to check the four-factor model's performance beyond the Kaiser's criterion test and a good fit was found. Factor loadings for the four-factor, 14-item, model are presented in Appendix C.

\subsection{Findings}

\subsubsection{Frequencies and descriptive statistics}

This section presents results of the descriptive statistics for the hypothesised variables of interest (Table 4). These scores show relatively high means for the conceptual variables, particularly for employee resilience. 
Table 4: Descriptive statistics of Phase 1 study variables

\begin{tabular}{|c|c|c|c|c|c|}
\hline & $\mathbf{N}$ & Min & Max & Mean & Std. Deviation \\
\hline Gender & 222 & & & & \\
\hline Management level & 222 & & & & \\
\hline $\begin{array}{l}\text { Uniformity and } \\
\text { Individualisation }\end{array}$ & 222 & 1.00 & 7.00 & 4.93 & 1.41 \\
\hline $\begin{array}{l}\text { Self- and Other- } \\
\text { Centeredness }\end{array}$ & 222 & 1.00 & 7.00 & 4.16 & 1.06 \\
\hline $\begin{array}{l}\text { Control and } \\
\text { Autonomy }\end{array}$ & 222 & 1.00 & 7.00 & 4.85 & 1.20 \\
\hline $\begin{array}{l}\text { Distance and } \\
\text { Closeness }\end{array}$ & 222 & 1.00 & 7.00 & 4.54 & 1.16 \\
\hline $\begin{array}{l}\text { Perceived } \\
\text { Organisational } \\
\text { Support }\end{array}$ & 222 & 1.00 & 7.00 & 4.63 & 1.22 \\
\hline $\begin{array}{l}\text { Employee } \\
\text { Resilience }\end{array}$ & 222 & 1.00 & 7.00 & 5.76 & .53 \\
\hline
\end{tabular}

Note: All variables, except control variables were measured on a 7-point Likert scale.

\subsubsection{Correlation analysis}

The table presented below (Table 5) shows the correlations between the conceptual variables measured in this phase.

Table 5: Correlations of measured variables

\begin{tabular}{|c|c|c|c|c|c|c|c|}
\hline & & 1. & 2. & 3. & 4. & 5. & 6. \\
\hline 1. & $\begin{array}{l}\text { Uniformity and } \\
\text { individualisation }\end{array}$ & $(.96)$ & & & & & \\
\hline 2. & Self- and other-centeredness & $.43^{* *}$ & $(.72)$ & & & & \\
\hline & Control and autonomy & $.42^{* *}$ & $.42^{* *}$ & $(.82)$ & & & \\
\hline & Distance and closeness & $.26^{* *}$ & $.30^{* *}$ & $.19^{* *}$ & (.79) & & \\
\hline & Employee resilience & $.20^{* *}$ & $.16^{*}$ & $.23^{* *}$ & .09 & $(.80)$ & \\
\hline & $\begin{array}{l}\text { Perceived organisational } \\
\text { support }\end{array}$ & $.56^{* *}$ & $.30^{* *}$ & $.26^{* *}$ & $.19^{* *}$ & $.31^{* *}$ & $(.91)$ \\
\hline
\end{tabular}

Note: N=222, Cronbach’s alphas displayed on the diagonal.

Table 5 reveals that the Cronbach's alphas for all variables are adequate (> . 70) (Nunnally, Bernstein, \& Berge, 1967). The majority of the variables reveal a score of above $>.80$, which is desirable for short to medium length scales (Cortina, 1993). All paradoxical leadership behaviours, except for maintaining distance and closeness, were all significantly correlated with employee resilience. POS is also significantly related to employee resilience, as well as to all dimensions of paradoxical leadership. The correlations between the dimensions of paradoxical leadership were all significant, however they were not high 
enough to raise concerns regarding unidimensionality (Cortina, 1993). This means each dimension was sufficiently unique to be classed as a single factor within a multidimensional scale.

Hierarchical regression analysis revealed that neither of the controls (gender or managerial level) had significant effects on POS or employee resilience. However, when included as covariates in the mediation analyses, managerial level was found to have a significant effect on POS. It was also deemed important to test whether managerial level made a significant difference to the indirect effects of each paradoxical leadership dimension through POS. This was done by running a moderated mediation model (Hayes’ PROCESS, Model 8) with managerial level moderating the mediation models. Differences were found between the direct and indirect effects, but all but one of these differences were not significant. The significant difference was found for the direct effect of Control and Autonomy, which was significant for non-managers $\left(\beta=.18^{* *}\right)$, but not for managers $(\beta=.04)$.

\subsubsection{Mediation analyses}

The coefficients of the mediation analysis are shown in Table 6 below. The direct effect of perceived organisational support on employee resilience was significant. In regards to the dimensions of paradoxical leadership, all indirect effects on employee resilience (via POS) were significant. However, the direct effect on employee resilience was only significant for control and autonomy, indicating that this dimension has a unique contribution to resilience that the others do not. In addition, all paradoxical leadership dimensions had significant effects on POS (path $a$ ). Uniformity and individualisation has a particularly strong path to POS as well as the strongest indirect effect out of all dimensions. Distance and closeness, on the other hand, was the weakest dimension in its relationship to employee resilience, both directly and indirectly through POS. 
Table 6: Total, direct and indirect effects on employee resilience, mediated by perceived organisational support.

\begin{tabular}{|c|c|c|c|c|c|c|c|c|}
\hline \multirow{2}{*}{$\begin{array}{l}\text { Predictor } \\
\text { variable }\end{array}$} & \multirow{2}{*}{$\begin{array}{l}\text { Total } \\
\text { Effect } \\
\text { (c) }\end{array}$} & \multirow{2}{*}{$\begin{array}{l}\text { Direct } \\
\text { Effect } \\
\left(c^{\prime} / b\right)\end{array}$} & \multirow{2}{*}{$\begin{array}{l}\text { Predict- } \\
\text { ing the } \\
\text { mediator } \\
\text { (a) }\end{array}$} & \multirow{2}{*}{$\begin{array}{l}\text { Indirect } \\
\text { Effect } \\
\text { via POS } \\
(a b)\end{array}$} & \multicolumn{4}{|c|}{ Indirect effect } \\
\hline & & & & & $\mathrm{SE}$ & $\begin{array}{l}95 \% \\
\text { CI } \\
\text { Lower }\end{array}$ & $\begin{array}{l}\text { 95\% } \\
\text { CI } \\
\text { Upper }\end{array}$ & $\begin{array}{l}p \text { - } \\
\text { value }\end{array}$ \\
\hline $\begin{array}{l}\text { Uniformity } \\
\text { and } \\
\text { individualis- } \\
\text { ation }\end{array}$ & $.22 * *$ & .04 & $.54^{* * *}$ & $.18^{* * *}$ & .04 & .08 & .24 & .0001 \\
\hline $\begin{array}{l}\text { Self- and } \\
\text { other- } \\
\text { centeredness }\end{array}$ & $.17^{* *}$ & .08 & $.30 * * *$ & $.10 * *$ & .03 & .04 & .15 & .002 \\
\hline $\begin{array}{l}\text { Control and } \\
\text { autonomy }\end{array}$ & $.23 * * *$ & $.15^{* *}$ & $.27 * * *$ & $.09 * *$ & .02 & .03 & .13 & .005 \\
\hline $\begin{array}{l}\text { Distance and } \\
\text { closeness }\end{array}$ & .09 & .03 & $.18^{* *}$ & $.06^{*}$ & .02 & .02 & .12 & .02 \\
\hline $\begin{array}{l}\text { Perceived } \\
\text { organisational } \\
\text { support }\end{array}$ & & $.33^{* * *}$ & & & & & & \\
\hline
\end{tabular}

\subsection{Integration}

Phase 1 set out to understand how paradoxical leadership might relate to employee resilience. There were two hypotheses proposed and tested in this phase. These were H1: Paradoxical leadership is positively related to employee resilience and H2: The relationship between paradoxical leadership is mediated by perceptions of organisational support.

\subsubsection{Hypotheses testing}

Only one dimension of paradoxical leadership, control and autonomy, had a significant direct relationship to resilience. H1 was therefore only partially supported. POS, however, mediated (or in the case of the control and autonomy dimension, partially mediated) the relationship between all paradoxical leadership dimensions and employee resilience. Support for $\mathrm{H} 2$ was therefore strong. In sum, these findings suggest that the POS (mediation) pathway between paradoxical leadership and employee resilience is more consistent across dimensions than the direct pathway. Arguably, this suggests that high quality social exchanges matter more than direct behaviour modelling within social learning interactions and the work environment itself, which were theorised as embedded in the direct relationship between paradoxical leadership and employee resilience. A lack 
of meaningful, motivational exchanges, rather than limited skill or highly controlled environments, could be the reason employees may not behave resiliently.

The one direct relationship - between control and autonomy and employee resilience suggests a unique role for this dimension in public sector work contexts. It may strongly reflect the work environments in public services that are largely controlled but, at the same time, require autonomy and discretion for real effectiveness in uncertain environments. The dimension may reflect leadership behaviours that directly influence resilience in employees by encouraging both controlled and discretionary behaviours and an awareness of the appropriate situations in which to engage in them. This also relates to this leadership dimension's ability to harness both bounded (controlled) and discretionary (autonomous) work environments in which employees know what is expected of them but are, in turn, given discretion to do their jobs (Zhang et al. 2015). This dimension corresponds to extensive, and long standing, arguments in the job design literatures for more autonomy (Wu, Griffin, \& Parker, 2015) and public administration research which expresses concern about red tape and controlling hierarchies (Colley, 2001; Giauque, Ritz, Varone, \& Anderfuhren-Biget, 2012). These findings show that this kind of contextual tension likely permeates down to line manager skillsets, and that these in turn may influence important employee behaviours.

The direct effect of control and autonomy was significant for non-managers, but nonsignificant for managers. This suggests that the maintenance of control, with the allowance of autonomy, might be a more important leadership paradox for employees who are more directly "controlled" by their manager and do not have management responsibilities requiring them to be more flexible in their approach. Perhaps managers value autonomy from their leaders, without an overarching air of supportive control. This result suggests that the explanation given in the above paragraph may apply more directly to non-managers than managers.

The fact that the manager group had a weaker indirect effect for control and autonomy than non-managers is also worth noting. Managers are exposed to more of the organisation, and hence have more sources of perceived support. They may therefore view POS as something quite distinct from how their bosses lead them. This difference would be useful to explore further, perhaps with a larger sample to check for significance.

In contrast to control and autonomy, the other dimensions (uniformity and individualisation, self- and other-centredness, distance and closeness) primarily concern the social, or relational exchange systems in organisations - in this case, public agencies and are related to resilience only through POS. This indicates that they act primarily as a 
means of motivation through social exchange. For example, considering individual needs equally, whilst showing concern for the wellbeing of the group, may reduce the potential for favouritism and the subsequent divisions it can foster within teams. The strength of the Uniformity and Individualisation dimension could be attributed to the role that individual consideration and fair recognition can play in enhancing perceptions of support (Allen, Shore, \& Griffeth, 2003). This dimension also reflects the emergence of more collective, relational approaches to leadership in public contexts, compared to the earlier, more controlling, NPM-forms of leadership (Dunoon, 2002; Ospina, 2016; Zeier et al., 2018).

Another more relational dimension that corresponds to the social aspects of work is selfand other-centeredness. The POS pathway was significant, but not as strong as uniformity and individualisation. Perhaps this signifies that this dimension is more about perceptions of the leader's personality i.e. their self-confidence and humility (Waldman \& Bowen, 2016), rather than what they actually provide for the employee in terms of support, trust, and high-quality interactions, although this is clearly still important.

\subsubsection{Resilience-enabling leadership}

If leadership behaviours match the reality of employees' jobs and is responsive to the needs of employees, they are more likely to have meaningful social exchanges and get the resources needed to support their performance and wellbeing (Van Wart, 2014). These resources may come in the form of leader behaviours, such as direction, delegation, support, allowing autonomy, or coaching, which may, in themselves be paradoxical, depending on the situation (Hersey \& Blanchard, 1972). For employees, having a leader who can alternate between different styles to effectively handle different situations can be helpful for resilience (Patel, 2010). Such a leader would also potentially model adaptive, resilient behaviours that are most necessary for a particular situation.

The situational and contextual nature of leadership behaviours indicate that the paradoxical leadership scale may not fully reflect leadership that matches the public-sector context. In other words, there may be a broader set of leader behaviours that more comprehensively match and reflect public administration. There are several potential reasons for this. First, the fact that the paradoxical leadership scale was developed in the Chinese context (Zhang et al., 2015) indicates a possibly limited applicability to the Western and New Zealand contexts. The strong mediation results through POS suggests that the impact of leadership may be more about social exchange than explicit capability development and modelling. Paradoxical leadership may match the job content of public servants, but it might not match the more relational, exchange-based, development needs of employees. Furthermore, not 
all daily experiences of public servants are paradoxical in nature. Thus, other forms of leadership, other than paradoxical, might be more appropriate.

The above arguments suggest that a reconsideration is needed, both of employee resilience and the forms of leadership that may more directly enable behaviours such as networkleveraging, learning, and adaptability in the public sector. More enquiry is required in this research to further explore what leadership behaviours and competencies can enable resilience in employees. To understand what these might be, it is necessary to reflect on the exact nature of resilient behaviours, and how leadership could both impact and reflect them, particularly within the public sector context. These ideas are developed below.

\subsubsection{Network leveraging ability}

Networking leveraging ability is, as established, a key behavioural component of employee resilience. It includes behaviours such as collaboration, seeking support and exchanging resources (Kuntz et al., 2017). Van Wart (2014) has emphasised the salience of collaborative leadership in the public sector context. Collaborative leadership is about facilitating individuals in "working with groups inside and outside of the organisation" (Hsieh \& Liou, 2016, p. 84). This matches the requirements of the public sector to engage effectively in intra- and inter-agency collaboration and networked governance (J. W. Campbell, 2016; Silvia \& McGuire, 2010; Stoker, 2006). Of note, Getha-Taylor (2008) argues that achieving public goals requires collaboration over more centralised decision authority. In order to address this need, she goes on to identify the collaborative competencies of employees in the public sector, and these constitute a key part of the behavioural repertoire of employee resilience. Effective collaboration relates to other resilient behaviours like problem solving, learning, adaptability, and flexibility (GethaTaylor, 2008; Kuntz et al., 2017; Lengnick-Hall et al., 2011). Thus, leadership that explicitly fosters, and even models, network development and collaboration is likely to be needed for this aspect of resilience to be activated in employees.

\subsubsection{Learning}

Learning is another key component of employee resilience (Kuntz et al., 2017). Thus, leadership that is geared towards employee learning and disseminating new knowledge is likely to be another enabler of employee resilience. Malik and Garg's (2017) study brings relevant insights into how employee learning can be facilitated by leaders. The authors studied the impact of learning organisations on employee resilience, and found that the strategic leadership component of learning organisations was positively related to 
employee resilience (Malik \& Garg, 2017). This relates to leadership that supports the learning-oriented goals of an organisation. Strategic leadership may well contribute to employee resilience by steering individuals toward a learning-orientation, and supporting them to engage in learning opportunities (Malik \& Garg, 2017). Both of these are important for resilience development as they speak directly to a number of resilient behaviours, namely problem-solving, learning from mistakes, adaptability, and re-evaluating performance.

Learning-centred leadership is another relevant idea that has been highlighted in public administration scholarship as an effective approach in the public context (Dunoon, 2002). Like resilience capacity, it "involves fostering the conditions under which people, working together, are better able to create new visions, productively deal with underlying issues . . . and change workplace cultures" (Dunoon, 2002, p.3). Learning-centred leadership is described here as being a combination of both leadership and management. While the former inspires individuals to cope with, and learn from, challenge and change, the latter helps employees maintain consistency, continuity, and stability (Dunoon, 2002). In sum, it is clear that an employee's will and ability to learn at work can only be fully enabled if they have a leader who openly facilitates and fosters learning in their organisation.

\subsubsection{Adaptability}

Certain forms or behaviours of leadership may enable the third key behavioural component of resilience, which is adaptability. Leadership that enables individuals to adapt to complex demands and changes in the public context is likely to be important in the development of employees' adaptive behaviours, such as the ability to cope with high workloads and use change as an opportunity for growth (Kuntz et al., 2017). Murphy, Rhodes, Meek and Denyer (2017) argue the need for complexity leadership in the public context, in order to help public servants "cope with the complex, collaborative, cross-boundary, and adaptive work" they are engaged in (p. 692). Broadly speaking, complexity leadership is leadership in and of complex systems (Uhl-Bien \& Marion, 2009). This area of leadership scholarship is likely to shed some light on how leadership can develop adaptive, collaborative, resilient employees (Uhl-Bien, Marion, \& McKelvey, 2007), particularly in the bureaucratic systems (Uhl-Bien \& Marion, 2009) that tend to exist in the public sector. Like the idea of adaptive authority (Heifetz, 1994), complexity leadership requires a figure of authority "to maintain a sense of stability in order to coordinate, structure and control organisational activity” (J. Murphy et al., 2017, p. 692). At the same time, complexity leadership must be able to enable the conditions for innovation and change, thus balancing administrative and 
adaptive functions that necessitate modern organisation (Heifetz, 1994; J. Murphy et al., 2017).

Similar to collaborative leadership, complexity leadership prioritises network leveraging as a key leadership principle (Uhl-Bien \& Arena, 2017). This occurs when leaders facilitate the movement and exchange of knowledge and ideas across an organisation (Uhl-Bien \& Arena, 2017). This likely fosters collaborative behaviours in employees, as well as across teams, and models an openness to learning via the exchange of ideas, thus helping to promote a capacity for resilience.

\subsubsection{Implications for subsequent phases}

What has been argued here is that it likely takes a complex set of behaviours, particularly those that relate to complexity, adaptability, collaboration and learning, to enable employee resilience in the public sector. This does not discount the role of paradoxical leadership in the development of employee resilience, rather it broadens the scope to allow for identification of other effective leadership behaviours. Paradoxical aspects may well exist, but they do not, in themselves, reflect the full behavioural repertoire of resilience-enabling leadership to meet employee as well as job requirements. However, it is still unclear what specific behaviours of leaders enable resilience in public sector employees. They likely consist of a diverse mix of behaviours best explored qualitatively, reflecting a more inductive form of theory development (Locke, 2007). Qualitative exploration will also provide a deeper consideration of context, which in this case will reflect the public sector environment. Thus, the following phase will consist of semi-structured interviews with public servants and managers, to elicit resilience-enabling leadership behaviours as experienced by individuals working in the public sector.

\subsection{Summary}

This chapter presented the methods and findings for the initial quantitative survey - Phase 1. It found partial support for H1, that paradoxical leadership would be positively related to employee resilience. H2 was more strongly supported, as POS mediated the relationships between the paradoxical leadership dimensions and employee resilience. Implications of these findings for subsequent phases were also discussed. The following chapter presents Phase 2 of this research, which uses interviews to further identify resilience-enabling leadership behaviours. 


\section{PHASE 2 - IDENTIFYING LEADERSHIP BEHAVIOURS}

\subsection{Introduction}

Phase 2 sought to draw on managers' and employees' experiences to identify leadership behaviours they considered to be beneficial for employee resilience. This phase was exploratory in nature, whereby the phenomenon of resilience-enabling leadership was explored. This phase explores further the research question of: What leadership behaviours enable employee resilience?

These interviews used the critical incident technique (Flanagan, 1954) to encourage participants to first identify an event that required resilience, and then discuss what leadership behaviours helped (or also hindered) an individual's ability to behave resiliently. Managers reported on the experience of managing individuals, whilst employees reported on their own experiences of being managed.

This phase aimed to develop an initial list of behavioural categories that were found to influence employee resilience in the public sector. This was a first step in establishing a framework for understanding resilience-enabling leadership behaviours, that will be further explored and tested in subsequent phases. In other words, this phase, along with insights from Phase 1, was about identifying behaviours, and helped to initiate the development of a resilience-enabling leadership framework that can be further explored, understood, and tested throughout this research.

\subsection{Method}

\subsubsection{Participants}

This phase consisted of 10 interviews with public sector employees (4) and managers (6). Although a relatively small sample size, this number satisfied the goal of analysis which was to meaningfully inform the subsequent phases of research (Bazeley, 2018; Guest, Bunce, \& Johnson, 2006; Marshall, Cardon, Poddar, \& Fontenot, 2013). Insights and contextual richness were sought over generalisability (Firestone, 1993), in contrast to the more generalisable, quantitative, and deductive, approach used in Phase 1. Insights, in the case of this research, relate to new knowledge and understandings, useful for subsequent stages in this research. The focused nature of the questions, which will be described below, also increased the likelihood that responses would be meaningful, and appropriate saturation would be reached (Mason, 2010). Saturation in this context relates to the 
generation of sufficient insights to establish preliminary knowledge to meaningfully inform, and explore further in, subsequent phases (Frels \& Onwuegbuzie, 2013; Sandelowski \& Given, 2008).

The sample group was a subset of the same wider purposive sample from the Phase 1 survey, which was generated by the organisation into a spreadsheet format. This sample was determined using a random number generator matching numbers to individuals listed in the spreadsheet of potential survey participants. The chosen individuals were invited to participate via email in batches of 10, so as not to accidentally over-extend the scope of this particular phase, which sought approximately 10 interviews. In the end, 31 individuals were contacted and invited to participate before 10 individuals responded indicating their willingness to participate.

\subsubsection{Procedure}

The invitation email included an information sheet about the purpose of the interviews, as well as clarifying the ethical considerations of the research and the fact that the phase of study had been approved by the university's ethics committee (approval number 00000236560). It also highlighted what the participants were likely to gain by participating in the research, such as a summary report upon completion of the thesis and of course, a chance to make a difference in developing understandings around what helps employees grow, develop, and be resilient at work.

The researcher ensured confidentiality for the research participants, meaning that the individual and their organisation would not be identified in the write-up of the study. Confidentiality would be ensured by using pseudonyms and only identifying participants by their broad job-type/occupation. Participants were given the option of withdrawing from the project within two weeks of the interview, whereby any interview data collected to that point would be destroyed. (Appendix B contains all documents related to research ethics for this phase, as well as Phases 1 and 3).

The participants involved in this phase of the study are listed in Table 7, by their pseudonym. The table also specifies their gender, job-type, and approximate tenure. The participant sample was $40 \%$ female, and had an average tenure of 6.4 years. 
Table 7: Participant characteristics

\begin{tabular}{llll}
\hline Pseudonym & Gender & Position & Tenure \\
\hline Diane & F & Employee, Policy & 15 years \\
Harry & M & Employee, Operations & 2.5 years \\
Patrick & M & Manager, Commercial & 2 years \\
Ellen & F & Employee, Policy & 1.5 years \\
Barry & M & Manager, Auditing & 8.5 years \\
Brian & M & Manager, Policy & 3 years \\
Zena & F & Manager, Operations & 19 years \\
Aaron & M & Manager, Operations & 7 years \\
Chelsea & F & Employee, Frontline & 2 years \\
Orson & M & Manager, Operations & 3 years \\
\hline
\end{tabular}

\subsubsection{Interview structure and design}

The Phase 2 interviews lasted between 25 and 45 minutes and were undertaken at an offsite location of the participants' preference. Locations included university meeting rooms and quiet cafes in central Wellington. One interview occurred over the phone, to accommodate a participant located outside of Wellington. All interviews were recorded.

The critical incident technique, defined as "a procedure for gathering certain facts concerning behaviours in defined situations” (Flanagan, 1954, p. 335), was chosen because of its capacity to gather precise information from an interviewee about the sequence and significance of "behaviours (their own or others') which significantly contribute to a specified outcome” (Woolsey, 1986, p. 242). Thus, each interview was focused around a specific probing question related to a particular event requiring resilience capacity: “Can you tell me about a significant challenge or crisis that required you/your employees to respond in an adaptive and resilient way?” The participant was asked to talk broadly about this situation and then about any leadership behaviours they experienced from their manager (or engaged in as a manager) during this event which helped or hindered the ability to respond resiliently. The word "adaptive" was incorporated in the primary question to allow respondents to think beyond their own, potentially more general, conception of resilience and to recognise that being adaptive is a key part of being resilient (Davis-Street, Frangos, Walker, \& Sims, 2018). At the beginning of the interview, the participants were also asked a general question about their broad job-type responsibilities and experiences working in the public sector. Most of the time, participants understood the questions they were asked, but on occasion they asked for more clarification, in which case a slight 
rewording of the question was given, along with an example. The interview guide is presented in Appendix D.

The critical incident technique is focused enough to maintain sufficient specificity in relation to the incident in question, but it is also relatively open in terms of the range of behaviours that can emerge in participants' responses to the question (Butterfield, Borgen, Amundson, \& Maglio, 2005). This more open approach is one that is necessary in leadership studies. This is because it potentially elicits a freer discussion of perceptions and behaviours related to leadership, which stands in contrast to methods that make use of prescribed models of leadership and are thus in danger of suggesting and imposing elements of pre-established constructs onto the respondent's representation of knowledge, perceptions and experiences (Alvesson \& Sveningsson, 2003; Fulop, 2012). This matches the goal of this phase, as well as the wider research goal, which is to identify key leadership behaviours, rather than solely using pre-defined models and theories of leadership to predict resilience capacity. The latter only tells a small part of the story, as seen in Phase 1.

\subsubsection{Analysis}

Content analysis (Drisko \& Maschi, 2015) was used to analyse the interviews from Phase 1. There were three main cycles of coding in this phase (Miles, Huberman, \& Saldana, 2014; Saldaña, 2015). First, structural coding was used to organise the responses to the key critical incident question and the subsequent probes (MacQueen, McLellan, Kay, \& Milstein, 2008). Responses related to both helpful and harmful leadership behaviours evident in critical incidents.

It was important here to retain participants' specific responses to the questions, which is something a critical incident approach can effectively enable. Thus, structural coding according to the exact words individuals used, (i.e. verbatim text), was employed. This process identified segments of text to form the basis of more specific, in-depth analysis. The units of analysis were manifest codes pertaining to the certain leadership behaviours identified by participants, such as being "supportive" or treating subordinates in an "individualised" manner, as well as more latent, formal codes that were derived from attitudes and preferences towards particular leadership approaches in the context of the event in question, such as "the importance of collaboration or the negative impacts of micromanagement” (Drisko \& Maschi, 2015). Aside from the central focus on leadership behaviours and resilience in the interview questions themselves, this cycle of coding was not informed by particular theory and was largely data-driven; it was primarily focused on organising ideas as they were described by participants (Namey, Guest, Thairu, \& Johnson, 
2008). This approach matches a priority of this research, which is to align data closely with the research question(s), emphasising the value of individuals' experiences as they are directly explained by participants.

The results of the structural coding process described above led to the identification of 22 categories of resilience-enabling leadership and three broad categories of resilienceharming leadership. This process was then followed by applying theory to the 22 resilienceenabling leadership categories to determine the theoretically relevant behaviours to continue exploring in Phase 3. This was the second coding cycle. Relevant theory in this context relates to the resilient employee behaviours as identified by Kuntz et al. (2017). The specific definition underpinning this understanding is "the capacity of employees to utilise resources to continually adapt and flourish at work, even when faced with challenging circumstances” (Kuntz et al., 2016, p. 460).

Theoretical saturation was sought in this cycle by organising the behavioural categories by the degree to which they contribute to relevant theory (Guest et al., 2006; Morse, 2004). Those that had resilience-related theoretical support were combined under broader thematic dimensions and retained for Phase 3 investigation (Kuntz et al., 2017). Theoretical support was determined by a leadership behaviour having an informed, theory-driven reason why it could relate to, and enable, resilience in employees. This provided further consideration of the participants' responses. For example, leadership behaviours centred around selfmanagement had logical connections to resilient behaviours, as such behaviours - being adaptive, learning, and managing high workloads - require a degree of self-management on the part of the employee. That is, the identified behaviours were not so much related to individuals' personal conceptions of the term resilience, but more so to the particular understanding of employee resilience used in this research, namely the behavioural capacity, combining network leveraging, adaptability and learning behaviours (Kuntz et al., 2017). The tentative labels for the behavioural categories carried through to Phase 3 are: fostering collaboration, encouraging an environment for learning, facilitating career and growth opportunities, providing 'support', recognising individual needs and contributions, and enabling self-management. Examples are provided for each category in the findings section of this phase.

These qualitative categories are hereafter termed "dimensions”, to more appropriately fit their usage in the development of the explanatory framework (Phase 3), and in the quantitative validation (Phase 4 and 5), whereby constructs are understood as multidimensional, a common view in leadership studies (Kalshoven, Den Hartog, \& De Hoogh, 2011; Liden \& Maslyn, 1998; Van Dierendonck \& Nuijten, 2011). These behavioural 
dimensions were not only the most theoretically relevant; they represented the most frequent. The coding frame for determining these final dimensions is shown alongside the respective findings later in this section.

In addition to the conceptually-driven coding processes described above, a more contextually driven coding cycle was undertaken as well. This was coding cycle three. This process was achieved by applying codes to participants' descriptions of both the concept of resilience and the public sector context. Participants' descriptions of the idea of resilience, according to their own understanding were identified in this phase. This was to give background to the participants' own general, but nuanced, understandings of resilience in their contexts.

Elements of the wider public sector context were also important identifiers in this phase, to contextualise the critical incidents and their associated behaviours. For the public context, words, such as "stakeholder involvement”, “complexity” and "bureaucracy” (Fossestøl et al., 2015; Head \& Alford, 2013), were applied to the data as context descriptors. Context descriptions were developed using theory of core aspects of the public sector context, and respondents' descriptions were matched to these where relevant. Explicit descriptions of the public context that did not relate to pre-established concepts such as those referred to above were also accounted for. This decision supported the notion that strict adherence to theory can limit the development of other important ideas that can meaningfully inform research findings and contributions (Namey et al., 2008). The context descriptions, and codes, are presented with the associated findings below. These helped to contextualise the critical incident experiences and leadership behaviours described by respondents.

As referred to above, coding frames were developed for the theory-driven parts of coding cycles two and three, focusing on elements of the public sector context and the resilienceenabling leadership behaviour, since both had theoretically-guided rules for identifying codes. These are presented in the appropriate findings sections to follow. The transcripts were annotated according to the concepts present within them. The coding frame development process was informed by that used by Kurasaki (2000). A coding frame is defined as "a scheme that lays out key concepts, their definitions, and criteria for recognition” (Benaquisto \& Given, 2008, p. 3). These annotations were sorted into categories and codes, as part of the second and third coding processes. Descriptions were then given to explain the final selection of codes to be taken through to Phase 3 , and how they were chosen by the coder. The number of cases out of ten that the code appeared in were also included, as well as the number of total references to the codes made across all interviews. These numbers show the distribution and frequency of the codes, which are 
important indicators of how influential the codes might be (Driscoll, Appiah-Yeboah, Salib, \& Rupert, 2007).

The coding frames were then modified through discussions with an external person for reliability purposes (J. L. Campbell, Quincy, Osserman, \& Pedersen, 2013). This is recommended in studies using content analysis, as it can help to increase coding quality and coder credibility (Burla et al., 2008). The external person coded a 20\% sample of the transcriptions, consistent with the approach employed by Kurasaki (2000). The annotated transcripts were then compared and similarities, differences, and disagreements were discussed. An intercoder reliability value of .90 was achieved as a result of these discussions.

\subsection{Findings}

This findings section will be organised in two main parts. The first will present the findings on both the concept of resilience and the public sector context. The second section will present examples from the interviews which reflect the initial cycle of coding, involving all 22 categories of leadership behaviour that were initially identified. It will then present further examples of the theoretically refined behavioural dimensions of resilience-enabling leadership that will progress through to subsequent phases. Resilience-harming behaviours that emerged in the analysis will also be presented, as individuals did experience times where resilience was not present, and was not supported by leaders, in the face of critical incidents. Note that organisation-specific critical incidents are not quoted to maintain confidentiality of individuals and the organisation.

\subsubsection{The concept of resilience and the public sector}

\subsubsection{Participants' perceptions of the concept of resilience}

The understandings of resilience that emerged in the interviews helped to shed light on participants' general understandings of the concept of resilience, and on the kind of situations where resilience is deemed relevant and important. The quotes given below are illustrative in purpose, and there are not enough shared understandings for them to be generalised into specific codes or themes.

Patrick, a manager, had a particularly strong view of resilience in his experience managing employees. He has described certain employees as being "not very resilient" as people. This suggests a traditional approach to understanding resilience, where it is viewed as a fixed trait or personality characteristic. Patrick also explained the variance between 
individuals when handling stressful situations, and relates this variance to resilience capacity:

I've seen that people respond to stressful situations in different ways. Some people are . . . personally quite resilient. It might be just that they have a degree of maturity, or that they will keep things in perspective or kind of, have their own personal ways of managing stuff. And other people can't, some people are just total stress bunnies and react to everything that happens in a negative way. And those people will struggle. - Patrick, Manager

In the quote below, Patrick describes in detail the behavioural characteristics of one of the employees he managed, who, according to him, lacked resilience capacity. Note that he refers to it being "just his personality":

He didn't cope with stress well. [He] was not very good at managing his own productivity and his own work. Not good at managing his priorities and um, he, regularly found things being a bit sort of overwhelming, and so in that environment, he really struggled. And also . . . just his personality, he really struggled with stressful situations, he'd take everything on board as a personal issue he had to deal with ... [but other] people on the team are all fairly ... ah, what's the word, resilient. - Patrick, Manager

Another manager, Brian, posits that a sense of purpose is associated with resilience, and overcoming adversity:

If they're having a rough time, they get some time to kind of go, "This is why I'm here," and then they can swing back in and it creates that kind of resilience to those things which seem incredibly painful at the time but in the overall sense of things, they are not - Brian, Manager

Brian also makes a connection between the constant change and challenge in policy work and employee resilience. He implies that only the resilient will "survive” this type of work:

We have the constant challenge that there's always churn and change so that does push us to, "Either you're resilient or you're not," and there's an element of that that comes through so some people find policy is not for them pretty quickly, but those who can survive ... well if you survive the first 12 months, you'll be fine! Brian, Manager

Resilience is also required beyond the policy level, in order to deal with the "tensions" of government. Such tensions correspond to those argued in the literature review of this research: 
We personally have to be resilient to the tensions [of government] but we also create ... do we create resilience? That might be stretching it too far but you know, we're part of that tension I guess. - Brian, Manager

Resilience may be related to feeling confident and clear about the future, as Aaron attests below:

Giving people some ideas of what the future could hold and how to get there. For resilience, understanding what your options are is an important part. - Aaron, Manager

Having a purpose, and motivation about that purpose, is potentially, as described by Aaron, another contributor to resilience:

Keeping people reminded of our successes, and where it fits into the big picture is important in maintaining that motivation and when you've got that motivation I think your resilience is up - Aaron, Manager

It is interesting to note that only managers referred specifically to the word resilience, indicating its common use (and misuse) by managers as a general term for effective employee performance. It is also a very popular term in organisations currently, and may be viewed as a more acceptable and desirable term than stress or coping.

These understandings of resilience help to illuminate its contextual nature and also show how definitions of the construct vary between persons. It is important to note however, that the aim of Phase 2 was not to get participants to define resilience, as the research is guided by a more specific definition of resilience: a behavioural capacity of employees (Kuntz et al., 2017). This more focused understanding guided the identification of critical incidents, and the associated leader behaviours presented in sections to follow.

\subsubsection{Participants' descriptions of the public sector context}

The context in which this research is situated is particularly relevant to better understanding the enablers of employee resilience. The nature of the public sector context might play a significant role in the kind of leadership behaviours that are perceived to enable resilience in public servants. As presented in the literature review of this research, leadership is contextual, and the context may play a significant role in determining what kind of leadership behaviours are effective (Getha-Taylor et al., 2011). Elements of this context, as described by participants, are given below. Since this cycle of coding was informed substantially by existing theory and research, reference to literature will be made where appropriate, to reflect the relevance of important ideas that are already well established 
beyond this research project. The coding frame for this section is presented in the table below.

Table 8: Coding frame for the public sector context

\begin{tabular}{|c|c|c|c|}
\hline Code & Description & $\begin{array}{l}\text { No. of } \\
\text { cases } / 10\end{array}$ & $\begin{array}{l}\text { No. of } \\
\text { code } \\
\text { references }\end{array}$ \\
\hline $\begin{array}{l}\text { Public sector } \\
\text { context }\end{array}$ & $\begin{array}{l}\text { Interpretations of organisational and institutional context } \\
\text { that are uniquely related to a government environment }\end{array}$ & & \\
\hline $\begin{array}{l}\text { Stakeholder } \\
\text { involvement }\end{array}$ & $\begin{array}{l}\text { A description of involvement with people and parties } \\
\text { outside of particular organisation }\end{array}$ & 10 & 30 \\
\hline $\begin{array}{l}\text { Resources } \\
\text { (constraints } \\
\text { and poor } \\
\text { allocation) }\end{array}$ & $\begin{array}{l}\text { A description of being constrained or held back by a type } \\
\text { of resource, e.g. labour, finance, capability, or resources } \\
\text { being poorly allocated across departments and } \\
\text { organisations }\end{array}$ & 5 & 11 \\
\hline Complexity & $\begin{array}{l}\text { Use of the words "complex" or "complicated" when } \\
\text { describing the government context and/or a description of } \\
\text { a complex situation, i.e. involving multiple/conflicting } \\
\text { parties or tasks }\end{array}$ & 6 & 11 \\
\hline Change & $\begin{array}{l}\text { A description of changes in a way that indicates it as } \\
\text { reoccurring and/or normal }\end{array}$ & 3 & 6 \\
\hline $\begin{array}{l}\text { Relationship } \\
\text { s }\end{array}$ & $\begin{array}{l}\text { A description of involvement with other government } \\
\text { agencies or industry and/or the use of the word "cross- } \\
\text { agency" in a description of the context }\end{array}$ & 3 & 6 \\
\hline $\begin{array}{l}\text { Task } \\
\text { demands }\end{array}$ & A description of government-specific job/task demands & 9 & 15 \\
\hline Bureaucracy & $\begin{array}{l}\text { Use of the word "bureaucracy" and/or a reference to } \\
\text { rules/regulations/hierarchy when describing context }\end{array}$ & 5 & 5 \\
\hline
\end{tabular}

\subsection{Stakeholder involvement}

Public sector stakeholders come in myriad forms (McAdam, Hazlett, \& Casey, 2005), but two obvious parties consistently referred to by participants were the New Zealand public and relevant industry bodies. Engaging with other individuals and parties outside one's immediate network in decision-making was described as a pertinent, and necessary, aspect of public sector work:

There's challenges working in a large organisation like ours in terms of working across and asking yourself who else needs to know? And you've got to keep asking yourself that, otherwise you can end up paddling without a paddle. - Zena, Manager

The value of involving stakeholders was also emphasised in relation to how it leads to more realistic and consultative decision-making processes: 
I guess what happened is as we started to talk to people, we recognised how much further we needed to take it and how far we needed to take stakeholders on the journey. So that alerted us quite early that we were going to be going a bit further than we'd originally planned. - Brian, Manager

\subsection{Relationships}

Similar to stakeholders was the more specific description of important relationships with external parties (Matthews \& Shulman, 2005). External relationships can be understood as an element of stakeholder engagement. However, compared with stakeholders, such relationships appeared to hold more intrinsic meaning and value for public servants. Ellen, below, valued the role of Māori as Treaty partners in her policy work. She viewed them as more than just stakeholders or "another person to consult":

We see Māori as Treaty partners. And quite often [others] across government just see them as stakeholders. So they're just another person to consult... you get on to business as usual and you'll just consult them with everyone else. Well, that's not how people who work in the Māori parts of government see it, they are actually Treaty partners and so they should be engaged at the beginning of all policy and at the beginning of all kind of work things and feed into that work so it's a joint effort for whatever you do. And then you don't have issues at the end when they say they haven't been consulted and stuff. - Ellen, Employee

Diane talked about external relationships in a slightly different way. Below she explained that dealing with people in the industry is a core element of an effective public sector skillset:

It's quite a tricky environment in the public sector where you know, there's a bit of a mix of the technical stuff plus there's a bit of politics and learning how to deal with [things]. If you're trying to bring in industry on the side of something, understanding that they might not be want to be on side! And that you need to move really slowly and what you think is kind of a small change could be a huge change once you translate that out to the whole industry. So it's about those kind of life skills, worldliness, kind of things as opposed to, "Yup, so you might be a food technologist, I've got my technical qualifications," but it's a bit more about how you deal with people and how you make things happen in this environment. Diane, Employee

Below, Brian explained that external relationships “outside of the bureaucracy” can give individuals energy to provide effective public services. As well as being necessary, as 
outlined by Diane above, external relationships can give individuals more meaning and a realisation of purpose in enacting public sector work:

The thing that's probably most energising is engaging with people outside of the bureaucracy. So as soon as you get out to the people who are actually doing stuff on the ground. Whether that's our frontline staff; I guess they're still in the bureaucracy but they're kind of a step removed. Or getting right out into industry and you make contact with people who are energised about making [public services] happen or they are people who can tell you what the impacts of [services] either working or failing are. That gives the greatest energy and that can sometimes be a way of topping people up. - Brian, Manager

\subsection{Bureaucracy}

The presence of bureaucracy in government organisations is a common and expected fact (Bozeman, 2000). Zena explained the limitations of bureaucratic processes as a manager. The lack of consensus around the way a process should be carried out, it appears, created a significant time burden on tasks and deliverables:

Just yesterday, I had a situation where ... we put a condition on his approval but they hadn't closed it out. They hadn't gone and got an evaluator to go into his business to decide whether we could remove that condition. So that's a process they could have managed way back in 2010 for God's sake. So that's how difficult it is. [It's] very time consuming for us because it takes us hours to figure out the paperwork from 2010 and how to go forward. So I got an ear bashing from the council saying why didn't you do your due diligence!? It's the processes - there's no broad understanding across what we do! - Zena, Manager

Bureaucratic systems mean different things to different people, according to Brian. He compared the "political realities" between the chief executive and front-line employees. Some projects and deliverables might be seen as more achievable depending on where one sits in the hierarchy, and on the different priorities at those levels. Here, it seems to be a battle between grand strategy and financial practicality:

Excitement within the bureaucracy is different at different levels. So the higher you go up to your chief executive, the more you're in an environment that has to deal with political reality. That political reality is quite different to the reality on the ground. So if you have an industry group and they have some specific concerns and then they have some real specific risks they're trying to manage, you can really get a good grip on that and it's easy to say, "Oh yeah, well we could manage this 
by doing all these kind of cool things." If you just swept all those up and then start delivering them in, they have flow-on implications so you wrap around a program with this industry and it's like, "Well, why didn't you do it with this [other] industry?" And then you go, "Okay, we can't actually afford to do all that." Brian, Manager

\subsection{Resources}

Limited public sector resources need to be used carefully and strategically (Hood, 1991). Participants described resource constraints and how poor resource use added further constraint. Resources used poorly in one area limited the effective deployment of resources in other areas, resulting in constrained resources:

When I came, one of my particular areas was to address this lost cause and the problem is that you cannot sacrifice [this service area] but you cannot just keep throwing resource at it. Additional resources aren't always the solution. All that does is exacerbates the problem and takes resources away from other areas of the business. - Orson, Manager

Reducing expenditure, rather than maximising profit, is a key priority in public service operations. Harry described that minimising cost is a key element of resource management in the public sector:

In the government sector, cost is more the driving factor cause you minimise what you cost. If you want to do something new, you've got to get the minister and a whole lot of people on board to ask for more money because you know, government funding is limited to what taxpayer funds are available so as far as that goes that's quite a different sphere moving from private to public. - Harry, Employee

Resource use and allocation was also a relevant factor in Barry's perception of the public context. Prioritisation of resourcing was noted as being particularly relevant:

In terms of how [priorities] stack up against each other and how we actually go about addressing them at a strategic level, we're not very well focused on that. That kind of goes down the line in terms of decisions we make about resources ... So that presents a challenge of knowing what's important. - Barry, Manager

\subsection{Task demands}

In New Zealand, public sector jobs are demanding, both in terms of the hours worked and the intellectual and cognitive load of job tasks (Plimmer \& Cantal, 2016). Task demands was one of the most widely experienced contextual factor described by participants in this 
research. Orson described how the accumulation of demands presents a challenge for the wellbeing of his staff:

When the queue starts extending, the people outside start demanding. When they start demanding, all the attention is focused on addressing those noises, as opposed to addressing the problem and all of a sudden it becomes this increasing spiral so it's very difficult for [staff] to find enough balance and measure to make sure that they've got wellbeing and welfare considered at the same time as delivery. - Orson, Manager

Patrick, a manager, reflected on the impact of workload on his employees. This is a demand that varies over time, and presents challenges for employees, most of whom can cope effectively:

Workload can sometimes be a challenge for some of the team, we have quite a cyclical process that we go through and it means there can be some times during the year where it's a peak workload. That can be challenging, particularly for some of the team who could be better at managing their priorities and end up with everything kind of crunching on one time and putting in the hours to get it done. Um, in general they cope with that pretty well. - Patrick, Manager

Harry explained that those working on the front line and who are accustomed to the nature of typical demands can deal with them better, particularly in terms of how they balance expectations within such a context:

If you've come from an environment where you're used to working in the front line, I think you deal with [certain demands] better. But if you're not, people can perhaps get overwhelmed or um, think that they have to do too much and it's just sort of getting that balance right as to, you know, how you sort of manage a situation like that. - Harry, Employee

Barry told of a particularly demanding task and the impact it had on increasing hours worked and other stressors:

[The task] presented huge challenges in getting things done within that time frame with a team of three people, it required quite a significant degree of management oversight to make sure that all the tasks that needed to be done were getting done and aware of what those across from us were doing. It required quite a lot of additional working hours over and above the standard eight to five, which inevitably creates stressors for people because there's only so much gas you have in the tank. - Barry, Manager 


\subsection{Change}

As well as being prominent in the literature (Karp \& Helg, 2008; Wallace \& Hoyle, 2012), change, and its impact, was a feature of the public context for several participants. Ellen, an employee working in policy, gave a particularly telling description of ministerial changes and the effect they had on how she felt she needed to approach her work to avoid "devastation":

New ministers came on board and the end of last year. Projects that have been ongoing for three or four years and the current minister is all up to date, a new minister comes in and you've got to do all of these briefings and all of this kind of work to get them up to speed in a really short period of time. And they might have a different view from the previous minister, so there's all this work that's been happening behind the scenes and it's changing depending on the minister ... So you can't really become so involved in your work that a change of minister who has ... who wants to scrap it, would be kind of like the end of your ... [laughs] you know, you feel devastated. You have to be adaptive all the time because you know that the government changes quite a lot and that's not really how the public sector should work. But it does work that way unfortunately. - Ellen, Employee

Brian gave a manager's perspective on managing the dynamic nature of public sector work, which involves working across networks and developing a breadth of understanding about issues in a fast-paced manner:

So I guess from a team perspective, we needed to adjust the team to alternately be able to do really in-depth thinking about issues to be able to jump to doing discussions with stakeholders to then completely changing the direction we were going to take because it wasn't going to be acceptable. So constant change in that sense. - Brian, Manager

\subsection{Complexity}

The complex, uncertain, and dynamic nature of the public sector workplace is well-known (Christensen \& Lægreid, 2011a; Fossestøl et al., 2015) and was a feature in participants' descriptions of the context. Below, Diane identified the challenge of dealing with unpredictable and uncertain tasks, crises, and events:

One of the challenging things about it is you don't know what's coming, so it's not like really transactional, "I go and process this" thing, it's you know, dealing with whatever ... crisis emerges [internationally] or whatever crops up, you know, an earthquake. - Diane, Employee 
In the statement below, public sector work is described as having "multiple sides” to it, and the "political realties" of such work contribute to this inevitable complexity:

But for the people who are working there on the projects at the time, the energy comes from knowing what the problem is and what they're trying to do and what's the good for New Zealand and they recognise the slightly demoralising part which is the dealing with the political realities is part of the job and that's how you move New Zealand forward and you have to accept that there's always two sides to everything, multiple sides, many sides. - Brian, Manager

\subsubsection{Leadership and employee resilience}

This section presents the interview findings related to the core purpose of this phase, which was to identify leadership behaviours that enable employee resilience. Resilience-harming behaviours also emerged throughout this endeavour, and are presented as an additional part in this section.

\subsubsection{Examples of the initial categories of resilience-enabling leadership}

Before outlining in-depth the final behavioural dimensions of resilience-enabling leadership derived from this phase of the research, it is helpful to first exemplify the broader behavioural categories that were identified by participants when they were describing leadership that enabled resilience during the identified critical incident. Some categories conceptually overlap, meaning that one example may have been attributed to two or more different categories in the coding process. It is also important to note that the highlighted categories in Table 9 below are those which were retained as key behavioural dimensions for further exploration. 


\section{Table 9: Initial categories of leader behaviours with examples}

\begin{tabular}{ll}
\hline $\begin{array}{l}\text { Category of } \\
\text { leadership } \\
\text { behaviour }\end{array}$ & Example \\
\hline Collaborative & $\begin{array}{l}\text { You need to have quite strong personal networks throughout the organisation } \\
\text { to be able to go, "Who do I know that knows things about this topic, who are } \\
\text { the key people to have on the team for this?" And you know, my own personal } \\
\text { experience [in my team] is that people do come together really well in those } \\
\text { situations ... - Diane, Employee }\end{array}$
\end{tabular}

Collected In general I'm a fairly calm sort of person. I always say, "Don't panic. First and foremost, don't panic, we've got this. When has the world turned into World War 3?” - Zena, Manager

Collective
$\begin{aligned} & \text { How I think I operate is probably different from how I actually operate. But I } \\ & \text { sort of think about treating the team as individuals but sort of having one } \\ & \text { overall way of managing the team. - Patrick, Manager }\end{aligned}$
Self-managing $\begin{aligned} & \text { He doesn't get into the details and he's not managing you, you know he } \\ & \text { believes you can do the job so he gives you the autonomy to do the job so he } \\ & \text { doesn't need to be taken into the minutia of all your work. - Ellen, Employee }\end{aligned}$

Performance Seeing people who do really well recognised is I think really helpful. So oriented success gets recognised, I won't say rewarded but good performance is recognised and that again is an important factor in keeping motivation within people. - Aaron, Manager

Consistent I think it's more just actually being consistent in their approach to management. So if you're gonna micromanage then always micromanage. If you're gonna be hands off then always be hands off. - Chelsea, Employee

Development If [employees] can see this is what I'm doing, this is the purpose, but these oriented other things are out there and I could go there or do this, it gives them a sense of what the future could hold. - Aaron, Manager

Directive When you're working [in such an event], what you've got to have is fast dynamic decision making and its almost two separate approaches. One is quite egalitarian, the other is quite hierarchical. Now the problem that you've got is that people moving from this egalitarian approach into the hierarchical approach under the structure sometimes think, "Oh what are you telling that for?” The reason why you're being told in this more directive manner [here] is because there's no time for you to be able to deliver with an egalitarian approach. - Orson, Manager

$\begin{array}{ll}\begin{array}{l}\text { Learning } \\ \text { oriented }\end{array} & \begin{array}{l}\text { What I say to them is, "Nothing is ever your fault, we all make mistakes, if } \\ \text { you don't make mistakes, you don't learn". - Zena, Manager }\end{array} \\ \text { Supportive } & \begin{array}{l}\text { People know that we will support them if they're in a tricky situation and that } \\ \text { helps them cope better, so I think that's an important thing too. - Patrick, } \\ \text { Manager }\end{array}\end{array}$

Crisis oriented Generally my team will give me the information and I respond to the crisis. Because that's a whole higher level than what they need to be at. I need them to do the work. So I'm there as the crisis person. I take the lead. So in terms of that I get onto it straight away, I ask the question who else needs to know? - Zena, Manager 

wishes on the whole of the team for a job well done, when what we really should do is highlight specifics for certain individuals and highlight different specifics for others. - Orson, Manager

Recognition oriented
I like to make sure that individuals are contributing to different things and are recognised for the contribution in the area not for the general contribution for the whole. - Orson, Manager

Humble

[The event] changed me from somebody that needed to stand under the light and have it shine on me to being able to put the light on every one of those and stand in the middle and the glow from everyone made the light even brighter and that was quite an important journey for me. - Orson, Manager

Trust-based

In some cases people can be micromanaged too much. Sometimes there is a job you have to do and it has to be done by timeline, that's fine. But giving people autonomy and trust I think is a key. And showing that little bit of trust for me is an important one. - Aaron, Manager

Public sector oriented

Purposeful

Proactive

People oriented

Transparent

Visible

Exposure
He knew the roles of government, he already had the machinery of government, he knew how to manage people. Because all of that is actually... government's quite conservative and there's things you need to take into account and there's ways that you have to, kind of, play your role and he knew all those kind of ins and outs so it was real easy. - Ellen, Employee

We know, in our team, how we want to organise ourselves and what role we play and our purpose. But, putting that out to the wider organisation is kind of .... It's good on the lower levels. It's the senior levels that we always seem to run into problems . . . . - Ellen, Employee

And I always say to them we don't want a lot of rework. So it's best to do things, you know, take that little bit more care up front, and time, to ensure that you don't have to rework things. You know, that's really really important. - Zena, Manager

For me, the best managers are people managers, they care about their staff, they put them into training, they develop them to become the best people they can. And then they know how to manage up. They're the best managers. Quite often you'll get managers that just manage up. So all they care about is looking good to the person above them and they don't care about the people below them. - Ellen, Employee

I think good management is just open and honest communication. I don't know if you've found that when you've interviewed people from government sector but it's not entirely transparent with the way we all communicate with each other so, you know, that would be a lot more helpful. - Chelsea, Employee

It's a real skill knowing how to do those various things, to be seen to be consistent in the behaviours you're demonstrating as a leader across the whole, wider team. - Barry, Manager

And we produce a piece of work and then it will hit kickback because someone, in my case my director, understands context that we don't and so this is where there is limits to the autonomy I can provide to my staff. So I try to make sure they hear as many conversations with my director as possible because that helps, she's quite good at feeding back. It gives them a flavour of context. - Brian, Manager 
The highlighted dimensions in the table above had theoretical relevance in the second coding cycle, and were thus combined into the behavioural dimensions of resilienceenabling leadership carried through to Phase 3. The correspondence between the initial categories of resilience enabling leadership and the behavioural dimensions are given in Table 10 below. This table also outlines the relevance of these behaviours to employee resilience. These six dimensions are expanded on in more detail next.

Table 10: Resilient behaviours and categories identified through analysis

\begin{tabular}{|c|c|c|}
\hline $\begin{array}{l}\text { Categories carried } \\
\text { through from } \\
\text { structural coding } \\
\end{array}$ & $\begin{array}{l}\text { Behavioural } \\
\text { dimensions for } \\
\text { categories }\end{array}$ & $\begin{array}{l}\text { Corresponding resilient behaviours } \\
\text { (Kuntz et al., 2017) }\end{array}$ \\
\hline \multirow[t]{4}{*}{$\begin{array}{l}\text { Collaborative } \\
\text { Collective }\end{array}$} & \multirow[t]{4}{*}{$\begin{array}{l}\text { Fostering } \\
\text { collaboration }\end{array}$} & $\begin{array}{l}\text { Collaborating internally with peers, } \\
\text { managers and teams }\end{array}$ \\
\hline & & $\begin{array}{l}\text { Collaborating with people and teams in } \\
\text { other organisations }\end{array}$ \\
\hline & & $\begin{array}{l}\text { Exchanging resources with peers and } \\
\text { managers }\end{array}$ \\
\hline & & Seeking resources from peers \\
\hline \multirow[t]{3}{*}{ Learning oriented } & \multirow{3}{*}{$\begin{array}{l}\text { Encouraging an } \\
\text { environment for } \\
\text { learning }\end{array}$} & Using mistakes as learning opportunities \\
\hline & & $\begin{array}{l}\text { Engaging in crisis management } \\
\text { effectively }\end{array}$ \\
\hline & & $\begin{array}{l}\text { Using change as an opportunity for } \\
\text { growth }\end{array}$ \\
\hline \multirow{2}{*}{$\begin{array}{l}\text { Development } \\
\text { oriented } \\
\text { Supportive }\end{array}$} & \multirow{2}{*}{$\begin{array}{l}\text { Facilitating growth } \\
\text { and career } \\
\text { opportunities } \\
\text { Providing support }\end{array}$} & $\begin{array}{l}\text { Re-evaluating performance on a } \\
\text { continuous basis to improve own work }\end{array}$ \\
\hline & & $\begin{array}{l}\text { Engaging in crisis management } \\
\text { effectively }\end{array}$ \\
\hline \multirow[t]{3}{*}{$\begin{array}{l}\text { Self-managing } \\
\text { Trust-based }\end{array}$} & \multirow[t]{3}{*}{$\begin{array}{l}\text { Enabling self- } \\
\text { management }\end{array}$} & $\begin{array}{l}\text { Managing resources effectively to cope } \\
\text { with high workloads when needed }\end{array}$ \\
\hline & & $\begin{array}{l}\text { Using feedback, including negative } \\
\text { feedback, for learning and improvement } \\
\text { of own work }\end{array}$ \\
\hline & & $\begin{array}{l}\text { Re-evaluating performance on a } \\
\text { continuous basis to improve own work }\end{array}$ \\
\hline $\begin{array}{l}\text { Individualised } \\
\text { Recognition oriented }\end{array}$ & $\begin{array}{l}\text { Recognising individual } \\
\text { needs and } \\
\text { contributions }\end{array}$ & $\begin{array}{l}\text { Using feedback, including negative } \\
\text { feedback, for learning and improvement } \\
\text { of own work }\end{array}$ \\
\hline
\end{tabular}

\subsubsection{Resilience-enabling leadership behaviours}

The behavioural dimensions retained from the first coding cycle are presented here. These are fostering collaboration, enabling self-management, fostering an environment for learning, facilitating career and growth opportunities, providing support and recognising 
individual needs and contributions. The coding frame for the retained dimensions is illustrated in the table below.

Table 11: Coding frame for resilience-enabling leadership

\begin{tabular}{|c|c|c|c|}
\hline Code & Description & $\begin{array}{l}\text { No. of } \\
\text { cases } / 10\end{array}$ & $\begin{array}{l}\text { No. of } \\
\text { code } \\
\text { references }\end{array}$ \\
\hline $\begin{array}{l}\text { Resilience } \\
\text { enabling } \\
\text { leadership }\end{array}$ & $\begin{array}{l}\text { Interpretations of leadership behaviours or factors } \\
\text { which enable resilient behaviours (in the context of } \\
\text { resilience-requiring critical incident) }\end{array}$ & & \\
\hline $\begin{array}{l}\text { Fostering } \\
\text { collaboration }\end{array}$ & $\begin{array}{l}\text { A response related to the encouragement of } \\
\text { employees working together and/or the } \\
\text { effectiveness or importance of working } \\
\text { together/collaborating }\end{array}$ & 7 & 18 \\
\hline $\begin{array}{l}\text { Encouraging } \\
\text { an } \\
\text { environment } \\
\text { for learning }\end{array}$ & $\begin{array}{l}\text { A response related to managers' orientation toward } \\
\text { employee learning and/or the effectiveness or } \\
\text { importance of employee learning }\end{array}$ & 5 & 13 \\
\hline $\begin{array}{l}\text { Facilitating } \\
\text { career and } \\
\text { growth } \\
\text { opportunities }\end{array}$ & $\begin{array}{l}\text { A response related to managers' role in employees' } \\
\text { growth and career prospects and/or its importance } \\
\text { or effectiveness }\end{array}$ & 6 & 16 \\
\hline $\begin{array}{l}\text { Providing } \\
\text { support }\end{array}$ & $\begin{array}{l}\text { Use of word "support" when describing the positive, } \\
\text { supportive, role of managers in challenging contexts } \\
\text { and explanations of participants' perceptions of } \\
\text { managerial support }\end{array}$ & 9 & 18 \\
\hline $\begin{array}{l}\text { Recognising } \\
\text { individual } \\
\text { needs and } \\
\text { contributions }\end{array}$ & $\begin{array}{l}\text { A response related to recognition of employees for } \\
\text { specific and unique work achievements. May be } \\
\text { used contrast to collective and generalised } \\
\text { recognition }\end{array}$ & 6 & 22 \\
\hline $\begin{array}{l}\text { Enabling self- } \\
\text { management }\end{array}$ & $\begin{array}{l}\text { Use of the word "autonomy" and/or reference to the } \\
\text { importance and/or effectiveness of enabling self- } \\
\text { management/autonomy. May be used in contrast to } \\
\text { descriptions of micromanagement }\end{array}$ & 8 & 17 \\
\hline
\end{tabular}

\subsection{Fostering collaboration}

In this phase, it was found that a leader or manager's ability to foster collaboration within the team had the potential to positively impact employee resilience. This relates to enabling communication and strengthening team cohesion. Being able to collaborate and draw on shared skills and competencies, appeared to help individuals deal with both the critical incidents and day to day work activities, both of which require resilience in some capacity. Without the ability to communicate and collaborate effectively with team members, inconsistencies and frustrations can be resulting factors. 
Patrick described an event which required his team to work in closer proximity with each other, which made it easier to engage in communication and mutual support. It also allowed them to recognise and draw on complementary skillsets and experiences:

So it's easy for them to say, "Hey I've got this challenge here. Who else has had this?" ... They valued the opportunity to interact like that ... They supported each other a lot with learning how to do something that they haven't encountered before that someone else might have dealt with. - Patrick, Manager

Zena, below, described her approach to managing as a "collaborative approach". Her approach involves both manager-employee collaboration and general teamwork:

So I always ask for a collaborative approach. And you know, bring them in as part of the situation. And work together on the result or an outcome, however we need to get there. - Zena, Manager

The same manager also described how she articulates this collaborative approach to her team, and highlights that such an approach enables task consistency across the team:

And I use that term ... you know, "Do you all understand what team means? T E A M." This person looked at me funny and I said, "Together, each achieves more." But it's about collaboration, and it is about working together to make sure you are all consistent in how you approach [things], okay? Because we need to be. - Zena, Manager

Articulation of a collaborative or team approach to managing is also evident in the response from Aaron below, who referred to it as "calibration”. He also explained that this approach is important for consistency, this time from a decision-making perspective:

In our team we just refer to it as calibration, just talking to each other, what's come up in the last week, what were the interesting things . . so that we're all aware of what each other's doing because the worst thing we could do is act in isolation and start making decisions which are inconsistent with others. - Aaron, Manager

An employee perspective is given below, supporting the importance of collaboration, particularly in situations that require resilience:

I guess that it is generally a different group of people depending what the issue is. So you kind of had to have quite strong personal networks throughout the organisation to be able to go, "Who do I know that knows things about this topic, who are the key people to have on the team for this?” And you know, my own 
personal experience [here] is that people do come together really well in those situations. - Diane, Employee

The value of sharing skillsets is also a key aspect of effective team collaboration, as Brian described:

Once you kind of introduce people's skillsets and what they can deliver [to each other], that really helps and they'll use them. Our team as a whole, we try to use each other's resources. We all have slightly different skillsets and knowledge so it's good to bounce ideas around between us all. - Brian, Manager

According to Aaron, more informal collaboration and team interactions can be helpful for growth and development as well, beyond informal channels of communication:

While your line manager might be able to give you some things for your development, you learn just as much from your colleagues about what they've done, what they've tried, what worked, what didn't. So I think there are a lot of informal channels that if the culture is right, are just as productive as the formal channels. - Aaron, Manager

The absence of team cohesion is, on the other hand, damaging for resilience capacity, supporting the need for managers to support collaboration and engage in this behaviour. Chelsea experienced poor collaboration, communication and cohesion in her team, and referred to the negative impacts below:

We mostly just end up with two people on either side of it being very frustrated, information being doubled up on or things not actually being done, that kind of thing ... . Yeah, I mean, the majority of our job . . . the difficulties that arise from it are to do with communicating to people and what goes wrong is . . . that communication isn't clear and people getting upset about that kind of thing. Chelsea, Employee

Although the above findings wholly support the need to manage the whole team, recognising and balancing the needs of individuals within the team is equally important. This is supported by the subsequent behaviours in the resilience-enabling leadership framework, as well as by the following quote from a manager:

I think it's important to treat the team as individuals but sort of having one overall way of managing the team. - Brian, Manager 


\subsection{Enabling self-management}

The following description from an employee evidences the importance of being afforded autonomy to engage in work and emphasises the role of support in helping to solve problems:

[All my managers here] have given me the autonomy to produce the work, and I just love that ... then if you have an issue or a problem and you can find a solution then they're around to talk about it . . . . - Ellen, Employee

Below, Ellen explained further her experience of an enabling manager, who believed in her capabilities and afforded her appropriate autonomy:

I don't quite know how my previous manager manages it so well .... But he's only really on the peripheral, he doesn't get into the details and he's not managing you, you know he believes you can do the job so he gives you the autonomy. - Ellen, Manager

One manager highlighted the need to assume capability in individuals and not micromanage them, but also argued that employees themselves should seek support when they need it. This is in some ways reflective of a dyadic exchange process, whereby employees take initiative to seek help, and managers respond through providing appropriate support. This approach appears to foster resilient and proactive help-seeking behaviours in employees:

Helping out team members when they need help but not micromanaging. That's what I try to do, assume that they are capable of doing their job and let them get on with it . . . expect them to hold up their hand if they need help and if need be, get alongside them to help. - Brian, Manager

Orson, a manager, expressed the role of trust in enabling individuals to reach aims and outcomes without frequent direction. His comments also reflect a balance between control and trust, such that control and direction need to exist before a trusting, self-managing, relationship can ensue. He explained how he works to build this trust:

What happens is you grow a trust with the individual you're working with and it might start off with direction but it ends up with suggestion. And that suggestion, once the trust is grown delivers what it was you want. Because you don't need somebody telling you to do it your way, you just need to make sure that the aim is achieved and you can't achieve the aim until you've built the trust. - Orson, Manager 
Once this trust is developed, individuals no longer need direction at every stage of a task, and instead they can autonomously reach an outcome:

You'll start by saying, "I'll need you to go to A via D to get to $B$ and bring back E," whereas later on you'll say, "I need you to bring back E." And it's only as the trust [develops] that you can take out those earlier letters of the alphabet. - Orson, Manager

Speaking more generally, Chelsea attested that enabling individuals to self-manage and make decisions individually is a characteristic of a good or "proper" manager:

And I mean if you're managing someone properly they should be able to make decisions that you would agree with when you're not there, that is kind of how I view a good manager. - Chelsea, Employee

The concept of trust emerged again in the quote by Aaron below, suggesting that allowing a degree of self-management in employees can foster a sense of trust and self-confidence and again, promoting help-seeking behaviours in employees:

If they're given a task and a time to be completed by, one follow up three-quarters of the way through saying, "How you going? Need any help?" And then wait for them to come back with it. Not be on their back every couple of hours saying, "How you going?” [It] can give people confidence that they are trusted. - Aaron, Manager

The quote from Brian below exemplifies the need to recognise competence and subsequently enable autonomy and self-management in employees, while at the same time exposing them to contexts that may be challenging:

While I'll try to give my staff as much autonomy as possible, I will give them as much access to environments that will give them as much understanding of context as possible, there are constraints. They are highly intelligent and highly effective analysts; they really do know what they're doing. They're in many cases much better than I am at this kind of work so they are the experts; there's no point me coming down on them and trying to micromanage. - Brian, Manager

Brian also viewed the work of employees as their own and recognised the importance of letting them maintain ownership of such work. Again, a strong belief in employee capabilities appears to be a significant part of this:

I'm not the type of who's out the front and just owning all the pieces of work that's coming out. They are other people's pieces of work and they should be seen to have 
ownership of it because it's theirs. They're producing high quality, there's no point in ... I don't have to protect them. There's nothing to protect. It's good work. Brian, Manager

\subsection{Fostering an environment for learning}

Fostering learning by providing room for individuals to grow and pushing boundaries was found to be beneficial for employee resilience. Part of this is the managers' learning orientation, and subsequently the way they deal with mistakes made within the team. A number of excerpts from Zena, below, exemplify these ideas.

Well I take them aside and I'd say to them, "So, what have you learnt from this?" You know, so I'd say there's always some learning. So, "What DID you learn and what do you think you could do better next time?" - Zena, Manager

In the above quote Zena was describing her response to incidents that require resilience capacity. Below, Zena reflected on her learning-orientation more generally:

I make them think about things. So I make them think about the situation and say, “Ok, I want you to put yourself in this situation, what would you do?” - Zena, Manager

In support of managers valuing mistakes as learning opportunities and recognising employees’ safe failures, Zena stated the following:

What I say to them is, "Nothing is ever all your fault, we all make mistakes, if you don't make mistakes, you don't learn”. - Zena, Manager

It is also important, according to this manager, not to catastrophise mistakes or errors for employees:

They need to know and understand that they have full support of their manager and their colleagues and to know that making an error, the world isn't going to crumble down around you. - Zena, Manager

This idea of providing a context for safe failures was evident for employees too. Diane, below, explained it as a way to develop in order to cope with further future challenges:

You know, like if you let people make a few mistakes in a really low ... [where] the potential negative is really quite minor, but you let them kind of fail, or also encourage them to deal with difficult situations that as a fresh new person, they're pretty stressful, but they're actually not, you know what I mean, in hindsight you go, "Yeah that wasn't really that bad". I think that helps you to then develop up and be able to deal with more and more difficult situations. - Diane, Employee 


\subsection{Facilitating career and growth opportunities}

Facilitating career and growth opportunities was another prominent behavioural dimension identified in this phase. The growth and development aspect of this dimension corresponds strongly to resilient employee behaviours which centre around learning, adaptation and growth. Objective career successes are also an element of this dimension, but seem to be peripheral, or even an outcome, to these more subjective growth experiences. Orson described the importance of growing and developing individuals so that they can successfully move to a "higher", more challenging role. This manager recognised that real personal development is not staying in the same role and unit for an entire career:

I know the people I've grown and nurtured - and I think it is my responsibility to grow and nurture them. I look on attrition as success if that attrition is from people moving higher or moving to where they want to be. Attrition is a failure if they're leaving because they don't want to be in your environment. And . . we've got people who don't want to leave and are having to grow them to the point that they do. - Orson, Manager

Aaron, a manager, explained that having a clear direction is empowering for employees and is something that helps individuals develop expectations toward the future.

I think giving people a clear direction of where their job is going and what the options are in front of them . . . and that empowers people. If they don't know and they're sitting in a vacuum and think this is a dead end, they can get claustrophobic and frustrated quite quickly. - Aaron, Manager

Manager Zena reflected on the lack of career development she can offer her employees, particularly young graduates. She explained that without a pathway for development, career-driven individuals leave and it is safer for her to employ people who are comfortable "just doing their job, and going home":

So right now they lack a career development path way. And that's not good. So I call these grads at the moment "two minute noodles" because they just want to go from A to B yesterday. You know, and they wanna be up there tomorrow. They're fast thinkers, they're fast innovators. They want your job tomorrow, you know. And if you haven't got a pathway, they're off ... I don't have a career pathway for my team ... I've got to the stage where I can't afford to keep taking grads because I'm losing them. I'm at the stage now where I'm taking someone who wants to come back into the workforce. And they just want to do a job, and go home. - Zena, Manager 


\subsection{Providing support}

Support at a personal level was seen by Patrick as an important way to help individuals deal better with challenging situations, “contributing to resilience'”

I think it's really important to have the flexibility, and the understanding, to help people out when they're going through tough private situations so where people, where there might be an illness in the family or ... they might be going through a difficult . . . personal situation. I've also been in organisations where they talk about support of people but people just quietly disappear from teams which kind of destroys culture. I've worked in organisations where if someone has an illness or some sort of personal issue they're dealing with ... [managers] will go beyond ... and that's a really positive thing in terms of having a strong culture and also contributing to resilience because people know that [someone] will support them if they're in a tricky situation and that helps them cope better. - Patrick, Manager

Diane explained that her manager is supportive, but also allows her to self-manage, suggesting that support may need to be balanced with behaviours that allow learning and autonomy:

My manager ... has a lot of faith in me to manage myself to some extent. In saying that, he's very supportive and you know that if something happens and you need help, he'll be there and he'll do whatever needs to be done to make that happen. Diane, Employee

The quote from Brian below is about the importance of supporting employees with goals and pathways, rather than just providing employees with new roles and positions:

[We] don't necessarily say, "You're an advisor now, you should be an advisor tomorrow, or whatever." We ... go, "This is a route that you could take and here's how you could be supported going down that route." - Brian, Manager

\subsection{Recognising individual needs and contributions}

Recognising individuals for their needs and contributions was also identified as a key leadership behaviour for employee resilience. It has strong resonance with findings in Phase 1 regarding the importance of recognising the individual, as an element of paradoxical leadership. This was often described as something that needs to exist in addition to more general, collective recognition, such that individuals feel valued for their contributions, and their unique needs are recognised. 
Diane explained that not only is the act of recognising important, but so is adapting to how an individual's needs might change and develop over time:

I think it is about a manager recognising where an individual person is at and their needs ... a and like I said I've been in essentially the same role with essentially the same manager, although we've switched a little bit, for 15 years and the style has needed to change over that time. - Diane, Employee

Recognising individuals' unique skillsets can also feed into, and support, collaboration, as diverse knowledge is valued and shared. Brian's quote below exemplifies this notion:

Once you kind of introduce people's skillsets and what they can deliver, that really helps and they'll use them. Our team as a whole, we try to use each other's resources. We all have slightly different skillsets and knowledge so it's good to bounce ideas around between us all. - Brian, Manager

Aaron explained that managers require a certain skillset to effectively recognise the uniqueness of individuals and how these differences influence the way a manager might most appropriately respond to them:

It's very dependent on the manager having a good skillset and being able to recognise different personality types and tailor the message to them and an individual level. Then at a group level. Whether it's a closely managed group, whether it's a hands off group - that's very dependent on the group. The other key thing is ... what's the bigger picture? It's a big organisation, we know our little piece, but keeping people reminded of our successes, and where it fits into the big picture is important in maintaining that motivation and when you've got that I think your resilience is up. - Aaron, Manager

Orson provided more detail on the different ways that individuals might prefer to be recognised. Part of a manager's role, particularly in challenging contexts, is to know what these differences are and how this might influence forms of acknowledgement and recognition:

You've got people with different motivations for being there. Some of them want to stand up and go look I've done my bit I want to recognise people who've done their bit, others go this is important because it's a historical significance and others want to say 'oh look I know some of my family might have been involved in that.' And all those reasons you've got to understand if you want to capture the whole audience and it's exactly the same sort of idea here when you're managing these diverse groups. You have to recognise the different triggers because if you pull the 
wrong one in the wrong environment you're going to fire in the wrong direction. Orson, Manager

Orson argued that individuals, and their specific contributions, need to be recognised, and that this needs to be done separately from recognising the contributions of the whole team:

So we give blanket praise because we consider it appropriate to bestow our best wishes on the whole of the team for a job well done, when what we really should do is highlight specifics for certain individuals and highlight different specifics for others. - Orson, Manager

\subsubsection{Resilience-harming leadership behaviours}

While identifying leadership behaviours that enable resilience in employees, harmful behaviours also emerged in participants' responses. These behaviours extend insight on the nature of harmful and destructive leadership in organisations and the public sector context (Reed \& Bullis, 2009; Schyns \& Schilling, 2013). These emerged primarily in participants’ descriptions of situations or events that were not dealt with in a resilient manner, or did not go as well as they could have.

\subsection{Micromanagement}

The most salient form of harmful leadership was micromanagement. In fact, all participants from Phase 1 described this behaviour to some degree.

If they're a micromanager ... and this is why it didn't work for me two years ago. She wanted to know every single minute of the day, whereas I like to know... so this is my work, you know, it gets done and it will get done on the time that we set for it to do. I just don't need to be you know managed all the way through that kind of work so I prefer a more hands off approach. - Ellen, Employee

One employee, Diane, explained that micromanagement had demoralising effects on their self-esteem and willingness to learn:

Other managers I would call micromanagers and I think that can be a bit demoralising to people. - Diane, Employee

In support of the quote above, Ellen also explained the effect micromanagement can have on self-esteem and learning, both essential for resilience:

It takes away self-esteem because they don't believe in your ability to do a job. Well when you feel like you're constantly being checked up on and you're not 
allowed to just go up and meet with people or do things without them being there.

.. you can't learn in that respect. - Ellen, Employee

Micromanagement was described as counterproductive to the performance of staff. This understanding appeared to be underpinned by the belief managers had in the abilities of their employees, as evidenced below:

There's not much you have to tell them because [they're] absorbing what's going on around them, they prefer not being told Policy 101 every day. - Brian, Manager

\subsection{Poor people management}

This harmful aspect of leadership has potential impacts on all resilience-enabling behavioural dimensions identified - since leading and managing essentially involves working with people - but it is most strongly connected to not enabling facilitating career and growth opportunities, in that it fundamentally undermines the development and growth of employees. Without good people management, none of the resilience-enabling leadership behaviours can be enacted effectively. One employee introduced the concept of “cloud managers", a notion supported by others reflecting the tendency of some managers to only focus on managing upwards, whilst ignoring the need to simultaneously manage down or "be a people manager”. One employee described the tendency for managers to only manage up:

[Managers] have someone like the minister or external advisory groups wanting to know what's happening now, now, now, so there's that constant pressure . . . and that is in the communication up to the top and then how does it filter down? Harry, Employee

Another employee supported this idea, and offered a reason for the desire to manage up at the expense of not being a people manager:

There was a change in the way [managers] were supposed to react to [senior management]. I know [they] don't like being told off by [them] and so it's all about the management of that relationship ... - Ellen, Employee

Ellen also mentioned the prevalence of only managing upwards in her organisational context, adding that by only managing up, subordinate needs are not considered and thus there is little investment in developing capacities like resilience:

Quite often you'll get managers that just manage up. So all they care about is looking good to the person above them and they don't care about the people below them. - Ellen, Employee 
The same employee commented that poor people managers can end up in management roles because of their expert knowledge, rather than more relational, "people” skills:

Some people become managers because they have nowhere else to go. And they're not necessarily great managers. It's just that there's nowhere left in their career, they've been in the same position, you know, so it's that time thing. Sometimes they are expert knowledge people, but not managers because they're not people managers. - Ellen, Employee

Manager, Barry, relayed a very similar point in this statement below:

You've still got a lot of the same people in those leadership positions that have been there for 10 or 15 years and they got there through hanging around and being quite senior and knowledgeable about their jobs rather than being leaders per-se. So in that situation you don't have people who necessarily have the right set of skills to lead or manage people. - Barry, Manager

\subsection{Lack of learning-oriented leadership}

It was clear in these interviews that managers who were not open to learning tended to produce unhelpful outcomes for employees. This harmful approach likely overlaps with, or contributes to, a manager's tendency to micromanage or behave in a reactive way.

Ellen's quote below equates an unwillingness to learn and engage with relevant people with a reactive way of managing, which does not help an employees' ability or willingness to learn. Such an approach to managing is associated with negative effects like stress and burnout, according to Ellen:

I thought for ages like, "Why is it all so reactive?" Because of the planning at the beginning . . . they don't give time to think about, they don't give time to engage with the right people right at the beginning. That's why people get burnt out or are stressed because everything's urgent . . . everything was due yesterday. - Ellen, Employee

This constant sense of urgency is antithetical to learning, and contributes to a climate that is not conducive to allowing individuals to take the time to learn from their mistakes. In another quote, Ellen described the intensity of having to teach her manager how to do things, when it arguably should be the other way around:

I was having to do four people's jobs and I kind of had to teach them how to, not how to do the job but um, everything I was doing, I had to re-teach them about how it all worked. - Ellen, Employee 
The quote below from Diane shows how a reluctance to embrace learning can flow into behaviours like micromanagement:

You complete a piece of work and then give that to [your manager] you know, for their review and to make sure it's okay before it's progressed any further and they'll kind of rewrite it to a massive extent, including kind of language styles and things . . . but I think managers should kind of let some of that stuff go because I think it's a bit crushing when it comes back all changed. - Diane, Employee

\subsection{Integration}

Phase 2 identified and explored several useful themes related to the aims of this research. It identified participants' descriptions of the concept of resilience, and of the public sector context. Most importantly however, it initiated identification of resilience-enabling leadership behaviours, which can be further explored and tested in subsequent phases.

Specifically, this phase found six key behavioural dimensions for resilience-enabling leadership. These are: fostering collaboration, enabling self-management, fostering an environment for learning, facilitating career and growth opportunities, providing support and recognising individual needs and contributions. These were identified via interviews using the critical incident technique to elicit leader behaviours that were important during an event or situation requiring a resilient, adaptive response from employees. This led to the identification of six resilience-enabling leadership dimensions - concepts central to the focus of this study - as well as a set resilience-harming leadership behaviours, which provided added richness to our understandings of resilience and its development.

\subsubsection{The identified behaviours}

The behaviours identified in Phase 2, for the most part, align clearly to employee resilience. For example, fostering collaboration, logically supports network leveraging behaviours in employees. Further, in relation to the self-management behavioural dimension, trusting individuals to self-manage is important in creating the conditions for interdependent and flexible teamworking (Bligh, Pearce, \& Kohles, 2006; Costa, Fulmer, \& Anderson, 2018). It is also a marker of social exchange in that treating individuals flexibly, as autonomous individuals, may mean they are more likely to engage in flexible, adaptive, discretionary behaviour. At the same time, this trust from leaders, particularly through enabling selfmanagement, promotes self-leadership capabilities in employees, which extend beyond self-managing and correspond strongly to resilient behaviours (Manz, 1986). For example, 
self-leadership entails an understanding of what needs to be done and how to complete it, reflecting a self-directed approach to one’s performance (Bligh et al., 2006).

The identified behaviours comprise a mixture of autonomy-allowing trust, with support and control. For instance, facilitating career and growth opportunities relates to hands-on, active guidance and support regarding employees' growth, development, and career pathways, while enabling self-management reflects a leader's willingness to trust employees to carry out their own work processes and self-manage. This balanced approach seems important for resilience, given the view that too much trust can lead to individuals straying from organisational objectives, while too much control and guidance can thwart autonomy and motivation (Weibel \& Six, 2013).

There is also partial correspondence between the findings of this phase and the leadership concepts raised in earlier phases of this research. For example, Malik and Garg's (2017) aforementioned findings on the role of strategic, learning-oriented leadership on employee resilience reflect the relevance of identifying fostering an environment for learning as a behavioural dimension of resilience-enabling leadership. Malik and Garg's (2017) argument was that this approach to leadership helps build resilience in employees by focusing them towards a learning mindset and helping them feel comfortable and motivated to engage in learning opportunities. This learning-oriented behaviour identified in Phase 2 may impact employee resilience in a similar fashion, namely by encouraging individuals to learn from their mistakes, problem-solve effectively, adapt to new knowledge and circumstances, and model pro-learning behaviours (Kuntz et al., 2017; Sims Jr \& Manz, 1982).

Enabling employees to self-manage means helping them engage in personal standardsetting, performance evaluation, and the associated consequences of such evaluations (Manz \& Sims, 1980). Self-managing behaviours have been found to be positively related to team effectiveness (S. G. Cohen, Chang, \& Ledford Jr, 1997), and can be seen clearly to be beneficial for resilience capacity and development. Self-management has been closely associated with self-leadership, which is defined as the "process through which people influence themselves to achieve the self-direction and self-motivation needed to perform" (Houghton, Neck, \& Manz, 2003, p. 126). It has been associated with innovative behaviours of employees, including seeking and generating new and creative ideas (Carmeli, Meitar, \& Weisberg, 2006). Self-leadership, in addition to comprising resiliencerelated behaviours, also promotes team working behaviours helpful for resilience (Bligh et al., 2006). 
These concepts surrounding self-management and leadership correspond not only to resilience itself, but also to certain components of paradoxical leadership investigated in Phase 1 . The dimension of maintaining control while allowing autonomy is a key example, which relates to providing a structure of control for employees in terms of what they are required to do, but giving employees space to behave flexibly and autonomously within that, so that they can experiment, grow, and develop (Zhang et al., 2015).

Recognising individual needs and contributions is likely to make employees feel valued and have confidence to pursue self-growth and development in their organisation. This behavioural dimension also resonates strongly with paradoxical leadership behaviours. It reflects the dimension of "treating individuals uniformly while allowing individualisation" (Zhang et al., 2015, p. 548). Whilst this dimension is about treating individuals equally, it also emphasises the importance of considering individual needs and recognising the different strengths and personalities of individuals (Zhang et al., 2015).

Although the connections between leadership and resilience might appear straightforward and clear, there remains a lack of specific understanding of how, and through what mechanisms such behaviours lead to resilience capacity in employees. Understanding these connections further is a key aim of Phase 3.

\subsubsection{Resilience-enabling leadership and the public sector context}

The identified behaviours are helpful for employee resilience, but they are also important in, and relevant to, resilience in the public sector context. Recognising the importance of context means taking the view that effective leadership is very often more a reflection of the context, and the realities of jobs and demands, than a prescription to a traditional, defined model of leadership theory (Bryman, Stephens, \& a Campo, 1996; Ospina, 2016).

Leadership that is concerned with employee learning and growth is likely to encourage learning-oriented behaviours that help employees confront and overcome so-called “wicked problems” that often arise in public service delivery efforts (M. M. Brown \& Brudney, 2003). Furthermore, problem solving, collaboration and other innovative skills, when developed by leaders, may promote adaptiveness to ongoing changes in the public environment (Hartley, Sørensen, \& Torfing, 2013). Large change not only occurs with the arrival of new governments and thus, differing stakeholder requirements, but also with the residue left by reform models, such as NPM and post-NPM, as well as shifting preferences toward performance management and total quality management models (Salge \& Vera, 2012). 
Public sector leaders could engage more meaningfully in employees' career trajectories. This would sustain a long-term organisational commitment and job/career satisfaction. Doing so is important because in order to fulfil public values of high-quality service delivery and contribution to the "greater good", employees need to be committed to enacting these values (Lyons, Duxbury, \& Higgins, 2006; Wright \& Kim, 2004). In regard to career satisfaction, career advancement is something that is valued among public employees (Frank \& Lewis, 2004). In many public contexts, upward mobility, or objective career advancement like promotion, is relatively limited (Lyons et al., 2006). This places extra pressure on leaders to foster and encourage employees' more subjective career successes, such as satisfaction and intrinsic motivation, in order to retain committed, satisfied, and thus, effective public servants (Ng, Eby, Sorensen, \& Feldman, 2005).

Of course, responsive and effective public services also rely on employees' ongoing engagement with the underlying processes of service delivery. Recognising individuals' contributions in specific and meaningful ways is an important part of a leader's job in nurturing commitment and career satisfaction. It also helps individuals to maximise their potential contribution to, and involvement in, the organisation (Karp \& Helg, 2008). Experiencing supervisory support in such a way can also contribute to an employee's sense of belonging in their organisation, and the teams and units within it (Wright \& Kim, 2004). Employees' identification with the organisation itself is important to maintain in public contexts where there is sometimes a predominant occupation with a wider service- or public cause- identity which can override efforts to associate and identify with a particular organisation (Perryer \& Jordan, 2005).

Mentioned in the integration of Phase 1 was the concept of collaborative leadership. As a concept, this clearly resonates with the identified behavioural dimension of fostering collaboration. Collaborative leadership is well-established in public administration scholarship, and is concerned with encouraging and facilitating individuals to work with groups both inside and outside of the organisation (Hsieh \& Liou, 2016; O'Leary \& Bingham, 2009; Van Wart, 2014). A collaborative approach to leadership is likely to contribute to employee resilience via its support for pro-social employee behaviours such as cooperative problem solving and learning, as well as openness and flexibility (GethaTaylor, 2008). Not only does fostering collaboration explicitly foster collaborative behaviours, it also may model network leveraging and other collaborative competencies that also work to enhance resilience (Decker, 1986). On top of this, such an approach to leadership is strongly reflective of the public sector context, where networked governance is now emphasised, along with the need to engage in intra- and inter-agency collaboration (J. W. Campbell, 2016; O'Toole, 2015; Silvia \& McGuire, 2010; Stoker, 2006). 
Weaknesses in public sector leadership were also previously discussed in this research and show some correspondence to resilience-harming behaviours. Managerialism and outputbased performance management were both referred to as prominent features of public sector organisations. A managerial focus on outputs, efficiency and adherance to rational control systems (Levine, 1979; Wallace \& Pocklington, 2002) is reflected in elements of micromanagement and a lack of learning-oriented leadership. These types of resilienceharming leadership behaviours punish mistakes, and leave little room for learning, innovation and growth.

It has also been established in this research that leaders in New Zealand public organisations are often unable to effectively balance conflicts, and inherent paradoxes existent in the context (Plimmer et al., 2011). Aspects of the resilience-harming behaviours identified evidence an inability to strike a balance in people management. For example, poor people management reflects a potential ability to manage up but not down, and micromanagement reflects a focus on control without any allowances for autonomy or discretion. These behaviours do not help resilience but are also antithetical to paradoxical leader behaviours.

\subsubsection{The relevance of social information processing theory}

Leadership influences employee behaviour. In retrospect, one way in which the findings of Phase 2 can be further understood is by applying social information processing theory (SIP) (Lord \& Maher, 2002) to employee attitudes of leadership. SIP relates to how the combination of social context and consequences of action can influence people's attitudes about their work (Salancik \& Pfeffer, 1978), and this includes perceptions they have of leaders and of the practice of leadership. Social context clearly played a role in participants' perceptions of resilience-enabling leadership. If we take an event that requires a resilient response as an element of the context, an individual is using certain information about the context to make an appropriate assessment of what an acceptable response from a leader might be, and this is based on socially acceptable beliefs and attitudes about leadership behaviour within this unique context (Salancik \& Pfeffer, 1978). Throughout the interviews, participants were drawing on the mental models within their long-term memory, allowing them to respond with helpful or harmful leadership behaviour(s) that was relevant to them during the time or event they recall as a critical incident. According to SIP theory, they identify these behaviours by "selecting, interpreting, simplifying, and integrating environmental information” to inform personal perceptions and attitudes (Lord \& Maher, 2002, p. 15). 
SIP theory helps explain how qualitative findings can increase our understandings about the contexts in which participants experience their realities (Bryman et al., 1996). When methods are combined as in this research, this qualitative enquiry works to "embed the quantitative data in a wider social context” (McDonald, 2005, p. 463).

SIP theory can be extended in subsequent phases by eliciting information regarding employees' mental models surrounding the identified leadership behaviours. This relates to first, whether they experience them; second, how (through what mechanisms) they experience them; and third, what perceived impact they have on followers, particularly regarding their resilience.

\subsubsection{Implications for subsequent phases}

As mentioned, the mechanisms and underlying explanatory processes of resilienceenabling leadership are not yet clear. To further understand how these leadership behaviours influence resilience in employees, it is important to understand the ways in which employees experience them, and the perceived impact they have on resilience. Thus, further inquiry is needed to explain and develop the insights gained from Phase 2. This will help to build an explanatory framework for leadership behaviours that enable employee resilience.

This third phase will emphasise follower perceptions of how a leadership behaviour might influence resilience in employees. These perceived mechanisms and outcomes are important elements to recognise in followers' perceptions of leadership and attribute meaning to leadership behaviours (R. J. Hall \& Lord, 1995), in turn revealing causal processes, or mechanisms that follow leadership through to employee resilience. Such an understanding represents the "so what?” of leadership behaviours. Follower perceptions of leader behaviours will help to clarify the perceived processes underlying resilienceenabling leadership behaviours experienced by employees. Although processes and outcomes may vary between followers, there may also be considerable agreement between them, pointing to some common dynamics (Rentsch \& Hall, 1994). Convergence in perspectives in the following phase will have explanatory power in building an understanding of resilience-enabling leadership.

\subsection{Summary}

This phase identified leadership behaviours that enable resilience in employees. It also presented other ideas that emerged in the interviews, such as understandings of resilience, descriptions of the public sector context, and resilience-harming 
leadership behaviours. The integration section provided a reflection on these findings. Resilience-enabling leadership is explored further in Phase 3, presented in the following chapter. 


\section{PHASE 3 - EXPLAINING LEADERSHIP BEHAVIOURS}

\subsection{Introduction}

The third phase of the study aimed to elicit employees' perspectives on their experiences of leadership. With this aim in mind, it focused on identifying the explanatory processes underlying the leadership behaviours experienced by employees, as described by participants in Phase 2. In other words, it sought to address the second research question regarding how employees experience the identified leadership behaviours. This includes the nature of these behaviours as experienced by employees, the mechanisms through which they were experienced, and the perceived outcomes of these behaviours on employee resilience. This knowledge expands and develops the framework for resilience-enabling leadership. Employees' perceptions and experiences were the focus of this phase, thus only employees were interviewed.

This employee perspective is supported by Collinson and Collinson, who argue it is important in studies of leadership “to explore respondents' [employees'] own definitions of effectiveness and attributions of causation” (Collinson \& Collinson, 2009, p. 368). Thus, employees, and their perceptions, play a key role in determining leader effectiveness, and what leadership behaviours might comprise effective leadership. Their attributions of causation are an important part of this. Eliciting respondents' causal attributions and mental models surrounding a question required a more structured approach than Phase 2. This is described in detail below.

\subsection{Method}

\subsubsection{Participants}

The sampling process of Phase 3 followed a very similar approach to that in Phase 2. Ten employees were sought, and then interviewed. Like Phase 2, this sample was generated randomly from the Phase 1 survey sample. A distribution across occupation, department, and gender was again sought. However, those with managerial responsibility were discarded from the potential sample due to the focus on gathering employee perspectives. Those with employee-, rather than manager- or team-leader status, were chosen to ensure potential interviewees were working for a manager, so that they could draw on their current experiences of being managed. Managerial responsibility was specified alongside participant details in the original Phase 1 sample document. After this purposive screening of the sample (Etikan et al., 2016), a random number generator was used to select potential 
participants to contact. Participants were contacted and interviewed in rounds of five. The decision to undertake two rounds of interviews reflects the value of following an iterative process, allowing for preliminary analysis of the first round to help inform and potentially modify the interview questions for round two (Willis, 2004).

The final list of potential participants were contacted via email with an invitation to participate in the interviews. This email included a description of the research, the purpose of this phase of the research, and the ethics-approved information sheet.

Ethical approval was granted for this phase, under the same approval application as Phase 1 and 2 (0000023656). (See Appendix B for all documents related to ethics for this phase, as well as Phase 1 and 2). This meant that the interviews were undertaken under the same ethical conditions as those in Phase 2, ensuring confidentiality of person and organisation, identification by job-type only, and the ability to withdraw from the project within twoweeks of the interview. Pseudonyms were again used to report responses from interviews. Participants had an average tenure of 7.5 years at the organisation, and the gender distribution was 50/50. More information is provided in the table below.

\section{Table 12: Participant characteristics}

\begin{tabular}{llll}
\hline Pseudonym & Gender & Position & Tenure \\
\hline Maree & F & Employee, Operations & 2 years \\
John & M & Employee, Operations & 2.5 years \\
Thomas & M & Employee, Operations & 14 years \\
Sarah & F & Employee, Policy & 9 months \\
Hunter & M & Employee, Operations & 8.5 years \\
Greer & F & Employee, Commercial & 9 years \\
Hera & F & Employee, Policy & 11 years \\
Trina & F & Employee, Policy & 10 years \\
Martin & $\mathrm{M}$ & Employee, Data & 14 years \\
Jackson & $\mathrm{M}$ & Employee, Policy & 3 years \\
\hline
\end{tabular}

\subsubsection{Interview structure and design}

This phase was informed by cognitive interviewing, whereby the primary questions were asked in a questionnaire format in order to "understand how respondents perceive and interpret questions" (Drennan, 2003, p. 57). These primary questions were related to leadership behaviours identified in phase one. The way in which an identified leadership behaviour was adapted to questionnaire format can be seen when enabling selfmanagement is translated to the question: "To what extent does your manager enable self- 
management?” This initial question gave the participants the opportunity to reflect on the extent to which they experience the leadership behaviour in question (i.e. from "not at all" to "to a large extent”). The extent of experience was then categorised into high or low examples during analysis. Gaining an understanding of the respondents' perspectives and giving them the freedom to think aloud gives insight into the respondents' (in this case, employees') mental models regarding the question (Beatty \& Willis, 2007). It also allows the researcher to pick up on any discrepancies between their own understanding of the question and that of the respondents'. Considering the ways in which individuals understand a particular behaviour helps to prompt responses related to the mechanisms by which individuals might experience these behaviours. Individuals' responses to the primary questions were then followed with probing questions, to allow individuals the opportunity to explicitly describe the mechanisms and outcomes of the leadership behaviours they experienced. These probing questions are outlined below.

Further information from the respondents was gathered from sub questions probing for the why and how behind the primary question. This was done in order to map the chain of logic used by each employee to explain their experience relating to the leadership behaviours within the primary questions. For the primary question of: "To what extent does your manager foster collaboration within your workgroup?", the sub questions were "Why/Why not? How?" and "What was the impact of this on your behaviour?” These sub questions sought to gain insight into respondents' mental models and attributions of causation regarding the leadership behaviour in question. It also allowed for explanations of negative leadership behaviours, or the absence of the particular behaviour in question, i.e. if a participant answered the primary question with "not at all” or "to a low extent”, further probing related to how or why they thought that was the case could be pursued. Taking this approach also provided a structure for relevant data to contribute to the resilience-enabling leadership framework, where the identified leadership behaviours are displayed with their underlying mechanisms and outcomes for resilience in employees. The interview guide for this phase is provided in Appendix D.

\subsubsection{Analysis}

Causation coding was employed to analyse these interviews (Miles et al., 2014) in order to identify perceived mechanisms and outcomes of resilience-enabling leadership and to explore the processes and experiences of individuals in context (Kazi, 2003). Causation coding allows for respondents' causal attributions or beliefs pertaining to a phenomenon to be mapped out in an explanatory way, both at the individual level and then potentially at the aggregated, more generalisable level. It uncovers antecedent conditions, mechanisms 
and perceived outcomes, and in doing so attempts to map a three-part process (Saldaña, 2015). In this case, the leadership behaviours identified in Phase 1 constituted the antecedent conditions. Codes were then attached to the mechanisms and outcomes described by participants, which helped to explain the way in which the antecedent condition contributed to a resilient outcome. Identifying the mechanisms and outcomes reflected the second and third part of the coding process. If the antecedent condition was not experienced by the respondent, an alternative, and often negative pathway was mapped onto the causation coding template based on experiencing the absence of the leadership behaviour in question, typically revealing a harmful effect on resilience. (See Table 13 for a distribution of answers).

\section{Table 13: Distribution of answers to primary question}

\begin{tabular}{lll}
\hline Leadership behaviour & Extent & $\begin{array}{l}\text { No. of } \\
\text { cases* }\end{array}$ \\
\hline To what extent does your manager foster collaboration in your & High & 8 \\
workgroup? & Low & 3 \\
To what extent does your manager enable self-management? & High & 9 \\
& Low & 4 \\
To what extent does your manager facilitate career and growth & High & 5 \\
opportunities? ** & Low & 4 \\
To what extent does your manager foster an environment for & High & 8 \\
learning? & Low & 5 \\
To what extent do you feel supported by your manager? & High & 6 \\
& Low & 5 \\
To what extent does your manager recognise your individual needs & High & 6 \\
and contributions? & Low & 5 \\
\hline
\end{tabular}

Note: *Some participants responded with experiences of both extents, due to reporting on more than one manager. ${ }^{* *}$ One participant did not give an answer to this question.

An example of the causation coding template with selected examples is given in Table 14 . This coding process allowed a chain of logic to be built, helping to support the development of a consolidated explanatory framework, to exemplify how particular leadership behaviours can foster resilience in employees. 
Table 14: Example of causation coding template

\begin{tabular}{|c|c|c|c|}
\hline Enabler & & Mechanism & Outcome \\
\hline \multirow[t]{5}{*}{$\begin{array}{l}\text { To what } \\
\text { extent do you } \\
\text { feel supported } \\
\text { by your } \\
\text { manager? }\end{array}$} & \multirow[t]{3}{*}{ High } & $\begin{array}{l}\text { Mostly being valued for my skills and contribution to the team, as } \\
\text { opposed to always doing things wrong which is not the case. Yeah just } \\
\text { those things really in a nut shell. I don't need pats on my back or } \\
\text { anything like that. - Thomas }\end{array}$ & $\begin{array}{l}\text { Oh, it makes me want to turn up. Just want to get stuck in } \\
\text { which is what it's about. - Thomas }\end{array}$ \\
\hline & & $\begin{array}{l}\text { There's definitely that feeling that you have support from your } \\
\text { manager, that she'll kind of back you I guess. Or you know, it's a case } \\
\text { of... she'll back you even if you might make a mistake. - Maree }\end{array}$ & $\begin{array}{l}\text { It does make things easier, definitely. Knowing that you're } \\
\text { not going to be needing to handle things by yourself I guess. } \\
\text { To front up to things that might not have gone so well by } \\
\text { yourself to have someone there to provide a senior level of } \\
\text { support definitely. - Maree }\end{array}$ \\
\hline & & $\begin{array}{l}\text { I feel supported, there is communication and openness about where I } \\
\text { am at. - John }\end{array}$ & $\begin{array}{l}\text { It gives me confidence, knowing that what's expected of me } \\
\text { is supported, and my manager feeds this up to higher } \\
\text { management. - John }\end{array}$ \\
\hline & \multirow[t]{2}{*}{ Low } & $\begin{array}{l}\text { Both my manager and my team leader are men and so that's one thing } \\
\text { where it's not like... a feminine quality can be useful with support. I } \\
\text { guess it's just the relationship you have with other men it's harder to } \\
\text { be like look I need a bit more clarity... I felt like there was a lack of } \\
\text { structure with what they were going to do with me. It's like the } \\
\text { inefficiencies of the public sector where they can afford to have } \\
\text { someone whose kind of running on idle for a little while. - Hunter }\end{array}$ & $\begin{array}{l}\text { I was left with relatively low job satisfaction for a long time. } \\
\text { - Hunter } \\
\text { [It] was frustrating. - Hunter }\end{array}$ \\
\hline & & $\begin{array}{l}\text { It's funny like personally I feel really well supported. But for my job } \\
\text { I'm still feeling quite new and not one hundred percent confident all } \\
\text { the time, sometimes I don't feel super supported so those two probably } \\
\text { even out to something in the middle. Because personally I feel a lot of } \\
\text { trust and like that's great but if I'm struggling with something it's not } \\
\text { always easy to access help so yeah there's advantages because it can } \\
\text { make you learn and it make you paddle your own canoe or whatever } \\
\text { but at the same time it can be quite stressful so yeah maybe there's like } \\
\text { somewhere in the middle. - Sarah }\end{array}$ & $\begin{array}{l}\text { There's advantages because it can make you learn and it } \\
\text { make you paddle your own canoe or whatever but at the } \\
\text { same time it can be quite stressful so yeah maybe there's } \\
\text { like somewhere in the middle. - Sarah }\end{array}$ \\
\hline
\end{tabular}




\subsection{Findings}

In addition to asking about the extent to which an individual experiences the leadership behaviours identified in Phase 2, the Phase 3 interviews also involved the sub-questions "How?" and "What impact does this have on you?" for each main question. These sub questions were designed to yield perceived mechanisms and outcomes of the leadership behaviour in question. In the section below, each enabling behaviour (fostering collaboration, enabling self-management, facilitating career and growth opportunities, fostering an environment for learning, providing support, and recognising individual needs and contributions) is presented with its associated mechanisms and outcomes. Resilienceharming mechanisms and outcomes are also presented.

\subsubsection{Resilience-enabling leadership}

\subsubsection{Fostering collaboration}

A leader who fosters collaboration was understood by participants as someone who sets collective tasks and makes collaboration a behavioural norm within the team. Setting collective tasks appeared to entail encouraging collective work, being open to employees seeking out their own co-collaborators, and matching a collective set of skills to a particular task so that the best way to work is to work together. Hunter described his experience below:

He'll put me on a project and tell me the people who need to be brought in on that project and he's also open to me bringing in more people if I think it's suitable. Hunter

Making collaboration a behavioural norm relates to creating a shared assumption that working together is a common, necessary, and expected activity within the team. A leader involving themselves in collaboration can contribute to the creation of this shared norm. In his response regarding the extent to which his manager fosters collaboration, Martin stated the following:

Definitely ... it's just assumed that we do that. So if an issue comes up and I need to tap one of my other team members on the shoulder, it's assumed I'm just going to do that. It would be considered out of the ordinary [if we didn't]. - Martin

Leadership that fosters collaboration influence a range of outcomes. Those identified in this phase include: enhanced interpersonal resources and networks, increased feelings of connection, and feeling more enabled to engage in necessary work tasks. Drawing on the 
skills and resources of others is an essential part of behaving resiliently. Below, Sarah described how working together can help utilise interpersonal resources:

When I talk about things with other people I get good ideas or like things become more clear to me so I find that really helpful. You can really get so much groundwork done working with other people's [work] that they did before. - Sarah

Feeling supported to collaborate can also give individuals energy at work. Maree explained how working and connecting with others gives her energy in her work tasks:

I thrive off being able to bounce ideas off other people just to make sure that what you're thinking and doing is the right thing. - Maree

\subsubsection{Enabling self-management}

Most participants explained that a leader who enables self-management focuses more on aims and outcomes, rather than only on the specifics of process, and this entails an element of trust in employees to achieve these aims and outcomes. Consistent with Phase 2, this finding also reflects a degree of manager/leader belief in employee ability and competency. Several participants also described that a healthy degree of self-management needed to be balanced by support from leaders when employees required it. The two excerpts below illustrate these ideas:

He fully respects our ability to do our jobs and he gives guidance where required but yeah, lets us do our own thing. - Thomas

"This is your work, this is what you've gotta get done, you guys understand your deadlines, you know, I really will come to you if you drop the ball." But he just had that [understanding] that we all knew what we were doing. - Greer

Perceived outcomes of leaders enabling self-management include greater autonomy, workrelated motivation, improved confidence and trust, higher quality work, and greater freedom. Thomas explained how feeling enabled to manage himself and his own work brings with it a sense of confidence and belief in competence, along with more freedom and motivation to engage in work:

I actually enjoy coming to work because you have the freedom to do stuff to a degree - in what we do but also how we do it because we are pretty much subject matter experts in our office. - Thomas 
Jackson described how being in control of his work made him want to take more pride in his work decisions, which is ultimately beneficial for organisational functioning as well as individual performance:

People will say, "Why have you done this?" or "Why have you done that?" and if you come up with a good answer then it'll stay so it really makes you think about what you put in to what you're doing because if someone questions you on it you need to be able to back yourself up. - Jackson

\subsubsection{Fostering an environment for learning}

An environment for learning was perceived by most participants as one where mistakes were treated as opportunities to learn, rather than a source for blame. This relates to a manager's ability to detect, and manage, safe failures within the team, or mistakes that individuals can safely learn from. A number of participants also described that a learningconducive environment occurred when leaders value employee knowledge and expertise, and show a general openness to learning. Relevant examples from Sarah and Jackson follow:

I would say for mistakes or for things not being done as well as they could its quite minimised. So it's quite like, “Okay this wasn't great but let's move on because we still need to get the job done." So yeah things are definitely not made into a big deal, it's always kept quite small. - Sarah

If we have to do something and I don't really know how to do it, I can ask [my manager] and he'll question me until I sort of figure out how to do it. He's just quite good at just guiding without telling. . . . I guess being able to just say what I'm thinking and run it past [him] ... in some other teams I found that there wasn't that opportunity to do that at the start so you could spend hours or days on something to find out you should have taken a different approach at the start, which is particularly frustrating. - Jackson

It is important to note that Jackson's response above also indicates that an openness to learning can prevent counterproductive actions and behaviours that stem from being reluctant to ask for help, which might in turn come from having a manager who is not concerned with fostering help-seeking and learning behaviours.

Having a leader who is keen on fostering an environment for learning can result in perceived outcomes such as improved confidence and better teamwork. For effective 
teamwork, team members need to be open to learning from each other. Sarah illustrated the latter in her comment below:

You can't function effectively within the team without being open to learning on a semi constant basis. So I think that that's quite good. - Sarah

\subsubsection{Facilitating career and growth opportunities}

Career and growth opportunities were facilitated by leaders in various ways. Leaders who supported employees to seek out opportunities themselves, advocated on behalf of employees for selection into opportunities, supported them to go on courses for training and development, and had open conversations about future career possibilities were resilience-enabling. A quote from Trina about being supported with opportunities supports this:

The courses I've gotten into are very competitive and I know that would have been influenced by my manager advocating for me .... And she's always encouraging all of us to think about travel opportunities, are there overseas conferences that we want to go to? ... So she's constantly thinking about that. - Trina

Leader facilitation of career opportunities enhanced commitment and confidence. In both examples below, participants explained the outcome of having their career opportunities considered, which helped Hunter reconsider his future in the organisation and for Sarah, realise new things about her own competence:

It feels really good. In fact it's made me reconsider my plan which was I'm going to stay for a year but I'm enjoying my work now more than I was expecting to and the fact that there's all these opportunities is kind of making me reassess that a little bit. - Hunter

To be honest to even have that brought to me as an opportunities kind of made me feel quite good because I wouldn't have thought I'd even be considered for this. As it happened I applied for it and didn't end up getting selected which was fine but it was even just to have that brought to me as something like, "Hey maybe you should do this." - Sarah

\subsubsection{Providing support}

Leader support worked through the mechanisms of backing the work and decisions of employees, supporting the personal needs of employees, and being open to ongoing communication. 
There's definitely that feeling that you have support from your manager, that she'll kind of back you I guess. Or you know, it's a case of . . she'll back you even if you might make a mistake. - Maree

Two participants alluded to the idea of social exchange, arising from feeling supported on a personal level. They explained how feeling supported as an individual made them want to put extra time or effort into their work and/or the organisation. Trina gave a rich description of her understanding of leader support below:

I quite often do quite a lot of hours extra over my role requirements and under our contract we're enabled to take time in lieu, not every team in the organisation enables that but she does. And she actually makes sure that I'm keeping that at a manageable level so encouraging me to take that time. She's there for me to talk to if I need someone to talk to. - Trina

Outcomes associated with support consisted of work-related motivation, reduced pressure and stress, improved confidence, and feeling valued. Examples of reduced pressure and improved confidence, respectively, are given below:

Yeah it does make this easier, definitely. Knowing that you're not going to be needing to handle things by yourself I guess. To front up to things that might not have gone so well by yourself to have someone there to provide a senior level of support definitely. - Maree

It gives me confidence, knowing that what's expected of me is supported. - John

\subsubsection{Recognising individual needs and contributions}

Recognising individual needs and contributions was experienced by participants through mechanisms such as providing feedback and recognition that is tailored and specific to the individual and their contribution, and publically recognising individual contributions in front of the workgroup:

When those things go really well you want to know about it because often you don't even know what the feedback is, good or bad. And then when you get asked to do another one you know what to avoid. - Greer

I did a document the other day and it was a tight turnaround so I did it and she copied everyone in and she goes, "Oh thanks, it's amazing that you delivered on that timeline." - Hera 
Tailored, specific and meaningful recognition of individual employee contributions appeared to improve intrinsic motivation, employees' confidence about their own performance, and feelings of appreciation. Trina supported the first outcome of intrinsic motivation in the following quote:

We're underpaid compared to other people in the organisation despite that I'm not looking to change to another part of the organisation - I have looked at jobs in the past and been told I can offer you at least 10,000 more than what you're on now . .. the money isn't enough to make me want to change. - Trina

\subsubsection{Resilience-harming leadership}

The resilience-harming leadership behaviours identified in Phase 2 were followed up in Phase 3, by analysing the mechanisms by which employees lacked the positive, resilienceenabling, leadership identified, and further explored throughout Phases 2 and 3. These negative leadership behaviours and experiences perceived by employees show how resilience can be harmed in public sector workplaces. It also shows how the absence of resilience-enabling leadership (i.e. the presence of micromanagement in the absence of self-management) can be detrimental to employee resilience.

\subsubsection{Micromanagement}

Several employees in Phase 3 described their experiences of micromanagement, and the negative impact it can have. Greer explained that her old manager had a tendency to micromanage, and described her thoughts and experiences regarding this kind of management:

My manager . . definitely had a tendency to micromanage. She just wanted to know everything that was going on and then there was an element of, "Is that kind of necessary information?" or "How about you let me kind of do the work first and then I can come to you as an outcome?", as opposed to handholding me through the process. - Greer

Jackson described his experience of micromanagement in relation to writing. This relates to Diane's point in Phase 2 regarding the role of micromanagers (over)-correcting employees' writing. It is important to note that Jackson referred to managers beyond his own team manager when describing his experience of micromanagement.

I used to get really annoyed with [micromanagement] because everyone has a slightly different way of writing and you write it one way and then your manager 
would change it, then a senior would change it, and then your manager would change it back and then the director would change it. - Jackson

Micromanagement, when disguised as performance management, is, according to Hera, the worst kind of micromanagement. Underlying this type of micromanagement is the intent of the manager to undermine the employees' performance and "set them up to fail”:

It's the micromanagement that is a disguise for performance management. It's like I hate that person, I'm going to ride them until they quit. And it's just like setting impossible goals, saying $\mathrm{OK}$, well there's a problem with your performance ... so your performance is here, we need you to get it to here, we're going to meet again on Friday, and I need you to have done this, this, this and this and then of course, that's not going to be possible because two or three of those things are going to be unobtainable. ... So that to me would be the worst type of micromanagement, where you're being set up to fail. - Hera

Both Hera and Thomas attempted to explain why it is that some managers have a tendency to micromanage. According to these employees, it is associated with a manager's insecurities and trust in one's self, such that managers resort to micromanagement when they do not know what else to do and project their insecurities of managing onto their employees:

When you've got a manager who is insecure at some point in the chain who's pushing that insecurity down on you. Or somebody who is just insecure and they think that's what management is, because maybe they've come from a sales environment to this environment and to me, the public service runs more like a university, you've got an assignment, it's got to be handed in at the end of the term, you'll get graded on it, if you fail you have to do it again. - Hera

Some managers don't trust themselves to get it right so there's only so many tools in the toolbox so if the only one they've got is being directive then that's their issue. So it's more of a skill base for managers. - Thomas

Participants reported various outcomes of micromanagement, all of which are antithetical to resilience development. Thomas described the effect that micromanagement had on his team. It impeded their willingness to engage in discretionary, extra-role behaviours, that are helpful for resilience:

We really didn't want to do anything else, we didn't want to do any more than our job. - Thomas 
Employees also felt it was a sign that managers lacked trust in employees, and Greer told of how it made her colleague feel "like a child". Treating employees in this way is clearly not conducive to promoting any form of employee growth or development:

It's quite negative, because you immediately feel like they don't trust what you're doing and you're feeling a little bit like... one of my colleagues who had the same thing happen to her with the same manager, she said to me afterwards, "I felt like a child, I felt like I was being treated like a child. Like, are you doing your homework?"-Greer

Another key outcome of micromanagement was how it prevented employees from feeling as though they had meaningful ownership of their own work. For Greer, when she felt "nagged" about her work, she did not feel personally motivated to do her work - the motivation instead came from someone telling her to do it. Quotes from Greer and Jackson, below, exemplify more of the impacts of micromanagement:

You feel a little bit like, oh they think that you only did it because you were nagged. There's that element of, you want to feel like you're presenting your work, because that's your job and that's what you were always going to do, you don't want to feel like you've done it because someone's on your case. - Greer

I'd just be like well someone's gonna change it later on I don't really need to spend that much time on it. - Jackson

\subsubsection{Poor people management}

Not effectively managing down, or being a poor people manager, can equate to rework and inconsistency. It also devalues employee expertise. These ideas were supported by Greer below:

I did have an example of it recently, so we have a whole lot of figures which relate to what we're funding ... and it hadn't come through me to give it a second check, yet it had been getting provided to the minister for a couple of weeks in a row. And then it's kind of like by then if I come in and say you are wrong . . . then it kind of changes the scope and you have the risk of the minister turning around and going this is completely different to what I've been seeing. So I had to highlight that all, you know, if you want to create these things that you want to report, you've got to work with us on that - we know the work we're doing. - Greer

Poor people management can also be experienced in relation to collaboration, an important element of resilience. Hera reflected on getting mixed messages from her manager about 
whether collaboration was a desired activity or not. This inconsistency is evidence of poor people management and sends confusing messages regarding desired behaviours:

With collaboration it's like, you know, "You all have to work together as a team", "Oh no there's too much talking”. You know, "You guys are wasting too much time because you're working together, I'm gonna get you to work on stuff individually." "But make sure you ask the senior people before you do anything, but don't talk to each other." Um so I guess that's the best way I can answer that is, you always think you're doing the wrong thing, you spend the whole day worried that you're gonna get told you did something wrong - Hera

\subsubsection{Lack of learning-oriented leadership}

The Phase 2 findings indicated the various ways in which a lack of learning-oriented leadership manifested in everyday practice, such as through reactive management. These Phase 3 findings show more specifically how individuals experience leadership that does not effectively foster learning. Firstly, Maree described, rather mildly, how encouraging employees to take generic courses and training modules does not necessarily promote true, experiential day-to-day learning:

We have training modules that you can do that are sort of quite generic across the agency. To improve your project management skills and presentation skills, all those sort of quite generic type courses. But I think in terms of areas, subject matter specific learning options and opportunities I think there could be more opportunities for us to improve on that. They should make available more opportunities to know things that are more related to our specific work. - Maree

Furthermore, John pointed out that a lack of learning can come from poor top-down feedback flows in the context of mistakes. He elaborated:

Sometimes the feedback regarding a mistake does not get fed back down to the team and stays with management so there's no learning. Higher level thinking is not communicated down to the team. - John

Greer supported the point made by John above. Instead of facilitating employees to learn from a mistake, her experience was that managers address the mistake themselves instead of feeding it back down:

If there has been something done and it's not quite right I think they have a tendency to just fix it themselves and not actually come back to you. ... 
if a mistake is made and it's pointed out no one really explains where it fell down. - Greer

Hera shed light on the role of context in the quote below, stating that in high stakes situations such as in her public sector work, it is difficult to use mistakes as learning opportunities. Saying they “don't make mistakes” indicates that making mistakes (and then learning from them) was not currently a norm in her workplace:

With what we do the stakes are really high, you can't do it wrong, because you're looking at the whole NZ economy ... so we can't afford to do that. We don't do that. We don't make mistakes. - Hera

Hera added to this by giving an extreme example, from her own experience, of what happens when an individual makes a mistake in such a context, exemplifying the high stakes nature of the work she is involved in:

All of a sudden, you're a leper, you're a bad person, "I can't be seen to be associated with that person." So what was your question, can you learn on the job? It's best that you don't. - Hera

When employees cannot take ownership over their own mistakes so that they can learn from them, and the mistakes are instead fixed by managers or those higher up in the hierarchy, employees can become frustrated and complacent, reducing opportunities to learn:

I think it can kind of allow people to get a bit complacent. Because you think, oh well, if no one's going to talk to me about this or if everything I'm doing is just going to be acceptable, in the sense that no ones ever gonna come back to me, you sort of get a bit complacent and think I'll just keep doing it the way I'm doing it because no one's telling me otherwise and then you don't learn to evolve or change with new approaches or that sort of thing. - Greer

\subsubsection{Unsupportive leadership}

From the findings of both Phase 2 and 3, it is known that supportive leadership can help to enable resilience. In contrast, the absence of support, or unsupportive leadership, can be damaging for resilience. This idea did not emerge in Phase 2, but did emerge when discussing the leader behaviour of providing support in Phase 3, where participants who did not experience support gave their views on what they experienced instead.

There were a number of different ways in which employees experienced a lack of support. One way, experienced by Hunter, was through feeling as though there was a lack of 
structure around what he was meant to be doing in his role, which left him without much direction for a period of time. His quote also illuminates how a lack of structure is potentially accommodated by the public sector context:

I felt like there was a lack of structure with what he was going to do with me. It's like the inefficiencies of the public sector where they can afford to have someone whose kind of running on idle for a little while. - Hunter

In the quote below, Sarah distinguished between feelings of personal and job-related support. Like Hunter, Sarah was quite new to her role and felt that she needed more guidance and direction in her job, despite experiencing personal support from her manager:

Personally, I feel really well supported. But for my job I'm still feeling quite new and not one hundred percent confident all the time, sometimes I don't feel super supported . . because personally I feel a lot of trust and like that's great but if I'm struggling with something it's not always easy to access help. - Sarah

Greer explained that she feels partially supported, in that she experiences support when she reaches out, but does not receive much directly from her manager:

I put things to him, he's supportive. But yeah not a lot that comes from him. So I guess yeah I feel supported in the ideas that I might pitch I guess. - Greer

Jackson's description of feeling unsupported is given below. It is of interest because he associated this with blame and a lack of trust coming from his manager:

I had one manager who blamed me for something that she'd signed out and given the ok for and I was sort of like you can blame me if you want but like you know in your heart that you shouldn't have signed it out in the first place. I think it's also the level of trust how she used to make me send her every email before I sent it. Jackson

Both Hunter and Jackson described that experiencing a lack of support was frustrating. Sarah stated that although there are advantages from the challenge of having to be entirely independent, a lack of job-related support can be stressful, and thus a balance between personal and job-related support is necessary:

There's advantages because it can make you paddle your own canoe or whatever but at the same time it can be quite stressful so yeah maybe there's like somewhere in the middle. - Sarah

Whilst experiencing poor structure in the way, Hunter revealed that he experienced low job-satisfaction as a result: 
I was left with relatively low job satisfaction for a long time. - Hunter

\subsection{Integration}

Phase 3 of this research made use of the value in employees' leadership perceptions (R. J. Hall \& Lord, 1995). This allowed for the generation of insights into what constitutes leader effectiveness for employees, and how effective leadership is experienced. Eliciting responses related to how participants experience the identified behaviours, and what impact these have on employee resilience, generated insights into how particular forms of leadership are perceived and experienced by employees, rather than only focusing on how they might be defined from a leader's perspective. Certain behaviours may be easily defined by leaders, but their effectiveness depends on how employees interpret and perceive them. Insight into an employee's perspective helps both scholars and leaders realise how and why a leadership style or behaviour is deemed so effective, both in theory and in practice. Understanding the mechanisms of how employees perceive and experience leadership helps to further broaden and develop our understanding of leadership itself, shifting away from prescribed leadership models and theory. Thus, it is not sufficient only to identify behaviours, as was done in Phases 1 and 2. It is also important, throughout the course of this research, to explain them, both in terms of how they are experienced, and in terms of what impact they have on employee resilience. This process helps to build content validity for the construct of resilience-enabling leadership, with a view of developing it into a measure in subsequent phases.

\subsubsection{Resilience-enabling leadership behaviours}

Phase 3 formed the structure of an explanatory framework for the identified leadership behaviours. The explanatory value of this phase plays a strong role in informing the subsequent phases in this research. The identified leadership behaviours are developmental - they foster growth, autonomy, self-management, and teamwork. Resilience-enabling leadership corresponds to calls for leadership models which facilitate employees’ personal and vocational development (Zhang \& Chen, 2013). However, many well-established leadership constructs focus more on directing and controlling employees toward achieving task and goal performance (Howell \& Avolio, 1993; Hargis, Watt \& Piotrowski, 2011), and there has been limited identification of more developmental forms of leadership (Zhang \& Chen, 2013). Furthermore, there is a lack of knowledge and research in the important area of developing the capacity of resilience in employees through leadership. This form of leadership is not only developmental in nature, but it likely helps employees develop 
their resilience so that they can more proactively grow and develop as individuals. These ideas correspond to what the new generation of workers want and need in their workplaces - to be treated as individuals with potential (Gursoy, Geng-Qing Chi \& Karadag, 2013; E. Ng, Lyons \& Schweitzer, 2018).

The preceding phases also highlight that leadership needs to take into account the context, because context does influence what kind of leadership is most appropriate and effective for employees and organisations (Oc, 2018). Constructs have already been established to measure the nature of public sector leadership (Tummers \& Knies, 2016), but such measures are not focused on the developmental employee requirements, nor on the demands that the public context places on resilience. This research recognises the role of the public sector context, and develops a framework which is built on the experiences of individuals working in this context. This framework is then developed into a scale for measuring resilience-enabling leadership. This will provide a tool for assessing the development capacities of leaders, which can be further tested by scholars and used for leadership development in organisations.

Phase 2 and 3 have worked to qualitatively "identify important variables to study quantitatively" (Creswell \& Clark, 2017, p. 75). The relevance and uniqueness of resilience-enabling leadership suggests that it would benefit from further conceptual refinement and validation. The following phases of this research work to achieve this. The final quantitative phase, in particular, tests the validity of the developed scale in a survey.

\subsubsection{Renaming of dimensions}

The mechanisms identified in Phase 3 provided insight into the way the leadership dimensions could be grouped and worded differently to more appropriately reflect the role they have on employee resilience. This can better capture and more fully express the underlying mechanisms and their associated dimensions. Four dimensions were renamed. These were fostering collaboration, fostering an environment for learning, facilitating career and growth opportunities and providing 'support'.

Fostering collaboration was changed to managing the whole team. This was because the mechanisms reflect the work the managers do to encourage team interaction and cohesion, which in turn, promotes the collaborative, network leveraging behaviours essential for resilience. It is about building the condition within the team for collaboration to be possible. In other words, this dimension is about much more than just fostering collaboration.

Fostering an environment for learning was changed to managing safe failures. Like collaboration above, these mechanisms appeared to be more specific than just learning. 
Rather, they were more about a manager creating the conditions for learning on the job to occur. These conditions, according to participants, related to feeling comfortable making mistakes and subsequently learning from them. Additionally, a manager's general openness toward learning includes being open about mistakes, and seeing them as learning opportunities.

Finally, providing 'support' and facilitating career and growth opportunities were combined into supporting personal growth and wellbeing. This addressed the conceptual overlap between these two dimensions. This decision broadened the conceptual scope of these underlying mechanisms so that it reflected more than career and growth opportunities. It comprises the recognition and acknowledgement of personal growth including both career and work-related opportunities as well as support for personal-level growth and development.

\subsubsection{Resilience-harming leadership behaviours}

The resilience-harming behaviours are important insights on their own as they provide a clear understanding of what types of leader behaviours can harm employee resilience. They also strengthen the findings related to the resilience-enabling behaviours. They do this by providing a contrasting picture of what can occur for employees when they do not experience resilience-enabling behaviour from leaders. Thus, the resilience-harming leadership behaviours work to illustrate the negative impacts of the absence of the enabling behaviours. For example, they show what occurs when micromanagement, instead of selfmanagement, is experienced by employees.

These harmful leadership behaviours also mirror those identified in studies of destructive leadership more generally. Destructive leadership consists of behaviours by leaders "that violate the legitimate interests of the organisation by undermining . . the organisation ... and/or the motivation, well-being or job satisfaction of subordinates” (Einarsen, Aasland, \& Skogstad, 2007, p. 208). These behaviours need not be direct and intentional, and could be due to the insensitivity, callousness or a leader's laissez faire approach (Einarsen et al., 2007; Sheard, Kakabadse, \& Kakabadse, 2013). The same notion applies to the resilienceharming behaviours identified in this research. Reed and Bullis (2009) found that it does not just undermine job satisfaction, but other forms of satisfaction as well, such as satisfaction with relationships, pay, benefits, and opportunities at work. Poor satisfaction across these factors is likely to harm any potential possibility for developing employee resilience (Itzhaki et al., 2015). 


\subsubsection{Resilience-enabling leadership explanatory framework}

As mentioned earlier, this phase, along with the inquiries preceding it, have led to the development of an explanatory framework for resilience-enabling leadership behaviours. This framework is presented in Figure 5 below.

The mechanisms are a primary feature of this framework. The Phase 3 findings helped to explain the perceived mechanisms underlying resilience-enabling leadership and resilient outcomes. These perceived connections are both indirect and direct. Fostering collaboration directly influences resilience because collaboration can clearly help employees to broaden their interpersonal networks and subsequently use the resources and skills held by others, as well as share their own. A leadership behaviour like enabling selfmanagement, on the other hand, works indirectly. It works through perceptions of trust between the leader and the employee, that allows employees to work autonomously in making decisions and taking ownership of their work. Individuals may consequently take better care with processes underlying their own performance. Self-awareness of work behaviours, coupled with self-confidence (G. Wang \& Netemeyer, 2002) gained through work ownership and leader-member trust, helps employees to effectively re-evaluate their own performance and learn as a result.

The framework bridges theory and data by illustrating the connections between the identified leadership behaviours and resilient behaviours in employees. It also initiates a structure from which a quantitative scale can be developed and measured. The process by which this structure was devised represents an inductive approach to scale development whereby a sample of respondents are asked "to provide descriptions of their feelings about their organisations or to describe some aspect of behaviour” (Hinkin, 1998, p. 107). This process of scale development and validation will be described in more detail in Phase 4. 


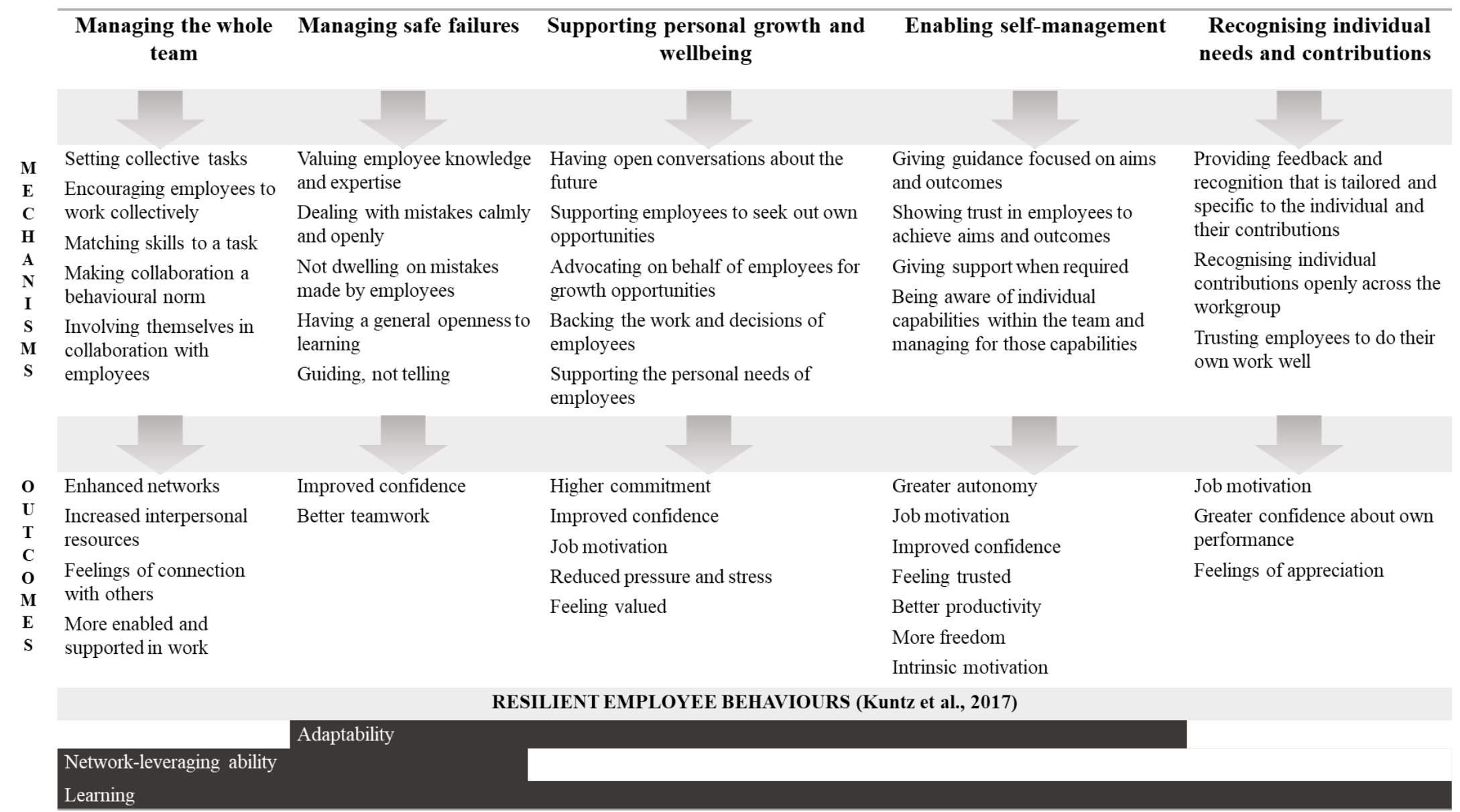

Figure 5: The resilience-enabling leadership explanatory framework 


\subsubsection{Implications for subsequent phases}

This research is ultimately about understanding what leadership behaviours enable employee resilience and establishing a measure to test these behaviours. Although this study has identified the leadership behaviours and mechanisms through which they influence resilience, they are not yet measurable and have not been verified in an independent sample. Therefore, the identified behaviours need to be incorporated into a format in which the behaviours can be further scrutinised and refined in the phases to follow, so that they can be further refined through quantitative testing (DeVellis, 2016). This means taking the leadership behaviours out of the explanatory framework and into their own leadership model that reflects a suitable scale for evaluation and measurement.

The approach used in Phase 3, informed by cognitive interviewing, elicited valid information regarding how individuals perceive the mechanisms through which leadership behaviours are experienced (Brenner, 2015). A model suitable for scale development must have a proposed item pool. These items must reflect the dimension, as well as the construct, of interest (DeVellis, 2016). Thus, it is appropriate to draw on the identified mechanisms as items which help exemplify our understanding of resilience-enabling leadership. Since there were particular mechanisms unique to each behavioural dimension, there was ample information within these mechanisms to transform them into items that could be effective at measuring a given dimension of the resilience-enabling leadership construct.

The mechanisms by which individuals experienced each leadership behaviour dimension identified in Phase 3 were used to illustrate and reflect the behavioural dimensions, and thus ultimately, the broader, multi-dimensional construct of resilience-enabling leadership. This new model is presented in Table 15 below. 
Table 15: Resilience-enabling leadership model for validity testing

\begin{tabular}{|c|c|}
\hline $\begin{array}{l}\text { Leadership } \\
\text { dimension }\end{array}$ & Examples (Items) \\
\hline $\begin{array}{l}\text { Managing the whole } \\
\text { team }\end{array}$ & $\begin{array}{l}\text { My manager encourages our team to work collectively when } \\
\text { appropriate } \\
\text { My manager expects me to collaborate with others when necessary } \\
\text { My manager involves themselves in collaboration with the team } \\
\text { My manager sets tasks which require us to work together }\end{array}$ \\
\hline $\begin{array}{l}\text { Enabling self- } \\
\text { management }\end{array}$ & $\begin{array}{l}\text { My managers gives guidance that is focused on outcomes, rather than } \\
\text { processes } \\
\text { My manager trusts me to achieve outcomes } \\
\text { My manager supports me when I need it } \\
\text { My manager knows what I am capable of } \\
\text { My manager lets me get on with my work } \\
\text { My manager does not micromanage }\end{array}$ \\
\hline Managing safe failures & $\begin{array}{l}\text { My manager values the knowledge I bring to the team } \\
\text { When I make a mistake, my manager stays calm } \\
\text { When I make a mistake, my manager helps me to learn from it } \\
\text { My manager shows a general openness toward learning }\end{array}$ \\
\hline $\begin{array}{l}\text { Supporting personal } \\
\text { growth and wellbeing }\end{array}$ & $\begin{array}{l}\text { I have open conversations with my manager about my future career } \\
\text { plans } \\
\text { My manager supports me to seek out opportunities for training and } \\
\text { development } \\
\text { My manager supports me to go on courses for training and } \\
\text { development } \\
\text { My manager backs the work decisions I make } \\
\text { My manager supports my personal needs } \\
\text { I feel comfortable talking honestly with my manager when I need } \\
\text { their advice } \\
\text { I feel comfortable seeking help from my manager }\end{array}$ \\
\hline $\begin{array}{l}\text { Recognising individual } \\
\text { needs and contributions }\end{array}$ & $\begin{array}{l}\text { My manager provides me with individualised feedback } \\
\text { My manager provides recognition that is specific to my real } \\
\text { contributions } \\
\text { My manager trusts me to do my own work well } \\
\text { Where possible, my manager is good at providing me with } \\
\text { meaningful non-monetary rewards }\end{array}$ \\
\hline
\end{tabular}

In the table above, the behavioural items mirror the mechanisms found in the explanatory framework (Figure 5). DeVellis' (2016) recommendations for item generation were taken into account here, where the relevant leadership behaviours were expressed using simple words, and double-barrelled items were avoided (see Tummers \& Knies, 2016). Reverse scored items were also avoided due to their potential to reduce the validity of a measure (Hinkin, 1995). Using participants' own descriptions as the basis for these items also helped with the process of developing items that were relevant and easily understood by members of the target population (in this case, public servants) (DeVellis, 2016). 
Although the previous phases of this study worked to generate the items for potential measurement, the process still requires further qualitative exploration, before quantitative testing. This is an important step in scale development, according to DeVellis (2016). Qualitative means of developing and validating scales has been commonly used in organisational scholarship (Levashina \& Campion, 2007; Liden \& Maslyn, 1998; Parasuraman, Zeithaml, \& Berry, 1988). Qualitative exploration here relates to the process of having the initial item pool being reviewed by experts. This involves consulting individuals regarding the clarity and readability of the items, as well as to "confirm or invalidate [the] definition of the phenomenon” (DeVellis, 2016, p. 135). These experts may also raise other items or descriptions reflecting the phenomenon that have not yet been included. Engaging in expert reviews, hereafter consultations, helps to maximise the content validity of a scale that is in development (DeVellis, 2016; Wynd, Schmidt, \& Schaefer, 2003).

\subsubsection{Considerations}

Participants' causal attributions made in this phase of inquiry are not the same as actual causality. Making causal attributions using qualitative findings can be seen as a limitation, as such an endeavour is more commonly pursued in quantitative research (Mohr, 1996). In contrast however, it has also been argued that qualitative field research "is far better than solely quantified approaches at developing explanations of what we call local causality - the actual events and processes that led to specific outcomes” (Miles \& Huberman, 1984, p. 132). This in no way undermines the role of quantitative approaches in establishing notions of causality (e.g. Cook, Campbell, \& Shadish, 2002). Instead, qualitative research complements statistical conclusions by offering explanatory power and insight, that is sensitive to the social context (Bryman et al., 1996).

In this research, employees' detailed, contextual experiences regarding the enablers and processes of leader behaviour are seen as an essential part of understanding effective leadership for resilience, which requires an understanding of the causal associations surrounding such behaviour. The context-dependent, sometimes even subjective, nature of leader effectiveness (Heres \& Lasthuizen, 2012) is, after all, not able to be understood solely through predictive, positivist methods, as this would risk losing the explanatory value and contextual knowledge evident in this study, provided here through in-depth qualitative research.

A limitation of this phase is the small sample size. However, this phase of inquiry sought explanatory insight and contextual richness over generalisability (Bryman et al., 1996), so this size of 10 employees was deemed sufficient (Guest et al., 2006). As a result, detailed 
descriptions of participants' perceptions of effective leadership for resilience were able to be gathered and analysed. Explanatory insight and contextual richness were subsequently achieved, particularly when combined with the understandings already developed in Phase 2. The distinctiveness and complementarity between the methods employed in these two phases has helped develop a potentially robust model of resilience-enabling leadership, explained through the framework in Figure 5.

\subsection{Summary}

This phase further explored the concepts of resilience-enabling leadership and resilienceharming leadership. In doing so, it produced an explanatory framework for resilienceenabling leadership behaviours, which will be developed into a measure for further examination and testing in the phases to follow. 


\section{PHASE 4 - SCALE DEVELOPMENT AND CONTENT VALIDITY}

\subsection{Introduction}

This phase comprises consultations with two different types of subject-matter experts to gather feedback on the RELS. The purpose of these consultations was to modify and validate the explanatory framework, developed through Phases 2 and 3, as a measurable leadership model.

First, a selection of members from the population under study were consulted (following the recommendation by DeVellis, 2016). These participants were those with public sector work experience and are referred to hereafter as population experts. Then, academic researchers in the areas of public administration and leadership were consulted. These individuals are referred to as content experts (Grant \& Davis, 1997). It is important to gather expert feedback during scale development so that the researcher can make informed decisions regarding "the clarity and comprehensiveness of dimension definitions . . . and the clarity and readability of items” (Linderbaum \& Levy, 2010, p. 1379).Consulting different types of experts is in line with Vogt, King and King's (2004) view, shared by DeVellis (2016), that “although the term 'expert' has typically been used to refer to researchers who are knowledgeable in the specific topic area, members of the population under study may also be considered 'experts'” (p. 232).

These validation processes helped to confirm and further develop the construct of resilienceenabling leadership. A tentative scale was developed as a result, which was fit for quantitative testing.

\subsection{Method}

To gather validation feedback from both groups of experts, three forms of data collection were undertaken: focus groups, interviews, and written feedback. Qualitative methods, particularly interviews and focus groups, are seen as an effective way to validate and refine survey instruments (DeVellis, 2016; Lo Cricchio et al., 2016; D. W. Stewart \& Shamdasani, 2014). Such methods allow the researcher to consult with potential respondents to gain an understanding of how they view issues in context and to identify any ambiguities regarding the researcher's own understanding of these issues. This type of inquiry can enhance the content validity of survey instruments (L. A. King, King, Vogt, Knight, \& Samper, 2006). 
Thus, qualitative methods are used in this phase of the research to enhance the content validity of the RELS. These methods are described within the appropriate sections below.

\subsubsection{Focus groups and interviews}

Population experts were consulted through focus groups and interviews. Group interaction in the focus groups was used to foster discussion on the items within the explanatory framework, as well as their broader dimensions. The three specific aims of the focus groups were informed by Lo Cricchio et al. (2016). These relate to scale development and consist of “(a) correcting the language, and in particular, the choice of words or expressions of items to better fit what is usual for possible respondents; (b) taking into account the context, and the differences due to age and educational background between the target population and the researchers who have generated the questionnaires; (c) improving the content, in particular, the appropriateness of content in questions relating to individuals' experiences and background” (Lo Cricchio et al., 2016, p. 395). Of particular interest too was whether the mechanisms (now reframed as the items) made sense conceptually to the participants, particularly in regard to how well they reflected the overarching dimension they belonged to.

The interviews had the same aims (Lo Cricchio et al., 2016) but were chosen as an additional and distinct method for two important reasons. Firstly, they provided a choice for individuals who were more comfortable engaging in a one-on-one discussion on this topic, rather than in a group context. And secondly, they were used as a control for any group interaction effects influencing responses in the focus groups.

A combination of focus groups and interviews was seen as the most effective approach for yielding balanced and meaningful data, as both methods have complementary strengths and weaknesses. In focus groups, for example, participants can interact and engage with each other, resulting in rich insights extending beyond answers to questions asked by the researcher (Carey \& Smith, 1994). In a practical sense, it is an efficient way to gather rich data in a short period of time. The deep and insightful nature of this data is thus appropriate to use to "clarify, extend, qualify or challenge" other forms of data collected already (Gill, Stewart, Treasure, \& Chadwick, 2008, p. 293). At the same time, the group interaction effect can skew data as particular views and personalities may dominate discussion and prevent any dissenting or challenging views from emerging that may be useful to the researcher (Asch, 1951). This means that the nature of data emerging from focus groups can often vary greatly from the insights gathered from interviews (Morgan \& Krueger, 1998). 
Interviews, on the other hand, reduce the likelihood of opinion convergence, and can highlight personal instead of group experiences (Lambert \& Loiselle, 2008). Described as qualitative-qualitative triangulation, combining focus groups with interviews can, in the appropriate research context, result in a more complete understanding of the research phenomenon (Lambert \& Loiselle, 2008; M. J. Sandelowski, 1995). It can also offset the limitations present in each method.

Appendices E and F cover ethics documents and additional content provided to participants in this phase.

\subsubsection{Written feedback}

Written feedback was gathered from the content experts. This was an additional way in which insights were generated to help confirm and validate the RELS. Known as judgementquantification (Grant \& Davis, 1997), this process involved consulting an expert panel of researchers, who gave written feedback on the individual items, the dimensions, and the scale overall. Using the written form as another medium for feedback allowed the researcher to deal directly with content experts' written word, which, for them, would have involved careful consideration of what the relevant issues were and of the specific wording choices. This differs from verbal feedback, which can be given instantly, but might not be as carefully considered. It also complements the verbal feedback gained through focus groups and interviews, by representing another way in which thoughts, experiences, and feedback can be transformed into communicable representations (Thorne, 2000). There was also a pragmatic rationale for using written feedback for the content experts. These busy individuals were located in various locations, so written consultation via email was seen as a low burden, time efficient way of utilising their expertise.

\subsubsection{Sample and design}

\subsubsection{Population experts, focus groups and interviews}

The first group of experts (population experts) were post-experience management students $(n=13)$ with experience working in the New Zealand public sector. This meant the former group had a solid grounding in management studies, as well as experience of either managing, or being managed, in a public sector work environment. This made them knowledgeable members of the population under study. This experience was vital to include in the validation phase of this research because in order to develop these behaviours into a usable scale, they need to be well understood and easily applied by potential respondents (population experts), not just by those who have expert content knowledge (DeVellis, 2016). 
When population experts have a clear understanding of what items within a measure mean, face validity is enhanced (Hardesty \& Bearden, 2004). The potential respondents of the final survey (Phase 5) were to be public servants and managers.

Two focus groups $(n=3,4)$ and six interviews $(n=6)$ were undertaken in this phase, and 13 participants were involved all together. Potential participants were first recruited via an email from post-experience programme directors to all students enrolled in the Masters of Business Administration and Masters of Public Management programmes at Victoria University of Wellington. The email addressed individuals with experience in the public sector and described the purpose and nature of the study. It then gave them the opportunity to contact the researcher if they were interested in participating. Interested individuals were then sent an email with more detail about the study, including the topic and aims of the research, the rules of confidentiality (with ethics approval number 0000025909), the choice of participating in a focus group or interview, and a proposed time to meet.

Those who replied to the email, expressing their interest in taking part in the research, were contacted further. An agenda, including discussion content, was emailed to these individuals prior to meeting for the interviews and focus groups. This content included a description of the purpose of this phase of study, which in short, was to "confirm and contrast findings to date”. This involved getting expert feedback on a) whether they agreed with the behaviours in terms of how they reflected the behavioural dimensions, b) what they perceived the behaviours to look like in practice c) whether they thought any of the behaviours needed to be worded differently, and d) whether they had any other specific examples of resilience enabling leadership behaviours. The content email also included two tables, as presented in Appendix F. Table C presented resilient employee behaviours (Kuntz et al., 2016; Näswall et al., 2015) and Table D showed the resilience-enabling leadership behaviours identified in Phases 1 to 3 in this research.

Focus groups and interviews followed the same structure. The general structure involved first gathering perceptions of general understandings of resilience in the workplace, including if and how their understanding of employee resilience corresponded to the resilient behaviours shown in Table $\mathrm{C}$ of the content document. The second, and primary, phase of the interview or focus group was engaging in rigorous discussion (according to $\mathrm{a}-\mathrm{d}$ above) about the leadership behaviours as shown in Table D. Inevitably, the experts raised issues beyond those initiated in $\mathrm{a}-\mathrm{d}$, which were also taken as feedback to inform and improve the validation of the behaviours for scale development. 


\subsubsection{Content experts and written feedback}

The second and content expert group were made up of academic researchers $(n=4)$ with expertise in public administration and/or leadership. This meant that they had expert knowledge on the topic in an academic sense, and could comment on both conceptual and methodological aspects of resilience-enabling leadership.

Four content experts were successfully recruited for this phase, exceeding the minimum number of three recommended by Lynn (1986). Content experts were defined as management academics who had extensive research or scale development experience in the scholarship areas of leadership and/or public administration and had published extensively in leadership and/or public administration. Six content experts were initially contacted by the researcher with an invitation to participate in providing feedback for the validation of a leadership scale. Four agreed to take part, and were subsequently contacted by the researcher. They were emailed with a consultation document attached (see Appendix F). This consultation document included an overview of the study, including brief summaries of the completed research phases, and the leadership framework of the scale items for confirmation and validation. Experts were then asked specifically to comment on: 1 ). The draft items and dimensions for the scale in terms of readability and content validity, and 2). Any additional comments in the proposed quantitative survey design (Phase 5), including comparative leadership constructs. Content experts responded with their comments through a reply email, as well as by placing comments on the consultation document.

Since this group of experts have developed knowledge and understanding regarding leadership and/or public administration constructs, including their measurement, insights specific to content validity were sought, including the processes undertaken to develop the items. In other words, these consultations were much more specific and targeted to content validity issues, than the focus groups and interviews, which were more general in purpose. It was also important to get their views on other variables for inclusion in the final survey which aimed to quantitatively test the RELS. Reasons for inclusion of these other measures relate to the need to ensure convergent and discriminant validity (DeVellis, 2016).

\subsubsection{Analysis}

Focus groups and interviews with population experts were recorded and transcribed, whilst the written feedback was provided directly by the content experts. Focus group and interview data were analysed using a very literal, systematic approach to the data. First, to document the responses and feedback, each participant's responses were applied to the researcher's copy of the content document (Appendix F). Areas where they had specific comments on the 
scale were annotated alongside the associated dimension or item in the framework, and more general comments were provided beneath the framework. The feedback from the focus groups and interviews was analysed first, so that the framework could be modified before sending to the content experts for their written feedback.

The data gathered from the written feedback were analysed by grouping responses initially according to global and local feedback. Global feedback relates to the general, "big” ideas that emerge in qualitative data. These ideas are described by Krueger (1998) as "trends or ideas that cut across the entire discussion” (p. 38). This relates to the global feedback participants gave on employee resilience and the leadership behaviours generally, not regarding the specific items or behaviours. Local feedback relates to participants' more specific responses regarding the clarity and readability of the scale's dimensions and their corresponding items (Linderbaum \& Levy, 2010).

\subsection{Findings}

The findings of the focus groups and interviews will be presented according to each behavioural dimension, in the order as follows: managing the whole team, enabling selfmanagement, managing safe failures, supporting personal growth and wellbeing, and recognising individual needs and contributions. For confidentiality reasons, participants' responses are again presented under pseudonyms.

\subsubsection{Focus groups and interviews}

\subsubsection{Managing the whole team}

A number of changes were made to this dimension during this stage of feedback. Three new items were added to this dimension, the reasons for which are described in more detail below. Suzanne raised the point that establishing the right kind of environment is important for developing team cohesion, such that the manager should help to set the conditions for collaboration within a team so that people feel willing to collaborate with each other. This was deemed a very relevant point, as an accommodating climate often needs to exist before individuals can engage in a particular behaviour (Neal \& Griffin, 2002). Taking this into account, the item: "My manager helps to create an environment where I want to collaborate" was added to the managing the whole team dimension.

Patricia emphasised the importance of having a manager who can control and manage conflict within a team. When conflict is handled or resolved effectively, collaboration is more 
likely (Weingart \& Jehn, 2017). Thus, "My manager is good at managing conflict within the team" was also included as part of the Managing the whole team dimension.

Mandy stressed that in developing collaborative working and network leveraging behaviours, it is not only important to maintain existing networks, but it is also necessary to develop new, wider networks to leverage. Part of managing the whole team and helping individuals work collaboratively is about building their broader networks to promote new experiences, ways of working, and ways of interacting with different parties. It was then decided that adding the item "My manager assists me in developing broader networks" was appropriate in helping to have more content added to reflect this dimension.

Focus group participants explained that managers should be more facilitative, and less directive, when it comes to collaboration. This would ensure managers behaved more inclusively, recognising that different people with different personalities have different desires and needs around collaboration. To acknowledge this, in "My manager sets tasks which require us to work together", the word "require” was changed to "encourage" to avoid connotations with forceful, directive forms of management which can work against collaboration. Related to the above statement, since collaborating is about working with others, and work can come in many different forms (not just communicating verbally), in "My manager expects me to collaborate with others when needed", the word "collaborate" was changed to "work". It was also discussed in the focus groups that the endings of some items (e.g. "when appropriate” and "when needed”) within this dimension were very subjective, as what is needed or appropriate is different for every individual. Thus, to elicit a more general impression of one's manager, these endings were removed.

\section{Table 16: Amendments to managing the whole team}

\begin{tabular}{l|l}
\hline Original items & $\begin{array}{l}\text { My manager encourages our team to work collectively when } \\
\text { appropriate } \\
\text { My manager expects me to collaborate with others when necessary } \\
\text { My manager involves themselves in collaboration with the team } \\
\text { My manager sets tasks which require us to work together }\end{array}$ \\
\hline Revised items & $\begin{array}{l}\text { My manager helps to create an environment where I want to } \\
\text { collaborate } \\
\text { My manager encourages our team to work collectively when } \\
\text { appropriate } \\
\text { My manager expects me to work with others when needed } \\
\text { My manager involves themselves in collaboration with the team } \\
\text { when appropriate } \\
\text { My manager sets tasks which encourage us to work together } \\
\text { My manager is good at managing conflict within the team } \\
\text { My manager assists me in developing broader networks }\end{array}$ \\
\hline
\end{tabular}




\subsubsection{Enabling self-management}

Enabling self-management for resilience was an idea supported by nearly all of the Phase 4 participants. It was described as empowering, capability-enhancing and an important part of a resilience-enabling leader's behavioural repertoire. The only change to these items was the removal of "My manager supports me when I need it" which was deemed to be a duplicate of item(s) in the supporting personal growth and wellbeing dimension. Changes are displayed below:

\section{Table 17: Amendments to enabling self-management}

\begin{tabular}{l|l}
\hline Original items & $\begin{array}{l}\text { My manager gives guidance that is focused on outcomes, rather than } \\
\text { processes } \\
\text { My manager trusts me to achieve outcomes } \\
\text { My manager supports me when I need it } \\
\text { My manager knows what I am capable of } \\
\text { My manager lets me get on with my work } \\
\text { My manager does not micromanage }\end{array}$ \\
\hline Revised items & $\begin{array}{l}\text { My manager gives guidance that is focused on outcomes, rather than } \\
\text { processes } \\
\text { My manager trusts me to achieve outcomes } \\
\text { My manager knows what I am capable of } \\
\text { My manager lets me get on with my work } \\
\text { My manager does not micromanage }\end{array}$ \\
\hline
\end{tabular}

\subsubsection{Managing safe failures}

No changes were made to this dimension through the focus group and interview analysis. Rather, it was confirmed by all participants as important in the context of resilience. Of particular note is the perceived importance of the item "When I make a mistake, my manager stays calm”, which was described as essential role modelling for individuals coping resiliently under pressure (Brown, Treviño \& Harrison, 2005). The responses also emphasised that it is important to recognise how challenging it can be for public sector managers to use mistakes as learning opportunities, given the control and accountability demands they are working under. This requires a nuanced approach by managers and leaders to identify and define the type and severity of a mistake, as well as the context under which it occurs, to decide whether it is appropriate to use it as a learning opportunity. 


\subsubsection{Supporting personal growth and wellbeing}

"My manager supports me to go on courses for training and development” was removed from this dimension because it was seen as too strongly dependent on external factors, i.e. time and money, which are prominent pressures in the public sector. Thus, even if a manager wanted to do this, the context might not allow for it. In addition, it was discussed that the entire scale is very much relational and interpersonal, whereas this item is quite transactional in its nature, which distinguishes it from the others. A new item was added to retain the active pursuit of managers in aiding employee growth and development, in a more personalised and relational way: "My manager looks out for new opportunities for me to be exposed to".

Focus group participants discussed the item: "My manager supports me to seek out opportunities for training and development", and commented that the term "supports" may be too passive for describing a resilience-enabling manager, and that "encourage" might be a more active, resilience-enhancing term to use, as it implies more participation by the employee to actively capitalise on such encouragement. "Training” was also removed to maintain consistency with the rationale of the previous paragraph, where options for training might be restricted or limited.

As a general point, it was also emphasised that ongoing attention to development needs to be emphasised over one-off opportunities. On the job learning, and support for learning and personal growth, correspond to the nature of resilience development, which is daily, continuous, and experiential (Yost, 2016). It was discovered throughout this process that these items reflected more than just “career” opportunities. They are about a person's own unique development. In other words, facilitating people’s careers is first about supporting their personal growth and development. Leadership needs to be oriented towards the individual and their unique potential, rather than orienting the individual to already established tangible and objective career opportunities, such as training and courses.

It became clear throughout this process that managers and leaders also need to respect that employees have their own career aspirations. This was raised by a number of participants. Part of a manager's job is valuing these aspirations in employees, rather than projecting their own ideas about where an employee's career should go. "My manager values my career aspirations" was added to this dimension as a result.

"I feel comfortable talking honestly with my manager when I need advice" was also modified. Participants explained that "advice” was too specific a reason to talk honestly with one's manager. Rather, it is always important for employees to feel comfortable talking honestly with their manager. Thus, "advice” was changed to "it” to broaden the behaviour, 
resulting in the modified item of "I feel comfortable talking honestly with my manager when I need it”. Amendments are shown below:

Table 18: Amendments to supporting personal growth and wellbeing

\begin{tabular}{l|l}
\hline Original items & $\begin{array}{l}\text { I have open conversations with my manager about my future career } \\
\text { plans } \\
\text { My manager requires me to seek out opportunities for development } \\
\text { My manager supports me to go on courses for training and } \\
\text { development } \\
\text { My manager backs the work decisions I make } \\
\text { My manager supports my personal needs } \\
\text { I feel comfortable talking honestly with my manager when I need their } \\
\text { advice } \\
\text { I feel comfortable seeking help from my manager }\end{array}$ \\
& $\begin{array}{l}\text { I have open conversations with my manager about my future career } \\
\text { plans } \\
\text { My manager encourages me to seek out opportunities for my } \\
\text { development } \\
\text { My manager looks out for new opportunities for me to be exposed to } \\
\text { My manager values my career aspirations } \\
\text { My manager backs the work decisions I make } \\
\text { My manager supports my personal needs } \\
\text { I feel comfortable talking honestly with my manager when I need it } \\
\text { I feel comfortable seeking help from my manager }\end{array}$ \\
\hline
\end{tabular}

\subsubsection{Recognising individual needs and contributions}

Focus group participants and four of the interviewed individuals highlighted that this dimension needed to reflect individual recognition at a personal level - i.e. valuing people for just "being themselves" - rather than focusing on task-related needs and contribution. The difference that a manager can make just by recognising someone's individual differences was also emphasised by a number of participants when discussing this dimension. Thus, it was agreed that two dimensions would be added to reflect this. These were: "My manager cares about me as a person” and "My manager values my differences”.

Focus group participants noted that "My manager trusts me to do my own work well" conceptually overlaps with elements in the "Enabling self-management dimension”. It was subsequently removed from this dimension for this reason. 
Table 19: Amendments to recognising individual needs and contributions

\begin{tabular}{l|l}
\hline Original items & $\begin{array}{l}\text { My manager provides me with individualised feedback } \\
\text { My manager provides recognition that is specific to my real } \\
\text { contributions } \\
\text { My manager trusts me to do my own work well } \\
\text { Where possible, my manager is good at providing me with meaningful } \\
\text { non-monetary rewards }\end{array}$ \\
\hline Revised items & $\begin{array}{l}\text { My manager cares about me as a person } \\
\text { My manager values my differences } \\
\text { My manager provides me with individualised feedback } \\
\text { My manager provides recognition that is specific to my real } \\
\text { contributions } \\
\text { Where possible, my manager is good at providing me with meaningful } \\
\text { non-monetary rewards }\end{array}$ \\
\hline
\end{tabular}

The overall modifications made to the RELS are provided in the table on the following page. 
Table 20: Changes to scale post-focus groups and interviews.

\begin{tabular}{|c|c|}
\hline Supervisory behaviour & Examples (Items) \\
\hline $\begin{array}{l}\text { Managing the whole } \\
\text { team }\end{array}$ & $\begin{array}{l}\text { My manager helps to create an environment where I want } \\
\text { to collaborate } \\
\text { My manager encourages our team to work collectively } \\
\text { appropriate } \\
\text { My manager expects me to work with others } \\
\text { My manager involves themselves in collaboration with the } \\
\text { team aphen appriate } \\
\text { My manager sets tasks which encourage us to work together } \\
\text { My manager is good at managing conflict within the team } \\
\text { My manager assists me in developing broader networks }\end{array}$ \\
\hline $\begin{array}{l}\text { Enabling self- } \\
\text { management }\end{array}$ & $\begin{array}{l}\text { My managers gives guidance that is focused on outcomes, } \\
\text { rather than processes } \\
\text { My manager trusts me to achieve outcomes } \\
\text { My manager supports me when I need it } \\
\text { My manager knows what I am capable of } \\
\text { My manager lets me get on with my work } \\
\text { My manager does not micromanage }\end{array}$ \\
\hline Managing safe failures & $\begin{array}{l}\text { My manager values the knowledge I bring to the team } \\
\text { When I make a mistake, my manager stays calm } \\
\text { When I make a mistake, my manager helps me to learn from it } \\
\text { My manager shows a general openness toward learning }\end{array}$ \\
\hline $\begin{array}{l}\text { Supporting personal } \\
\text { growth and wellbeing }\end{array}$ & $\begin{array}{l}\text { I have open conversations with my manager about my future } \\
\text { career plans } \\
\text { My manager encourages me to seek out opportunities for my } \\
\text { development } \\
\text { My manager supports me to go on courses for training and } \\
\text { development } \\
\text { My manager looks out for new opportunities for me to be } \\
\text { exposed to } \\
\text { My manager values my career aspirations } \\
\text { My manager backs the work decisions I make } \\
\text { My manager supports my personal needs } \\
\text { I feel comfortable talking honestly with my manager when I } \\
\text { need it } \\
\text { I feel comfortable seeking help from my manager }\end{array}$ \\
\hline $\begin{array}{l}\text { Recognising individual } \\
\text { needs and contributions }\end{array}$ & $\begin{array}{l}\text { My manager cares about me as a person } \\
\text { My manager values my differences } \\
\text { My manager provides me with individualised feedback } \\
\text { My manager provides recognition that is specific to my real } \\
\text { contributions } \\
\text { My manager trusts me to do my on ork well } \\
\text { Where possible, my manager is good at providing me with } \\
\text { meaningful non-monetary rewards }\end{array}$ \\
\hline
\end{tabular}

Note: Added words and items are bolded, while removed items are crossed out. 


\subsubsection{Written feedback}

The feedback from the content experts was analysed by organising it into categories of global and local evaluative commentary. The global commentary consisted of general comments participants had about the behaviours and resilience-enabling leadership generally and the local commentary involved specific feedback on the behavioural examples (items). There were positive and negative aspects raised for both of these commentaries.

\subsubsection{Global commentary}

The section below presents the global, or general, comments the content experts had on the RELS. It also explains what was changed in response to these comments. To maintain confidentiality, content experts are referred to by their job roles only.

Table 21: Global commentary on resilience enabling leadership

\begin{tabular}{l|l}
\hline Issue & Comment \\
\hline Distinct \\
contribution & $\begin{array}{l}\text { The dimensions that you suggest parallel closely with Ryan and Deci } \\
\text { (2000)'s self-determination theory. Servant leadership behaviours also } \\
\text { capture some of the dimensions you suggest. You need to be explicit in } \\
\text { the distinct contribution you are making. I do not know your work, but I } \\
\text { quite like the idea of "resilience enabling leadership behaviours." It is a } \\
\text { worthwhile field of inquiry to see what leadership behaviours build } \\
\text { employee resilience. - Associate Professor in Leadership }\end{array}$ \\
\hline Readability & $\begin{array}{l}\text { Readability is excellent and the items seem straightforward for a lay } \\
\text { person to understand (no jargon) - Senior Lecturer in Organisational } \\
\text { Psychology }\end{array}$ \\
\hline construct & $\begin{array}{l}\text { I always think it's important to identify the focus of your construct (the } \\
\text { "who" of the items - self/other - and perceptions, attitudes, or } \\
\text { behaviours), and then the items are drawn from that orientation. In your } \\
\text { case I think the focus is on the respondent's observations of managerial } \\
\text { competence/behaviours - Senior Lecturer in Management }\end{array}$ \\
\hline $\begin{array}{l}\text { General } \\
\text { impression }\end{array}$ & $\begin{array}{l}\text { I can see how you would come to these items, and I can imagine how they } \\
\text { could be theoretically justified - Professor of Public Management }\end{array}$ \\
\hline Dimensions & $\begin{array}{l}\text { You have many dimensions and it is unlikely that EFA will lead to a } \\
\text { matching factor solution. Also, unless some of these are based on already } \\
\text { widely used and validated scales, you may not find sufficient alpha values } \\
\text { from only four untested items. . . Typically, one sees constructs with 2-4 } \\
\text { dimensions, and, at this point in the study, about 7-8 items per subscale, } \\
\text { in order to find out which items actually scale and, hence which should } \\
\text { be retained. - Professor of Public Management }\end{array}$ \\
\hline
\end{tabular}

Changes were made to the scale's composition in response to the expert comments. These are presented under the relevant issue subheadings below. 


\subsection{Distinct contribution}

Sufficient distinctions between this scale, self-determination theory, and servant leadership do exist, and this is explained further in the integration section to follow. No changes were made to the actual scale based on this comment because this question is primarily theoretical, and therefore the distinctions can be delivered theoretically, rather than empirically. However, this comment did raise awareness of the importance of testing the scale's predictive and discriminant validity.

\subsection{Readability}

This comment on readability is a positive one to receive at the global level. However, readability issues did exist at the local level, and are presented in the following section.

\subsection{Nature of construct}

It was noted in response to this comment that the focus of this scale, in terms of whether it is behavioural, attitudinal, or emotional, was not fully clear. Indeed, it is the case that the scale is about perceptions of managers' leadership behaviours. Again, there are specific items at the local level that were addressed in order to make the scale more consistent with this focus.

\subsection{General impression}

This comment that the expert understands how the scale was developed and theoretically justified is a positive one as it suggests the scale makes sense at face value and is not confusing as an overall measure. It also indicates the dimensions are straight-forward in why and how they might reflect an overarching construct of resilience-enabling leadership.

\subsection{Dimensions}

A very pertinent and valuable comment made by the Professor of Public Administration concerning the scale’s dimensions. A significant response was taken to address this.

The dimensions were carefully scrutinised as a result of this comment and although the first two dimensions (managing the whole team and enabling self-management) were distinct as stand-alone dimensions, the last three were not so clear-cut upon further inspection. First, the third (managing safe failures) and fourth (supporting personal growth and wellbeing) contained a large degree of conceptual overlap. Many of these items appear to relate to individuals feeling safe to learn around, and seek help from, their manager. Four items from supporting personal growth and wellbeing were combined with those from managing safe failures, resulting in a new dimension titled creating a safe climate for learning. The 
remaining items from supporting personal growth and wellbeing, regarding support for career and personal growth, aligned conceptually with the final dimension, recognising individual needs and contributions. These items reflect managers' support for, and encouragement of, employees' personal development, whether it be through facilitating growth opportunities or providing effective individual feedback. These items were combined after this consideration, and renamed as supporting personal growth.

It should be noted that factor analysis in the following phase will also indicate the nature of dimensionality for this scale.

\subsubsection{Local commentary}

This section presents the local, or specific, feedback the content experts had on the RELS, (See the Table on the following page for an overview). The section also outlines the response taken to these comments. 
Table 22: Local commentary on resilience enabling leadership

\begin{tabular}{|c|c|}
\hline Issue & Comment \\
\hline $\begin{array}{l}\text { Nature of } \\
\text { construct }\end{array}$ & $\begin{array}{l}\text { In regards to Enabling self-management: } \\
\text { These are all behaviours, value neutral, and consistent .- Senior Lecturer in } \\
\text { Management } \\
\text { In regards to “... is good at managing conflict within the team": } \\
\text { This is the only item that has a positive value embedded in it - "good.” The other } \\
\text { items are statements of behaviour whereas this is a perception. Could be changed } \\
\text { to "manages conflict" to align with the other behavioural items. - Senior } \\
\text { Lecturer in Management } \\
\text { In regards to “... stays calm when I make a mistake": } \\
\text { This item is getting at emotional self-control, and the fourth item is a personality } \\
\text { trait, while the other two are behaviours. Could they be rewritten to be more } \\
\text { behavioural like the other items? - Senior Lecturer in Management }\end{array}$ \\
\hline Wording & $\begin{array}{l}\text { In regards to the opening statement of "My manager...": } \\
\text { Some employees have more than one manager they report to and/or at different } \\
\text { levels within the organisation. It would be helpful to define this so there is } \\
\text { consistency across respondents, e.g. "my immediate manager" or "the manager } \\
\text { I report to", "my team leader", etc - Senior Lecturer in Management }\end{array}$ \\
\hline Dimensions & $\begin{array}{l}\text { In regards to Managing the whole team: } \\
\text { I wonder if it might be better labelled as: Developing collaborative working? The } \\
\text { items seem more specific to developing a collaborative culture/climate rather } \\
\text { than general management. - Senior Lecturer in Organisational Psychology } \\
\text { There are certain items that I am not sure how they fit with the dimension: } \\
\text { Managing the whole team. For example, “. . . assists me in developing broader } \\
\text { networks" is not clear. The broader networks, for me, means boundary spanning } \\
\text { and developing networks of relationship with others who are outside the team. Is } \\
\text { that what you intend the one who rates to think? Most of the items that pertain to } \\
\text { this dimension has to do with team collaboration. Is this what the dimension } \\
\text { captures? Does team collaboration relate to employee resilience? - Associate } \\
\text { Professor in Leadership }\end{array}$ \\
\hline Meaning & $\begin{array}{l}\text { In regards to “. . . gives guidance that is focused on outcomes, rather than } \\
\text { processes": } \\
\text { A manager who "gives guidance that is focused on outcomes, rather than } \\
\text { processes" might not also be able to score highly on all the process items in } \\
\text { Managing the whole team. - Senior Lecturer in Organisational Psychology } \\
\text { I would reword the item ". . gives guidance that is focused on outcomes, rather } \\
\text { than processes". I know what you mean, but it will not be clear for practitioners } \\
\text { who will use your instrument. - Associate Professor in Leadership }\end{array}$ \\
\hline $\begin{array}{l}\text { Conceptual } \\
\text { overlap }\end{array}$ & $\begin{array}{l}\text { In regards to overlap between dimensions: } \\
\text { I'm not sure why "values the knowledge I bring to the team" is considered so } \\
\text { different from "knows what I am capable of" that it's in a different dimension. - } \\
\text { Senior Lecturer in Organisational Psychology } \\
\text { In regards to Enabling self-management: } \\
\text { The item "does not micromanage" is a redundant item. If the manager does } \\
\text { everything you state in the first } 4 \text { items, then the manager is not micromanaging } \\
\text { - Associate Professor in Leadership } \\
\text { In regards to Supporting personal growth: } \\
\text { I feel that the item "... is good at providing me with meaningful non-monetary } \\
\text { rewards where possible" is redundant as it is captured by the item "... provides } \\
\text { recognition that is specific to my real contributions". - Associate Professor in } \\
\text { Leadership }\end{array}$ \\
\hline
\end{tabular}




\subsection{Nature of construct}

To align with other behavioural items, “. . . is good at managing conflict within the team” was changed to ". . . manages conflict within the team”; “. . . stays calm when I make a mistake” was also changed to “. . . acts calm . ..." in order to reflect a behaviour rather than an emotional state.

\subsection{Wording}

To improve clarity regarding the manager that respondents are reporting on, "My manager . .. ." was changed to "The manager I report to .. .”.

\subsection{Dimensions}

The first and second comments for this issue relate to the dimension of managing the whole team. The comments highlight the fact that the items relate more to collaboration than to managing teams. Thus, upon reflection, this dimension was changed to developing collaborative working, similar to its original title.

\subsection{Meaning}

In terms of the item, “. . . gives guidance that is focused on aims and outcomes, rather than processes”, the latter part of the sentence: “. . . rather than processes” was removed to communicate that managers could still be sensitive to process, such as the processes required for encouraging collaborative working, whilst still focusing on outcomes to enable a degree of self-management. Another reason for this decision was to improve general clarity for this issue, as highlighted in the second comment.

\subsection{Conceptual overlap}

Comments related to conceptual overlap were largely related to the potential redundancy of certain items. The item “. . . values the knowledge I bring to the team” from the learning dimension was removed, not only due to the conceptual overlap with “. . . knows what I am capable of", but also because it did not clearly or adequately reflect a type of behaviour that could be easily defined and understood.

The final two comments regarding the redundancy of items in both enabling selfmanagement and supporting personal growth and wellbeing were deemed relevant and logical. However, these potential redundant items were still retained. This was to allow quantitative testing to help determine the strength of these items (versus the other conceptually similar items) in reflecting and explaining the dimension it is supposed to be measuring. 


\subsubsection{Final changes}

The wording of two items were changed upon reflecting on feedback. In particular, feedback on the nature of the construct. This construct is about the perceptions of one's manager. Two items were changed to become perceptions of one’s manager, rather than self-perceptions. Thus, "I feel comfortable talking honestly with my manager when I need it" and "I feel comfortable seeking help from my manager” were changed to “. . . makes me feel comfortable talking honestly to them” and “... makes me feel comfortable seeking help from them.” This also suited the wording of the scale more appropriately, as “The manager I report to ..." could then be an appropriate prefix for all items.

The wording of the dimensions was also modified to appear more active. For example, Developing collaboration was changed to Develops collaboration. More detail on the changes made here are provided in the following section, and presented in Table 23.

\subsection{Integration}

Phase 4 sought to gather expert feedback on the resilience-enabling leadership behaviours identified. A five-dimension 28-item scale resulted from these consultations. The revised scale for quantitative testing in Phase 5 is presented in Table 23 below. 
Table 23: Revised RELS for quantitative testing

\begin{tabular}{l|l}
\hline $\begin{array}{l}\text { Leadership } \\
\text { behaviour }\end{array}$ & Examples (Items) \\
\hline \multicolumn{1}{l}{$\begin{array}{l}\text { Develops } \\
\text { collaboration }\end{array}$} & $\begin{array}{l}\text { expects me to work with others } \\
\text { helps to create an environment where I want to collaborate } \\
\text { encourages our team to work collectively } \\
\text { involves themselves in collaboration with the team } \\
\text { sets tasks which encourage us to work together } \\
\text { manages conflict within the team } \\
\text { assists me in developing broader networks }\end{array}$ \\
\hline $\begin{array}{l}\text { Enables self- } \\
\text { management }\end{array}$ & $\begin{array}{l}\text { gives guidance that is focused on outcomes } \\
\text { trusts me to achieve outcomes } \\
\text { knows what I am capable of } \\
\text { lets me get on with my work } \\
\text { does not micromanage }\end{array}$ \\
\hline $\begin{array}{l}\text { Creates a safe } \\
\text { climate for } \\
\text { learning }\end{array}$ & $\begin{array}{l}\text { acts calm when I make a mistake } \\
\text { helps me to learn from mistakes I make } \\
\text { shows a general openness toward learning } \\
\text { backs the work decisions I make } \\
\text { supports my personal needs } \\
\text { makes me feel comfortable talking honestly to them } \\
\text { makes me feel comfortable seeking help from them }\end{array}$ \\
\hline $\begin{array}{l}\text { Supports } \\
\text { personal and } \\
\text { career growth }\end{array}$ & $\begin{array}{l}\text { has open conversations with me about my future career plans } \\
\text { encourages me to seek out opportunities for my development } \\
\text { looks out for new opportunities for me to be exposed to } \\
\text { values my career aspirations } \\
\text { cares about me as a person } \\
\text { values my differences } \\
\text { provides me with individualised feedback } \\
\text { provides recognition that is specific to my real contributions } \\
\text { is good at providing me with meaningful non-monetary rewards } \\
\text { where possible }\end{array}$ \\
\hline
\end{tabular}

This phase has exemplified the value of expert engagement in the scale development process. Moreover, it shows that different types of experts can provide complementary feedback on the potential practical, scholarly, and statistical relevance of a scale. This phase further shows that qualitative approaches, such as focus groups (Krueger \& Casey, 2014), interviews (DeWalt, Rothrock, Yount, \& Stone, 2007), and written feedback (Fowler, Staudt, Greenberg, \& Oppenheim, 2009), are all effective for determining how a phenomenon, and its proposed items, will be perceived, understood, and responded to by members of the target population. These more context-aware, interactive approaches are likely to provide a careful, 
nuanced understanding of the ambiguities in, and necessary modifications to, the scale before it is tested in a quantitative manner using statistics, for processes such as reliability tests and factor analyses.

A large part of this phase was understanding how followers might perceive, and ultimately respond to, leadership behaviours. This has implications for predictive validity, or how resilience-enabling leadership might predict behaviours in employees. When employees perceive these behaviours as resilience-enabling, the associated response to these behaviours might be for employees to behave resiliently. It is expected that employees would experience a resilience-enabling effect, whereby they experience the confidence, skills, and motivation to perform resilient behaviours, similar to views on effect of transformational leadership (Barbuto, 1997), whereby followers "feel trust and respect towards leaders, and are motivated to perform extraordinary behaviours” (Mester et al., 2003). It is not yet clear whether these leadership behaviours are actually resilience-enabling. That is, do they predict resilience in employees? The final phase to follow set out to test the predictive validity of these behaviours, as part of assessing the overall validity of the measure (Posner \& Kouzes, 1988).

The distinctiveness of the construct is another important issue to explore further in Phase 5. The content expert comment on similarities between the construct of resilience-enabling leadership, self-determination theory and servant leadership warrants consideration. Selfdetermination theory certainly shares similarities with the constructs under study in this research. Self-determination theory concerns the importance of individuals' self-motivation and wellbeing, through satisfying needs for competence, relatedness, and autonomy (Ryan \& Deci, 2000). These needs are central to the behaviours of a resilient employee and are likely, to some extent, to be able to be encouraged by the behaviours of a resilience-enabling leader. Resilience-enabling leadership may foster both autonomous and controlled motivation too (Gagné \& Deci, 2005), but it more importantly goes beyond influencing the motivational state of an individual and is instead designed to enable definable behaviours in employees, namely those centered around network-leveraging, learning, and adaptability (Kuntz et al., 2017). Resilience-enabling leadership is also distinct from self-determination theory as the latter is a way of understanding motivation, not a leadership style or theory.

Servant leadership also shares similarities with resilience-enabling leadership with respect to its potential role in fostering learning, growth and autonomy (Bass, 2000). Although outcomes might converge, the nature of the constructs are distinct. Resilience-enabling leadership is not so much about "serving” others (Parris \& Peachey, 2013), than it is about leadership that enables employees to better serve the organisation. It also does not assume 
that resilience-enabling leaders have the foresight, healing and stewardship characteristics of servant leaders as expressed by Spears (1998). Behaviours, rather than leadership characteristics, are central to resilience-enabling leadership. What would be valuable in future studies once resilience-enabling leadership is validated is to examine the variability between these two leadership constructs in their ability to predict resilient behaviours in employees. The above distinctions do not discount the need for discriminant validity checks in the processes of scale development, and as will discussed in Phase 5, the construct of LMX (Graen \& Uhl-Bien, 1995) will be included in the final survey to assess its performance alongside resilience-enabling leadership. LMX is better suited as a discriminant validity variable because, like resilience-enabling leadership, it measures employee perceptions of leader behaviour, and is partly geared towards fostering positive behaviours in employees (Graen \& Uhl-Bien, 1995). Difference lie in that fact that resilience-enabling leadership is not primarily based on social exchange (although certain elements might be), and it does not explicitly measure leader-follower relationship quality.

The results of this phase illustrated some of the fundamental truth assumptions held in this study, informed by pragmatism. That is, understandings can be developed, revised, and reinformed through engagement with diverse forms of knowledge. This approach to research and to different types of research sources (i.e. population vs content experts) helps to provide a robust and well-rounded understanding of a phenomenon. Although truth is never concrete or certain, it is true that we come to know more, and more usefully, through taking multiple, complementary but different, steps through inquiry.

\subsection{Summary}

This phase helped to refine the RELS, particularly regarding its content validity. Population and content experts provided meaningful feedback on the scale. This has led to a revised 28item scale for quantitative testing in the next phase of research. 


\section{PHASE 5 - VALIDATION STUDY}

\subsection{Introduction}

The purpose of Phase 5 was to test and validate the RELS. The process used to develop this scale was largely informed by DeVellis' (2016) recommended steps in scale development, including item generation, expert feedback, and survey validation. These steps are seen as credible in management and public administration scholarship, and have been widely applied (Delmotte, De Winne, \& Sels, 2012; Flatten, Engelen, Zahra, \& Brettel, 2011). This validation phase involved two main data collection processes: a pilot survey $(n=30)$ and a final validation survey ( $n=893)$. Both surveys were anonymous. These surveys helped the researcher understand how individual items performed so that a valid scale can be developed, consisting of relevant, appropriate, and statistically valid items (DeVellis, 2016). These are described below.

\subsection{Pilot survey}

The pilot survey was administered for development purposes (i.e. to improve the scale's content validity). This is consistent with DeVellis' (2016) recommendation to administer newly developed items to a development sample, before evaluation. The pilot survey allowed for any final adjustments to be made before administering the final survey to a larger sample. The focus of the pilot survey was to gain feedback on the design of the survey, and on the RELS specifically. The design of the survey relates to the readability of the survey overall, and the user experience. In terms of the RELS, feedback was sought on the clarity and readability of the specific items. Due to these aims, and the small sample size, the pilot survey statistics were not analysed in-depth.

\subsubsection{Sample and design}

The survey was piloted with two separate participant groups. The first group was a distinctly defined subset of the intended final survey sample (members of a large public sector network), and the second group were past participants of this research (from Phases 2, 3, and 4). These participants were recruited because they were public sector professionals and they fit the profile of potential respondents (DeVellis, 2017). This selection of participants was therefore expected to be able to provide meaningful feedback on the nature, design, and items within the proposed survey. Two different recruitment methods were used. The sample subset was approached by the organisers of the network, via an email with an anonymous 
link (see Appendix G). The researcher also sent emails (see Appendix G) to the past participants, welcoming their feedback and participation in the pilot survey, and included an anonymous link for them to click if they wished to take part.

The survey was designed and administered using the survey programme Qualtrics, also employed in Phase 1 of this research. Thirty responses were received before the survey was closed. This number is recommended for pilot surveys "where the purpose is preliminary survey or scale development” (Johanson \& Brooks, 2010, p. 399). Preliminary descriptive statistics for the RELS are provided in Appendix H. Due to the small sample size, no additional statistical analyses were conducted.

\subsubsection{Pilot revisions}

Each newly developed resilience-enabling leadership dimension was presented on a separate page of the survey. At the bottom of each page was an open comment box where respondents could place any final feedback on the clarity and readability of the items in question.

Fourteen respondents (46.7\%) commented on the survey, on areas ranging from the design and layout to the clarity and readability of the RELS. Most of these comments were about the survey design or the applicability of the question to the respondent, rather than item clarity and/or readability. Nevertheless, some comments informed modifications to the survey for the distribution of the final version. The comments, along with any subsequent revisions, are outlined below.

There were comments revealing the constraint of context on respondents' abilities to answer the survey accurately, which is a measurement issue to be expected. For example, one participant responded with "Depends on the level of workload pressure" to the leadership behaviours and another stated, "My manager is quite self-oriented: he has no clue and no training in the nuances you are referring to here, and the type of approach you are referring to is not fostered in my organisation.” These comments do not challenge the scale's potential validity, but they do highlight the role of other factors in influencing responses. This gives some support to the inclusion of certain additional influencing variables in future studies to assess potential relationships with resilience-enabling leadership (Spector \& Brannick, 2010).

One respondent commented on the dimension of supports personal and career growth in regards to the clarity and readability of two items. The respondent commented on the original items of “. . . makes me feel comfortable talking honestly to them” and “. . . makes me feel comfortable seeking help from them”, stating that "the use of the verb 'makes' implies power no manager has and negates the stem 'support.," 
This person suggested changing the verb of these sentences to "works". These items then became “. . . works to ensure I can feel comfortable talking honestly with them” and “. . . works to ensure I can feel comfortable asking for their help”. This comment was deemed valuable and the items were subsequently amended ahead of the final full survey.

No other comments led to any further amendments of the scale. This piloting process prepared the survey for final distribution (DeVellis, 2017). Aside from these revisions, the pilot survey was identical in design to the final survey presented below.

\subsection{Final survey}

The final validation survey was designed for evaluation purposes (i.e. to assess the scale's reliability and validity) (DeVellis, 2017). After the final survey was administered and responses were collected, the items of the RELS were evaluated. This includes assessing reliability and dimensionality of the RELS. Exploratory and confirmatory factor analyses were a key part of this evaluation, along with assessing the scale's predictive validity (as in Posner \& Kouzes, 1988). These analyses led to the development of a final three-factor, 15item, RELS fit for use in future research. Additional scales were included in the surveys for construct and predictive validity purposes (DeVellis, 2016). The rationale behind the inclusion of additional variables will be discussed below.

\subsubsection{Sample and design}

The final survey was also designed and administered through Qualtrics. The primary sample were members of a large public sector network in New Zealand. Resilience-enabling leadership, leader-member exchange, and employee resilience were the key variables of interest. Controls were included as well. These factors will all be elaborated on in the sections to follow.

\subsubsection{Sample}

The final validation survey was administered to all members of a large public sector network in New Zealand $(n=8,622)$. This survey was part of a larger ongoing study on public sector dynamics in New Zealand. It was administered through the organisation's database. An email was sent to all members on the database by the network administrator. The email included information about the study, ethical considerations, and the anonymous survey link (see Appendix G). The survey link was live for approximately three weeks. After one week, a reminder email was sent to the members from the network administrator. 
Nine hundred and eighty one individuals responded to the survey, reflecting a low response rate of $11.3 \%$ (Baruch, 1999). Reasons for the lower response rate could be due to the lack of multiple follow up reminders (Wensing, Mainz, Kramme, Jung \& Ribacke, 1999), the perceived intrusiveness of the online format (and email reminder) (Manfreda, Bosnjak, Berzelak, Haas \& Vehovar, 2008), members not checking or discarding non-urgent emails, the length of the survey, or not receiving any tangible personal incentives for participating (Singer \& Ye, 2012).

Representativeness is arguably more important than response rate in survey research of this scale (Baruch \& Holtom, 2008; Cook, Health \& Thompson, 2000). Respondents share many similarities with public sector workers. For example, survey respondents were $33.7 \%$ male and $65.4 \%$ female. Despite this clear difference, it fits closely with the gender distribution of the New Zealand public sector workforce, which is 60.9\% female (SSC, 2017b). The majority of respondents held non-managerial positions, and the results show that policy advisors, professionals, and scientists make up the majority of respondents. These are all common public service jobs (SSC, 2017a). The proportion of workers over 55 comprise $27.6 \%$ of respondents, which is slightly higher than, but similar to, the $24.1 \%$ of New Zealand's total public sector (SSC, 2017b). The distribution in ethnicities reflects the ethnically diverse public sector overall, however the survey had lower numbers of Māori, Pasifika and Asian peoples than the public sector averages (16\%, 9.1\% and 10.1\% respectively) (SSC, 2017b). Respondent characteristics are presented in the table below. 
Table 24: Respondent characteristics

\begin{tabular}{|c|c|c|c|}
\hline & & Frequency & Percentage \\
\hline \multirow[t]{3}{*}{ Gender } & Male & 256 & $33.7 \%$ \\
\hline & Female & 497 & $65.4 \%$ \\
\hline & Gender diverse & 7 & $.9 \%$ \\
\hline \multirow[t]{6}{*}{ Age } & $18-24$ & 29 & $4.5 \%$ \\
\hline & $25-34$ & 133 & $20.8 \%$ \\
\hline & $35-44$ & 138 & $21.6 \%$ \\
\hline & $45-54$ & 162 & $25.4 \%$ \\
\hline & $55-64$ & 144 & $22.6 \%$ \\
\hline & 65 or older & 32 & $5.0 \%$ \\
\hline \multirow[t]{9}{*}{ Ethnicity } & NZ European & 582 & $74.0 \%$ \\
\hline & Māori & 49 & $6.2 \%$ \\
\hline & Samoan & 8 & $1.0 \%$ \\
\hline & Cook Islands Māori & 5 & $.6 \%$ \\
\hline & Tongan & 3 & $.3 \%$ \\
\hline & Niuean & 1 & $.12 \%$ \\
\hline & Chinese & 15 & $1.9 \%$ \\
\hline & Indian & 14 & $1.8 \%$ \\
\hline & Other & 109 & $22.5 \%$ \\
\hline \multirow{3}{*}{$\begin{array}{l}\text { Managerial } \\
\text { responsibility }\end{array}$} & No managerial responsibility & 553 & $65.6 \%$ \\
\hline & Team leader or middle manager & 165 & $19.6 \%$ \\
\hline & Senior-level manager & 125 & $14.8 \%$ \\
\hline \multirow{7}{*}{$\begin{array}{l}\text { Occupational } \\
\text { category }\end{array}$} & Clerical or Administrative Worker & 33 & $3.9 \%$ \\
\hline & Policy advisor & 207 & $24.4 \%$ \\
\hline & Inspection or Regulation Worker & 133 & $15.7 \%$ \\
\hline & $\begin{array}{l}\text { Manager (e.g. manager, team } \\
\text { leader) }\end{array}$ & 7 & $.8 \%$ \\
\hline & $\begin{array}{l}\text { Professional (e.g. legal } \\
\text { professional, HR professional) }\end{array}$ & 172 & $20.3 \%$ \\
\hline & Scientist & 284 & $33.5 \%$ \\
\hline & Other & 11 & $1.2 \%$ \\
\hline
\end{tabular}

\subsubsection{Measures}

All measures, except for demographic variables, were measured on Likert scales (7-point) (1 $=$ strongly disagree; $7=$ strongly agree). These measures relate to both the pilot survey and the final validation survey. 


\subsection{Control and demographic variables}

Control variables were important to include for the predictive validity analysis in this phase. These were gender, managerial level, employment status, tenure, and time with manager.

As in Phase 1, gender was included as a control due to its potential to influence social phenomena (Callanan \& Davis, 2012; LaGrange \& Silverman, 1999).

Managerial level (no managerial responsibility vs. managerial responsibility) was chosen as a control variable because resilience-enabling leadership and LMX may differ depending on one’s managerial responsibilities. For example, those with more responsibility and autonomy may require less support for resilience from their own manager. Employee resilience may also differ between these groups. Managers might have more access to resources which support resilience, for instance.

Employment status was another control included in this analysis. It is expected that employment status (fixed term vs. permanent) would influence one's dependency and involvement with a manager, thus impacting their experiences of resilience-enabling leadership. Permanent staff may be more likely to receive ongoing, rather than sporadic, support for their resilience at work.

Tenure and time with manager were also included as controls. The duration of one's experience at their workplace, and with their manager, could potentially influence one's experience of resilience-enabling support, and of other behaviours from their managers, such as LMX.

Other demographic variables, such as age and ethnicity, were also included in the survey to help characterise the sample of respondents.

\subsection{Conceptual variables}

\section{Resilience-enabling leadership}

The revised, four dimensional, 28-item RELS was included in this survey as the main measure for validity testing. Respondents were asked to respond with their degree of agreement with the item statements. For example, “The manager I report to acts calm when I make a mistake”.

\section{Leader-Member Exchange (LMX)}

LMX was chosen because of its potential effectiveness at helping to assess the discriminant validity of the RELS. LMX relates to the effective leadership relationships that "develop between dyadic 'partners' in and between organisations” (Graen \& Uhl-Bien, 1995, p. 225). It is distinct from the resilience-enabling leadership in two key ways: a) it is about the 
perception of the quality of the working relationship between leader and follower, not about follower perceptions of leader behaviour (as in the RELS), and b) LMX is strongly underpinned by followers' obligations to reciprocate with exchange behaviours (Wayne et al., 1997), which is not a key feature in the resilience-enabling leadership measure. However, it is similar enough to be a conceptually comparative measure. It is about positive, adaptive, leader-follower relations which are likely to have social influence and exchange effects. (See Section 4.1 for a discussion of LMX). It was measured using the 7-item LMX-7 scale developed by Graen and Uhl-Bien (1995). An example item is "I have an effective working relationship with my manager”.

\section{Employee resilience}

Employee resilience was measured by the same 10-item Employee Resilience Scale (EmpRes) (Näswall et al., 2015) used in Phase 1 of this research.

\subsubsection{Data screening}

Eight hundred and ninety three (893) of the 981 responses were usable after cleaning the data and performing missing values analysis. As such, 88 empty or nearly empty responses were removed and 893 were retained as complete responses. Like in Phase 1, Little’s MCAR test was used to analyse the nature of the missing values of variables in the original dataset. This was used to determine whether missing data was missing in a random, or non-random way, so that the appropriate replacement technique could be employed (Tabachnick \& Fidell, 2007). The results of Little's MCAR test were: $\chi^{2} / \mathrm{df}=2032.413 / 2135, p=.94$. This nonsignificant value indicated that the data was in fact missing completely at random. Thus, the missing values could be replaced using the Estimation Maximisation (EM) technique (Enders, 2003). This resulted in a more complete dataset where variables could start to be analysed in terms of their reliability, validity, and factor structure.

Subsequent data screening involved computing variables. A key step in determining whether, and how, a set of items can be computed into overarching dimensions or composite measures is through undertaking factor analysis. This is especially important for newly established scales (Worthington \& Whittaker, 2006). Thus, factor analysis (both exploratory and confirmatory) was performed on the RELS to determine its composition. The results of this are explained in detail in the latter sections of this phase.

\subsubsection{Common method bias}

Common method bias (CMB) is a topical phenomenon that needs to be considered when research is undertaken using the same data source to measure independent and dependent 
variables at the same time (George \& Pandey, 2017; Jakobsen \& Jensen, 2015; Spector, 2006). Acknowledging CMB is important for addressing variables within a dataset that may have inflated (or deflated) (Siemsen, Roth, \& Oliveira, 2010) correlations due to shared biases (Spector, 2006). For example, the independent variable of resilience-enabling leadership could have an inflated correlation with the dependent variable, employee resilience.

Perspectives on CMB vary, with some scholars arguing for the importance of preventative measures in the survey administration and design phase (Brannick, Chan, Conway, Lance, \& Spector, 2010), others claiming the need to perform post-hoc statistical procedures to manage for it (Lindell \& Whitney, 2001), and some even arguing that it is 'mythical' (Spector, 1987). Nevertheless, steps were taken to address CMB in both the administration of this survey and in the post-hoc statistical analyses that followed (Podsakoff \& Organ, 1986; Richardson, Simmering, \& Sturman, 2009). This reflects an implementation of both "procedural and statistical methods of control” (Podsakoff, MacKenzie, Lee, \& Podsakoff, 2003, p. 900).

\subsection{Procedural controls}

The fact that this study underwent a series of qualitative validation procedures, including gathering feedback on the clarity, relevance, readability, and construct validity, helps prevent CMB by ensuring respondents have the understanding and the motivation to answer questions with patience and with low-bias (Jakobsen \& Jensen, 2015; MacKenzie \& Podsakoff, 2012). High bias could alternatively occur, for example, if questions do not make sense, or are not relevant, to participants (Hoinville \& Jowell, 1978).

During survey administration, including design and distribution, anonymity of responses was ensured, and this was communicated to respondents via a written consent form at the beginning of the survey (prior to questions). This method has been recommended to reduce CMB by helping individuals feel comfortable to express their opinions honestly without feeling pressured to modify their answers to be more socially desirable or acceptable (Vaccaro, Jansen, Van Den Bosch, \& Volberda, 2012).

\subsection{Statistical controls}

Harman's one-factor test has been a popular procedure for assessing CMB in the past, although is losing its relevance among scholars (Jakobsen \& Jensen, 2015; Podsakoff et al., 2003). This test involves conducting an exploratory factor analysis to load all items suspected of CMB on to one factor and assess whether it explains the majority of variance between items. If the single factor loads below $50 \%$, it is assumed CMB is not an issue in the data 
(Chang, Van Witteloostuijn, \& Eden, 2010). This method is deemed insufficient by a number of scholars because of the low likelihood of a single factor fitting the data in any case, and due to the fact that if it did fit the data, there could be other explanations for this beyond the existence of CMB, such as a lack of discriminant validity (Jakobsen \& Jensen, 2015; Podsakoff et al., 2003). Nevertheless, it is still employed as a tool within the wider repertoire of statistical controls for CMB in management studies (Vaccaro et al., 2012; Y. Wang \& Feng, 2012; Zheng, Yang, \& McLean, 2010), and was therefore used in this study as well. A single factor of above 50\% variance was not obtained (39.39\%), suggesting a low likelihood of CMB according to the test's assumptions.

The common latent factor test was also conducted on the RELS (the revised, 15-item version). This is a test that loads all items onto their theoretical factors, as well as on a common factor to "examine the significance of theoretical constructs with or without the common factor method" (Chang et al., 2010, p. 181). This test was performed on AMOS. The test detected two paths affected by CMB (a moderate effect coefficient change of >.2) (J. Cohen, 1969). That is, these were the only two paths with a significant change between the theoretical model and the model which loaded all items onto the common factor. These were the last two items of the Employee Resilience scale ("I seek assistance and resources when I need them at work" and "I approach managers when I need their support"). The existence of bias could be due to: attempts by respondents to maintain consistency in responses to similar items, scale/item social desirability, or positive affective reactions to these behaviours, positively skewing responses (Podsakoff, MacKenzie, Lee \& Podsakoff, 2003; Waston \& Clark, 1984). However, it is arguably impossible to discern the exact cause or reason for $\mathrm{CMB}$ occurring, particularly after procedural controls have been put in place.

It is also important to note that sometimes the shared variance between confounded variables is legitimate, and adjusting for CMB can remove meaningful variances that are caused by other, more legitimate, factors (Martinko, Harvey \& Mackey, 2014). The primary findings of this phase were not CMB-adjusted. But for illustrative purposes, a CMB-adjusted dataset was created to show that the effect of resilience-enabling leadership on employee resilience is still sustained when $\mathrm{CMB}$ is accounted for $\left(B=.55^{* * *}\right)$. This is presented alongside the regression analysis of the original data.

\subsubsection{Reliability analysis and descriptive statistics}

Before engaging in factor analysis of the RELS, a preliminary analysis of the scale's statistics was undertaken. Its reliability was high for the 28 -item version of the scale $(\alpha=.98)$. As expected, items were well-correlated with each other $($ Mean $=.60$, Min $=.31$, Max $=.92)$, indicating that they are conceptually similar (Gliem \& Gliem, 2003). 
The alpha for LMX was .94, and for employee resilience it was .89. Both of these measures are deemed unidimensional in nature (Joseph, Newman, \& Sin, 2011; Näswall et al., 2019), so they were both analysed at the composite-level. Descriptive statistics for variables of interest are included in the table below.

Table 25: Descriptive statistics for study variables

\begin{tabular}{lllll}
\hline & Minimum & Maximum & Mean & Std. Deviation \\
\hline LMX & 1 & 7 & 5.27 & 1.19 \\
$\begin{array}{l}\text { Resilience-enabling } \\
\text { leadership }\end{array}$ & 1 & 7 & 5.38 & 1.10 \\
Employee resilience & 1 & 7 & 5.82 & .60 \\
\hline
\end{tabular}

\subsection{The resilience-enabling leadership scale}

This section focuses on the RELS specifically. It establishes the scale's validity by presenting results related to factor analysis and predictive validity. These results support a three-factor structure for the RELS, with a revised number of 15 items.

\subsubsection{Factor analysis}

This phase included conducting both Exploratory Factor Analysis (EFA) and Confirmatory Factor Analysis (CFA), as both are deemed important in the process of scale development (Hinkin, 1998; Linderbaum \& Levy, 2010).

The data file was split into two random halves for exploratory and confirmatory factor analyses (Rice, Cole, \& Lapsley, 1990; Siebert \& Siebert, 2005). This allowed the researcher to distinguish between two potential samples- one of 447 cases (Sample 1), and one of 446 cases (Sample 2). The former became the EFA dataset, and the latter became the CFA dataset.

\subsubsection{Exploratory factor analysis}

EFA was performed first. As in Phase 1, Principal Axis Factoring was used for the extraction method and Direct Oblimin was chosen as the rotation method. The KMO and Bartlett's test, showed a high level of sampling adequacy $(.96, p=.00)$ showing that the scale was a good fit for performing factor analysis on. This initial analysis was exploratory in nature, thus no specific number of factors/dimensions were stipulated when performing the analysis. This meant that items were unrestricted in terms of the factors they could load onto. 
The criteria for factor retention decisions included factor loadings $>.40$, no cross loadings above .3 (DeVellis, 2016), communalities >.5, Kaiser's criterion (eigenvalues $>1$ ), and scree plot inspection (Hayton et al., 2004; Kaiser, 1960). Reliability tests were also used during exploration, to determine whether decisions were leading to greater, lesser or equal Cronbach's alpha values for each factor (Santos, 1999).

\subsection{Results}

The first aspects of the factor analysis output that were inspected were the item communalities. All except for one item had strong communality values (>.5). The communality value for “. . . expects me to work with others” was .24. This was noted for subsequent analyses, as a low communality score indicates that an item or variable may struggle to load significantly onto any factor (Stevens, 2012).

The EFA returned a three-factor solution, explaining $72.02 \%$ of the variance. Initial Eigenvalues of the three factors ranged from 17.08 to 1.20 (matching criteria of Eigenvalues $>1$ ). Nine items were removed that did not meet the retention criteria for items (Netemeyer, Bearden, \& Sharma, 2003). These changes are outlined below= and are also reflected in the pattern matrix in Table 26.

\section{Statistical modifications}

Due to high cross loadings on two or more factors (>.4), the following items were removed:

- “. . helps to create an environment where I want to collaborate”

- “. . . assists me in developing broader networks”

- “. . gives guidance that is focused on outcomes"

- “. . . helps me learn from mistakes I make”

- “. . . works to ensure I can feel comfortable talking honestly with them”

- “. . . works to ensure I can feel comfortable asking for their help”.

- “. . . values my differences”

- “... provides recognition that is specific to my real contributions"

The item “. . . cares about me as a person” had factor loadings that were all above .2 and below .4. Because of this statistical ambiguity, it was also discarded from subsequent analyses.

This first iteration of item removal resulted in a 19-item scale, which retained the same 3 factor structure as the initial 28 item EFA. 
Table 26: Pattern matrix for RELS

\begin{tabular}{|c|c|c|c|}
\hline \multirow[b]{2}{*}{ “The manager I report to . ..” } & \multicolumn{3}{|c|}{ Factor } \\
\hline & 1 & 2 & 3 \\
\hline acts calm when I make a mistake & .674 & .046 & .160 \\
\hline helps me to learn from mistakes I make & .417 & 210 & .349 \\
\hline shows a general openness toward learning & .471 & .269 & .270 \\
\hline gives guidance that is focused on outcomes & .408 & 172 & .325 \\
\hline trusts me to achieve outcomes & .864 & .010 & -.004 \\
\hline knows what I am capable of & .591 & .195 & .043 \\
\hline lets me get on with my work & 1.016 & -.107 & -.077 \\
\hline does not micromanage & .829 & .024 & -.096 \\
\hline expects me to work with others & .177 & -.078 & .409 \\
\hline helps to create an environment where I want to collaborate & .372 & .075 & .522 \\
\hline encourages our team to work collectively & .107 & .077 & .748 \\
\hline involves themselves in collaboration with the team & -.073 & -.011 & .966 \\
\hline sets tasks which encourage us to work together & -.136 & .141 & .761 \\
\hline manages conflict within the team & .153 & .147 & .494 \\
\hline assists me in developing broader networks & .015 & .518 & .315 \\
\hline has open conversations with me about my future career plans & -.073 & .921 & -.020 \\
\hline encourages me to seek out opportunities for my development & .009 & .930 & -.082 \\
\hline looks out for new opportunities for me to be exposed to & -.007 & .860 & .039 \\
\hline values my career aspirations & .083 & .913 & -.060 \\
\hline backs the work decisions I make & .787 & .043 & .075 \\
\hline supports my personal needs & .459 & .232 & .166 \\
\hline $\begin{array}{l}\text { works to ensure I can feel comfortable tallking honestly with } \\
\text { them }\end{array}$ & 463 & .212 & 328 \\
\hline works to ensure I can feel comfortable asking for their help & .497 & 146 & 369 \\
\hline Eares about me as a person & .282 & .392 & .240 \\
\hline values my differences & .452 & .317 & .206 \\
\hline provides me with individualised feedback & .071 & .555 & .232 \\
\hline provides recognition that is specific to my real contributions & 338 & 496 & .127 \\
\hline $\begin{array}{l}\text { is good at providing me with meaningful non-monetary } \\
\text { rewards where possible }\end{array}$ & .230 & .486 & .171 \\
\hline
\end{tabular}

Note: Extraction Method: Principal Axis Factoring. Rotation Method: Oblimin with Kaiser Normalization. Removed items are crossed out.

After removing the nine items above and rerunning the analysis (as per Fabrigar \& Wegener, 2011), an additional item was removed due to a newfound low communality of .24. This was the item “... expects me to work with others”. All communalities were then deemed adequate (above .5 (Fabrigar, Wegener, MacCallum \& Strahan, 1999)). This resulted in an 18-item scale for further testing. A new reliability analysis was performed on each factor, as well as overall, as presented in the following table. 
Table 27: Cronbach's alphas after initial EFA

\begin{tabular}{lll}
\hline & Cronbach's alpha & N of Items \\
\hline Overall & .96 & 18 \\
Factor 1 & .94 & 6 \\
Factor 2 & .94 & 8 \\
Factor 3 & .86 & 4 \\
\hline
\end{tabular}

\section{Theoretical modifications}

The revisions made above were in response to the statistical results of the EFA. Another aspect of exploratory factor analysis is making decisions that are theoretically driven. This is because scales need to make sense theoretically as well as empirically (Den Hartog, Van Muijen, \& Koopman, 1997).

Three additional items were subsequently removed after further theoretical consideration. The item “. . . supports my personal needs” was removed due to lacking face validity, particularly in correspondence with the other items that loaded onto its factor, which are more representative of trust. After removing this item, the model was improved overall. The Cronbach's alpha remained the same, but the model's variance explained rose to $76.14 \%$ (from $70.63 \%$ ).

The item ". . . does not micromanage" was also removed. This follows the comment raised in Phase 4 about its redundancy among the other items, but it is also conceptually similar to “. . . lets me get on with my work”. This improved the theoretical clarity of the scale, whilst the alpha remained high at .93 .

The final item that was removed was “. . . provides meaningful non-monetary rewards”. This item loaded on to Factor 1, albeit not very strongly at .40. The other items within this factor were concerned with managers showing consideration of employees' personal growth and development. This particular item appeared at odds with these ideas, as it is more concerned with specific and tangible recognition, and the idea of contingent-reward. After removing this item, Factor 1's 59.47\% variance increased to $60.31 \%$, and its alpha remained high at .94 .

The decisions made throughout EFA resulted with a 15-item scale for resilience-enabling leadership, presented in the table below. Factor 1, named Growth, included five items, Factor 2 (Trust) had six items, and Factor 3 (Collaboration) had four. The item content of Growth consists of are all career- and personal-development oriented. Trust relates to items reflecting a manager's ability to trust employees' capabilities and provide them with respective autonomy. Collaboration very closely matches the develops collaboration dimension 
identified through Phase 4. These items are all about fostering team working and team cohesion.

Table 28: EFA factor structure

\begin{tabular}{lccc}
\hline Factors and items & F1 & F2 & F3 \\
\hline F1: Growth & \multicolumn{3}{l}{} \\
has open conversations with me about my career plans & .92 & \\
encourages me to seek out opportunities for my development & .98 & \\
looks out for new opportunities for me to be exposed to & .81 & \\
values my career aspirations & .89 & \\
provides me with individualised feedback & .49 & \\
\hline F2: Trust & & .67 \\
acts calm when I make a mistake & & .47 \\
shows a general openness toward learning & & .88 \\
trusts me to achieve outcomes & & .58 \\
knows what I am capable of & & .7 .03 & \\
lets me get on with my work & & & \\
backs the work decisions I make & & & .70 \\
\hline F3: Collaboration & & & .99 \\
encourages our team to work collectively & & & .77 \\
involves themselves in collaboration with the team & & .57 \\
sets tasks which encourage us to work together & 9.05 & 1.57 & 1.05 \\
manages conflict within the team & 60.32 & 10.48 & 6.97 \\
\hline Eigenvalues & .94 & .93 & .89 \\
\hline Common variance explained by each factor* (\%) & & & \\
\hline Cronbach's alpha & & & \\
\hline
\end{tabular}

Note: $\mathrm{N}=893$; * The proportion of variance shared among the items for each factor (Preacher \& MacCallum, 2003)

\subsubsection{Confirmatory factor analysis}

The next stage in the development of this scale was performing confirmatory factor analysis (CFA) on the three-factor solution determined through EFA. AMOS for SPSS was used here (Albright \& Park, 2009). The purpose of conducting a CFA is to further the understandings gained from EFA to psychometrically evaluate the measure and ensure its construct validity (Harrington, 2009). CFA requires a strong theoretical and empirical basis from which to start, and thus is "usually supported by prior exploratory analyses” (T. A. Brown \& Moore, 2012). The primary Goodness-of-Fit Indices (GFI) used in the CFA were RMSEA, CFI, and RMR (Beauducel \& Wittmann, 2005).

Three factors were stipulated in the development of the CFA model, and the respective items according to the EFA results were attached to each factor. All items loaded highly (above .7) 
onto each factor. The fit indices were: $\chi^{2} / \mathrm{df}=602.87 / 87, p=.00$; CFI $=.92$; GFI $=.85$; RMSEA $=.12$. Overall, these indices suggest the fit is decent, but not ideal (Sun, 2005).

\subsection{Relative model fit}

As is common practice in scale development, this three-factor model was compared against models with different factor structures (Tims, Bakker \& Derks, 2012; Tucker \& Turner, 2011). The comparative models were: a single-factor model with all items loaded on one factor, a two-factor model with Growth and Trust loaded on to factor one and Collaboration on factor two, a second two-factor model with Growth and Collaboration on factor one and Trust on factor two, and a third two-factor model with Trust and Collaboration on factor one and Growth on factor two. Having three different two-factor models meant that all possible two factor structures could be tested with the three dimensions. These models are presented in Table 29.

This tested for overall discriminability of the model and assessed the comparative differences in GFI (El Akremi, Gond, Swaen, De Roeck, \& Igalens, 2018; Kinicki, Jacobson, Peterson, \& Prussia, 2013). Table 29 shows that the three-factor model has considerably better fit indices than all two-factor, and single-factor, alternatives. This is seen by the three-factor model having the lowest $\chi 2$ value, the highest CFI and GFI, and the lowest RMSEA and RMR. The single-factor model performed the worse out of all the alternative models ( $\chi 2$ /df $=1666.54 / 90, p=.00 ; \mathrm{CFI}=.74 ; \mathrm{GFI}=.58$; RMSEA $=.20$ ). The three two-factor models had similar fit indices, but all performed poorly in relation to the three-factor solution. These comparisons show that the three-factor model is the one which best fits the data. The high reliability estimates from the EFA also suggest this model is an appropriate fit for the data. It was therefore decided that the three-factor, 15-item, model would be the one used in the subsequent predictive validity analysis. 
Table 29: CFA model comparisons

\begin{tabular}{|c|c|c|c|c|c|}
\hline Model & $\chi^{2} / \mathbf{d f}$ & CFI & GFI & RMSEA & RMR \\
\hline $\begin{array}{l}\text { Three-Factor 15-item EFA } \\
\text { Model }\end{array}$ & $602.87 / 87$ & .92 & .85 & .12 & .14 \\
\hline \multicolumn{6}{|l|}{ Comparing to two-factor models } \\
\hline $\begin{array}{l}\text { F1: Growth \& Trust, F2: } \\
\text { Collaboration }\end{array}$ & $1340.07 / 89$ & .80 & .62 & .18 & .16 \\
\hline $\begin{array}{l}\text { F1: Growth \& Collaboration, } \\
\text { F2: Trust }\end{array}$ & $1157.68 / 89$ & .83 & .69 & .16 & .19 \\
\hline $\begin{array}{l}\text { F1: Trust \& Collaboration, F2: } \\
\text { Growth }\end{array}$ & $1006.52 / 89$ & .85 & .72 & .15 & .15 \\
\hline \multicolumn{6}{|l|}{ Comparing to single-factor model } \\
\hline $\begin{array}{l}\text { Single-Factor 15-item CFA } \\
\text { Model }\end{array}$ & $1666.54 / 90$ & .74 & .58 & .20 & .18 \\
\hline
\end{tabular}

Note: F1 = Factor 1; F2 = Factor 2

\subsection{Modification indices}

Some scholars suggest that checking the modification indices of a model, and covarying high error values can improve the overall fit of the model (T. A. Brown \& Moore, 2012; Musil, Jones, \& Warner, 1998). Even though the three-factor 15-item model performed better than the alternatives in the relative fit approach employed above, it still did not meet some of the ideal criteria for model fit (Sun, 2005). The modification indices were checked, but only as a post-hoc, exploratory exercise, as there is a risk of covarying meaningful variances that should remain in the model (Kenny, 2011). Thus, this additional analysis should be interpreted cautiously.

The modification indices give an indication of how the overall $\chi 2$ will improve (decrease) if parameters, such as error covariances, that are fixed to zero are freely estimated (T. A. Brown \& Moore, 2012). It was found that there were a number of high covariances between error values, meaning that the $\chi^{2}$ might decrease meaningfully if freely estimated. These error relationships were all between items of the same factor, signalling conceptual similarity. This meant they were able to be covaried, or "freed up" to improve the fit of a structural model, before re-running the analysis (Musil et al., 1998). After re-running the analysis, the model fit statistics largely improved $(\chi 2 / \mathrm{df}=300.58 / 76, \mathrm{p}=.00$; CFI $=.96$; GFI $=.92$; RMSEA $=$ .08 ), meeting the desired requirements for model fit (Schreiber, Nora, Stage, Barlow, \& King, 2006). Appendix I shows the steps taken throughout this process. 


\subsection{The three-factor model}

A visual representation of the factor structure for the final scale is given in Figure 6. This includes the factor loadings for items within each factor, as well as the covariances between the three factors. 


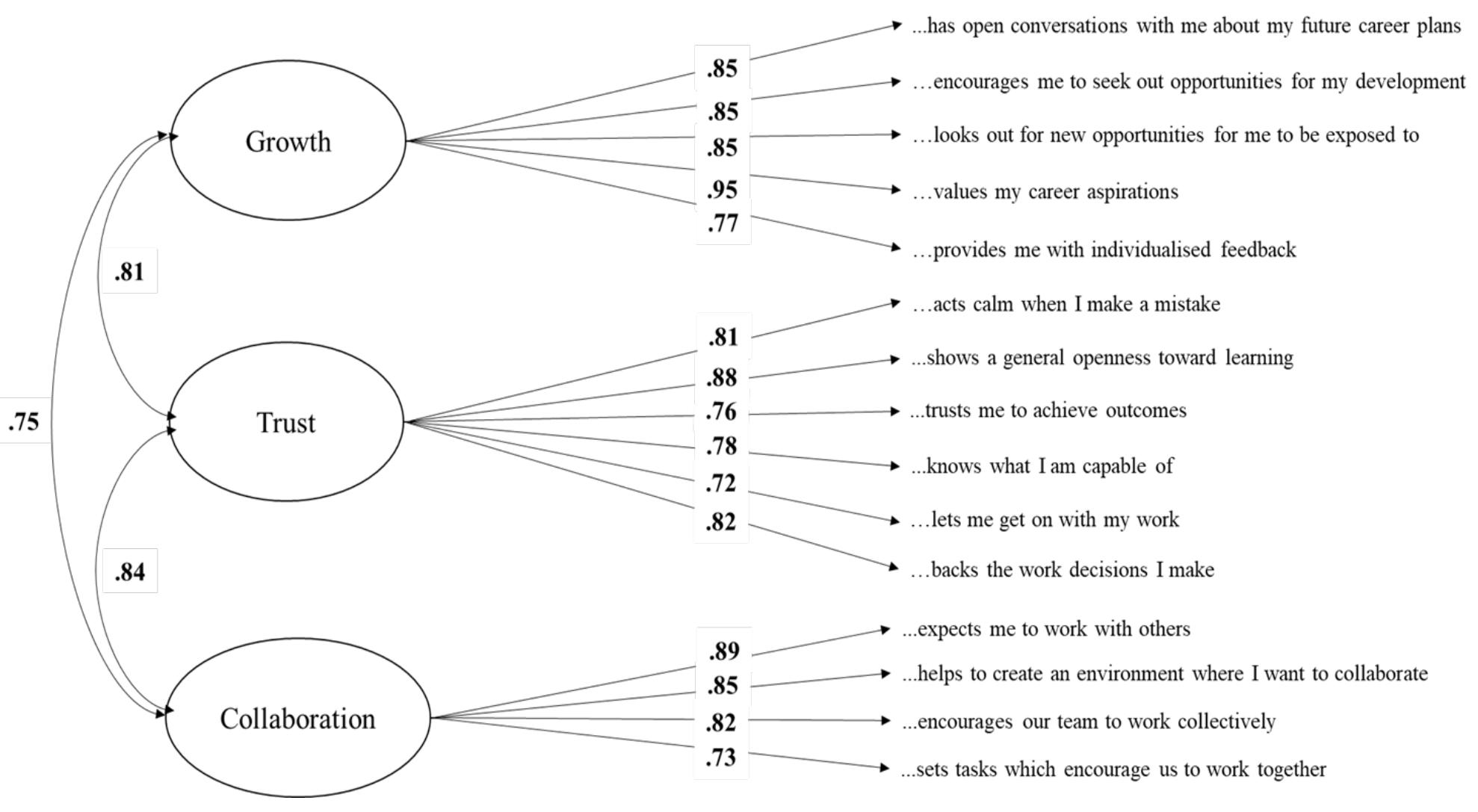

Figure 6: The revised three-factor, 15-item, RELS 


\subsection{Convergent validity, discriminant validity, and multi-collinearity tests}

Tests for convergent and discriminant validity were undertaken on the revised 15-item model. A scale's convergent validity is important to test because it indicates the agreement between the factors and items that represent a measure (Guo, Aveyard, Fielding, \& Sutton, 2008). Discriminant validity, when performed at the factor-level (rather than between scales), tests the distinctness of the factors within a measure to show that "the hypothesised separateness of subscales is real” (Carter, 2016, p. 733). It is expected that variables relate more strongly to their own subscale/factor than they do to any other factor in the model.

Convergent validity was achieved. This is indicated by adequate composite reliability (.97 (calculated according to Raykov, 1997)) and average variance extracted (.70) (Raykov, 1997) scores (as supported by Hair, Black, Babin, \& Anderson, 2010). Discriminant validity of the factor structure was also achieved, with the maximum shared variance (MSV) exceeding (albeit only slightly) the average variance extracted (AVE) score (MSV $=.71>$ AVE .70) (Hair et al., 2010).

Multi-collinearity is another important statistical issue to test for, particularly before engaging in regression analysis (Mansfield \& Helms, 1982). Referred to as "the linear relation between two or more variables" (Alin, 2010, p. 370), multi-collinearity reduces the generalisability of a regression model. LMX and resilience-enabling leadership are two key independent variables used in the regression analysis below. As discussed earlier, these two variables are theoretically distinct, but also share similarities as leadership measures that might influence multi-collinearity. Therefore, a undertaking a test for multi-collinearity was deemed necessary.

The variance-inflation factor (VIF) test was chosen for investigating multi-collinearity. The VIF shows how much the $R^{2}$ (proportion of variance) of a model is degraded by multicollinearity (Schroeder, 1990). All VIF statistics (for the relationship between resilience enabling leadership factors and LMX) were below 2.5, indicating that multi-collinearity is unlikely to be a problem (Schroeder 1990). Tolerances (the variability in an independent variable that is not explained by the other variables in a model (Norusis, 1983)) were above .2, which also suggests a low concern for multi-collinearity (Menard, 2002).

\subsubsection{Predictive validity}

An important step in developing the RELS is addressing its role in predicting employee resilience. The qualitative research undertaken in this study (Phases 2, 3, and 4) suggest that the behaviours measured in this scale are likely predictors of resilient employee behaviours. Testing this quantitatively provides added assurance (Creswell, 2013). 
Predictive validity studies also commonly concern how a scale might compare to similar measures. Thus, LMX, discussed variously throughout this research, was included in the analysis, alongside five additional control variables: gender, employment status, tenure, managerial level, and length of time with current manager.

As in Van Dyne and LePine (1998), hierarchical regression analysis was used to assess the extent to which resilience-enabling leadership is shown to predict employee resilience, beyond the effects of LMX and the control variables. 
Table 30: Regression table for controls, LMX, and resilience-enabling leadership

\begin{tabular}{|c|c|c|c|c|c|c|c|c|c|c|c|}
\hline & & Beta & $S E$ & B & $t$ & $p$ & $R^{2}$ & $\Delta R^{2}$ & $\Delta F$ & $p$ & $\begin{array}{l}\text { CMB } \\
\text { adj. B }\end{array}$ \\
\hline \multirow[t]{7}{*}{1} & (Constant) & 5.17 & .13 & & 38.64 & .00 & & & & & \\
\hline & Employment status & .07 & .04 & .06 & 1.63 & .10 & & & & & \\
\hline & Tenure & -.01 & .02 & -.03 & -.74 & .46 & & & & & \\
\hline & Time with manager & .02 & .03 & .03 & .91 & .36 & & & & & \\
\hline & Managerial level & .20 & .03 & .24 & 6.49 & .00 & & & & & \\
\hline & Gender & .16 & .05 & .13 & 3.45 & .00 & & & & & \\
\hline & & & & & & & .07 & & 10.57 & .00 & \\
\hline \multirow[t]{8}{*}{2} & (Constant) & 4.39 & .15 & & 28.99 & .00 & & & & & \\
\hline & Employment status & .06 & .04 & .05 & 1.52 & .13 & & & & & \\
\hline & Tenure & -.01 & .02 & -.02 & -.43 & .67 & & & & & \\
\hline & Time with manager & .01 & .02 & .02 & .48 & .63 & & & & & \\
\hline & Managerial level & .19 & .03 & .22 & 6.38 & .00 & & & & & \\
\hline & Gender & .15 & .04 & .12 & 3.48 & .00 & & & & & \\
\hline & $\begin{array}{l}\text { Leader-Member } \\
\text { Exchange }\end{array}$ & .16 & .02 & .32 & 9.40 & .00 & & & & & $.32 * * *$ \\
\hline & & & & & & & .17 & .10 & 88.39 & .00 & \\
\hline \multirow[t]{9}{*}{3} & (Constant) & 4.20 & .16 & & 26.56 & .00 & & & & & \\
\hline & Employment status & .08 & .04 & .07 & 2.07 & .04 & & & & & \\
\hline & Tenure & -.01 & .02 & -.02 & -.71 & .48 & & & & & \\
\hline & Time with manager & .02 & .02 & .03 & .71 & .48 & & & & & \\
\hline & Managerial level & .19 & .03 & .23 & 6.79 & .00 & & & & & \\
\hline & Gender & .15 & .04 & .12 & 3.43 & .00 & & & & & \\
\hline & $\begin{array}{l}\text { Leader-Member } \\
\text { Exchange }\end{array}$ & .03 & .04 & .06 & .74 & .46 & & & & & \\
\hline & $\begin{array}{l}\text { Resilience-enabling } \\
\text { Leadership }\end{array}$ & .16 & .04 & .29 & 3.73 & .00 & & & & & $.55^{* * *}$ \\
\hline & & & & & & & .18 & .02 & 13.88 & .00 & \\
\hline
\end{tabular}

The Model 1 control variables explained 7\% of the variance. Model 2 with LMX added explained an additional $10 \%$. The addition of resilience-enabling leadership produced a significant increase in $\mathrm{R}^{2}$ (2\%), with LMX becoming nonsignificant. Further analysis found that when LMX and resilience-enabling leadership were swapped in the regression model, the latter explained an additional $12 \%$ of variance beyond the control variables, whilst LMX failed to produce a significant $\mathrm{R}^{2}(.01 \% ; p=.46)$ when added last in the model. Swapping variables in the regression model allows us determine the relative importance of each predictor, to identify the 'most important' predictor in the model (Budescu, 1993). The unique additional variance explained by resilience-enabling leadership indicates that it significantly predicts employee resilience beyond LMX (Darlington, 1990). The small 
but significant change in $R^{2}$ does suggest, however, that the two independent variables likely share a lot of variance in this model, where employee resilience is the dependent variable.

\subsection{Integration}

This phase validated the RELS, which was developed throughout this thesis. The revised and test scale is presented in questionnaire format in the table below. This process of scale development was inductive in that it was based on data, rather than pre-established theory (Hinkin, 1995). This results in the "capacity to identify the various environmental cues and social dynamics that employees draw from to make sense of [their] . . . environments, which may not be intuitively apparent to researchers” (O'Neill \& Sevastos, 2013, p. 240).

Similar processes for scale development have been used in leadership research. Servant, public, and authentic leadership are three examples (Barbuto Jr \& Wheeler, 2006; Tummers \& Knies, 2016; Walumbwa, Avolio, Gardner, Wernsing, \& Peterson, 2008). These reflect conceptually unique, statistically valid, measurements of leadership types. It is important to test the scale alongside similarly developed leadership scales, in addition to LMX, to further test its discriminant/predictive validity.

This phase signifies the progress made on the RELS since its conception. The concept has undergone many iterations, and has changed from a five dimensional explanatory framework to a three-factor measurable scale. The three factors are Growth $(\alpha=.94)$, Trust ( $\alpha=.93)$ and Collaboration $(\alpha=.89$ ). The RELS scale is measured on a 7-point Likert scale $(1=$ strongly disagree, 7 = strongly agree). All items measure employee perceptions regarding the manager they report to.

This transition, and the three key modifications of the scale are presented in the table below. 
Table 31: Key steps in the development of the RELS

\begin{tabular}{|c|c|c|c|c|}
\hline \multicolumn{5}{|c|}{ Explanatory framework (Phases 2 and 3) } \\
\hline $\begin{array}{l}\text { Managing the whole } \\
\text { team }\end{array}$ & Managing safe failures & $\begin{array}{l}\text { Supporting personal } \\
\text { growth and wellbeing }\end{array}$ & $\begin{array}{l}\text { Enabling self- } \\
\text { management }\end{array}$ & $\begin{array}{c}\text { Recognising } \\
\text { individual needs } \\
\text { and contributions }\end{array}$ \\
\hline $\begin{array}{l}\text { - sets collective tasks } \\
\text { - encourages } \\
\text { employees to work } \\
\text { collectively } \\
\text { - matches skills to a } \\
\text { task } \\
\text { - makes collaboration } \\
\text { a behavioural norm } \\
\text { - involves themselves } \\
\text { in collaboration } \\
\text { with employees }\end{array}$ & $\begin{array}{l}\text { - values employee } \\
\text { knowledge and } \\
\text { expertise } \\
\text { - deals with mistakes } \\
\text { calmly and openly } \\
\text { - does not dwell on } \\
\text { mistakes made by } \\
\text { employees } \\
\text { - has a general openness } \\
\text { to learning } \\
\text { - guides, does not tell }\end{array}$ & $\begin{array}{l}\text { - has open } \\
\text { conversations about } \\
\text { the future } \\
\text { - supports employees } \\
\text { to seek out own } \\
\text { opportunities } \\
\text { - advocates on behalf } \\
\text { of employees for } \\
\text { growth opportunities } \\
\text { - backs the work and } \\
\text { decisions of } \\
\text { employees } \\
\text { - supports the personal } \\
\text { needs of employees }\end{array}$ & $\begin{array}{l}\text { - gives guidance } \\
\text { focused on aims } \\
\text { and outcomes } \\
\text { - shows trust in } \\
\text { employees to } \\
\text { achieve aims and } \\
\text { outcomes } \\
\text { - gives support when } \\
\text { required } \\
\text { - is aware of } \\
\text { individual } \\
\text { capabilities within } \\
\text { the team and } \\
\text { manages for those } \\
\text { capabilities }\end{array}$ & $\begin{array}{l}\text { - provides } \\
\text { feedback and } \\
\text { recognition that } \\
\text { is tailored and } \\
\text { specific to the } \\
\text { individual and } \\
\text { their } \\
\text { contributions } \\
\text { - recognises } \\
\text { individual } \\
\text { contributions } \\
\text { openly across } \\
\text { the workgroup } \\
\text { - trusts } \\
\text { employees to } \\
\text { do their own } \\
\text { work well } \\
\end{array}$ \\
\hline
\end{tabular}

\section{9-item scale (Phase 4)}

\begin{tabular}{|c|c|c|c|c|}
\hline $\begin{array}{l}\text { Develops } \\
\text { collaboration }\end{array}$ & \multicolumn{2}{|c|}{ Enables self-management } & Creates a safe climate for learning & $\begin{array}{c}\text { Supports personal and career } \\
\text { growth }\end{array}$ \\
\hline $\begin{array}{l}\text { - expects me to work } \\
\text { with others } \\
\text { - helps to create an } \\
\text { environment where } \\
\text { I want to } \\
\text { collaborate } \\
\text { - encourages our } \\
\text { team to work } \\
\text { collectively } \\
\text { - involves themselves } \\
\text { in collaboration } \\
\text { with the team } \\
\text { - sets tasks which } \\
\text { encourage us to } \\
\text { work together } \\
\text { - manages conflict } \\
\text { within the team } \\
\text { - assists me in } \\
\text { developing broader } \\
\text { networks }\end{array}$ & \multicolumn{2}{|c|}{$\begin{array}{l}\text { - gives guidance that is } \\
\text { focused on outcomes } \\
\text { - trusts me to achieve } \\
\text { outcomes } \\
\text { - knows what I am } \\
\text { capable of } \\
\text { - lets me get on with my } \\
\text { work } \\
\text { - does not micromanage }\end{array}$} & $\begin{array}{l}\text { - } \text { acts calm when I make a mistake } \\
\text { - helps me to learn from mistakes I } \\
\text { - shows a general openness toward } \\
\text { learning } \\
\text { - backs the work decisions I make } \\
\text { - supports my personal needs } \\
\text { - makes me feel comfortable talking } \\
\text { honestly to them } \\
\text { - makes me feel comfortable } \\
\text { seeking help from them }\end{array}$ & $\begin{array}{l}\text { - has open conversations with } \\
\text { me about my future career } \\
\text { plans } \\
\text { - encourages me to seek out } \\
\text { opportunities for my } \\
\text { development } \\
\text { - looks out for new } \\
\text { opportunities for me to be } \\
\text { exposed to } \\
\text { - values my career aspirations } \\
\text { - cares about me as a person } \\
\text { - values my differences } \\
\text { - provides me with } \\
\text { individualised feedback } \\
\text { - provides recognition that is } \\
\text { specific to my real } \\
\text { contributions } \\
\text { - is good at providing me with } \\
\text { meaningful non-monetary } \\
\text { rewards where possible }\end{array}$ \\
\hline \multicolumn{5}{|c|}{ 15-item scale (Phase 5) } \\
\hline \multicolumn{2}{|l|}{ Growth } & \multicolumn{2}{|r|}{ Trust } & Collaboration \\
\hline \multicolumn{2}{|c|}{$\begin{array}{l}\text { - has open conversations with me } \\
\text { about my career plans } \\
\text { - encourages me to seek out } \\
\text { opportunities for my development } \\
\text { - looks out for new opportunities for } \\
\text { me to be exposed to } \\
\text { - values my career aspirations } \\
\text { - provides me with individualised } \\
\text { feedback }\end{array}$} & \multicolumn{2}{|c|}{$\begin{array}{l}\text { - acts calm when I make a mistake } \\
\text { - shows a general openness toward learning } \\
\text { - trusts me to achieve outcomes } \\
\text { - knows what I am capable of } \\
\text { - lets me get on with my work } \\
\text { - backs the work decisions I make }\end{array}$} & $\begin{array}{l}\text { ourages our team to work } \\
\text { ectively } \\
\text { lves themselves in } \\
\text { aboration with the team } \\
\text { tasks which encourage us to } \\
\text { k together } \\
\text { lages conflict within the team }\end{array}$ \\
\hline
\end{tabular}




\subsection{Summary}

This chapter has presented the findings from the final survey in this research. This final survey aimed to test the scale of resilience-enabling leadership. In this phase, the scales general reliability and validity was tested, largely through factor analyses and predictive validity tests. The scale went from being a 28-item measure prior to testing, to a 15-item, three factor measure post-analyses. The initial tests of predictive validity indicate that resilience-enabling leadership contributes to employee resilience. 


\section{GENERAL DISCUSSION AND CONCLUSIONS}

This final chapter provides an overview of the five phases, and the respective findings of each. It discusses newfound understandings regarding the concept of employee resilience. It also highlights the role of leadership in influencing employee resilience. It reflects on the contextual nature of employee resilience, and its development by leaders. It then outlines the relevance of mixed-method, multi-phase research, in serving the aims of the study. Finally, the implications for scholarship and practice are discussed.

\subsection{Overview}

This research sought to a) identify resilience-enabling leadership behaviours and b) explain how they enable employee resilience. It found that resilience-enabling leadership matters to employees and their resilience, and can be measured quantitatively. Further, it identified mechanisms through which leadership may influence employee resilience. The research also identified behaviours by leaders that can harm resilience in employees.

Five phases of mixed-method research were conducted to address the aims of this study. These aims relate to two key research questions: What leadership behaviours enable resilience in employees? and How do these behaviours enable employee resilience? The research thus sought to first identify resilience-enabling leadership behaviours and then explain how they influenced employee resilience. It found that leadership centred on fostering growth, trust and collaboration can enable employee resilience. These core behaviours also work through various mechanisms, that will be discussed later in this chapter.

Phase 1 consisted of collecting and analysing data from a quantitative survey, Phase 2 and Phase 3 involved two distinct sets of interviews, Phase 4 was a combination of focus groups, interviews, and consultations, and Phase 5 comprised a pilot and final survey. The descriptions of each phase below show, in more detail, how these aims were empirically achieved.

The quantitative survey in Phase 1 aimed to identify variables hypothesised to contribute to employee resilience, and what mechanism(s) might underlie this process. The findings from this phase indicate that resilience capacity in employees can be enhanced through a paradoxical approach to leadership and perceptions of organisational support. Results also indicate that paradoxical leadership works primarily through POS, rather than modelling of resilience-enabling behaviours. The findings thus raised further questions regarding 
whether there might be more to resilience-enabling leadership than just a paradoxical approach and that non-paradoxical behaviours are likely to contribute to employee resilience as well.

Phase 2 and 3 involved two rounds of sequential interviews. Phase 2 consisted of identifying other resilience-enabling leadership behaviours through qualitative inquiry with public sector employees and managers. Phase 3 involved substantiating these behaviours with a different sample of public sector employees, and examining how these behaviours were perceived and experienced by the participants, including the perceived impact, if any, they had on resilient employee behaviours. Using these attributions of leadership as perceived by employees, an explanatory framework of resilience-enabling leadership was developed. As well as having standalone explanatory value, this framework was used as a form of inductive scale development for testing and use in subsequent phases (Hinkin, 1998).

Phase 4 aimed to validate the findings of the explanatory framework that was developed in Phases 2 and 3, for scale development purposes. Focus groups, interviews, and consultations with content experts were conducted to elicit feedback on the validity of the resilience-enabling behaviours identified, and their mechanisms. A wide range of feedback was received and used to prepare the explanatory framework as a set of leadership behaviours for quantitative testing. A 28-item scale for quantitative testing was developed and refined in this phase.

Phase 5 involved the use of a final quantitative survey testing the newly developed RELS for various forms of statistical validity. This included exploratory and confirmatory factor analyses, as well as checking for convergent and discriminant validity and assessing the scale's predictive validity in relation to employee resilience. This final phase revealed that resilience-enabling leadership has a good-fit as a three-factor, 15-item scale, and that it significantly predicts employee resilience.

Ultimately, this research - consisting of interviews, focus groups and surveys - has led to the development of a comprehensive explanatory framework and a valid, measurable scale for resilience-enabling leadership. These outputs have practical and scholarly value.

\subsection{Conceptual and theoretical contributions}

\subsubsection{The construct of employee resilience}

This research shows that managers play a pivotal role in influencing employee wellbeing and behaviour, in ways that both enable and harm resilience. This challenges views that 
resilience is a fixed, trait-based characteristic (Coutu, 2002). This research extends scholarship on employee resilience in other ways too. It has further established the validity of the construct's measurement (Näswall et al., 2019), and shown how it corresponds to the demands of the public sector. As defined in this research, employee resilience is understood as a developable behavioural capacity comprised of networking leveraging, learning and adaptability (Kuntz et al., 2017). This section presents findings that correspond to resilience, including its different understandings and its developable nature. First, this study has enriched our understandings of resilience capacity in employees, both in a tangible, quantifiable, way and in a more nuanced contextual manner through the qualitative phases. The quantitative phases of this research have helped to support the construct's validity as a reliable construct for measurement, using the Employee Resilience Scale (or EmpRes) developed by Näswall et al. (2015; 2019). As a case in point, this study supports that we can reliably measure network leveraging ability by asking employees the degree to which they “. . . effectively collaborate with others to handle unexpected challenges at work” (Näswall et al., 2015, p. 3). Network leveraging was also described from a qualitative perspective. Interview participant Sarah showed that an orientation toward network leveraging is seen when one "thrive[s] off being able to bounce ideas off other people to make sure that what [they're] thinking and doing is the right thing." Similar parallels are seen across other behavioural dimensions too. Learning, for instance, is quantitatively reflected by one's ability to “. . . learn from mistakes at work and improve the way [they] do [their] job” (Näswall et al., 2015, p. 3), and equally, in a qualitative way, by an individual having the belief that "there's always things to learn [and] you can't function effectively within the team without being open to learning on a semi constant basis.”

The above examples reflect specific aspects of resilient employee behaviours. However, several interview participants, all managers, revealed their own, more general understandings regarding resilience. These understandings of resilience were largely underpinned by a trait-based view, like the related concepts of hardiness or grit (Kobasa, 1979; Duckworth et al., 2007) discussed at the beginning of this research. Below is an example quote from interview participant, Patrick:

Some people are . . personally quite resilient. It might be just that they have a degree of maturity, or that they will keep things in perspective or kind of, have their own personal ways of managing stuff. And other people can't, some people are just total stress bunnies and react to everything that happens in a negative way. 
These understandings reflect the idea that people are either resilient, or they are not. This is a convenient view for managers as, under a fixed, trait-based understanding, there is not much one can do to develop an employee who is “unresilient”. Patrick also explained that "unresilient” employees in his team needed to be micromanaged as he lacked confidence in their abilities. For employees, however, their psychological state seemed to be viewed as dependent on the way their managers behaved towards them. In other words, their resilience was both developable and damageable, and managers played a role. A quote about the impact of micromanagement supports this:

It takes away self-esteem because they don't believe in your ability to do a job. Well when you feel like you're constantly being checked up on and you're not allowed to just go up and meet with people or do things without them being there, you know. . . You can't learn in that respect. - Ellen, Employee

Viewing resilience as a fixed trait within an individual is counterproductive as it reduces the responsibility for managers to develop employees, which means that employees lack the means and the resources to develop, maintain, and practice resilience at work (Hobfoll, 2011). To thrive, employees need to have managers who enable their ability to collaborate, learn, and adapt, so they can self-manage and perform in ways that promote individual effectiveness at work and lessen the load for managers and organisations. Resilienceenabling leadership, as a construct that emphasises the development needs of employees, is therefore important to, and beneficial for, employees and organisations.

\subsubsection{Resilience and development}

Managers have a responsibility to focus on employee development. Developing employees helps them to become more conscientious, committed, and competent members of organisations (Kuvaas \& Dysvik, 2010; Pierce \& Maurer, 2009). This means managers' leadership activities should extend beyond influencing and controlling the task-related aspects of employees' work experiences. Many existing leadership constructs that have been studied extensively in management and public administration, such as transformational and transactional models, emphasise the role leaders play in employees' task compliance and job performance (Hater \& Bass, 1988; Paarlberg \& Lavigna, 2010; H. Wang, Law, Hackett, D. Wang \& Chen, 2005). They tend to lack the important dimension of responding to the development needs of employees, which is at the core of resilienceenabling leadership. This research has shown that employees want to grow and develop in their jobs, and become more autonomous. They also want managers to support these needs. This research has developed a scale which is specifically development-oriented. This scale, of resilience-enabling leadership, shows us that support for growth, trust and collaboration 
matters in the development of employees, as gives them the growth opportunities, the trust for autonomy, and the relational resources to develop and flourish in their jobs.

Resilience development in organisations matches calls for more adaptive workforces in environments where there are increasingly more challenges and crises to confront (Nyambe, Breen \& Fincham, 2007). One could argue it is even becoming part of an organisation's social responsibility to focus on resilience development. After all, resilience workforces are ones that "effectively absorb, develop situation-specific responses to, and ultimately engage in transformative activities to capitalise on disruptive surprises that potentially threaten organisation survival” (Lengnick-Hall et al., 2011, p. 244). Organisational scholars, as well as organisations, now have a leadership scale which contributes to this focus on development, responds to the need for adaptability, and helps organisations and employees better address the increasingly complex demands of modern work. Traditional, top-down, command and control models, historically prevalent in government organisations (Denhardt et al., 2012), are no longer sufficient and are unlikely to aid individual and organisational responsiveness to change and challenge.

\subsubsection{Enabling employee resilience}

We now know more about the nature of employee resilience, and how it is distinct from fixed, trait-based constructs like grit, hardiness, and coping. Recognising its developable nature helps to broaden our understandings about the ways in which employee resilience can be developed by leaders in organisations. There is certainly more research to be done on the enablers of employee resilience, particularly in relation to leadership. This research has identified paradoxical leadership and organisational support as key potential enablers. The research also tells us that leadership centred on fostering growth, trust and collaboration (the three-factor RELS) is important for employee resilience too.

Research on other personal and organisational factors to support employee resilience is still under-developed. For example, employees' motivational states, backgrounds, and job roles might indeed play a role in the enactment of resilient behaviours by employees. Factors in the organisational environment, too, are likely to play a role in influencing resilience in good and bad ways. For example, positive climates that contribute to wellbeing, such as those that foster psychosocial safety, learning and innovation, might be positively associated with resilience in employees (Dollard \& Bakker, 2010; Hsu \& Chen, 2017).

This research also illuminates the existence of behaviours that can harm resilience in the workplace. Certain resilience-harming behaviours were identified, including micromanagement, lack of learning oriented leadership, and unsupportive leadership. The 
existence of resilience inhibitors have been previously posited in studies in management (Giustiniano et al., 2018) and psychology (Grotberg, 1995), but empirical research is scant. To better understand the dynamic nature of resilience in organisations, research on resilience-harming or resilience-inhibiting factors and behaviours in organisations needs to be explicitly established and further developed. We know, for example, that 'bad' leadership has been studied for decades (Kets de Vries, 2003; McCall \& Lombardo, 1983), but not in relation to resilience. Resilience-harming behaviours provide as much understanding about resilience as a concept as resilience-enabling behaviours. Understanding the factors that harm a phenomenon are thus equally important in understanding that phenomenon (Higgs, 2009). In practice, it is also true that resilience cannot be built if an organisation and its employees are damaged by a toxic culture and environment. After all, “. . . it is (toxic) behavior that, over the long-term, destroys the ability of people to work together productively in an organization” (Benson \& Hogan, 2008, p. 12), and working productively together is an essential foundation of a resilient workforce.

Although various organisational factors are important to consider when addressing resilience development, this study focused on leadership specifically. The section below summarises the findings of resilience-enabling leadership, including their nature, their relationship to context, and their mechanisms.

\subsubsection{Summarising resilience-enabling leadership}

Resilience-enabling leadership is comprised of growth, trust and collaboration. Reflections on each dimension are provided below.

Growth is the first dimension of resilience-enabling leadership. Generally speaking, leaders contribute to the growth and career outcomes of employees (Neubert, Kacmar, Carlson, Chonko, \& Roberts, 2008; Wakabayashi, Graen, Graen, \& Graen, 1988). This research also indicates that leaders who are growth-oriented support employee resilience too. Leader support for growth may occur partly through a transactional process, whereby leaders emphasise and encourage opportunities and development pathways for employees, perhaps in exchange for long-term commitment and career satisfaction (Graen \& Scandura, 1986; Scandura \& Williams, 2004). The growth dimension of resilience-enabling leadership is also very relational and reflects a willingness to attend to the development needs of employees. Although perhaps partly transactional, this reflects a relationship-based approach, centred on trust, respect, and a high consideration for the individual needs of employees (Graen \& Uhl-Bien, 1995). Encouraging employee growth through resilienceenabling leadership reflects a genuine willingness to invest in employee needs and 
aspirations, and an awareness of how these investments might differ depending on the individual. In sum, this research provides empirical support to the classic argument that leadership centered on employee growth and development needs can bring about positive outcomes for individuals and organisations (Beer, 1964). Employee resilience is one such outcome, and is an extremely relevant one for effective organising in times to come.

The second dimension of resilience-enabling leadership is trust. Trust is defined as "a psychological state comprising the intention to accept vulnerability based upon positive expectations of the intentions or behavior of another” (Rousseau, Sitkin, Burt, \& Camerer, 1998, p. 395). Trust-based leadership can also be seen as transactional or exchange based (Dirks \& Ferrin, 2002). Similar to social exchange, trust between leader and follower reflects a high quality relationship where care and consideration are reciprocated (Whitener, Brodt, Korsgaard, \& Werner, 1998). In this research, it can be seen through allowing autonomy and receiving discretionary efforts. The promotion of trust by leaders is also an important aspect of perceived leader effectiveness (Hogan, Curphy, \& Hogan, 1994; Lombardo, Ruderman, \& McCauley, 1988). Underpinning this dimension is a leader's belief in one's potential ability to do a job well. It is about having a belief in employees' knowledge, skills, and abilities and trusting that they will make good use of these qualities. This ties in clearly with the definition given by Rousseau et al. (1998): Resilience-enabling leaders show trust when they relinquish power and control over employees, showing vulnerability by holding positive expectations of their competence and autonomous behaviours.

Collaboration represents the third dimension of resilience-enabling leadership. It relates to leaders enabling and supporting employees to work effectively within a team. This approach is supported by literature on team-centered leadership, where leaders are proactive in inspiring collective working, establishing methods of mutual support between team members, and providing clear, straight-forward opportunities for teamworking and collaboration (Maddux, 1994). Setting collective tasks and encouraging collective work assumes that employees have useful individual competencies that, when shared, become complementary. Utilising complementary capabilities, sharing knowledge, and engaging in collective problem-solving are all important collaborative activities for employees today, particularly in the public sector environment (J. V. Denhardt \& Denhardt, 2007; Zeier et al., 2018). This leadership dimension also highlights the importance of a more inclusive approach to leadership (Janakiraman, 2011), emphasising that, to be resilient, wicked problems and challenges are best confronted together, leveraging diverse capabilities, rather than alone, using isolated, individual attempts (Getha-Taylor, 2008; Kuntz et al., 2016). 
Resilience-enabling leadership is associated with the provision of resources. An employee with a resilience-enabling leader is provided with clear pathways for personal and professional growth, individualised feedback, trust and autonomy, as well as a functional norm for teamworking. These resources are like to help develop resilient behaviours, maintain resilience capacity in the face of challenges, and grow even more resilient as a result. This mirrors conservation of resources theory (Hobfoll, 1989), suggesting that when individuals gain resources, they protect and invest in them, and then become better placed to gain more resources (Ng \& Feldman, 2012; Demerouti, Bakker \& Bulters, 2004). In contrast, a resilience-harming manager may contribute to a reduction in resources. For example, poor or unclear feedback might mean that employees "are more likely to engage in feedback avoidance in order to avoid further resource losses from interacting with the abusive supervisor” (Halbesleben, Neveu, Paustian-Underdahl \& Westman, 2014, p. 1336). They may also be reluctant to show vulnerability, i.e. through problem solving or experimenting, in attempts to protect any remaining resources (Halbesleben 2010). Resource provision, or loss, is relevant to the resilience development process, and needs to be considered when understanding how resilience can be both enabled and harmed by managers in organisations.

Resilience-enabling leaders are also capability, competence and confidence-enhancing. They use their authority to develop adaptive, independent and autonomous employees, rather than relying on it to perpetuate traditional worker-manager dependencies and maintain command and control power structures (Heifetz, 1994; Wilson, Cummings, Jackson \& Proctor-Thompson, 2017). The latter does not help employee growth and development and is increasingly ill-suited to today's dynamic environments. Resilient employees are likely to have the support, skills and means to engage in meaningful followership behaviours, such as critically reflecting on performance, voicing concerns regarding leadership, and actively participating in decision making (Can \& Aktaş, 2012).

\subsubsection{Resilience-enabling leadership in context}

Public leaders who are equipped to build resilience in employees gives public organisations the ability to address complexity and dynamism, engage effectively with diverse stakeholders, provide high-quality public services, and, ultimately, contribute to public value.

As implied above, the growth dimension of the RELS is largely about fostering the personal development of individual employees (i.e. “. . . looks out for new opportunities to be exposed to”; “. . . values my career aspirations”). Employees subsequently feel valued by 
their manager in regards to their growth and their career prospects. This corresponds to the experience of subjective career successes, defined as the "person's own preferences for development in an occupation, that is his/her individual perception of career experience" (Gattiker \& Larwood, 1986, p. 80). Public employees value career advancement (Frank \& Lewis, 2004). However, objective successes, such as promotion and pay increases are relatively limited in this context (Lyons et al., 2006). Thus, a public manager who enables resilience in employees by valuing their growth and potential is behaving appropriately for the context, and is subsequently developing committed and effective public servants $(\mathrm{Ng}$ et al., 2005).

Positive leader-follower exchanges, underpinned by trust, matter in public contexts, and predict motivation among public sector employees (Gould-Williams \& Davies, 2005). This is especially so when employees lack confidence in public leaders and ministers (Miao, Newman, Schwarz, \& Xu, 2014). Leaders showing trust in employee autonomy and capability (i.e. “. . . knows what I am capable of” and “. . . trusts me to achieve outcomes”) likely gives employees confidence to address, experiment with, and learn from the challenges of government. It gives them trust in the leader-follower dynamic, even if trust is lacking elsewhere. This makes sense since "direct leaders (e.g. supervisors) appear to be a particularly important referent of trust” (Dirks \& Ferrin, 2002, p. 611). Trust-based experiences with a leader may also foster organisational commitment among public servants (Miao et al., 2014).

Collaborative leadership approaches have been discussed earlier in this study, particularly in regards to their relevance to the public sector. Leadership that encourages employees to work “with groups inside and outside of the organisation” (Hsieh \& Liou, 2016, p. 84) suits demands for network-leveraging and resilience but also for the intra- and inter-agency collaboration, and networked governance, required for effective public service operations (J. W. Campbell, 2016; Silvia \& McGuire, 2010; Stoker, 2006). Effective collaboration is not just a product of network leveraging ability. It also relates to increased learning, problem solving, and adaptability in employees, all of which tie in to employee resilience (Getha-Taylor, 2008; Kuntz et al., 2017; Lengnick-Hall et al., 2011).

\subsubsection{Mechanisms}

This research found that resilience-enabling leadership is experienced through a variety of mechanisms. Processes related to existing theory, such as social learning and social exchange, help to explain the influence of paradoxical leadership on employee resilience, particularly through POS as a mediator. However, many other mechanisms arose in the 
qualitative phases of this research, where employees expressed the identified leadership behaviours and explained how they experienced them. These mechanisms are now reflected in the items of the RELS. Some mechanisms reflect elements of social learning and/or exchange, but others also stand uniquely as emergent mechanisms.

Social learning, as discussed earlier in this research, is when leaders influence followers via a modelling process (M. E. Brown et al., 2005). This can be seen in elements of the framework and scale for resilience-enabling leadership. For example, “. . . acts calm when I make a mistake" is a behaviour that models a calm response to errors and challenges. This type of approach gives individuals more capacity for relevant learning and problem solving, compared to a sudden and intense reaction exacerbating unnecessary cognitive overload (Jaeggi et al., 2007; Rosaen \& Benn, 2006). “. . . shows a general openness to learning” is another learning-oriented modelling behaviour, which promotes an open orientation towards learning. The collaboration item of “... involves themselves in collaboration with the team" is also reflective of social learning in that individuals may learn norms of collaboration through their managers' taking part in the manifestation of these norms.

Social exchange is a more indirect, dyadic trust-based process that is built on the obligations that arise out of person-to-person interaction (Cropanzano \& Mitchell, 2005). This process has been alluded to in the summaries of the behaviours above, and theorised throughout this research. Two key exchange based items are “. . . trusts me to achieve outcomes” and “. . . backs the work decisions I make.” Two examples from the interviews illustrate how these self-managing and trusting behaviours by managers can be reciprocated by employees. The first is by Sarah and reflects a sense of responsibility gained from interaction "[when] they've given me that respect. . . it's my responsibility to make sure that I get my work done.” Thomas, on the other hand, experiences a sense of motivation to work and freedom when he feels trusted “. . . I actually enjoy coming to work because you have the freedom to do stuff."

Social exchange can also work in a negative and harmful way, whereby "employees will respond negatively to unfair treatment” (Boddy, 2014, p. 116). In this research, some employees who experienced micromanagement, for instance, would reciprocate with more counterproductive behaviours. Thomas spoke on behalf of his team when he said "We really didn't want to do anything else, we didn't want to do any more than our job.” In regards to a lack of learning-oriented leadership, Greer noted that it "can allow people to get a bit complacent. Because you think if no one is going to talk to me about this or if everything I'm doing is just going to be acceptable ... you sort of get a bit complacent and 
think I'll just keep doing it the way I'm doing it because no one's telling me otherwise and you don’t learn to evolve or change.”

Another way some of the mechanisms for resilience-enabling leadership can work is through enabling the conditions for certain behaviour to occur. Explicitly encouraging employees, for instance, to “. . . seek out opportunities . . .” and “. . . work collectively” are some ways that leaders can license and attempt to elicit particular behaviour in employees. Setting tasks which are collective in nature is also a potential way to enable the conditions for collaboration as a behavioural norm. There are some items which are more simply about respectful treatment, "i.e. “. . . values my career aspirations” and “. . . lets me get on with my work”, allowing individuals to feel valued and empowered in their work.

\subsubsection{Further insights on leadership}

The value of seeking followers' attributions of leadership has been demonstrated in this study. Doing so extends understanding further than solely identifying antecedents and enablers of a phenomenon and recognises that the mechanisms underlying enablers matter as well. Understanding mechanisms is most effectively achieved by combining methods of inquiry. Quantitative studies might give an indication of the mechanisms which might help explain relationships between antecedents and outcomes. For example, POS, LMX, trust, and other organisational/group processes, are all popular mediating variables for leadership influence (Bai, Li, \& Xi, 2012; Casimir, Ngee Keith Ng, Yuan Wang, \& Ooi, 2014; Jung \& Avolio, 2000; Yukl, 2002). This was employed in Phase 1 of this research, through POS mediating the relationship between PL and employee resilience. Qualitative inquiry, on the other hand, can help identify mechanisms of influence in more nuanced and contextual ways. This might be through documenting individuals' causal attributions surrounding a particular behaviour. This was examined in Phases 2 and 3 of this research - by first identifying enabling leadership behaviours and then exploring the perceptions followers had regarding these behaviours. Understanding causal inferences in regards to leadership was largely established through enquiry on leader's causal attributions of follower behaviour (Green \& Mitchell, 1979; Kelley, 1973). But this idea needs to be developed further in future studies regarding followers' perception of leader behaviour (Martinko \& Gardner, 1987), as this research only briefly addressed attributional processes in the context of leadership. There remains room for extensive development of understanding the causal attributions surrounding resilience-enabling and resilience-harming leadership. 


\subsubsection{Resilience and context}

Resilience has been described throughout this thesis as a contextual phenomenon. In the workplace context, employee resilience is contextual because it is enacted through behaviours. Behaviours interact with, and are shaped by, the context (Johns, 2006). Behaviour is something that develops internally within an individual, but becomes external to the individual when enacted. Context is comprised of both constraints and opportunities for behaviour (Mowday \& Sutton, 1993). This understanding brings with it the consideration that resilient behaviours might differ depending on the context. Network leveraging, learning and adaptability might all take unique forms in particular contexts, for example when dealing with particular tasks, engaging with certain groups or stakeholders of a particular organisation, and when confronted by organisational or industry-specific demands and challenges.

The public sector context demands resilient employees, workforces, and institutions. This is exemplified by the collaboration and learning required for addressing 'wicked problems' (Stoker, 2006), and the adaptiveness demanded by uncertain environments (Karp \& Helg, 2008). This research has supported this argument, and shown more specifically how factors in the public sector context can influence resilience. For example, an excerpt from the qualitative data illustrates the impact of government changes on adaptability:

You can't become so involved in your work that a change of minister [comes] who ... wants to scrap it . . you have to be adaptive all the time because . . . the government changes a lot. - Ellen, Employee

Another quote emphasises the importance of working with others to make progress in the public environment:

It's more about how you deal with people and how you make things happen in this environment. - Diane, Employee

Resilient behaviours - network-leveraging, learning and adaptability - help employees deal with complex public sector realities. Such behaviours are pertinent at the individual and team level, but they also model effective behaviours at higher levels in the public system. Governments, for example, need to engage in collaboration, be adaptive, and problemsolve if they are to satisfy complex stakeholder demands and create public value (Bovaird, 2005). The ideas of this research have the potential to aggregate and inform norms and behaviours at multiple levels, contributing to the resilience of the wider public sector system. 


\subsubsection{Resilience, leadership and context}

As well as helping us understand resilience as contextual, this research has emphasised the contextual nature of leadership in relation to resilience as well. The identification of resilience-enabling leadership throughout the multiple phases of this research has been influenced by the public sector context.

First, this study theorised that paradoxical leadership would correspond strongly to employee resilience in the public sector context because it adequately matches the paradoxical realities of public servants' jobs. While public work is indeed paradoxical at times, it is not always so, and there are many other complex realities in such work that help to inform appropriate leadership behaviours. Paradoxical leadership was also initially developed in the Chinese context, so differences in applicability were expected. It is also helpful to note that, in their respective models, resilience-enabling leadership, in the final survey, predicted employee resilience more strongly than paradoxical leadership did in the first survey ( $\beta=.35^{* * *}$ vs. $\beta=.26^{* * *}$ ). The fact that paradoxical leadership only partially reflected the realities and challenges in public sector work meant more exploration was necessary to identify leadership behaviours that adequately recognised and addressed public servants' needs and experiences.

Subsequent qualitative phases, with public servants and managers, identified and explained (Phases 2 and 3) a set of leadership behaviours that more adequately fit the nature of the public sector context, which demands collaborative, thoughtful, and adaptive responses to public sector challenges (Getha-Taylor, 2008; Hendrikx \& van Gestel, 2016), including both daily experiences and larger, more adverse incidents that form public servants' work experiences. The identified leadership dimensions were fostering collaboration, managing safe failures, supporting personal growth and wellbeing, enabling self-management, and recognising individual needs and contributions. These behaviours formed an explanatory framework for resilience-enabling leadership in the public sector.

The explanatory framework was then developed into a scale for measuring resilienceenabling leadership and tested in a survey of public sector workers. Results showed that the scale of resilience-enabling leadership had a good fit with this particular sample, and that it predicted employee resilience. This suggests that the construct of resilience-enabling leadership could more accurately reflect the context than that of paradoxical leadership.

It is important to consider individuals' perceptions regarding the degree to which they actually experience resilience-enabling leadership in the New Zealand public sector context. Figure 7 presents the distribution for the RELS overall. Respondents rated their manager very positively overall $($ Mean $=5.38, \mathrm{SD}=1.10$, Min $=1$, Max $=7$ ), indicating 
that this kind of leadership exists in the public sector. However, results also show that, on average, $13.30 \%$ (119) of respondents were neither positive or negative in their responses regarding their immediate manager. $11.50 \%$ of respondents rated their manager poorly on the RELS, suggesting they may instead be experiencing poor leadership, that does not foster employee growth, trust, or collaboration. Such leadership may reflect top-down, bureaucratic, and directive forms of leadership that seem to persist in government (Plimmer et al., 2017).

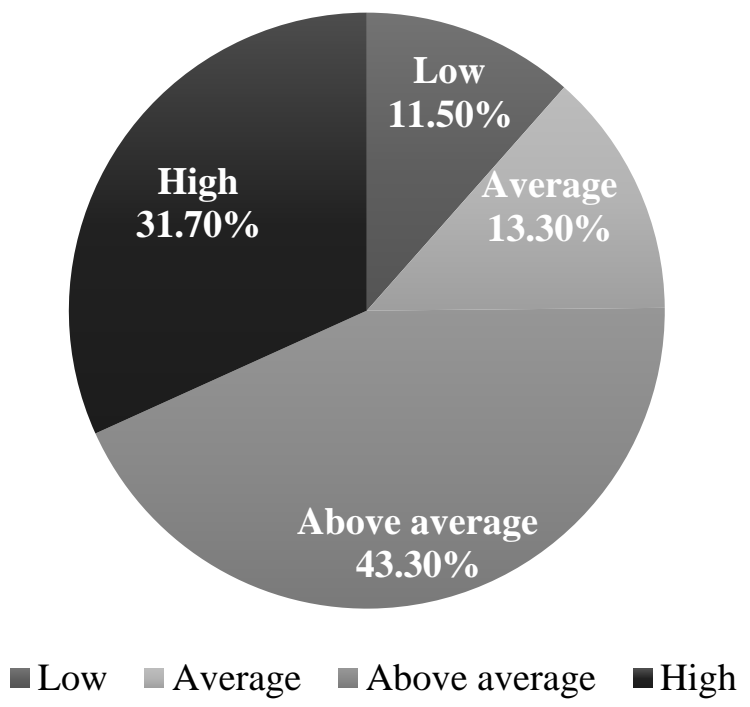

Note: Responses are categorised as: Low = Strongly disagree to Disagree; Average = Neither agree nor disagree; Above average $=$ Somewhat agree to Agree; High = Strongly agree .

\section{Figure 7: Respondent experiences of resilience-enabling leadership}

Although resilience-enabling leadership was borne out of research in the public sector context, it should be tested in other organisational settings as well. Leadership that enables employees to learn, grow, and work well with each other has been associated with positive work outcomes in studies across different organisational types (Brower, Schoorman, \& Tan, 2000; Döös, Johansson, \& Wilhelmson, 2015; D. Vera \& Crossan, 2004). Applying resilience-enabling leadership across contexts, industries, and locations, is a necessary endeavour, as every organisation demands resilience and has for a long time (Horne \& Orr, 1997; Kantur \& İşeri-Say, 2012). Organisations therefore have a responsibility to understand how to build it, and one way is through leadership. 


\subsection{The relevance of mixed-method, multi-phase research}

Developing such rich and detailed insights was made possible by employing an integrated mixed-method research design. This research design was used because it matched the goals of this research, which related to identifying phenomena and then explaining them. It relates strongly to Bazeley's (2018) claim that both quantities and qualities are important to consider when developing and expanding understandings about the world. Quantitative inquiry was beneficial in order to initiate the identification of the potential enablers of employee resilience, and then to test the inductively-developed scale of resilience-enabling leadership. This scale was developed by engaging with qualitative understandings of the nature of resilience and the subsequent role of leadership in both enabling and harming this capacity. Thus, the RELS, although now quantitative in nature, consisted primarily of qualitative inquiry for its development.

The integrated nature of this research design allowed the researcher to integrate findings after each empirical phase. These integrations allowed the researcher to reflect on the findings of each phase, combine insights from multiple phases, and propose the courses of action for subsequent phases. This kind of approach emphasises the unique value that both quantitative and qualitative methods bring to research inquiry, and illustrates how they can be meaningfully combined (Creswell \& Clark, 2017). Reflecting on findings throughout the research process, rather than only at the end, means that well-considered and informed conclusions can be made about the meaning of a research project. For example, reflections on Phases 2 and 3 before engaging in Phase 4 meant that findings could be compared to existing theory and research. It also meant that the framework could be further developed and prepared for the feedback and validation in Phases 4 and 5 .

\subsection{Implications for the future of work}

Workplaces need to ensure they are future-ready. Much discussion in this area has covered the need for investment in human capabilities, labour institutions, technological advancement and decent and sustainable work (ILO, 2019). The future of work requires individuals to have the ability to engage in continuous learning, develop new skills, and be adaptive in the face of change (OECD, 2019). The ILO (2019) calls for a human-centered agenda when it comes to the future of work, whereby people are organisations' highest priority. It is clear that employee resilience is a central part of this, since, as stressed throughout this research, network leveraging, learning, and adaptability all work to confront the dynamic challenges and promote future thriving. 
What this human-centered agenda does not emphasise enough, is that future-ready, resilient employees, need to be supported and developed. Leaders and managers are key agents of influence here (Nguyen et al., 2016; Zhang, Wang, \& Pearce, 2014). Despite emphasis on future demands for employee skills and capabilities, attention on leaders, and what type of leadership is needed going forward, is relatively scant. As we know, leaders can effectively enable resilience in employees. Resilience-enabling leadership also responds to the development needs of employees, and promotes their ability to grow in their roles and throughout their careers. This form of leadership also accounts for the collaborative demands present in new ways of working, within and between organisations and agencies (Getha-Taylor, Blackmar, \& Borry, 2016). The trust-based nature of resilience-enabling leadership also reflects an implicit belief in an employee's ability to do a job well, and even self-lead or self-manage.

A number of scholars discuss the importance of shifting towards self- or shared- leadership, particularly in high-complexity knowledge work contexts (Bligh et al., 2006; Zeier et al., 2018). Some even argue that a paradoxical combination of both is what is needed to deal effectively with the increasing tensions between long and short-term goals (Pearce, Wassenaar, Berson, \& Tuval-Mashiach, 2019). Resilience-enabling leaders help employees develop the competence, and experience the trust required, to engage in the selfleadership activities (such as self-evaluation, self-goal setting and autonomous learning (Kuntz et al., 2016; G. L. Stewart, Courtright, \& Manz, 2010)) that are so needed in the future of work (ILO, 2019; Pearce et al., 2019). They also provide the motivation and the conditions for employees to build collaborative and effective teams, sharing leadership amongst each other, and leveraging members' key knowledge, skills and abilities (Pearce, 2004). Whether leadership is shared or confined to individual selves, vertical leadership is very often needed to “actively legitimise” such behaviours (G. L. Stewart et al., 2010; Zeier et al., 2018, p. 15). Formal leadership is also required for empowering employees to lead individually, but provide control and support when the situation calls for it (Heifetz, 1994; Pearce et al., 2019; Redman, Plimmer \& Blumenfeld, 2012; Zhang et al., 2015).

When addressing the potential solutions for coping with the future of work, leaders matter. Resilient employees are well equipped to confront the increasingly uncertain and dynamic nature of workplaces, but they need to be supported and developed. Resilience-enabling leadership is an approach that is well suited to cope with the demands of the future. It is also a key way in which organisations can build and sustain resilient workforces going forward. 


\subsection{Further implications, and limitations}

This study has important implications for public leadership scholarship and subsequent further research. First, it highlights the relevance and importance of a paradoxical approach to leadership, how it might suit the complex and sometimes contradictory nature of much public sector work, and how it might build employee resilience. It identifies other dimensions of interpersonal leadership behaviours that are relevant to the public sector environment and employee resilience. Many existing studies of public sector leadership are concerned with functional and structural aspects, or with governance and managing relationship with multiple stakeholders (Van Wart, 2014). Few are concerned with the more prosaic task of managing staff. This research addresses that void. Resilience-enabling leadership represents an extension of research on person-oriented, relational forms of leadership, as opposed to more common instrumental and functional approaches (Brower et al., 2000).

The leadership behaviours explored in this research reflect calls for more complex, adaptive and inevitably contradictory, forms of leadership to address contemporary public sector dynamics (Dunoon, 2002; J. Murphy et al., 2017; Van Wart, 2014). Adapting our leadership models to cope with the future is important. Traditional models are no longer sufficient.

This study's cross-sectional nature means that inferences about causation should be interpreted cautiously. Further research, perhaps longitudinal, would be beneficial in further validating and establishing the scale. However, cross-sectional studies are still helpful in exploring new relationships and constructs (Spector, 2019).

The RELS has conceptual similarities with other leadership variables, like LMX as studied in this research. Other constructs, such as servant leadership and perceived supervisory support are also likely to share conceptual and statistical similarities with resilienceenabling leadership. Therefore, further research should specifically target the assessment of resilience-enabling leadership’s nomological network and discriminant validity (Byrne, 1984).

In addition, due to the small sample of earlier phases, and the limited settings the study was conducted in, the findings should be replicated in other samples to allow for greater generalisability. The public sector context in which the research was situated limits the generalisability of these findings to that particular context. Within this context too, only line manager behaviours were investigated, so such conclusions cannot be drawn regarding senior or political leaders of public administration at this stage of inquiry. 
It should be noted, however, that participants worked in a broad range of jobs and levels within the public sector, so conclusions are not limited to one particular job or occupation within the public service. In addition, the final survey yielded a very meaningful sample size, and respondent characteristics were representative of the wider public sector.

In sum, this study contributes to research on both resilience in organisations and public management by proposing a model that enhances resilience for public, and other, organisations. It does this by illustrating the types of leader behaviours that are beneficial for employee resilience, and revealing the mechanisms by which this process may be experienced by employees, reinforcing the importance of leadership in resilience development (Kuntz et al. 2016).

\subsection{Practical implications}

As emphasised throughout this research, important outcomes of the study were an explanatory framework, and a scale, for resilience-enabling leadership. The explanatory framework contributes to organisations' understandings of employee resilience and the processes by which leaders can enable it. This study has shown not only what resilienceenabling leadership looks like, but also how, and through what kind of mechanisms it is experienced by employees. This helps organisations understand the empirical and conceptual foundations of the RELS. The RELS is a useful tool in assessing and measuring leadership capacity in the public sector. The factors of this scale - growth, trust, and collaboration - also send a key message to organisation that leaders who enable these qualities are very important, and are likely to positively contribute to employee growth, learning, and adaptability.

The prosaic nature of the RELS, as a set of daily behaviours performed by managers, is a welcome contribution to the area of leadership development (Ready \& Conger, 2003). This is particularly true for the public sector, where much attention is given to the development of senior managers and executives (Fitzpatrick, 2011; SSC, 2018), but not to the majority: line managers and their front-line teams. More attention and resources need to be given the development of line managers and employees; focusing primarily on the development of senior potential is not a sufficient way to build capabilities across the wider public service. This research provides agencies with an evidence-based tool to understand, explain, and measure resilience-enabling leadership behaviours by line managers (through the RELS), as well as an illustration of the importance of employee resilience, and its development, in public organisations. 
To actualise resilience-enabling leadership in organisations and subsequently develop employees, it needs to be legitimised by supportive third parties (Bronfenbrenner, 2005). This means that in organisations, other managers and employees, need to also, in their own ways, support and legitimise leaders as agents capable of developing resilience in employees. Without a supportive, resilience-enabling system, leaders will lack the resources, incentives and motivations to engage in resilience-enabling leadership behaviours.

These findings point to tractable competencies that can hopefully be developed in managers. Developing capabilities in leaders so that they can develop resilience in their employees will help build resilient organisations for resilient societies and systems.

\subsection{Final conclusions}

The uncertain and dynamic nature of today's organisational environments requires resilience from employees. This research highlights how public organisations, working in complex and dynamic contexts, can foster resilience in their workplaces. How managers behave and enact leadership can influence whether employee resilience is enabled or harmed. This research specifically shows the key role of public sector managers, and how their actions can affect resilience capacity in employees.

Specifically, this study contributes to research on both resilience in organisations and public leadership by proposing a model and measure that enhances resilience for public, and potentially other, organisations. It does this by illustrating the types of leader behaviours that are beneficial for employee resilience, and revealing the mechanisms by which this process may be experienced by employees, reinforcing the importance of leadership in resilience development (Kuntz et al. 2016).

Important leadership behaviours can now be measured with the RELS. This is a significant tangible outcome of this research and warrants a specific reiteration of its importance in this conclusion. Scholars are likely to find this scale meaningful for three key reasons. First, the development of the RELS, through a series of query-driven qualitative and quantitative studies, represents a pragmatic, innovative and robust approach to scale development. It extends beyond the use of literature reviews and theoretical deduction which drive much scale development research (Hinkin, 1995). The study indicates the added value of incorporating inductive approaches in scale development pursuits and involving the opinions of not only content experts, but also members of the target population, in the process (Morgado et al., 2018). 
Second, the prosaic nature of these behaviours, and their applicability to line managers, should be particularly refreshing to scholars confronted with a new leadership scale. The RELS responds to leadership models which, commonly, have focused on the styles, traits, or values of senior leaders and executives (Agho, 2009; Beddoes-Jones \& Swailes, 2015; Eid et al., 2006). Senior and executive leaders are clearly important, and even essential (Zaccaro, 2001), but the daily interactions between employees and their line managers are often discounted, despite the fact that they also matter for individuals and organisations both in private and public sectors (Audenaert et al., 2019; Purcell \& Hutchison, 2007; Van der Weide \& Wilderom, 2004).

Third, although this is a scale about leadership, not followership, it works to support good followership in employees. The RELS is not a task- or performance-focused leadership scale; it is developmental. Resilient employees have agency. They seek support, voice concerns, and have the confidence and ability to critically reflect on performance - not just their own, but their managers' (Carsten, 2017). The RELS reflects managers who use their formal authority adaptively, empowering employees to be better leaders and followers - of themselves, of those formally 'leading' them, and of their organisations.

The items of the RELS are presented in Table 32 below.

Table 32: Final scale for measuring resilience-enabling leadership

\begin{tabular}{|c|c|c|c|c|c|c|c|}
\hline \multirow[t]{2}{*}{ The manager I report to ... } & \multicolumn{4}{|c|}{ Strongly disagree } & \multicolumn{3}{|c|}{ Strongly agree } \\
\hline & 1 & 2 & 3 & 4 & 5 & 6 & 7 \\
\hline $\begin{array}{l}\text { 1. has open conversations with me about my } \\
\text { career plans }\end{array}$ & & & & & & & \\
\hline $\begin{array}{l}\text { 2. encourages me to seek out opportunities for } \\
\text { my development }\end{array}$ & & & & & & & \\
\hline $\begin{array}{l}\text { 3. looks out for new opportunities for me to be } \\
\text { exposed to }\end{array}$ & & & & & & & \\
\hline 4. values my career aspirations & & & & & & & \\
\hline 5. provides me with individualised feedback & & & & & & & \\
\hline 6. acts calm when I make a mistake & & & & & & & \\
\hline 7. shows a general openness toward learning & & & & & & & \\
\hline 8. trusts me to achieve outcomes & & & & & & & \\
\hline 9. knows what I am capable of & & & & & & & \\
\hline 10. lets me get on with my work & & & & & & & \\
\hline 11. backs the work decisions I make & & & & & & & \\
\hline 12. encourages our team to work collectively & & & & & & & \\
\hline $\begin{array}{l}\text { 13. involves themselves in collaboration with } \\
\text { the team }\end{array}$ & & & & & & & \\
\hline $\begin{array}{l}\text { 14. sets tasks which encourage us to work } \\
\text { together }\end{array}$ & & & & & & & \\
\hline 15. manages conflict within the team & & & & & & & \\
\hline
\end{tabular}


This research also prompts further scholarly consideration of how resilience-enabling leadership can be practically developed and further tested in organisations. The findings also point to the importance of developing resilient capacities at all levels so that employees, organisations, and societies can be adaptive to effectively confront the demands of the future. 


\section{REFERENCES}

Adger, W. N. (2000). Social and ecological resilience: Are they related? Progress in Human Geography, 24(3), 347-364. doi:10.1191/030913200701540465

Ager, A. K., Lembani, M., Mohammed, A., Ashir, G. M., Abdulwahab, A., Pinho, H., . . . Zarowsky, C. (2015). Health service resilience in Yobe state, Nigeria in the context of the Boko Haram insurgency: A systems dynamics analysis using group model building. Conflict and Health, 9(30), 1-14. doi:10.1186/s13031-015-0056-3

Agho, A. O., Price, J. L. and Mueller, C. W. (1992), Discriminant validity of measures of job satisfaction, positive affectivity and negative affectivity. Journal of Occupational and Organizational Psychology, 65(3), 185-195. doi:10.1111/j.2044-8325.1992.tb00496.x

Agho, A. O. (2009). Perspectives of senior-level executives on effective followership and leadership. Journal of Leadership \& Organizational Studies, 16(2), 159166. https://doi.org/10.1177/1548051809335360

Albright, J. J., \& Park, H. M. (2009). Confirmatory factor analysis using amos, LISREL, Mplus, SAS/STAT CALIS. Retrieved from http://hdl.handle.net/2022/19736

Alford, J., \& O'Flynn, J. (2009). Making sense of public value: Concepts, critiques and emergent meanings. International Journal of Public Administration, 32(3-4), 171191. doi:10.1080/01900690902732731

Alin, A. (2010). Multicollinearity. Wiley Interdisciplinary Reviews: Computational Statistics, 2(3), 370-374.

Allen, D. G., Shore, L. M., \& Griffeth, R. W. (2003). The role of perceived organizational support and supportive human resource practices in the turnover process. Journal of Management, 29(1), 99-118.

Allison, S. D., \& Martiny, J. B. H. (2008). Resistance, resilience, and redundancy in microbial communities. In Proceedings of the National Academy of Sciences of the United States of America, 105(Supplement 1), 11512-11519. doi: $\underline{10.1073 / \text { pnas.0801925105 }}$

Alvesson, M., \& Sveningsson, S. (2003). The great disappearing act: Difficulties in doing "leadership". The Leadership Quarterly, 14(3), 359-381.

Andersen, J. A. (2014). Ladies and gentlemen: Leadership has left the building. Leadership and the Humanities, 2(2), 94-107.

Andrew, S., Arlikatti, S., Siebeneck, L., Pongponrat, K., \& Jaikampan, K. (2016). Sources of organisational resiliency during the Thailand floods of 2011: A test of the bonding and bridging hypotheses. Disasters, 40(1), 65-84.

Andrews, R., Boyne, G. A., \& Enticott, G. (2006). Performance failure in the public sector. Public Management Review, 8(2), 273-296. doi:10.1080/14719030600587612

Armstrong, M. I., Birnie-Lefcovitch, S., \& Ungar, M. T. (2005). Pathways between social support, family well being, quality of parenting, and child resilience: What we know. Journal of Child and Family Studies, 14(2), 269-281.

Aryee, S. (1992). Public and private sector professionals: A comparative study of their perceived work experience. Group \& Organization Management, 17(1), 72-85. doi:10.1177/1059601192171006 
Asch, S. E. (1951). Effects of group pressure upon the modification and distortion of judgments. In H. Guetzkow (Ed.), Groups, leadership and men: Research in human relations (pp. 177-190). Oxford, UK: Carnegie Press.

Audenaert, M., Decramer, A., George, B., Verschuere, B., \& Van Waeyenberg, T. (2019). When employee performance management affects individual innovation in public organizations: The role of consistency and LMX. The International Journal of Human Resource Management, 30(5), 815-834.

Bai, Y., Li, P. P., \& Xi, Y. (2012). The distinctive effects of dual-level leadership behaviors on employees' trust in leadership: An empirical study from China. Asia Pacific Journal of Management, 29(2), 213-237.

Bandura, A. (1977). Social learning theory. Oxford, UK: Prentice Hall.

Barasa, E., Mbau, R., \& Gilson, L. (2018). What is resilience and how can it be nurtured? A systematic review of empirical literature on organizational resilience. International Journal of Health Policy and Management, 7(6), 491-503.

Barbuto, J. E. (1997). Taking the charisma out of transformational leadership. Journal of Social Behavior and Personality, 12(3), 689-697.

Barbuto Jr, J. E., \& Wheeler, D. W. (2006). Scale development and construct clarification of servant leadership. Group and Organization Management, 31(3), 300-326.

Baron, R. M., \& Kenny, D. A. (1986). The moderator-mediator variable distinction in social psychological research: Conceptual, strategic, and statistical considerations. Journal of Personality and Social Psychology, 51(6), 1173.

Bartone, P. T. (2007). Test-retest reliability of the dispositional resilience scale-15, a brief hardiness scale. Psychological Reports, 101(3), 943-944. doi:0.2466/PR0.101.7.943-944

Baruch, Y. (1999). Response rate in academic studies: A comparative analysis. Human Relations, 52(4), 421-438. https://doi.org/10.1177/001872679905200401

Baruch, Y., \& Holtom, B. C. (2008). Survey response rate levels and trends in organizational research. Human Relations, 61(8), 1139-1160. https://doi.org/10.1177/0018726708094863

Bass, B. M. (1985). Leadership and performance beyond expectations. London, UK: Collier Macmillan.

Bass, B. M. (1990). From transactional to transformational leadership: Learning to share the vision. Organizational Dynamics, 18(3), 19-31.

Bass, B. M. (2000). The future of leadership in learning organizations. Journal of Leadership Studies, 7(3), 18-40.

Bass, B. M., \& Avolio, B. J. (1997). Full range leadership development: Manual for the multifactor leadership questionnaire. Palo Alto, CA. Mind Garden.

Bazeley, P. (2016). Mixed or merged? Integration as the real challenge for mixed methods. Qualitative Research in Organizations and Management: An International Journal, 11(3), 189-194.

Bazeley, P. (2018). Integrating analysis in mixed methods research. Thousand Oaks, CA: Sage.

Beatty, P. C., \& Willis, G. B. (2007). Research synthesis: The practice of cognitive interviewing. Public Opinion Quarterly, 71(2), 287-311. doi:10.1093/poq/nfm006 
Beauducel, A., \& Wittmann, W. W. (2005). Simulation study on fit indexes in CFA based on data with slightly distorted simple structure. Structural Equation Modeling: A Multidisciplinary Journal, 12(1), 41-75. doi:10.1207/s15328007sem1201_3

Beddoes-Jones, F. \& Swailes, S. (2015), Authentic leadership: development of a new three pillar model. Strategic HR Review, 14(3), 94-99.

Beer, M. (1964). Leadership, employee needs, and motivation (Doctoral dissertation, Ohio State University, Columbus, $\mathrm{OH}$ ). Retrieved from ohiolink.edu.

Bellé, N. (2014). Leading to make a difference: A field experiment on the performance effects of transformational leadership, perceived social impact, and public service motivation. Journal of Public Administration Research and Theory, 24(1), 109136. https://doi.org/10.1093/jopart/mut033

Beltman, S., Mansfield, C., \& Harris, A. (2015). Quietly sharing the load? The role of school psychologists in enabling teacher resilience. School Psychology International, 37(2), 172-188. doi:10.1177/0143034315615939

Benaquisto, L., \& Given, L. (2008). The SAGE encyclopedia of qualitative research methods. New York, NY: Sage.

Benard, B. (1993). Fostering resiliency in kids. Character Education, 51(3), 44-48.

Benson, M. J., \& Hogan, R. (2008). How dark side leadership personality destroys trust and degrades organisational effectiveness. Organisations and People, 15(3), 1018.

Better Public Services Advisory Group. (2011). Better public services advisory group report. Retrieved from https://www.ssc.govt.nz/sites/all/files/bps-reportnov2011_0.pdf

Bhamra, R., Dani, S., \& Burnard, K. (2011). Resilience: The concept, a literature review and future directions. International Journal of Production Research, 49(18), 53755393.

Bligh, M. C., Pearce, C. L., \& Kohles, J. C. (2006). The importance of self-and shared leadership in team based knowledge work: A meso-level model of leadership dynamics. Journal of Managerial Psychology, 21(4), 296-318.

Block, J. (1950). An experimental investigation of the construct of ego-control. (Doctoral dissertation, Stanford University, Stanford, CA). Retrieved from https://searchworks.stanford.edu

Block, J., \& Kremen, A. M. (1996). IQ and ego-resiliency: Conceptual and empirical connections and separateness. Journal of Personality and Social Psychology, 70(2), 349-361. doi:http://dx.doi.org/10.1037/0022-3514.70.2.349

Block, J. L. H. (1951). An experimental study of a topological representation of egostructure. Stanford University Bulletin, Abstracts of Dissertations, 8(67), 230-232.

Boddy, C. R. (2014). Corporate psychopaths, conflict, employee affective well-being and counterproductive work behaviour. Journal of Business Ethics, 121(1), 107-121. doi:10.1007/s10551-013-1688-0

Bogard, K., \& Wertz, F. J. (2006). The introduction of a qualitative perspective in advanced psychological research training: narrative of a mixed methods doctoral dissertation. The Humanistic Psychologist, 34(4), 369-398.

Bonanno, G. A. (2004). Loss, trauma, and human resilience: Have we underestimated the human capacity to thrive after extremely aversive events? American Psychologist, 59(1), 20-28. 
Bonanno, G. A. (2005). Clarifying and extending the construct of adult resilience. American Psychologist, 60(3), 265-267. doi:10.1037/0003-066X.60.3.265b

Bovaird, T. (2005). Public governance: balancing stakeholder power in a network society. International Review of Administrative Sciences, 71(2), 217228. https://doi.org/10.1177/0020852305053881

Bowes, L., \& Jaffee, S. R. (2013). Biology, genes, and resilience: Toward a multidisciplinary approach. Trauma, Violence, and Abuse, 14(3), 195-208.

Bozeman, B. (2000). Bureaucracy and red tape. Upper Saddle River, NJ: Prentice Hall.

Brannen, J. (2017). Mixing methods: Qualitative and quantitative research. London: Routledge.

Brannick, M. T., Chan, D., Conway, J. M., Lance, C. E., \& Spector, P. E. (2010). What is method variance and how can we cope with it? A panel discussion. Organizational Research Methods, 13(3), 407-420. https://doi.org/10.1177/1094428109360993

Brennan, E. J. (2017). Towards resilience and wellbeing in nurses. British Journal of Nursing, 26(1), 43-47.

Brenner, P. S. (2015). Narratives of response error from cognitive interviews of survey questions about normative behavior. Sociological Methods \& Research, 46(3), 540-564. doi:10.1177/0049124115605331

Bronfenbrenner, U. (2005). Making human beings human: Bioecological perspectives on human development. Thousand Oaks, CA: Sage.

Brough, P., O'Driscoll, M., \& Kalliath, T. (2005). Confirmatory factor analysis of the Cybernetic coping scale. Journal of Occupational and Organizational Psychology, 78(1), 53-61. doi:10.1348/096317904X23754

Brower, H. H., Schoorman, F. D., \& Tan, H. H. (2000). A model of relational leadership: The integration of trust and leader-member exchange. The Leadership Quarterly, 11(2), 227-250.

Brown, D. L. (2008). African American resiliency: Examining racial socialization and social support as protective factors. Journal of Black Psychology, 34(1), 32-48.

Brown, M. E., Treviño, L. K., \& Harrison, D. A. J. (2005). Ethical leadership: A social learning perspective for construct development and testing. Organizational behavior and human decision processes, 97(2), 117-134.

Brown, M. M., \& Brudney, J. L. (2003). Learning organizations in the public sector? A study of police agencies employing information and technology to advance knowledge. Public Administration Review, 63(1), 30-43.

Brown, T. A., \& Moore, M. T. (2012). Confirmatory factor analysis. In R. H. Hoyle (Ed.), Handbook of structural equation modeling (pp. 361-379). New York, NY: The Guilford Press.

Bryman, A. (1992). Charisma and leadership in organizations. London: Sage.

Bryman, A., Stephens, M., \& a Campo, C. (1996). The importance of context: Qualitative research and the study of leadership. The Leadership Quarterly, 7(3), 353-370.

Bryson, J. M., Crosby, B. C., \& Bloomberg, L. L. (2014). Public value governance: Moving beyond traditional public administration and the new public management. Public Administration Review, 74(4), 445456. https://doi.org/10.1111/puar.12238

Bryson, J. M., Crosby, B. C., \& Bloomberg, L. (2015). Discerning and assessing public value: Major issues and new directions. In J. M. Bryson, B. C. Crosby, \& L. 
Bloomberg (Eds.), Public value and public administration (pp. 1-22). Washington, DC: Georgetown University Press.

Budescu, D. V. (1993). Dominance analysis: A new approach to the problem of relative importance of predictors in multiple regression. Psychological Bulletin, 114(3), 542-551. http://dx.doi.org/10.1037/0033-2909.114.3.542

Burla, L., Knierim, B., Barth, J., Liewald, K., Duetz, M., \& Abel, T. (2008). From text to codings: Intercoder reliability assessment in qualitative content analysis. Nursing Research, 57(2), 113-117. doi: 10.1097/01.NNR.0000313482.33917.7d

Burnard, K., \& Bhamra, R. (2011). Organisational resilience: Development of a conceptual framework for organisational responses. International Journal of Production Research, 49(18), 5581-5599.

Butterfield, L. D., Borgen, W. A., Amundson, N. E., \& Maglio, A-S. T. (2005). Fifty years of the critical incident technique: 1954-2004 and beyond. Qualitative Research, 5(4), 475-497. doi:10.1177/1468794105056924

Byrne, B. M. (1984). The General/Academic Self-Concept Nomological Network: A review of construct validation research. Review of Educational Research, 54(3), 427-456. https://doi.org/10.3102/00346543054003427

Caillier, J. G. (2014). Toward a better understanding of the relationship between transformational leadership, public service motivation, mission valence, and employee performance: A preliminary study. Public Personnel Management, 43(2), 218-239.

Callanan, V. J., \& Davis, M. S. (2012). Gender differences in suicide methods. Social Psychiatry and Psychiatric Epidemiology, 47(6), 857-869.

Cameron, A. (1998). The elasticity of endurance: Work intensification and workplace flexibility in the Queensland public hospital system. New Zealand Journal of Employment Relations, 23(3), 133.

Campbell, J. L., Quincy, C., Osserman, J., \& Pedersen, O. K. (2013). Coding in-depth semistructured interviews: Problems of unitization and intercoder reliability and agreement. Sociological Methods \& Research, 42(3), 294-320. doi:10.1177/0049124113500475

Campbell, J. W. (2016). A collaboration-based model of work motivation and role ambiguity in public organizations. Public Performance \& Management Review, 39(3), 655-675.

Can, A., \& Aktaş, M. (2012). Cultural values and followership style preferences. ProcediaSocial and Behavioral Sciences, 41, 84-91.

Carey, M. A., \& Smith, M. W. (1994). Capturing the group effect in focus groups: A special concern in analysis. Qualitative Health Research, 4(1), 123-127. http://dx.doi.org/10.1177/104973239400400108

Carmeli, A., Meitar, R., \& Weisberg, J. (2006). Self-leadership skills and innovative behavior at work. International Journal of Manpower, 27(1), 75-90.

Carter, S. R. (2016). Using confirmatory factor analysis to manage discriminant validity issues in social pharmacy research. International Journal of Clinical Pharmacy, 38(3), 731-737.

Carsten, M. K. (2017). Followership development: a behavioral approach. In M. G. Clark \& C. G. Gruber (Eds.) Leader Development Deconstructed (pp. 143-161). New York, NY: Springer International Publishing. 
Casimir, G., Ng, Y., Wang, K., \& Ooi, G. (2014). The relationships amongst leadermember exchange, perceived organizational support, affective commitment, and in-role performance: A social-exchange perspective. Leadership \& Organization Development Journal, 35(5), 366-385.

Cattell, R. B. (1966). The scree test for the number of factors. Multivariate Behavioral Research, 1(2), 245-276.

Chang, S.-J., van Witteloostuijn, A., \& Eden, L. (2010). From the editors: Common method variance in international business research. Journal of International Business Studies, 41(2), 178-184.

Christensen, T. (2014). New Public Management and beyond: The hybridization of public sector reforms. In G. S. Drori, M. A. Hollerer, \& P. Walgenbach (Eds.), Global themes and local variations in organizations and management: Perspectives on globalization (pp. 161-174). New York, NY: Routledge.

Christensen, T., \& Lægreid, P. (2011a). Complexity and hybrid public administration: Theoretical and empirical challenges. Public Organization Review, 11(4), 407423. doi:10.1007/s11115-010-0141-4

Christensen, T., \& Lægreid, P. (2011b). Democracy and administrative policy: Contrasting elements of New Public Management (NPM) and post-NPM. European Political Science Review, 3(01), 125-146.

Clegg, S. R., Cunha, J. V., \& Cunha, M. P. (2002). Management paradoxes: A relational view. Human Relations, 55(5), 483-503.

Cohen, J. (1969). Statistical power analysis for the behavioral sciences. New York, NY: Routledge.

Cohen, S. G., Chang, L., \& Ledford Jr, G. E. (1997). A hierarchical construct of selfmanagement leadership and its relationship to quality of work life and perceived work group effectiveness. Personnel Psychology, 50(2), 275-308.

Colley, L. J. A. (2001). The changing face of public sector employment. Australian Journal of Public Administration, 60(1), 9-20. doi: 10.1111/1467-8500.00194

Collinson, D., \& Collinson, M. (2009). 'Blended leadership': Employee perspectives on effective leadership in the UK further education sector. Leadership, 5(3), 365-380.

Cook, C., Heath, F., \& Thompson, R. L. (2000). A meta-analysis of response rates in web or internet-based surveys. Educational and psychological measurement, 60(6), 821-836.

Cook, T. D., Campbell, D. T., \& Shadish, W. (2002). Experimental and quasi-experimental designs for generalized causal inference. Boston, MA: Houghton Mifflin.

Cooke, F. L., Cooper, B., Bartram, T., Wang, J., \& Mei, H. (2016). Mapping the relationships between high-performance work systems, employee resilience and engagement: A study of the banking industry in China. The International Journal of Human Resource Management, 1-22. doi:10.1080/09585192.2015.1137618

Cortina, J. M. (1993). What is coefficient alpha? An examination of theory and applications. Journal of Applied Psychology, 78(1), 98. doi: 10.1037/0021$\underline{9010.78 .1 .98}$

Costa, A. C., Fulmer, C. A., \& Anderson, N. R. (2018). Trust in work teams: An integrative review, multilevel model, and future directions. Journal of Organizational Behavior, 39(2), 169-184. 
Costello, A. B., \& Osborne, J. W. (2005). Best practices in exploratory factor analysis: Four recommendations for getting the most from your analysis. Practical Assessment, Research \& Evaluation, 10(7), 1-9.

Credé, M., Tynan, M. C., \& Harms, P. D. (2017). Much ado about grit: A meta-analytic synthesis of the grit literature. Journal of Personality and Social Psychology, 113(3), 492.

Creedon, P. S., \& Hayes, A. F. (2015, May). Small sample mediation analysis: How far can we push the bootstrap. Poster sesssion presented at the Annual Conference of the Association for Psychological Science, New York, NY.

Creswell, J. W. (1999). Mixed-method research: Introduction and application. In G. J. Cizek (Ed.), Handbook of Educational Policy (pp. 455-47). New York, NY: Academic Press.

Creswell, J. W. (2013). Research design: Qualitative, quantitative, and mixed methods approaches ( $4^{\text {th }}$ ed.). London: Sage.

Creswell, J. W., \& Clark, V. L. P. (2017). Designing and conducting mixed methods research. ( $3^{\text {rd }}$ ed.). Thousand Oaks, CA: Sage.

Cropanzano, R., \& Mitchell, M. S. (2005). Social exchange theory: An interdisciplinary review. Journal of Management, 31(6), 874-900.

Cutter, S. L., Barnes, L., Berry, M., Burton, C., Evans, E., Tate, E., \& Webb, J. (2008). A place-based model for understanding community resilience to natural disasters. Global Environmental Change, 18(4), 598-606.

Darlington, R. B. (1990). Regression and linear models. New York, NY: McGraw-Hill.

Davis-Street, J., Frangos, S., Walker, B., \& Sims, G. (2018, April). Addressing adaptive and inherent resilience: Lessons learned from Hurricane Harvey. Paper presented at the SPE International Conference and Exhibition on Health, Safety, Security, Environment, and Social Responsibility, Abu Dhabi, United Arab Emirates.

Day, A. L., \& Livingstone, H. A. (2001). Chronic and acute stressors among military personnel: Do coping styles buffer their negative impact on health? Journal of Occupational Health Psychology, 6(4), 348-360. doi: http://dx.doi.org/10.1037/1076-8998.6.4.348

Kets de Vries, M. F. R. (2003). Leaders, fools and impostors: Essays on the psychology of leadership (Rev. ed.). Lincoln, NE: IUniverse.

De Waal, A. A. (2010). Achieving high performance in the public sector: What needs to be done? Public Performance \& Management Review, 34(1), 81-103.

Decker, P. J. (1986). Social learning theory and leadership. Journal of Management Development, 5(3), 46-58.

Delmotte, J., De Winne, S., \& Sels, L. (2012). Toward an assessment of perceived HRM system strength: Scale development and validation. The International Journal of Human Resource Management, 23(7), 1481-1506. doi:10.1080/09585192.2011.579921

Demerouti, E., Bakker, A. B., Bulters, A. (2004). The loss spiral of work pressure, workhome interface and exhaustion: Reciprocal relations in a three-wave study. Journal of Vocational Behavior, 64(1), 131-149.

Den Hartog, D. N., Van Muijen, J. J., \& Koopman, P. L. (1997). Transactional versus transformational leadership: An analysis of the MLQ. Journal of Occupational and Organizational Psychology, 70(1), 19-34. 
Denhardt, J. V., \& Denhardt, R. B. (2007). The new public service: Serving, not steering. Amonk, NY: ME Sharpe.

Denhardt, R. B., Denhardt, J. V., \& Aristigueta, M. P. (2012). Managing human behavior in public and nonprofit organizations ( $3^{\text {rd }}$ ed.). Thousand Oaks, CA: Sage.

DeVellis, R. F. (2016). Scale development: Theory and applications (Vol. 26). Thousand Oaks, CA: Sage.

DeWalt, D. A., Rothrock, N., Yount, S., \& Stone, A. A. J. M. c. (2007). Evaluation of item candidates: The PROMIS qualitative item review. Medical Care, 45, S12-S21.

Dewey, J. (1929). Experience and nature. Chicago, IL: Dover.

Diehl, M., Hay, E. L., \& Chui, H. (2012). Personal risk and resilience factors in the context of daily stress. Annual Review of Gerontology \& Geriatrics, 32(1), 251-274. doi:10.1891/0198-8794.32.251

Dirks, K. T., \& Ferrin, D. L. (2002). Trust in leadership: Meta-analytic findings and implications for research and practice. Journal of Applied Psychology, 87(4), 611628. doi:http://dx.doi.org/10.1037/0021-9010.87.4.611

Dixon-Woods, M., Baker, R., Charles, K., Dawson, J., Jerzembek, G., Martin, G., ... \& Willars, J. (2014). Culture and behaviour in the English National Health Service: Overview of lessons from a large multimethod study. BMJ Quality \& Safety, 23(2), 106-115.

Dobbin, F., \& Boychuk, T. (1999). National employment systems and job autonomy: Why job autonomy is high in the Nordic countries and low in the United States, Canada, and Australia. Organization Studies, 20(2), 257-291.

Dollard, M. F., \& Bakker, A. B. (2010). Psychosocial safety climate as a precursor to conducive work environments, psychological health problems, and employee engagement. Journal of Occupational and Organizational Psychology, 83(3), 579599. doi:10.1348/096317909X470690

Döös, M., Johansson, P., \& Wilhelmson, L. (2015). Beyond being present: Learningoriented leadership in the daily work of middle managers. Journal of Workplace Learning, 27(6), 408-425.

Drennan, J. (2003). Cognitive interviewing: Verbal data in the design and pretesting of questionnaires. Journal of Advanced Nursing, 42(1), 57-63. doi:10.1046/j.13652648.2003.02579.x

Driscoll, D. L., Appiah-Yeboah, A., Salib, P., \& Rupert, D. J. (2007). Merging qualitative and quantitative data in mixed methods research: How to and why not. Ecological and Environmental Anthropology (University of Georgia), 3(1), 18-28. Retrieved from http://eea.snthro.uga.edu/index.php/eea/index

Drisko, J. W., \& Maschi, T. (2015). Qualitative content analysis: Oxford, UK: Oxford University Press.

Duckworth, A. L., Peterson, C., Matthews, M. D., \& Kelly, D. R. (2007). Grit: Perseverance and passion for long-term goals. Journal of Personality and Social Psychology, 92(6), 1087-1101. doi:10.1037/0022-3514.92.6.1087

Dunoon, D. (2002). Rethinking leadership for the public sector. Australian Journal of Public Administration, 61(3), 3-18.

Edward, K.-l., \& Warelow, P. (2005). Resilience: When coping is emotionally intelligent. Journal of the American Psychiatric Nurses Association, 11(2), 101-102. 
Efron, B., \& Tibshirani, R. J. (1994). An introduction to the bootstrap. Boca Raton, FL: CRC Press.

Eid, J., Johnsen, B. H., Brun, W., Laberg, J., Nyhus, J. K. \& Larsson, G. (2004) Situation awareness and transformational leadership in senior military leaders: An exploratory study. Military Psychology, 16(3), 203209, DOI: $10.1207 / \mathrm{s} 15327876 \mathrm{mp} 16034$

Einarsen, S., Aasland, M. S., \& Skogstad, A. (2007). Destructive leadership behaviour: A definition and conceptual model. The Leadership Quarterly, 18(3), 207-216.

Eisenberger, R., Huntington, R., Hutchison, S., \& Sowa, D. (1986). Perceived organizational support. Journal of Applied Psychology, 71(3), 500-507. doi: http://dx.doi.org/10.1037/0021-9010.71.3.500

Eisenberger, R., \& Stinglhamber, F. (2011). Perceived organizational support: Fostering enthusiastic and productive employees. Washington, DC: American Psychological Association.

El Akremi, A., Gond, J.-P., Swaen, V., De Roeck, K., \& Igalens, J. (2018). How do employees perceive corporate responsibility? Development and validation of a multidimensional corporate stakeholder responsibility scale. Journal of Management, 44(2), 619-657.

Emerson, R. M. (1976). Social exchange theory. Annual Review of Sociology, 2(1), 335362.

Enders, C. K. (2003). Using the expectation maximization algorithm to estimate coefficient alpha for scales with item-level missing data. Psychological Methods, 8(3), 322337.

Etikan, I., Musa, S. A., \& Alkassim, R. S. J. (2016). Comparison of convenience sampling and purposive sampling. American Journal of Theoretical Applied Sttistics, 5(1), $1-4$.

Fabrigar, L. R., \& Wegener, D. T. (2011). Exploratory factor analysis. Oxford, UK: Oxford University Press.

Fabrigar, L. R., Wegener, D. T., MacCallum, R. C., \& Strahan, E. J. (1999). Evaluating the use of exploratory factor analysis in psychological research. Psychological Methods, 4(3), 272-299. doi:http://dx.doi.org/10.1037/1082-989X.4.3.272

Feilzer, M. Y. (2010). Doing mixed methods research pragmatically: Implications for the rediscovery of pragmatism as a research paradigm. Journal of Mixed Methods Research, 4(1), 6-16.

Firestone, W. A. (1993). Alternative arguments for generalizing from data as applied to qualitative research. Educational Researcher, 22(4), 16-23.

Fishman, D. (1999). The case for pragmatic psychology. New York, NY: NYU Press.

Fitzpatrick, A. C. (2011). Report on representation and development of women for top leadership roles in the New Zealand public service. Victoria University of Wellington.

Flanagan, J. C. (1954). The critical incident technique. Psychological Bulletin, 51(4), 327358.

Flatten, T. C., Engelen, A., Zahra, S. A., \& Brettel, M. (2011). A measure of absorptive capacity: Scale development and validation. European Management Journal, 29(2), 98-116. https://doi.org/10.1016/j.emj.2010.11.002 
Folke, C., Carpenter, S., Walker, B., Scheffer, M., Chapin, T., \& Rockström, J. (2010). Resilience thinking: Integrating resilience, adaptability and transformability. Ecology \& Society, 15(4).

Folkman, S. (2008). The case for positive emotions in the stress process. Anxiety, Stress, and Coping, 21(1), 3-14.

Folkman, S. (2013). Stress: Appraisal and coping. In M. Gellman \& J. R. Turner (Eds.), Encyclopedia of behavioral medicine (pp. 1913-1915). New York, NY: Springer.

Folkman, S., \& Moskowitz, J. T. (2000a). Positive affect and the other side of coping. American Psychologist, 55(6), 647-654.

Folkman, S., \& Moskowitz, J. T. (2000b). Stress, positive emotion, and coping. Current Directions in Psychological Science, 9(4), 115-118. doi:10.1111/1467-8721.00073

Folkman, S., \& Moskowitz, J. T. (2007). Positive affect and meaning-focused coping during significant psychological stress. In M. Hewstone, H. A. W. Schut, J. B. F. De Wit, K. Van Den Bos, \& M. S. Stroebe (Eds.), The scope of social psychology: Theory and applications (pp. 193-208). New York, NY: Psychology Press.

Ford, J. K., MacCallum, R. C., \& Tait, M. (1986). The application of exploratory factor analysis in applied psychology: A critical review and analysis. Personnel Psychology, 39(2), 291-314.

Fossestøl, K., Breit, E., Andreassen, T. A., \& Klemsdal, L. (2015). Managing institutional complexity in public sector reform: Hybridization in front-line service organizations. Public Administration, 93(2), 290-306.

Fowler, E. G., Staudt, L. A., Greenberg, M. B., \& Oppenheim, W. L. J. (2009). Selective control assessment of the lower extremity (SCALE): Development, validation, and interrater reliability of a clinical tool for patients with cerebral palsy. Developmental Medicine \& Child Neurology, 51(8), 607-614.

Frank, S. A., \& Lewis, G. B. (2004). Government employees: Working hard or hardly working? The American Review of Public Administration, 34(1), 36-51.

Franken, E., \& Plimmer, G. (2019). Mediocre and harmful public sector leadership. International Journal of Public Leadership, 15(4), 274-286. https://doi.org/10.1108/IJPL-09-2019-0058

Franken, E., Plimmer, G., \& Malinen, S. (2019). Paradoxical leadership in public sector organisations: Its role in fostering employee resilience. Australian Journal of Public Administration, 1-18. https://doi.org/10.1111/1467-8500.12396

Frels, R. K., \& Onwuegbuzie, A. J. (2013). Administering quantitative instruments with qualitative interviews: A mixed research approach. Journal of Counseling \& Development, 91(2), 184-194. doi:10.1002/j.1556-6676.2013.00085.x

Froehlich, R. M. (2013). Building community resilience post-disaster: The 9/11 attack on America and lessons on how to rebuild a mixed-use business district. Journal of Affordable Housing \& Community Development Law, 21(3/4), 335-357.

Fulop, L. (2012). Leadership, clinician managers and a thing called "hybridity". Journal of Health Organization and Management, 26(5), 578-604. doi:10.1108/14777261211256927

Gagné, M., \& Deci, E. L. (2005). Self-determination theory and work motivation. Journal of Organizational Behavior, 26(4), 331-362. doi:10.1002/job.322

Garmezy, N. (1971). Vulnerability research and the issue of primary prevention. American Journal of Orthopsychiatry, 41(1), 101-116. doi:http://dx.doi.org/10.1111/j.19390025.1971.tb01111.x 
Gattiker, U. E., \& Larwood, L. (1986). Subjective career success: A study of managers and support personnel. Journal of Business and Psychology, 1(2), 78-94.

George, B., \& Pandey, S. K. (2017). We know the yin—but where is the yang? Toward a balanced approach on common source bias in public administration scholarship. Review of Public Personnel Administration, 37(2), 245-270. doi:10.1177/0734371X17698189

Getha-Taylor, H. (2008). Identifying collaborative competencies. Review of Public Personnel Administration, 28(2), 103-119.

Getha-Taylor, H., Blackmar, J., \& Borry, E. L. (2016). Are competencies universal or situational? A state-level investigation of collaborative competencies. Review of Public Personnel Administration, 36(3), 306-320. doi:10.1177/0734371X15624132

Getha-Taylor, H., Holmes, M. H., Jacobson, W. S., Morse, R. S., \& Sowa, J. E. (2011). Focusing the public leadership lens: Research propositions and questions in the Minnowbrook tradition. Journal of Public Administration Research and Theory, 21(Supplement 1), i83-i97.

Giauque, D., Ritz, A., Varone, F., \& Anderfuhren-Biget, S. (2012). Resigned but satisfied: The negative impact of public service motivation and red tape on work satisfaction. Public Administration, 90(1), 175-193.

Gill, P., Stewart, K., Treasure, E., \& Chadwick, B. J. (2008). Methods of data collection in qualitative research: interviews and focus groups. British Dental Journal, 204(6), 291. https://doi.org/10.1038/bdj.2008.192

Gittell, J. H., Cameron, K., Lim, S., \& Rivas, V. (2006). Relationships, layoffs, and organizational resilience airline industry responses to September 11. The Journal of Applied Behavioral Science, 42(3), 300-329.

Giustiniano, L., Clegg, S. R., e Cunha, M. P., \& Rego, A. (2018). Elgar introduction to theories of organizational resilience. Cheltenham, UK: Edward Elgar Publishing.

Gliem, J. A., \& Gliem, R. R. (2003). Calculating, interpreting, and reporting Cronbach's alpha reliability coefficient for Likert-type scales. In Midwest Research to Practice Conference in Adult, Continuing, and Community Education (pp. 82-88). Columbus, OH: Ohio State University.

Gorard, S. (2010). Research design, as independent of methods. In A. Tashakkori \& C. Teddlie (Eds.), Handbook of mixed methods in social and behavioral research (2nd ed., pp. 237-251). Thousand Oaks, CA: Sage.

Gottfredson, R. K., \& Aguinis, H. (2017). Leadership behaviors and follower performance: Deductive and inductive examination of theoretical rationales and underlying mechanisms. Journal of Organizational Behavior, 38(4), 558-591.

Gottlieb, B. H., \& Gignac, M. A. M. (1996). Content and domain specificity of coping among family caregivers of persons with dementia. Journal of Aging Studies, 10(2), 137-155. doi:https://doi.org/10.1016/S0890-4065(96)90010-9

Gould-Williams, J., \& Davies, F. (2005). Using social exchange theory to predict the effects of hrm practice on employee outcomes. Public Management Review, 7(1), 1-24. doi:10.1080/1471903042000339392

Graen, G. B., \& Scandura, T. A. (1986). A theory of dyadic career reality. In K. Rowland \& G. Ferris (Eds.), Research in personnel human resources management (Vol. 4, pp. 147-181). Greenwich, CT: JAI Press. 
Graen, G. B., \& Uhl-Bien, M. (1995). Relationship-based approach to leadership: Development of leader-member exchange (LMX) theory of leadership over 25 years: Applying a multi-level multi-domain perspective. The Leadership Quarterly, 6(2), 219-247.

Grant, J. S., \& Davis, L. L. (1997). Selection and use of content experts for instrument development. Research in Nursing \& Health, 20(3), 269-274.

Green, S. G., \& Mitchell, T. R. (1979). Attributional processes of leaders in leadermember interactions. Organizational Behavior and Human Performance, 23(3), 429-458.

Griffin, M. A., Neal, A., \& Parker, S. K. (2007). A new model of work role performance: Positive behavior in uncertain and interdependent contexts. Academy of Management Journal, 50(2), 327-347.

Grotberg, E. H. (1995). A guide to promoting resilience in children: Strengthening the human spirit. The Hague, Netherlands: Bernard van Leer Foundation.

Guest, G., Bunce, A., \& Johnson, L. (2006). How many interviews are enough? An experiment with data saturation and variability. Field Methods, 18(1), 59-82.

Guo, B., Aveyard, P., Fielding, A., \& Sutton, S. (2008). Testing the convergent and discriminant validity of the Decisional Balance Scale of the Transtheoretical Model using the Multi-Trait Multi-Method approach. Psychology of Addictive Behaviors, 22(2), 288-294. http://dx.doi.org/10.1037/0893-164X.22.2.288

Guo, M., Gan, Y., \& Tong, J. (2013). The role of meaning-focused coping in significant loss. Anxiety, Stress, \& Coping, 26(1), 87-102. doi:10.1080/10615806.2011.627507

Guyon, H., Kop, J.-L., Juhel, J., \& Falissard, B. (2018). Measurement, ontology, and epistemology: Psychology needs pragmatism-realism. Theory \& Psychology, 28(2), 149-171. https://doi.org/10.1177/0959354318761606

Gursoy, D., Chi, C. G. Q., \& Karadag, E. (2013). Generational differences in work values and attitudes among frontline and service contact employees. International Journal of Hospitality Management, 32, 40-48.

Hair, J., Black, W., Babin, B., \& Anderson, R. (2010). Multivariate data analysis (7th ed.). Upper Saddle River, NJ: Prentice-Hall, Inc.

Halbesleben, J. R. B. (2010). The role of exhaustion and workarounds in predicting occupational injuries: A cross-lagged panel study of health care professionals. Journal of Occupational Health Psychology, 15(1), 1-16. http://dx.doi.org/10.1037/a0017634

Halbesleben, J. R. B., Neveu, J.-P., Paustian-Underdahl, S. C., \& Westman, M. (2014). Getting to the "COR": Understanding the role of resources in conservation of resources theory. Journal of Management, 40(5), 1334-1364. https://doi.org/10.1177/0149206314527130

Hall, P. A. (2003). Aligning ontology and methodology in comparative research. In J. Mahoney \& D. Rueschemeyer (Eds.), Comparative historical analysis in the social sciences (pp. 373-404). Cambridge, UK: Cambridge University Press.

Hall, R. J., \& Lord, R. G. (1995). Multi-level information-processing explanations of followers' leadership perceptions. The Leadership Quarterly, 6(3), 265-287.

Hardesty, D. M., \& Bearden, W. O. (2004). The use of expert judges in scale development: Implications for improving face validity of measures of unobservable constructs. 
Journal of Business Research, 57(2), 98-107. doi:https://doi.org/10.1016/S01482963(01)00295-8

Hardy, C., Lawrence, T. B., \& Grant, D. (2005). Discourse and collaboration: The role of conversations and collective identity. Academy of Management Review, 30(1), 5877.

Hargis, M. B., Watt, J. D., \& Piotrowski, C. (2011). Developing leaders: Examining the role of transactional and transformational leadership across business contexts. Organization Development Journal, 29(3), 51.

Harland, L., Harrison, W., Jones, J. R., \& Reiter-Palmon, R. (2005). Leadership behaviors and subordinate resilience. Journal of Leadership \& Organizational Studies, 11(2), 2-14. doi:10.1177/107179190501100202

Harney, P. A. (2007). Resilience processes in context. Journal of Aggression, Maltreatment \& Trauma, 14(3), 73-87. doi:10.1300/J146v14n03_05

Harrington, D. (2009). Confirmatory factor analysis. Oxford: UK: Oxford University Press.

Hartley, J., \& Allison, M. (2000). The modernization and improvement of government and public services. Public Money \& Management, 20(2), 35-40. doi:10.1111/14679302.00209

Hartley, J., Sørensen, E., \& Torfing, J. (2013). Collaborative innovation: A viable alternative to market competition and organizational entrepreneurship. Public Administration Review, 73(6), 821-830.

Hater, J. J., \& Bass, B. M. (1988). Superiors' evaluations and subordinates' perceptions of transformational and transactional leadership. Journal of Applied Psychology, 73(4), 695-702.

Hayes, A. F. (2012). PROCESS: A versatile computational tool for observed variable mediation, moderation, and conditional process modeling [White paper]. Retrieved from http://www.afhayes.com/ public/process2012.pdf

Hayes, A. F. (2013). Introduction to mediation, moderation, and conditional process analysis: A regression-based approach. New York, NY: Guilford Press.

Hayton, J. C., Allen, D. G., \& Scarpello, V. (2004). Factor retention decisions in exploratory factor analysis: A tutorial on parallel analysis. Organizational research methods, 7(2), 191-205.

Head, B. W., \& Alford, J. (2013). Wicked problems. Administration \& Society, 47(6), 711739. doi:10.1177/0095399713481601

Heifetz, R. A. (1994). Leadership without easy answers (Vol. 465). Cambridge, MA: Harvard University Press.

Heres, L. \& Lasthuizen, K. (2012). What's the difference? Ethical leadership in public, hybrid and private sector organizations. Journal of Change Management, 12(4), 441-466. doi:10.1080/14697017.2012.728768

Hobfoll, S. E.(1989). Conservation of resources: A new attempt at conceptualizing stress. American Psychologist, 44(3), 513-524.

Hoinville, G., \& Jowell, R. (1978). Survey research practice. London, UK: Heinemann.

Hendrikx, W., \& van Gestel, N. (2016). The emergence of hybrid professional roles: GPs and secondary school teachers in a context of public sector reform. Public Management Review, 19(8), 1-19. 
Hernandez, L. P. (1993). The role of protective factors in the school resilience of Mexican American high school students (Doctoral dissertation, Stanford University, Stanford, CA). Retrieved from http://www.pellinstitute.org/downloads/publications-TRIO_Dissertations_19902017.pdf

Hersey, P., \& Blanchard, K. (1972). Management of organization behavior ( $2^{\text {nd }}$ ed.). New York, NY: Prentice-Hall.

Higgs, M. J. (2009). The good, the bad and the ugly: Leadership and narcissism. Journal of Change Management, 9(2), 165-178.

Hinkin, T. R. (1995). A review of scale development practices in the study of organizations. Journal of Management, 21(5), 967-988.

Hinkin, T. R. (1998). A brief tutorial on the development of measures for use in survey questionnaires. Organizational Research Methods, 1(1), 104-121.

Hitt, M. A., Bierman, L., Shimizu, K., \& Kochhar, R. (2001). Direct and moderating effects of human capital on strategy and performance in professional service firms: A resource-based perspective. Academy of Management Journal, 44(1), 13-28.

Hobfoll, S. E. (2011). Conservation of resources theory: Its implication for stress, health, and resilience. In S. Folkman (Ed.), Oxford library of psychology. The Oxford handbook of stress, health, and coping (pp. 127-147). New York, NY: Oxford University Press.

Hodliffe, M. C. (2014). The development and validation of the employee resilience scale (EmpRes): The conceptualisation of a new model. (Doctoral dissertation, University of Canterbury, Christchurch, New Zealand). Retrieved from https://ir.canterbury.ac.nz/handle/10092/9184

Hogan, R., Curphy, G., \& Hogan, J. (1994). What we know about leadership: Effectiveness and personality. The American Psychologist, 49(6), 493-504.

Holling, C. S. (1973). Resilience and stability of ecological systems. Annual Review of Ecology and Systematics, 4(1), 1-23.

Hood, C. (1991). A public management for all seasons? Public Administration, 69(1), 319. doi:10.1111/j.1467-9299.1991.tb00779.x

Horne, J. F., \& Orr, J. E. (1997). Assessing behaviors that create resilient organizations. Employment Relations Today, 24(4), 29-39.

Horton, T. V., \& Wallander, J. L. (2001). Hope and social support as resilience factors against psychological distress of mothers who care for children with chronic physical conditions. Rehabilitation Psychology, 46(4), 382-399. doi:http://dx.doi.org/10.1037/0090-5550.46.4.382

Houghton, J. D., Neck, C. P., \& Manz, C. C. (2003). Self-leadership and superleadership: The heart and art of creating shared leadership in teams. In C. L. Pearce \& J. A. Conger (Eds.), Shared leadership: Reframing the hows and whys of leadership (pp. 123-140). Thousand Oaks, CA: Sage.

House, R. J. (1976). A 1976 Theory of charismatic leadership (Working paper series 7606). Toronto, Canada: Faculty of Management Studies, University of Toronto.

Howell, D. C. (2008). The analysis of missing data. In W. Outhwaite \& S. Turner, T. (Eds.), Handbook of social science methodology (pp. 208-224). Thousand Oaks, CA: Sage.

Howell, J. M., \& Avolio, B. J. (1993). Transformational leadership, transactional leadership, locus of control, and support for innovation: Key predictors of 
consolidated-business-unit performance. Journal of Applied Psychology, 78(6), 891.

Hsieh, J. Y., \& Liou, K. T. (2016). Collaborative leadership and organizational performance: Assessing the structural relation in a public service agency. Review of Public Personnel Administration, 38(1), 83-109. doi:10.1177/0734371X15623619

Hsu, M. L. A., \& Chen, F. H. (2017). The cross-level mediating effect of psychological capital on the organizational innovation climate-employee innovative behavior relationship. The Journal of Creative Behavior, 51(2), 128-139. doi:10.1002/jocb.90

Hu, L.-T., \& Bentler, P. M. (1998). Fit indices in covariance structure modeling: Sensitivity to underparameterized model misspecification. Psychological Methods, 3(4), 424453.

Igbaekemen, G. O. (2014). Impact of leadership style on organisation performance: A strategic literature review. Public Policy Administration Research, 4(9), 126-135.

ILO. (2019). Global commission on the future of work: Work for a brighter future. Geneva, Switzerland: International Labour Organisation.

Itzhaki, M., Peles-Bortz, A., Kostistky, H., Barnoy, D., Filshtinsky, V., \& Bluvstein, I. (2015). Exposure of mental health nurses to violence associated with job stress, life satisfaction, staff resilience, and post-traumatic growth. International Journal of Mental Health Nursing, 24(5), 403-412.

Ivankova, N. V., Creswell, J. W., \& Stick, S. L. (2006). Using mixed-methods sequential explanatory design: From theory to practice. Field Methods, 18(1), 3-20.

Iwasaki, Y., MacTavish, J., \& MacKay, K. (2005). Building on strengths and resilience: Leisure as a stress survival strategy. British Journal of Guidance \& Counselling, 33(1), 81-100.

Jacquette, D. (2002). Ontology. Chesham, UK: Acumen.

Jaeggi, S. M., Buschkuehl, M., Etienne, A., Ozdoba, C., Perrig, W. J., \& Nirkko, A. C. (2007). On how high performers keep cool brains in situations of cognitive overload. Cognitive, Affective, \& Behavioral Neuroscience, 7(2), 75-89. doi:10.3758/CABN.7.2.75

Jakobsen, M., \& Jensen, R. (2015). Common method bias in public management studies. International Public Management Journal, 18(1), 3-30. doi:10.1080/10967494.2014.997906

Janakiraman, M. (2011). Inclusive leadership: Critical for a competitive advantage. Berlitz cultural insights series. Retrieved from http://www.tmcorp.com/

Jay, J. (2013). Navigating paradox as a mechanism of change and innovation in hybrid organizations. Academy of Management Journal, 56(1), 137-159.

Jensen, U. T., Andersen, L. B., Bro, L. L., Bøllingtoft, A., Eriksen, T. L. M., Holten, A.L., ... Salomonsen, H. H. (2019). Conceptualizing and measuring transformational and transactional leadership. Administration \& Society, 51(1), 3-33.

Jóhannsdóttir, H. L., \& Ólafsson, R. F. (2004). Coping with bullying in the workplace: The effect of gender, age and type of bullying. British Journal of Guidance Counselling, 32(3), 319-333.

Johanson, G. A., \& Brooks, G. P. (2010). Initial scale development: Sample size for pilot studies. Educational and Psychological Measurement, 70(3), 394-400. https://doi.org/10.1177/0013164409355692 
Joseph, D. L., Newman, D. A., \& Sin, H.-P. (2011). Leader-Member Exchange (LMX) measurement: Evidence for consensus, construct breadth, and discriminant validity. In D. D. Bergh \& D. J. Ketchen Jr. (Eds.), Building methodological bridges (pp. 89-135). Bingley, UK: Emerald Group Publishing Limited.

Judge, T. A., \& Piccolo, R. F. (2004). Transformational and transactional leadership: A meta-analytic test of their relative validity. Journal of Applied Psychology, 89(5), 755.

Jung, D. I., \& Avolio, B. J. (2000). Opening the black box: An experimental investigation of the mediating effects of trust and value congruence on transformational and transactional leadership. Journal of Organizational Behavior, 21(8), 949-964.

Kachali, H., Stevenson, J., Whitman, Z., Seville, E., Vargo, J., \& Wilson, T. (2012). Organisational resilience and recovery for Canterbury organisations after the 4 September 2010 earthquake. Australasian Journal of Disaster and Trauma Studies, 1, 11-19.

Kaiser, H. F. (1960). The application of electronic computers to factor analysis. Educational and Psychological Measurement, 20(1), 141-151.

Kalshoven, K., Den Hartog, D. N., \& De Hoogh, A. H. B. (2011). Ethical leadership at work questionnaire (ELW): Development and validation of a multidimensional measure. The Leadership Quarterly. 22(1), 51-69.

Kantur, D., \& İşeri-Say, A. (2012). Organizational resilience: A conceptual integrative framework. Journal of Management \& Organization, 18(6), 762-773.

Kantur, D., \& İşeri-Say, A. (2015). Organizational resilience: A conceptual integrative framework. Journal of Management \& Organization, 18(6), 762-773. doi:10.1017/S1833367200000420

Kaplan, A. (1964). The conduct of inquiry methodology for behavioral science. San Francisco, CA: Chandler.

Kaplan, H. B. (2005). Understanding the concept of resilience. In S. Goldstein \& R. B. Brooks (Eds.), Handbook of resilience in children (pp. 39-47). New York, NY: Springer.

Karp, T., \& Helg, T. I. (2008). From change management to change leadership: Embracing chaotic change in public service organizations. Journal of Change Management, 8(1), 85-96.

Kazi, M. (2003). Realist evaluation for practice. The British Journal of Social Work, 33(6), 803-818. doi:10.1093/bjsw/33.6.803

Kelley, H. H. (1973). The processes of causal attribution. American Psychologist, 28(2), 107-128.

Kelly, D. R., Matthews, M. D., \& Bartone, P. T. (2014). Grit and hardiness as predictors of performance among West Point cadets. Military Psychology, 26(4), 327-342.

Kelman, H. C. J. (1958). Compliance, identification, and internalization three processes of attitude change. Journal of Conflict Resolution, 2(1), 51-60.

Kenny, D. A. (2011, September 11). Respecification of latent variable models. Retrieved from http://davidakenny.net/cm/respec.htm.

Khan, Z., Rao-Nicholson, R., Akhtar, P., Tarba, S. Y., Ahammad, M. F., \& Vorley, T. (2017). The role of HR practices in developing employee resilience: A case study from the Pakistani telecommunications sector. The International Journal of Human Resource Management, 30(8), 1-28. 
Kim, S. (2004). Individual-level factors and organizational performance in government organizations. Journal of Public Administration Research and Theory, 15(2), 245261. doi:10.1093/jopart/mui013 \%J Journal of Public Administration Research and Theory

King, D. W., King, L. A., Foy, D. W., Keane, T. M., \& Fairbank, J. A. (1999). Posttraumatic stress disorder in a national sample of female and male Vietnam veterans: Risk factors, war-zone stressors, and resilience-recovery variables. Journal of Abnormal Psychology, 108(1), 164-170. doi:http://dx.doi.org/10.1037//0021-843X.108.1.164

King, L. A., King, D. W., Vogt, D. S., Knight, J., \& Samper, R. E. (2006). Deployment risk and resilience inventory: A collection of measures for studying deploymentrelated experiences of military personnel and veterans. Military Psychology, 18(2), 89-120.

Kinicki, A. J., Jacobson, K. J., Peterson, S. J., \& Prussia, G. E. (2013). Development and validation of the performance management behavior questionnaire. Personnel Psychology, 66(1), 1-45.

Kitano, M. K., \& Lewis, R. B. (2005). Resilience and coping: Implications for gifted children and youth at risk. Roeper Review, 27(4), 200-205. doi:10.1080/02783190509554319

Kobasa, S. C. (1979). Stressful life events, personality, and health: An inquiry into hardiness. Journal of Personality and Social Psychology, 37(1), 1-11.

Kobasa, S. C., Maddi, S. R., \& Kahn, S. (1982). Hardiness and health: A prospective study. Journal of Personality and Social Psychology, 42(1), 168-177.

Kozlowski, S. W. J., \& Klein, K. J. (2000). A multilevel approach to theory and research in organizations: Contextual, temporal, and emergent processes. In K. J. Klein \& S. W. J. Kozlowski (Eds.), Multilevel theory, research, and methods in organizations: Foundations, extensions, and new directions (pp. 3-90). San Francisco, CA: Jossey-Bass.

Krueger, R. A., \& Casey, M. A. (2014). Focus groups: A practical guide for applied research (5th ed.). Thousand Oaks, CA: Sage.

Kuhn, T. (1962). The structure of scientific revolutions. Chicago, IL: Chicago University Press.

Kuhnert, K. W., \& Lewis, P. (1987). Transactional and transformational leadership: A constructive/developmental analysis. The Academy of Management Review, 12(4), 648-657.

Kuntz, J. R., Malinen, S., \& Näswall, K. (2017). Employee resilience: Directions for resilience development. Consulting Psychology Journal: Practice and Research, 69(3), 223-242.

Kuntz, J. R., Näswall, K., \& Malinen, S. (2016). Resilient employees in resilient organizations: Flourishing beyond adversity. Industrial and Organizational Psychology, 9(02), 456-462.

Kurasaki, K. S. (2000). Intercoder reliability for validating conclusions drawn from openended interview data. Field Methods, 12(3), 179-194. doi:10.1177/1525822X0001200301

Kuvaas, B., \& Dysvik, A. (2010). Exploring alternative relationships between perceived investment in employee development, perceived supervisor support and employee outcomes. Human Resource Management Journal, 20(2), 138-156. 
Ladd, D., \& Henry, R. A. (2000). Helping coworkers and helping the organization: The role of support perceptions, exchange ideology, and conscientiousness. Journal of Applied Social Psychology, 30(10), 2028-2049.

LaGrange, T. C., \& Silverman, R. A. J. C. (1999). Low self-control and opportunity: Testing the general theory of crime as an explanation for gender differences in delinquency. Criminology, 37(1), 41-72. doi:10.1111/j.1745-9125.1999.tb00479.x

Lambert, S. D., \& Loiselle, C. G. (2008). Combining individual interviews and focus groups to enhance data richness. Journal of Advanced Nursing, 62(2), 228-237.

Lazarus, R. S. (1966). Psychological stress and the coping process. New York, NY: McGraw-Hill.

Lazarus, R. S. (1990). Theory-based stress measurement. Psychological Inquiry, 1(1), 313. doi:10.1207/s15327965pli0101_1

Lazarus, R. S., \& Folkman, S. (1984). Stress, appraisal, and coping. New York, NY: Springer.

Lee, A. V., Vargo, J., \& Seville, E. (2013). Developing a tool to measure and compare organizations’ resilience. Natural Hazards Review, 14(1), 29-41.

Leipold, B., \& Greve, W. (2009). Resilience: A conceptual bridge between coping and development. European Psychologist, 14(1), 40-50.

Lengnick-Hall, C. A., \& Beck, T. E. (2003, August). Beyond bouncing back: The concept of organizational resilience. Paper presented at the National Academy of Management Meetings, Seattle, WA.

Lengnick-Hall, C. A., Beck, T. E., \& Lengnick-Hall, M. L. (2011). Developing a capacity for organizational resilience through strategic human resource management. Human Resource Management Review, 21(3), 243-255.

Levashina, J., \& Campion, M. A. (2007). Measuring faking in the employment interview: Development and validation of an interview faking behavior scale. Journal of Applied Psychology, 92(6), 1638-1656.

Levine, C. H. (1978). Organizational decline and cutback management. Public Administration Review, 38(4), 316-325.

Levine, C. H. (1979). More on cutback management: Hard questions for hard times. Public Administration Review, 39(2), 179-183.

Liden, R. C., \& Maslyn, J. M. (1998). Multidimensionality of leader-member exchange: An empirical assessment through scale development. Journal of Management, 24(1), 43-72.

Lin, T. H. (2010). A comparison of multiple imputation with EM algorithm and MCMC method for quality of life missing data. Quality \& Quantity, 44(2), 277-287. doi:10.1007/s11135-008-9196-5

Lindell, M. K., \& Whitney, D. J. (2001). Accounting for common method variance in crosssectional research designs. Journal of Applied Psychology, 86(1), 114-121.

Linderbaum, B. A., \& Levy, P. E. (2010). The development and validation of the Feedback Orientation Scale (FOS). Journal of Management, 36(6), 1372-1405.

Lipsky, M. (2010). Street-level bureaucracy: Dilemmas of the individual in public service ( $30^{\text {th }}$ anniversary expanded ed.). New York, NY: Russell Sage Foundation.

Lo Cricchio, M. G., Lo Coco, A., Ingoglia, S., Liga, F., Di Maria, R., Inguglia, C., \& Musso, P. (2016). Using focus group in the development of UNIPA emotional autonomy inventory. The Qualitative Report, 21(2), 393-406. 
Locke, E. A. (2007). The case for inductive theory building. Journal of Management, 33(6), 867-890.

Lok, P., \& Crawford, J. (2004). The effect of organisational culture and leadership style on job satisfaction and organisational commitment: A cross-national comparison. Journal of Management Development, 23(4), 321-338.

Lombardo, M. M., Ruderman, M. N., \& McCauley, C. D. (1988). Explanations of success and derailment in upper-level management positions. Journal of Business and Psychology, 2(3), 199-216.

Lord, R. G., \& Maher, K. J. (2002). Leadership and information processing: Linking perceptions and performance. London, UK: Routledge.

Luthans, F. (2002a). The need for and meaning of positive organizational behavior. Journal of Organizational Behavior, 23(6), 695-706. doi:10.1002/job.165

Luthans, F. (2002b). Positive organizational behavior: Developing and managing psychological strengths. The Academy of Management Executive, 16(1), 57-72.

Luthans, F., Vogelgesang, G. R., \& Lester, P. B. (2006). Developing the psychological capital of resiliency. Human Resource Development Review, 5(1), 25-44.

Luthar, S. S., \& Zigler, E. (1991). Vulnerability and competence: a review of research on resilience in childhood. American Journal of Orthopsychiatry, 61(1), 6.

Lynn, M. R. (1986). Determination and quantification of content validity. Nursing Research, 35(6), 382-385. http://dx.doi.org/10.1097/00006199-198611000-00017

Lyons, S. T., Duxbury, L. E., \& Higgins, C. A. (2006). A comparison of the values and commitment of private sector, public sector, and parapublic sector employees. Public Administration Review, 66(4), 605-618.

MacCallum, R. C., Widaman, K. F., Zhang, S., \& Hong, S. (1999). Sample size in factor analysis. Psychological Methods, 4(1), 84-99. http://dx.doi.org/10.1037/1082989X.4.1.84

MacDermid Wadsworth, S. M. (2010). Family risk and resilience in the context of war and terrorism. Journal of Marriage and Family, 72(3), 537-556. doi:10.1111/j.17413737.2010.00717.x

MacKenzie, S. B., \& Podsakoff, P. M. (2012). Common method bias in marketing: Causes, mechanisms, and procedural remedies. Journal of Retailing, 88(4), 542-555. doi:https://doi.org/10.1016/j.jretai.2012.08.001

MacKenzie, S. B., Podsakoff, P. M., \& Rich, G. A. (2001). Transformational and transactional leadership and salesperson performance. Journal of the Academy of Marketing Science, 29(2), 115-134. http://dx.doi.org/10.1177/03079459994506

MacQueen, K., McLellan, E., Kay, K., \& Milstein, B. (2008). Codebook development for team-based qualitative analysis. Cultural Anthropology Methods, 10(2), 31-36.

Maddi, S. R., Harvey, R. H., Khoshaba, D. M., Lu, J. L., Persico, M., \& Brow, M. (2006). The personality construct of hardiness, III: Relationships with repression, innovativeness, authoritarianism, and performance. Journal of Personality, 74(2), 575-598.

Maddux, R. B. (1994). Team building: An exercise in leadership ( $2^{\text {nd }}$ ed.). London, UK: Kogan Paul.

Malik, P., \& Garg, P. (2017). Learning organization and work engagement: The mediating role of employee resilience. The International Journal of Human Resource Management. https://doi.org/10.1080/09585192.2017.1396549 
Mallak, L. (1998, November/December). Putting organizational resilience to work. Industrial Management, 40(6), 8-13.

Manfreda, K. L., Bosnjak, M., Berzelak, J., Haas, I., \& Vehovar, V. (2008). Web surveys versus other survey modes: A meta-analysis comparing response rates. International Journal of Market Research, 50(1), 79-104. https://doi.org/10.1177/147078530805000107

Mansfield, C., Beltman, S., \& Price, A. (2014). 'I'm coming back again!': The resilience process of early career teachers. Teachers and Teaching, 20(5), 547-567.

Mansfield, E. R., \& Helms, B. P. (1982). Detecting multicollinearity. The American Statistician, 36(3a), 158-160.

Manz, C. C. (1986). Self-leadership: Toward an expanded theory of self-influence processes in organizations. 11(3), 585-600. doi:10.5465/amr.1986.4306232

Manz, C. C., \& Sims, H. P. (1980). Self-management as a substitute for leadership: A social learning theory perspective. Academy of Management Review, 5(3), 361-367. doi:10.5465/amr.1980.4288845

March, J. G. (1991). Exploration and exploitation in organizational learning. Organization Science, 2(1), 71-87.

Marshall, B., Cardon, P., Poddar, A., \& Fontenot, R. (2013). Does sample size matter in qualitative research?: A review of qualitative interviews in IS research. Journal of Computer Information Systems, 54(1), 11-22.

Martin, J. J., Byrd, B., Watts, M. L., \& Dent, M. J. (2015). Gritty, hardy, and resilient: Predictors of sport engagement and life satisfaction in wheelchair basketball players. Journal of Clinical Sport Psychology, 9(4), 345-359. http://dx.doi.org/10.1123/jcsp.2015-0015

Martinko, M., \& Gardner, W. (1987). The leader/member attribution process. The Academy of Management Review, 12(2), 235-249.

Mason, M. (2010). Sample size and saturation in $\mathrm{PhD}$ studies using qualitative interviews. Forum Qualitative Sozialforschung/Forum: Qualitative Social Research, 11(3). https://nbn-resolving.org/urn:nbn:de:0114-fqs100387

Masten, A. S. (2001). Ordinary magic: Resilience processes in development. American Psychologist, 56(3), 227-238. doi:http://dx.doi.org/10.1037/0003-066X.56.3.227

Masten, A. S. (2013). Global perspectives on resilience in children and youth. Child Development, 85(1), 6-20. doi:10.1111/cdev.12205

Masten, A. S., \& Coatsworth, J. D. (1998). The development of competence in favorable and unfavorable environments: Lessons from research on successful children. American Psychologist, 53(2), 205-220.

Masten, A. S., Cutuli, J., Herbers, J. E., \& Reed, M.-G. (2009). Resilience in Development. In C. R. Snyder S. \& J. Lopez (Eds.), Handbook of positive psychology $\left(2^{\text {nd }}\right.$ ed., pp. 117-131). New York, NY: Oxford University Press.

Masten, A. S., Garmezy, N., Tellegen, A., Pellegrini, D. S., Larkin, K., \& Larsen, A. (1988). Competence and stress in school children: The moderating effects of individual and family qualities. Journal of Child Psychology and Psychiatry, 29(6), 745-764.

Masten, A. S., Hubbard, J. J., Gest, S. D., Tellegen, A., Garmezy, N., \& Ramirez, M. (1999). Competence in the context of adversity: Pathways to resilience and maladaptation from childhood to late adolescence. Development and Psychopathology, 11(1), 143-169. 
Masten, A. S., \& Reed, M.-G. J. (2002). Resilience in development. In C. R. Snyder \& S. J. Lopez (Eds.), Handbook of positive psychology (pp. 74-88). New York, NY: Oxford University Press.

Matthews, J., \& Shulman, A. D. (2005). Competitive advantage in public-sector organizations: Explaining the public good/sustainable competitive advantage paradox. Journal of Business Research, 58(2), 232-240.

McAdam, R., Hazlett, S. A., \& Casey, C. (2005). Performance management in the UK public sector: Addressing multiple stakeholder complexity. International Journal of Public Sector Management, 18(3), 256-273. doi:10.1108/09513550510591542

McCall, M. W., \& Lombardo, M. M. (1983). Off the track: Why and how successful executives get derailed. (Technical Report No. 21). Greensboro, NC: Center for Creative Leadership.

McDonald, S. (2005). Studying actions in context: A qualitative shadowing method for organizational research. Qualitative Research, 5(4), 455-473. doi:10.1177/1468794105056923

McManus, S., Seville, E., Vargo, J., \& Brunsdon, D. (2008). Facilitated process for improving organizational resilience. Natural Hazards Review, 9(2), 81-90.

Menand, L. (2001). The Metaphysical Club. London: Harper Collins.

Menard, S. (2002). Applied logistic regression analysis ( $2^{\text {nd }}$ ed.). Thousand Oaks, CA: Sage.

Mester, C., Visser, D., Roodt, G., \& Kellerman, R. (2003). Leadership style and its relation to employee attitudes and behaviour. SA Journal of Industrial Psychology, 29(2). doi:10.4102/sajip.v29i2.100

Meyer, B. B., Markgraf, K. M., \& Gnacinski, S. L. (2017). Examining the merit of grit in women's soccer: Questions of theory, measurement, and application. Journal of Applied Sport Psychology, 29(3), 353-366. http://dx.doi.org/10.1080/10413200.2016.1255277

Miao, Q., Newman, A., Schwarz, G., \& Xu, L. (2014). Servant leadership, trust, and the organizational commitment of public sector employees in China. Public Administration, 92(3), 727-743.

Miles, M. B., \& Huberman, A. M. (1984). Qualitative data analysis: A sourcebook of new methods. Thousand Oaks, CA: Sage.

Miles, M. B., Huberman, A. M., \& Saldana, J. (2014). Qualitative data analysis: A method sourcebook. Thousand Oaks, CA: Sage.

Mittal, R., \& Elias, S. M. (2016). Social power and leadership in cross-cultural context. Journal of Management Development, 35(1), 58-74.

Mitchell, G. E., O’Leary, R., \& Gerard, C. (2015). Collaboration and performance: Perspectives from public managers and NGO leaders. Public Performance \& Management Review, 38(4), 684-716.

Mohr, L. B. (1996). The causes of human behavior: Implications for theory and method in the social sciences: Ann Arbor, MI: University of Michigan Press.

Morgado, F. F., Meireles, J. F., Neves, C. M., Amaral, A. C., \& Ferreira, M. E. (2018). Scale development: Ten main limitations and recommendations to improve future research practices. Psicologia: Reflexão e Crítica, 30(1), 3 - 20. 
Morgan, D. L. (2007). Paradigms lost and pragmatism regained: Methodological implications of combining qualitative and quantitative methods. Journal of Mixed Methods Research, 1(1), 48-76.

Morgan, D. L. (2013). Integrating qualitative and quantitative methods: A pragmatic approach. Thousand Oaks, CA: Sage.

Krueger, R. A. (1998). Analyzing and reporting focus group results (Focus Group Kit 6): Thousand Oaks, CA: Sage.

Morris, M. H., \& Jones, F. F. (1999). Entrepreneurship in established organizations: The case of the public sector. Entrepreneurship Theory \& Practice, 24(1), 71-91.

Morse, J. M. (2004). Theoretical saturation. In M. S. Lewis-Beck, A. Bryman, \& T. F. Liao (Eds.), The Sage encyclopedia of social science research methods (p. 1122-1123). Thousand Oaks, CA: Sage.

Munn, K., \& Smith, B. (Eds.). (2008). Applied ontology: An introduction. Frankfurt, Germany: Ontos Verlag.

Murphy, J., Rhodes, M. L., Meek, J. W., \& Denyer, D. (2017). Managing the entanglement: Complexity leadership in public sector systems. Public Administration Review, 77(5), 692-704.

Murphy, L. B. (1965). The widening world of childhood. New York, NY: Basic Books.

Musil, C. M., Jones, S. L., \& Warner, C. D. (1998). Structural equation modeling and its relationship to multiple regression and factor analysis. Research in Nursing \& Health, 21(3), 271-281. doi:10.1002/(SICI)1098-240X(199806)21:3<271::AIDNUR10>3.0.CO;2-G

Namey, E., Guest, G., Thairu, L., \& Johnson, L. (2008). Data reduction techniques for large qualitative data sets. Handbook for team-based qualitative research, 2(1), 137161.

Näswall, K., Kuntz, J., Hodliffe, M., \& Malinen, S. (2015). Employee Resilience Scale (EmpRes): Technical Report. Christchurch, New Zealand: University of Canterbury.

Näswall, K., Malinen, S., Kuntz, J. \& Hodliffe, M. (2019). Employee resilience: Development and validation of a measure. Journal of Managerial Psychology, 34(5), 353-367.

Neal, A., \& Griffin, M. (2002). Safety climate and safety behaviour. Australian Journal of Management, 27, 67-75.

Netemeyer, R. G., Bearden, W. O., \& Sharma, S. (2003). Scaling procedures: Issues and applications. Thousand Oaks, CA: Sage.

Neubert, M. J., Kacmar, K. M., Carlson, D. S., Chonko, L. B., \& Roberts, J. A. (2008). Regulatory focus as a mediator of the influence of initiating structure and servant leadership on employee behavior. Journal of Applied Psychology, 93(6), 12201233.

Neuman, W. L. (2013). Social research methods: Qualitative and quantitative approaches ( $7^{\text {th }}$ ed.). Harlow, UK: Pearson Education.

Ng, T. W. H., Feldman, D. C. (2012). Employee voice behavior: A meta-analytic test of the conservation of resources framework. Journal of Organizational Behavior, 33(2), 216-234. 
Ng, T. W., Eby, L. T., Sorensen, K. L., \& Feldman, D. C. (2005). Predictors of objective and subjective career success: A meta-analysis. Personnel Psychology, 58(2), 367408.

Ng, E. S., Lyons, S. T., \& Schweitzer, L. (2018). Generational career shifts: How Matures, Boomers, Gen Xers, and Millennials view work. Emerald Publishing Limited.

Nguyen, Q., Kuntz, J. R., Näswall, K., \& Malinen, S. (2016). Employee resilience and leadership styles: The moderating role of proactive personality and optimism. New Zealand Journal of Psychology, 45(2), 13-21.

Nikalant, V., Walker, B., Kuntz, J., de Vries, H., Malinen, S., Näswall, K., \& van Heugten, K. (2016). Dynamics of organisational response to a disaster: A study of organisations impacted by earthquakes. In C. M. Hall, S. Malinen, R. Wordsworth, \& R. Vosslamber (Eds.), Business and post-disaster management: Business, organisational and consumer resilience and the Christchurch earthquakes (pp. 3547). Abingdon, UK: Routledge.

Noblet, A., Rodwell, J., \& McWilliams, J. (2006). Organizational change in the public sector: Augmenting the demand control model to predict employee outcomes under New Public Management. Work \& Stress, 20(4), 335-352.

Noblet, A. J., \& Rodwell, J. (2009). Identifying the predictors of employee health and satisfaction in an NPM environment: Testing a comprehensive and non-linear demand-control-support model. Public Management Review, 11(5), 663-683. https://doi.org/10.1080/14719030902798214

Northouse, P. G.. (1997). Leadership: Theory and practice. Thousand Oaks, CA: Sage.

Norušis, M. J. (1982). SPSS introductory guide: Basic statistics and operations. New York, NY: McGraw-Hill.

Nunnally, J. C., Bernstein, I. H., \& Berge, J. M. t. (1967). Psychometric theory (Vol. 226): New York, NY: McGraw-Hill.

Nyambe N., Breen C., Fincham R. (2007) Organisational culture as a function of adaptability and responsiveness in public service agencies. In: Turton A.R., Hattingh H.J., Maree G.A., Roux D.J., Claassen M., Strydom W.F. (Eds.), Governance as a trialogue: Government-society-science in transition (pp. 197214). Berlin: Springer.

O'Leary, R., \& Bingham, L. B. (2009). The collaborative public manager: New ideas for the twenty-first century. Washington, DC: Georgetown University Press.

O'Neill, P., \& Sevastos, P. (2013). The development and validation of a new multidimensional Job Insecurity Measure (JIM): An inductive methodology. Journal of Occupational Health Psychology, 18(3), 338-349. doi:http://dx.doi.org/10.1037/a0033114

O'Reilly, D., \& Reed, M. (2011). The Grit in the oyster: Professionalism, managerialism and leaderism as discourses of UK public services modernization. Organization Studies, 32(8), 1079-1101. doi:10.1177/0170840611416742

O'Toole, L. J. (2015). Networks and networking: The public administrative agendas. Public Administration Review, 75(3), 361-371.

Oc, B. (2018). Contextual leadership: A systematic review of how contextual factors shape leadership and its outcomes. The Leadership Quarterly, 29(1), 218-235. https://doi.org/10.1016/j.leaqua.2017.12.004

OECD (2019). Getting skills right: Future-ready adult learning systems. Paris, France: OECD Publishing. Retrieved from https://doi.org/10.1787/9789264311756-en 
Ortiz-de-Mandojana, N., \& Bansal, P. (2015). The long-term benefits of organizational resilience through sustainable business practices. Strategic Management Journal, 37(8),1615-1631.

Osborne, S. P. (2010). The new public governance: Emerging perspectives on the theory and practice of public governance. Abingdon, UK: Routledge.

Ospina, S. M. (2016). Collective leadership and context in public administration: Bridging public leadership research and leadership studies. Public Administration Review, 77(2), 275-287

Owens, B. P., Wallace, A. S., \& Waldman, D. A. (2015). Leader narcissism and follower outcomes: The counterbalancing effect of leader humility. Journal of Applied Psychology, 100(4), 1203-1213.

Paarlberg, L. E., \& Lavigna, B. (2010). Transformational leadership and public service motivation: Driving individual and organizational performance. Public Administration Review, 70(5), 710-718.

Paauwe, J., \& Farndale, E. (2017). Strategy, HRM, and performance: A contextual approach. Oxford: Oxford University Press.

Page, M. B. (2016). Public leadership: Navigating leadership challenges and operating in service of the common good in an interconnected world. International Journal of Public Leadership, 12(2), 112-128. doi:10.1108/IJPL-12-2015-0030

Pandey, S. K. (2010). Cutback management and the paradox of publicness. Public Administration Review, 70(4), 564-571.

Parasuraman, A., Zeithaml, V. A., \& Berry, L. L. (1988). Servqual: A multiple-item scale for measuring consumer perceptions of service quality. Journal of Retailing, 64(1), $12-40$.

Park, C. L., \& Folkman, S. (1997). Meaning in the context of stress and coping. Review of General Psychology, 1(2), 115-144.

Parris, D. L., \& Peachey, J. W. (2013). A systematic literature review of servant leadership theory in organizational contexts. Journal of Business Ethics, 113(3), 377-393.

Patel, B. (2010). The importance of resilience in leadership. Retrieved from https://nfpsynergy.net/press-release/importance-resilience-leadership\#downloads

Patterson, J. M. (2002). Integrating family resilience and family stress theory. Journal of Marriage and Family, 64(2), 349-360.

Pearce, C. L. (2004). The future of leadership: Combining vertical and shared leadership to transform knowledge work. Academy of Management Perspectives, 18(1), 4757.

Pearce, C. L., Wassenaar, C. L., Berson, Y., \& Tuval-Mashiach, R. (2019). Toward a theory of meta-paradoxical leadership. Organizational Behavior and Human Decision Processes. doi:https://doi.org/10.1016/j.obhdp.2019.03.003

Perryer, C., \& Jordan, C. (2005). The influence of leader behaviors on organizational commitment: A study in the Australian public sector. International Journal of Public Administration, 28(5-6), 379-396.

Pierce, H. R., \& Maurer, T. J. (2009). Linking employee development activity, social exchange and organizational citizenship behavior. International Journal of Training and Development, 13(3), 139-147.

Plimmer, G., \& Cantal, C. (2016). Workplace dynamics in New Zealand public services: A survey report prepared for the Public Service Association (PSA). Te Pukenga Here 
Tikanga Mahi. Wellington, New Zealand: Centre for Labour, Employment and Work, Victoria University of Wellington.

Plimmer, G., Bryson, J., Donnelly, N., Wilson, J., Ryan, B., \& Blumenfeld, S. (2017). The legacy of New Public Management (NPM) on workers, management capabilities, and organisations. New Zealand Journal of Employment Relations, 42(1), 19-34.

Plimmer, G., Gill, D., \& Norman, R. (2011). Skills and people capability in the future state: Needs, barriers and opportunities. In B. Ryan \& D. Gill (Eds.), Future state (pp 281-305). Wellington, New Zealand: VUW Press.

Podsakoff, P. M., MacKenzie, S. B., \& Bommer, W. H. (1996). Transformational leader behaviors and substitutes for leadership as determinants of employee satisfaction, commitment, trust, and organizational citizenship behaviors. Journal of Management, 22(2), 259-298. http://dx.doi.org/10.1016/S0149-2063(96)90049-5

Podsakoff, P. M., MacKenzie, S. B., Lee, J.-Y., \& Podsakoff, N. P. (2003). Common method biases in behavioral research: A critical review of the literature and recommended remedies. Journal of Applied Psychology, 88(5), 879-903.

Podsakoff, P. M., \& Organ, D. W. (1986). Self-reports in organizational research: Problems and prospects. Journal of Management, 12(4), 531-544. http://dx.doi.org/10.1177/014920638601200408

Posner, B. Z., \& Kouzes, J. M. (1988). Development and validation of the leadership practices inventory. Educational and Psychological Measurement, 48(2), 483-496.

Preacher, K. J., \& MacCallum, R. C. (2003). Repairing Tom Swift's electric factor analysis machine. Understanding Statistics, 2(1), 13-43.

Purcell, J., \& Hutchinson, S. (2007). Front-line managers as agents in the HRMperformance causal chain: theory, analysis and evidence. Human Resource Management Journal, 17(1), 3-20.

Ray, R., \& Brown, J. (2015). Reassessing student potential for medical school success: distance traveled, grit, and hardiness. Military Medicine, 180(4), 138-141.

Raykov, T. (1997). Estimation of composite reliability for congeneric measures. Applied Psychological Measurement, 21(2), 173-184.

Redman, T., Plimmer, G., \& Blumenfeld, S. (2012). Trade union delegate leadership and membership commitment: A cross-sectional analysis. Leadership \& Organization Development Journal. 33(8), 750-762.

Ready, D. A., \& Conger, J. A. (2003). Why leadership-development efforts fail. MIT Sloan Management Review, 44(3), 83-88.

Reed, G. E., \& Bullis, R. C. (2009). The impact of destructive leadership on senior military officers and civilian employees. Armed Forces \& Society, 36(1), 5-18. doi:10.1177/0095327X09334994

Rentsch, J. R., \& Hall, R. J. (1994). Members of great teams think alike: A model of team effectiveness and schema similarity among team members. In M. M. Beyerlein \& D. A. Johnson (Eds.), Advances in interdisciplinary studies of work teams: Theories of self-managing work teams (Vol. 1, pp. 223-261). Greenwich, CT: Elsevier Science/JAI Press.

Rescher, N. (1977). Methodological pragmatism: A systems-theoretic approach to the theory of knowledge. Oxford: Blackwell.

Rhoades, L., \& Eisenberger, R. (2002). Perceived organizational support: A review of the literature. Journal of Applied Psychology, 87(4), 698-714. 
Rhodes, R. A. W. (1996). The new governance: Governing without government. Political Studies, 44(4), 652-667.

Rice, K. G., Cole, D. A., \& Lapsley, D. K. (1990). Separation-individuation, family cohesion, and adjustment to college: Measurement validation and test of a theoretical model. Journal of Counseling Psychology, 37(2), 195-202. doi:10.1037/0022-0167.37.2.195

Richardson, H. A., Simmering, M. J., \& Sturman, M. C. (2009). A tale of three perspectives: Examining post hoc statistical techniques for detection and correction of common method variance. Organizational Research Methods, 12(4), 762-800. doi:10.1177/1094428109332834

Robson, C., \& McCartan, K. (2016). Real world research (4 ${ }^{\text {th }}$ ed.). West Sussex, UK: Wiley.

Rorty, R. (1980). Pragmatism, relativism, and irrationalism. Proceedings and Addresses of the American Philosophical Association, 53(6), 717 - 738. doi:10.2307/3131427

Rosaen, C., \& Benn, R. (2006). The experience of transcendental meditation in middle school students: A qualitative report. Explore, 2(5), 422-425. doi:https://doi.org/10.1016/j.explore.2006.06.001

Rousseau, D. M., Sitkin, S. B., Burt, R. S., \& Camerer, C. (1998). Not so different after all: A cross-discipline view of trust. Academy of Management Review, 23(3), 393-404.

Rutter, M. (1979). Protective factors in children's responses to stress and disadvantage. Annals of the Academy of Medicine, Singapore, 8(3), 324-338.

Rutter, M. (1987). Psychosocial resilience and protective mechanisms. American Journal of Orthopsychiatry, 57(3), 316-331. doi:http://dx.doi.org/10.1111/j.19390025.1987.tb03541.x

Rutter, M. (2006). The Promotion of resilience in the face of adversity. In A. ClarkeStewart \& J. Dunn (Eds.), The Jacobs Foundation series on adolescence. Families count: Effects on child and adolescent development (pp. 26-52). New York, NY: Cambridge University Press. http://dx.doi.org/10.1017/CBO9780511616259.003

Ryan, R. M., \& Deci, E. L. (2000). Self-determination theory and the facilitation of intrinsic motivation, social development, and well-being. American Psychologist, 55(1), 68-78.

Salancik, G. R., \& Pfeffer, J. (1978). A social information processing approach to job attitudes and task design. Administrative Science Quarterly, 23(2), 224-253.

Saldaña, J. (2015). The coding manual for qualitative researchers ( $3^{\text {rd }}$ ed.). London, UK: Sage.

Salge, T. O., \& Vera, A. (2012). Benefiting from public sector innovation: The moderating role of customer and learning orientation. Public Administration Review, 72(4), 550-559.

Samba, C., Vera, D., Kong, D., \& Maldonado, T. (2017, August). Organizational resilience and positive leadership: An integrative Framework. Paper presented at Academy of Management Atlanta, GA.

Sandelowski, M., (2008). Theoretical saturation. In L. M. Given, (Ed.), The Sage encyclopedia of qualitative research methods (Vol. 2, p. 875-876). Thousand Oaks, CA: Sage.

Sandelowski, M. J. (1995). Triangles and crystals: on the geometry of qualitative research. Research in Nursing and Health, 18(6), 569-574. 
Santos, J. R. A. (1999). Cronbach's alpha: A tool for assessing the reliability of scales. Journal of Extension, 37(2), 1-5.

Sarkar, M., \& Fletcher, D. (2014). Psychological resilience in sport performers: A review of stressors and protective factors. Journal of Sports Sciences, 32(15), 1419-1434.

Sawalha, I. H. S. (2015). Managing adversity: Understanding some dimensions of organizational resilience. Management Research Review, 38(4), 346-366.

Scandura, T. A., \& Williams, E. A. (2004). Mentoring and transformational leadership: The role of supervisory career mentoring. Journal of Vocational Behavior, 65(3), 448-468. doi:https://doi.org/10.1016/j.jvb.2003.10.003

Schaefer, J. A., \& Moos, R. H. (1992). Life crises and personal growth. In B. N. Carpenter (Ed.), Personal coping: Theory, research, and application (pp. 149-170). Westport, CT: Praeger Publishers/Greenwood Publishing Group.

Schaufeli, W. B., Bakker, A. B., \& Salanova, M. (2006). The measurement of work engagement with a short questionnaire: A cross-national study. Educational and Psychological Measurement, 66(4), 701-716.

Schelvis, R. M., Zwetsloot, G. I., Bos, E. H., \& Wiezer, N. M. J. (2014). Exploring teacher and school resilience as a new perspective to solve persistent problems in the educational sector. Teachers and Teaching, 20(5), 622-637.

Schillemans, T., \& Busuioc, M. (2015). Predicting public sector accountability: From agency drift to forum drift. Journal of Public Administration Research and Theory, 25(1), 191-215.

Schreiber, J. B., Nora, A., Stage, F. K., Barlow, E. A., \& King, J. (2006). Reporting structural equation modeling and confirmatory factor analysis results: A review. The Journal of Educational Research, 99(6), 323-338.

Schriesheim, C. A., Powers, K. J., Scandura, T. A., Gardiner, C. C., \& Lankau, M. J. (1993). Improving construct measurement in management research: Comments and a quantitative approach for assessing the theoretical content adequacy of paperand-pencil survey-type instruments. Journal of Management, 19(2), 385-417.

Schroeder, M. A., Lander, J., \& Levine-Silverman, S. (1990). Diagnosing and dealing with multicollinearity. Western Journal of Nursing Research, 12(2), 175-187.

Schyns, B., \& Schilling, J. (2013). How bad are the effects of bad leaders? A meta-analysis of destructive leadership and its outcomes. The Leadership Quarterly, 24(1), 138158. http://dx.doi.org/10.1016/j.leaqua.2012.09.001

Shaw, J. B., Erickson, A., \& Harvey, M. (2011). A method for measuring destructive leadership and identifying types of destructive leaders in organizations. The Leadership Quarterly, 22(4), 575-590.

Sheard, A. G., Kakabadse, N., \& Kakabadse, A. (2013). Destructive behaviours and leadership: The source of the shift from a functional to dysfunctional workplace. International Journal of Social Science Studies, 1(1), 7389. doi:10.11114/ijsss.v1i1.31

Siebert, D. C., \& Siebert, C. F. (2005). The caregiver role identity scale: A validation study. Research on Social Work Practice, 15(3), 204-212. http://dx.doi.org/10.1177/1049731504272779

Siemsen, E., Roth, A., \& Oliveira, P. (2010). Common method bias in regression models with linear, quadratic, and interaction effects. Organizational Research Methods, 13(3), 456-476. 
Silvia, C., \& McGuire, M. (2010). Leading public sector networks: An empirical examination of integrative leadership behaviors. The Leadership Quarterly, 21(2), 264-277. doi:https://doi.org/10.1016/j.leaqua.2010.01.006

Simmons, J. (2004). Managing in the post-managerialist era: Towards socially responsible corporate governance. Management Decision, 42(3/4), 601-611. doi:10.1108/00251740410518985

Sims, H. P. (1977). The leader as a manager of reinforcement contingencies: An empirical example and a model. In J. G. Hunt \& L. L. Larson (Eds.), Leadership: The cutting edge (pp. 121-137). Carbondale, IL: Southern Illinois University Press.

Sims Jr., H. P., \& Manz, C. C. (1982). Social learning theory: The role of modeling in the exercise of leadership. Journal of Organizational Behavior Management, 3(4), 5563.

Singer, E., \& Ye, C. (2013). The use and effects of incentives in surveys. The Annals of the American Academy of Political and Social Science, 645(1), 112-141. https://doi.org/10.1177/0002716212458082

Skogstad, A., Einarsen, S., Torsheim, T., Aasland, M. S., \& Hetland, H. J. (2007). The destructiveness of laissez-faire leadership behavior. Journal of Occupational Health Psychology, 12(1), 80-92.

Smith, B. W., Dalen, J., Wiggins, K., Tooley, E., Christopher, P., \& Bernard, J. (2008). The brief resilience scale: Assessing the ability to bounce back. International Journal of Behavioral Medicine, 15(3), 194-200. doi:10.1080/10705500802222972

Smith, W. K., \& Lewis, M. W. (2011). Toward a theory of paradox: A dynamic equilibrium model of organizing. Academy of Management Review, 36(2), 381-403.

Smith, W. K., \& Lewis, M. W. (2012). Leadership skills for managing paradoxes. Industrial and Organizational Psychology, 5(2), 227-231.

Smith, W. K., \& Tushman, M. L. (2005). Managing strategic contradictions: A top management model for managing innovation streams. Organization Science, 16(5), 522-536.

Snow, J., \& Mann, M. (2013). Qualtrics survey software: Handbook for research professionals. Provo, UT: Qualtrics Labs, Inc.

Snyder, C. R., \& Lopez, S. J. (Eds.). (2009). Oxford handbook of positive psychology (2nd ed.). New York, NY: Oxford University Press.

Spears, L. C. (Ed.). (1998). Insights on leadership: Service, stewardship, spirit, and servant-leadership. New York, NY: Wiley.

Spector, P. E. (1987). Method variance as an artifact in self-reported affect and perceptions at work: Myth or significant problem? Journal of Applied Psychology, 72(3), 438.

Spector, P. E. (2006). Method variance in organizational research: Truth or urban legend? Organizational Research Methods, 9(2), 221-232. doi:10.1177/1094428105284955

Spector, P. E. (2019). Do not cross me: Optimizing the use of cross-sectional designs. Journal of Business and Psychology, 34(2), 125-137.

Spector, P. E., \& Brannick, M. T. (2010). Methodological urban legends: The misuse of statistical control variables. Organizational Research Methods, 14(2), 287-305. doi:10.1177/1094428110369842 
State Services Commission. (2017a). Workforce. Retrieved from http://www.ssc.govt.nz/public-service-workforce-data/hrc-workforce

State Services Commission. (2017b). Workforce diversity. Retrieved from http://www.ssc.govt.nz/public-service-workforce-data/hrc-diversity

State Services Commission (2018). Leadership and talent - Senior leaders. Retrieved from: https://ssc.govt.nz/resources/leadershipandtalent-seniorleaders/

Stats New Zealand. (2015). Occupation classification. Retrieved from http://www.stats.govt.nz/surveys_and_methods/methods/classifications-andstandards/classification-related-stats-standards/occupation.aspx

Steinhardt, M., \& Dolbier, C. (2008). Evaluation of a resilience intervention to enhance coping strategies and protective factors and decrease symptomatology. Journal of American College Health, 56(4), 445-453.

Steup, M. (2005). Epistemology. In Stanford encyclopedia of philosophy. Stanford, CA: Stanford University.

Stevens, J. P. (2012). Applied multivariate statistics for the social sciences ( $5^{\text {th }}$ ed.). New York, NY: Routledge.

Stevenson, J. R. (2014). Organisational resilience after the Canterbury earthquakes: A contextual approach (Doctoral dissertation, Canterbury University, Christchurch, New Zealand). Retrieved from https://ir.canterbury.ac.nz/handle/10092/10032

Stewart, D. W., \& Shamdasani, P. N. (2014). Focus groups: Theory and practice ( $3^{\text {rd }}$ ed.). Thousand Oaks, CA: Sage.

Stewart, G. L., Courtright, S. H., \& Manz, C. C. (2010). Self-leadership: A multilevel review. Journal of Management, 37(1), 185-222. doi:10.1177/0149206310383911

Stewart, M., Reid, G., \& Mangham, C. (1997). Fostering children's resilience. Journal of Pediatric Nursing, 12(1), 21-31.

Stoker, G. (2006). Public value management: A new narrative for networked governance? The American Review of Public Administration, 36(1), 41-57.

Stokes, P., Smith, S., Wall, T., Moore, N., Rowland, C., Ward, T., \& Cronshaw, S. (2018). Resilience and the (micro-)dynamics of organizational ambidexterity: Implications for strategic HRM. The International Journal of Human Resource Management, 1-36. doi:10.1080/09585192.2018.1474939

Sun, J. (2005). Assessing goodness of fit in confirmatory factor analysis. Measurement and Evaluation in Counseling and Development, 37(4), 240-256.

Tabachnick, B. G., \& Fidell, L. S. (2007). Using multivariate statistics (5th ed.). Boston, MA: Allyn \& Bacon/Pearson Education.

Tashakkori, A., \& Teddlie, C. (Eds.). (2010). Sage Handbook of mixed methods in social \& behavioral research. Thousand Oaks, CA: Sage.

Taylor, J. (2017). Management of Australian water utilities: The significance of transactional and transformational leadership. Australian Journal of Public Administration, 76(1), 18-32.

Tepper, B. J., \& Taylor, E. C. (2003). Relationships among supervisors' and subordinates' procedural justice perceptions and organizational citizenship behaviors. Academy of Management Journal, 46(1), 97-105.

Thorne, S. (2000). Data analysis in qualitative research. Evidence-Based Nursing, 3(3), 6870. 
Tims, M., Bakker, A. B., \& Derks, D. (2012). Development and validation of the job crafting scale. Journal of Vocational Behavior, 80(1), 173-186.

Tucker, S., \& Turner, N. (2011). Young worker safety behaviors: Development and validation of measures. Accident Analysis \& Prevention, 43(1), 165-175.

Tugade, M. M., \& Fredrickson, B. L. (2004). Resilient individuals use positive emotions to bounce back from negative emotional experiences. Journal of Personality and Social Psychology, 86(2), 320.

Tummers, L., \& Knies, E. (2016). Measuring public leadership: Developing scales for four key public leadership roles. Public Administration, 94(2), 433-451.

Uhl-Bien, M., \& Arena, M. (2017). Complexity leadership: Enabling people and organizations for adaptability. Organizational Dynamics, 46(1), 9-20. doi:https://doi.org/10.1016/j.orgdyn.2016.12.001

Uhl-Bien, M., Marion, R., \& McKelvey, B. (2007). Complexity leadership theory: Shifting leadership from the industrial age to the knowledge era. The Leadership Quarterly, 18(4), 298-318.

Uhl-Bien, M., \& Marion, R. (2009). Complexity leadership in bureaucratic forms of organizing: A meso model. The Leadership Quarterly, 20(4), 631-650.

Ungar, M. (2012). Social ecologies and their contribution to resilience. In M. Ungar (Ed.), The social ecology of resilience: A handbook of theory and practice (pp. 13-31). New York, NY: Springer Science + Business Media. http://dx.doi.org/10.1007/978-1-4614-0586-3_2

Uzzi, B. (1997). Social structure and competition in interfirm networks: The paradox of embeddedness. Administrative Science Quarterly, 42(1), 35-67.

Vaccaro, I. G., Jansen, J. J., Van Den Bosch, F. A., \& Volberda, H. W. (2012). Management innovation and leadership: The moderating role of organizational size. Journal of Management Studies, 49(1), 28-51.

Valero, J. N., Jung, K., \& Andrew, S. A. (2015). Does transformational leadership build resilient public and nonprofit organizations? Disaster Prevention and Management: An International Journal, 24(1), 4-20. doi:10.1108/DPM-04-20140060

Välikangas L. (2016) Strategic resilience. In M. Augier \& D. Teece (Eds.), The Palgrave encyclopedia of strategic management (pp.1-4). London, UK: Palgrave Macmillan.

van Breda, A. D. (2011). Resilient workplaces: An initial conceptualization. Families in Society, 92(1), 33-40. doi:10.1606/1044-3894.4059

Van der Weide, J., \& Wilderom, C. (2004). Deromancing leadership: what are the behaviours of highly effective middle managers?. International Journal of Management Practice, 1(1), 3-20.

Van Dierendonck, D., \& Nuijten, I. (2011). The servant leadership survey: Development and validation of a multidimensional measure. Journal of Business Psychology and Health, 26(3), 249-267.

Van Dyne, L., \& LePine, J. A. (1998). Helping and voice extra-role behaviors: Evidence of construct and predictive validity. Academy of Management Journal, 41(1), 108119. doi: $10.5465 / 256902$

Van Thiel, S., \& Leeuw, F. L. (2002). The performance paradox in the public sector. Public Performance \& Management Review, 25(3), 267-281. 
Van Wart, M. (2014). Dynamics of leadership in public service: Theory and practice (2 ${ }^{\text {nd }}$ ed.). Abingdon, UK: Routledge.

Vera, D., \& Crossan, M. (2004). Strategic leadership and organizational learning. Academy of Management Review, 29(2), 222-240.

Vera, M., Rodríguez-Sánchez, A. M., \& Salanova, M. (2017). May the force be with you: Looking for resources that build team resilience. Journal of Workplace Behavioral Health, 32(2), 119-138.

Verreynne, M. L., Ho, M., \& Linnenluecke, M. (2018). Editorial for the special issue on: organizational resilience and the entrepreneurial firm. International Journal of Entrepreneurial Behavior \& Research, 24(7), 1122-1128.

Vogt, D. S., King, D. W., \& King, L. A. (2004). Focus groups in psychological assessment: Enhancing content validity by consulting members of the target population. Psychological Assessment, 16(3), 231-243. doi:http://dx.doi.org/10.1037/10403590.16.3.231

Vogt, W. P. (1993). Dictionary of statistics and methodology: A nontechnical guide for the social sciences. Thousand Oaks, CA: Sage.

Vogus, T. J., \& Sutcliffe, K. M. (2007, October). Organizational resilience: Towards a theory and research agenda. Paper presented at the 2007 IEEE International Conference on Systems, Man and Cybernetics, Montreal, Canada.

Wakabayashi, M., Graen, G., Graen, M., \& Graen, M. (1988). Japanese management progress: Mobility into middle management. Journal of Applied Psychology, 73(2), 217-227.

Waldman, D. A., \& Bowen, D. E. (2016). Learning to be a paradox-savvy leader. The Academy of Management Perspectives, 30(3), 316-327.

Wallace, M., \& Hoyle, E. (2012). The dynamics of irony in organizational change: Coping with a school merger. Public Administration, 90(4), 974-999.

Wallace, M., \& Pocklington, K. (2002). Managing complex educational change: Largescale reorganisation of schools. London, UK: Routledge.

Wällstedt, N., \& Almqvist, R. (2015). From 'either or'to 'both and': Organisational management in the aftermath of NPM. Scandinavian Journal of Public Administration, 19(2), 7-25.

Walumbwa, F. O., Avolio, B. J., Gardner, W. L., Wernsing, T. S., \& Peterson, S. (2008). Authentic leadership: Development and validation of a theory-based measure. Journal of Management, 34(1), 89-126.

Wang, G., \& Netemeyer, R. G. (2002). The effects of job autonomy, customer demandingness, and trait competitiveness on salesperson learning, self-efficacy, and performance. Journal of the Academy of Marketing Science, 30(3), 217-228.

Wang, H., Law, K. S., Hackett, R. D., Wang, D., \& Chen, Z. X. (2005). Leader-member exchange as a mediator of the relationship between transformational leadership and followers' performance and organizational citizenship behavior. Academy of Management Journal, 48(3), 420-432.

Wang, M., Haertel, G., \& Walberg, H. (1994). Educational resilience in inner cities. In M. Wang \& E. Gordon (Eds.). Educational resilience in inner-city America; Challenges and prospects (pp. 45-72) Hillsdale, NJ: Erlbaum.

Wang, Y., \& Feng, H. (2012). Customer relationship management capabilities: Measurement, antecedents and consequences. Management Decision, 50(1), 115129. 
Warner, M. E. (2008). Reversing privatization, rebalancing government reform: Markets, deliberation and planning. Policy and Society, 27(2), 163-174.

Wayne, S. J., Shore, L. M., Bommer, W. H., \& Tetrick, L. E. (2002). The role of fair treatment and rewards in perceptions of organizational support and leader-member exchange. Journal of Applied Psychology, 87(3), 590-598. http://dx.doi.org/10.1037/0021-9010.87.3.590

Wayne, S. J., Shore, L. M., \& Liden, R. C. (1997). Perceived organizational support and leader-member exchange: A social exchange perspective. Academy of Management Journal, 40(1), 82-111. doi:10.2307/257021

Weibel, A., \& Six, F. J. (2013). Trust and control: The role of intrinsic motivation. In R. Bachmann \& A. Zaheer (Eds.), Handbook of advances in trust research (pp. 5781). Cheltenham, UK: Edward Elgar.

Weinberger, D. A., Schwartz, G. E., \& Davidson, R. J. (1979). Low-anxious, high-anxious, and repressive coping styles: psychometric patterns and behavioral and physiological responses to stress. Journal of Abnormal Psychology, 88(4), 369380 .

Weingart, L., \& Jehn, K. A. (2017). Manage intra-team conflict through collaboration. In E. A. Locke (Ed.), Handbook of principles of organizational behaviour, (2nd ed., pp 327-346). Chichester, UK: Wiley.

Wensing, M., Mainz, J., Kramme, O., Jung, H. P., \& Ribacke, M. (1999). Effect of mailed reminders on the response rate in surveys among patients in general practice. Journal of Clinical Epidemiology, 52(6), 585-587.

Werner, E. E. (2000). Protective factors and individual resilience. In J. P. Shonkoff \& S. J. Meisels (Eds.), Handbook of early childhood intervention ( $2^{\text {nd }}$ ed., pp. 115-132) New York, NY: Cambridge Univeristy Press.

Whitener, E. M., Brodt, S. E., Korsgaard, M. A., \& Werner, J. M. (1998). Managers as initiators of trust: An exchange relationship framework for understanding managerial trustworthy behavior. Academy of Management Review, 23(3), 513530.

Willis, G. B. (2004). Cognitive interviewing: A tool for improving questionnaire design. Thousand Oaks, CA: Sage.

Winters, D., \& Latham, G. P. (1996). The effect of learning versus outcome goals on a simple versus a complex task. Group and Organization Management, 21(2), 236250.

Wilson, S., Cummings, S., Jackson, B., Proctor-Thomson, S. (2017). Revitalising leadership: Putting theory and practice into context. London, UK: Routledge.

Witesman, E. M., \& Wise, C. R. (2009). The centralization/decentralization paradox in civil service reform: How government structure affects democratic training of civil servants. Public Administration Review, 69(1), 116-127.

Wolters, C. A., \& Hussain, M. (2015). Investigating grit and its relations with college students' self-regulated learning and academic achievement. Metacognition and Learning, 10(3), 293-311.

Woolsey, L. K. (1986). The critical incident technique: An innovative qualitative method of research. Canadian Journal of Counselling Psychotherapy/Revue canadienne de counseling et de psychothérapie, 20(4). 242-254. 
Worthington, R. L., \& Whittaker, T. A. (2006). Scale development research: A content analysis and recommendations for best practices. The Counseling Psychologist, 34(6), 806-838.

Wright, B. E., \& Kim, S. (2004). Participation's influence on job satisfaction: The importance of job characteristics. Review of Public Personnel Administration, 24(1), 18-40.

Wright, B. E., Moynihan, D. P., \& Pandey, S. K. (2012). Pulling the levers: Transformational leadership, public service motivation, and mission valence. Public Administration Review, 72(2), 206-215.

Wu, C.-H., Griffin, M. A., \& Parker, S. K. (2015). Developing agency through good work: Longitudinal effects of job autonomy and skill utilization on locus of control. Journal of Vocational Behaviour, 89, 102-108.

Wynd, C. A., Schmidt, B., \& Schaefer, M. A. (2003). Two quantitative approaches for estimating content validity. Western Journal of Nursing Research, 25(5), 508-518.

Yang, K., \& Pandey, S. K. (2008). How do perceived political environment and administrative reform affect employee commitment? Journal of Public Administration Research Theory, 19(2), 335-360.

Yeager, D. S., \& Dweck, C. S. (2012). Mindsets that promote resilience: When students believe that personal characteristics can be developed. Educational Psychologist, 47(4), 302-314.

Yost, P. R. (2016). Resilience practices. Industrial and Organizational Psychology, 9(2), 475-479. doi:10.1017/iop.2016.42

Youssef, C. M., \& Luthans, F. (2007). Positive organizational behavior in the workplace the impact of hope, optimism, and resilience. Journal of Management, 33(5), 774800.

Yu, C. H. (2003). Resampling methods: Concepts, applications, and justification. Practical Assessment, Research \& Evaluation, 8(19), 1-23.

Yukl, G. A. (2002). Leadership in organizations (5 ${ }^{\text {th }}$ ed.). Upper Saddle River, NJ: Prentice Hall.

Yukl, G.A. (1989), Managerial leadership: A review of theory and research. Journal of Management, 15(2), 251-289.

Zaccaro, S. J. (2001). The nature of executive leadership: A conceptual and empirical analysis of success. Washington, DC: American Psychological Association.

Zautra, A. J., \& Reich, J. W. (2011). Resilience: The meanings, methods, and measures of a fundamental characteristic of human adaptation. In S. Folkman (Ed.), Oxford library of psychology. The Oxford handbook of stress, health, and coping (pp. 173185). New York, NY: Oxford University Press.

Zeffane, R. (1994). Patterns of organizational commitment and perceived management style: A comparison of public and private sector employees. Human Relations, 47(8), 977-1010.

Zeier, K., Plimmer, G., \& Franken, E. (2018). Developing shared leadership in a public organisation: Processes, paradoxes and consequences. Journal of Management \& Organization, 1-18. doi:https://doi.org/10.1017/jmo.2018.78

Zhang, W., Wang, H., \& Pearce, C. L. (2014). Consideration for future consequences as an antecedent of transformational leadership behavior: The moderating effects of perceived dynamic work environment. The Leadership Quarterly, 25(2), 329-343. doi:https://doi.org/10.1016/j.leaqua.2013.09.002 
Zhang, Y., \& Chen, C. C. (2013). Developmental leadership and organizational citizenship behavior: Mediating effects of self-determination, supervisor identification, and organizational identification. The Leadership Quarterly, 24(4), 534-543.

Zhang, Y., Waldman, D. A., Han, Y.-L., \& Li, X.-B. (2015). Paradoxical leader behaviors in people management: Antecedents and consequences. Academy of Management Journal, 58(2), 538-566.

Zhao, X., Lynch Jr, J. G., \& Chen, Q. (2010). Reconsidering Baron and Kenny: Myths and truths about mediation analysis. Journal of Consumer Research, 37(2), 197-206.

Zheng, W., Yang, B., \& McLean, G. N. (2010). Linking organizational culture, structure, strategy, and organizational effectiveness: Mediating role of knowledge management. Journal of Business Research, 63(7), 763-771. 


\section{APPENDIX A: FIELDS, LEVELS, AND DEFINITIONS OF RESILIENCE}

Table A: Fields, levels, and definitions of resilience

\begin{tabular}{|c|c|c|c|}
\hline Field & $\begin{array}{l}\text { Level/unit } \\
\text { of analysis }\end{array}$ & Definition/s & Other components and/or notes on conceptualisation \\
\hline \multirow[t]{3}{*}{ Psychology } & Child & $\begin{array}{l}\text { A class of phenomena “characterised by good outcomes in } \\
\text { spite of serious threats to [a child's] adaptation or } \\
\text { development” (Masten, 2001, p. 228) }\end{array}$ & $\begin{array}{l}\text { Emerges through normal processes of human adaptation, including: } \\
\text { - Cognition development } \\
\text { - Behaviour regulation } \\
\text { - Environmental interactions } \\
\text { (Armstrong, Birnie-Lefcovitch, \& Ungar, 2005; Masten, 2001) }\end{array}$ \\
\hline & Adult & $\begin{array}{l}\text { "The ability of adults in otherwise normal circumstances who } \\
\text { are exposed to an isolated and potentially highly disruptive } \\
\text { event, such as the death of a close relation or a violent or life- } \\
\text { threatening situation, to maintain relatively stable, healthy } \\
\text { levels of psychological and physical functioning” (Bonanno, } \\
\text { 2004, p. 20) }\end{array}$ & $\begin{array}{l}\text { Emphasis on trauma and adversity in evoking a resilient response } \\
\text { (Bonanno, 2005). } \\
\text { Purported elements supporting adult resilience include: } \\
\text { - Positive emotions } \\
\text { - Coping } \\
\text { - Hardiness } \\
\text { (Bonanno, 2004; Kobasa, Maddi, \& Kahn, 1982; Weinberger, Schwartz, } \\
\text { \& Davidson, 1979) }\end{array}$ \\
\hline & Family & $\begin{array}{l}\text { "The processes by which families are able to adapt and } \\
\text { function competently following exposure to significant } \\
\text { adversity or crises" (Patterson, 2002) }\end{array}$ & $\begin{array}{l}\text { Families are most resilient when they can effectively fulfil the functions } \\
\text { of: } \\
\text { - Membership formation for a sense of collective belonging } \\
\text { - Economic support for basic needs } \\
\text { - Nurturing, education, and socialisation to promote personal } \\
\text { development and instil values and norms }\end{array}$ \\
\hline
\end{tabular}


- Protection of members that are vulnerable, i.e. children, elderly, ill or disabled

(Patterson, 2002)

\begin{tabular}{|c|c|c|c|}
\hline Ecology & Ecosystem & $\begin{array}{l}\text { No precise definition, but described as "the buffer capacity or } \\
\text { the ability of a system to absorb perturbations, or the } \\
\text { magnitude of disturbance that can be absorbed before a } \\
\text { system changes its structure by changing the variables and } \\
\text { processes that control behaviour" (Adger, 2000, p. 349) }\end{array}$ & $\begin{array}{l}\text { Its conceptualisation involves four key principles: } \\
\text { - Resilience is facilitated by social and physical environmental factors } \\
\text { - Facilitative factors are complex, infinite, and context-dependent } \\
\text { - Resilience is a culturally, temporally, historically, contextually } \\
\text { embedded construct } \\
\text { (Ungar, 2012) }\end{array}$ \\
\hline \multirow[t]{3}{*}{ Education } & Student & $\begin{array}{l}\text { "The heightened likelihood of success in school and other } \\
\text { life accomplishments despite environmental adversities } \\
\text { brought about by early traits, conditions, and experiences" } \\
\text { (M. Wang, Haertel, Walberg, \& prospects, 1994). }\end{array}$ & $\begin{array}{l}\text { Comprised of: } \\
\text { - } \text { Social competence } \\
\text { - } \text { Problem-solving skills } \\
\text { - } \text { Autonomy } \\
\text { - } \quad \text { A sense of purpose } \\
\text { (Benard, 1993) }\end{array}$ \\
\hline & Teacher & $\begin{array}{l}\text { A capacity which "enables teachers to persist in the face of } \\
\text { challenges" (Beltman et al., 2015, p. 185). }\end{array}$ & $\begin{array}{l}\text { Protective factors of teacher resilience include: } \\
\text { - } \quad \text { Personal attributes, i.e. altruism and humour } \\
\text { - } \quad \text { Self-efficacy } \\
\text { - } \quad \text { Coping skills } \\
\text { - } \quad \text { Teaching skills } \\
\text { - } \quad \text { Professional reflection and growth } \\
\text { - Self-care } \\
\text { (Beltman et al., 2015) }\end{array}$ \\
\hline & School & $\begin{array}{l}\text { "The ability of an individual, team or school to adapt to } \\
\text { changing demands, to recover, and to remain vigorous after }\end{array}$ & $\begin{array}{l}\text { Comprised of: } \\
\text { - Anticipation and preparation }\end{array}$ \\
\hline
\end{tabular}


the changes have occurred" (Schelvis, Zwetsloot, Bos, \& Wiezer, 2014)
- Awareness and monitoring

- Responding and recovering

- Learning and adapting

(Schelvis et al., 2014)

\begin{tabular}{|c|c|c|c|}
\hline \multirow[t]{3}{*}{ Management } & Employee & $\begin{array}{l}\text { "The capacity of employees to utilise resources to } \\
\text { continually adapt and flourish at work, even when faced with } \\
\text { challenging circumstances” (Kuntz, Näswall, \& Malinen, } \\
\text { 2016, p. 460). }\end{array}$ & $\begin{array}{l}\text { A behavioural capacity, comprised of : } \\
\text { - Network leveraging, } \\
\text { - Learning, } \\
\text { - } \quad \text { and Adaptability } \\
\text { (Kuntz et al., 2017) }\end{array}$ \\
\hline & Organisation & $\begin{array}{l}\text { An organisation’s ability “to withstand systematic } \\
\text { discontinuities as well as the capability to adapt to new risk } \\
\text { environments” (Burnard \& Bhamra, 2011, p. 5583). }\end{array}$ & $\begin{array}{l}\text { Organisational resilience is an emergent property residing in } \\
\text { - Individuals, } \\
\text { - Systems } \\
\text { - Structures } \\
\text { - } \text { Procedures } \\
\text { - Infrastructure } \\
\text { - } \quad \text { HR Practices and Policies of an organisation. } \\
\text { (Burnard \& Bhamra, 2011; Lengnick-Hall et al., 2011) }\end{array}$ \\
\hline & Workplace & $\begin{array}{l}\text { "The characteristics, dimensions, and properties of } \\
\text { workplaces that help workplaces to be resistant to disruption } \\
\text { in the face of change and adaptive in the face of crisis } \\
\text { situations" (van Breda, 2011, p. 35). }\end{array}$ & $\begin{array}{l}\text { As a social system, the workplace is made up of: } \\
\text { - Characteristics and } \\
\text { - Processes. } \\
\text { Protective factors, such as: } \\
\text { - Supportive networks } \\
\text { - Problem solving } \\
\text { - Harmony, } \\
\text { all contribute to the resilience of a workplace system (van Breda, 2011). }\end{array}$ \\
\hline
\end{tabular}




\section{APPENDIX B: $\quad$ ETHICS DOCUMENTS (PHASES 1, 2 \& 3)}

\section{B.1: Participant information email (Phase 1)}

\section{Building employee resilience in the public sector}

Participant Information

With [name of organisation], Victoria University is researching what public sector organisations can do to help employees grow and develop in their jobs. Your participation would be much appreciated - please have your say.

I am asking a number of supervisors and employees currently working at MPI to help explain what public sector organisations and supervisors do that helps or hinders growth and development. The survey covers questions about the organisation, leadership and teams. The survey is anonymous, and should not take any longer than 15 minutes to complete (probably less).

When you are taking the survey:

- If a question is not relevant to you -- please move on to the next question.

- You can close the survey tab or window at any time and return to it later. Your answers will be saved (to reload your survey, simply access the link sent to you in the invitation email).

- When you have completed the survey, you will be presented with a message thanking you for your participation.

Your anonymous responses will be accessed only by myself and my supervisors, and will not have your name attached to them. Data will be secured in a password protected file. Only summary information about patterns and trends across the organisation will be reported back to [name of organisation].

After the survey responses are analysed the findings may be used for academic publications, conference presentations, and public reports. The findings of this research will be used for a Masters thesis that is publically available. The thesis will be submitted for marking to the School of Management, and subsequently deposited in the University Library. All data collected from participants will be kept in a password protected file and will be destroyed within 5 years after the completion of the project.

Your answers to this survey will be anonymous. Your participation in this survey is taken as consent.

Please do not hesitate to contact me or my primary supervisor (details below) if you have any questions:

Esme [Franken], School of Management, Victoria University of Wellington esme.cleave@vuw.ac.nz

Dr Geoff Plimmer, School of Management, Victoria University

geoff.plimmer@vuw.ac.nz 


\title{
B.2: Initial email to potential participants (Phase 2)
}

\author{
Good Afternoon,
}

You have been invited as a potential interview participant for the VUW-[name of organisation] Employee Resilience Study. The purpose of the interview is to identify what supervisors do to either help or hinder employee growth and development at work. Shortly you will receive an email invitation from Esme [Franken], a VUW post graduate student, to participate in an interview. Participation is voluntary and if you choose to participate, it will be undertaken at a location that works best for you. If you are away from Wellington, a phone or Skype interview can be arranged.

The criteria for invitation was a) a mix of job types and levels in the organisation, then b) random selection.

The interview's purpose is to build upon the recent survey done at [name of organisation] on employee resilience. [Name of organisation] will be able to use both the survey and interviews to identify how we can improve practices that help both employees and [name of organisation] with leadership and employee resilience. HR will incorporate the findings into current leadership development and assessment tools and other HR practices and resources. If you choose to participate in this interview, you can request to be provided with a summary of the findings.

Should you participate in the interview, your identity will be kept confidential to the VUW researchers. The interview should not exceed more than half an hour and will be recorded. The interviewer will not use any quotations where participants or their employer can be identified. You are able to withdraw from the project within two weeks of the interview. Any interview data collected up to that point will be destroyed. All data collected from interview participants will be kept in a password protected file and will be destroyed within 5 years after the completion of the project. More information about the interviews will be given in the upcoming email from VUW.

Thanks in advance for your support,

[name of organisation] 


\section{B.3: Example email to participant (Phase 3)}

Good morning [name],

My name is Esme Franken, and I am a PhD student in the School of Management at Victoria University. I am doing a thesis on employee resilience in the public sector, aimed at identifying what managerial factors help people to grow and develop in their jobs.

I am inviting you to participate in an interview that should last no longer than 30 minutes. Participation is voluntary. [name of organisation] staff have been selected to ensure a mix of job types and levels in the organisation.

Attached is an interview information sheet, which covers issues like confidentiality and other university ethics matters. If you are happy to participate, we can organise a time and location that suits you.

I am planning for the interview to take place between Thursday the $15^{\text {th }}$ and Friday the $30^{\text {th }}$ March at an offsite location nearby, but I am flexible. If you are located outside of Wellington, we can do the interview via phone or Skype.

Below is a list of preliminary times that I am available. Please indicate any that suit you, and I can send through an email invite. If not, send through any times that suit you outside of these hours and I can let you know if they work.

Thursday $15^{\text {th }}$ March: Anytime between 10am and 12pm, and then between 2pm and 4pm in the afternoon.

Friday $16^{\text {th }}$ March: Anytime between 11 am and 1pm, and then between 2pm and $4 p m$ in the afternoon.

Monday $19^{\text {th }}$ March: Free until 2pm.

Tuesday $20^{\text {th }}$ March: All day.

OR - If a later date suits you - name a time and I will do my best to work around it!

I really appreciate the time you are taking to consider your involvement in this research project and look forward to your reply. If you have any questions, please do not hesitate to email or call me.

Many thanks,

Esme Franken

School of Management

Victoria University, Wellington

0279436292 


\section{B.4: Participant information sheet (Phases 2 \& 3)}

\section{Building employee resilience in the public sector Participant Information Sheet - Interviews}

My name is Esme [Franken], and I am conducting research at [name of organisation] as part of an $\mathrm{PhD}$ thesis. This research project studies what public sector organisations can do to help employees grow and develop in their jobs.

I am asking a number of supervisors and employees currently working at [name of organisation] to help explain what supervisors and organisations do to help or hinder growth and development. This stage of the project involves an interview that should not exceed more than half an hour. It will be undertaken at an offsite location and will be recorded. An interview summary will be available on request and you can give comments and feedback if you wish.

All material collected will be kept confidential, and will be viewed only by myself and my supervisor. The project is based at Victoria University of Wellington, and is being conducted as part of a PhD in Human Resource Management and Industrial Relations.

Should you participate, your identity will be kept confidential. In addition to this, the name of your employer will not be made open to the public. I will not use any quotations where participants or their employer can be identified. Should you wish to withdraw from the project, you may do so within two weeks of the interview by emailing esme.cleave@vuw.ac.nz. Any interview data collected up to that point will be destroyed. All data collected from participants will be kept in a password protected file and will be destroyed within 5 years after the completion of the project.

After the interviews and other data are analysed the findings may be used for academic publications, conference presentations, and public reports. The findings of this research will be used for a PhD thesis that is publically available. The thesis will be submitted for marking to the School of Management, and subsequently deposited in the University Library.

Permission to undertake this research has been obtained by management at [name of organisation]. This research has also been approved by the Victoria University Human Ethics Committee with approval number 00000236560. If you have any ethics queries, you may contact the Human Ethics Committee Convener, AProf Susan Corbett at susan.corbett@vuw.ac.nz, or by telephone on 044635480.

Please do not hesitate to contact the researcher or primary supervisor (details below) if you have any questions.

Researcher:
Esme Cleave, School of Management, Victoria
University of Wellington
esme.cleave@vuw.ac.nz

Primary Supervisor:

Dr Geoff Plimmer, School of Management, Victoria University of Wellington, 463-5700, geoff.plimmer@vuw.ac.nz 


\section{B.5: Participant consent form (Phases $2 \& 3$ )}

\section{Building employee resilience in the public sector Participant Consent Form - Interviews}

I have read the Information Sheet and the project has been explained to me. My questions have been answered to my satisfaction. I understand that I can ask further questions at any time.

I understand that:

- I may withdraw from this study within two weeks of the interview.

- The information I provide will be destroyed 5 years after the research is finished.

- Any information I provide will be kept confidential to the researcher and the supervisors.

- Collected data will be secured in password protected files.

- The results will be used for a $\mathrm{PhD}$ thesis and a summary of the results may be used in academic reports and/or presented at conferences.

- My name will not be used in reports, nor will any information that would identify me.

I agree:

- To take part in an audio recorded interview

- That I may be identified by occupational category (job type) only

I would like a summary of my interview and have added my email address below

Signature of participant:

Name of participant:

Date:

Email address (optional):

\begin{tabular}{|l|l|}
\hline Researcher: & Primary Supervisor: \\
Esme Cleave, School of Management, Victoria & Dr Geoff Plimmer, School of Management, \\
University of Wellington & Victoria University of Wellington, 463-5700, \\
esme.cleave@vuw.ac.nz & geoff.plimmer@vuw.ac.nz \\
\hline
\end{tabular}




\section{APPENDIX C: FACTOR LOADINGS FOR PARADOXICAL \\ LEADERSHIP}

Table B: Pattern matrix

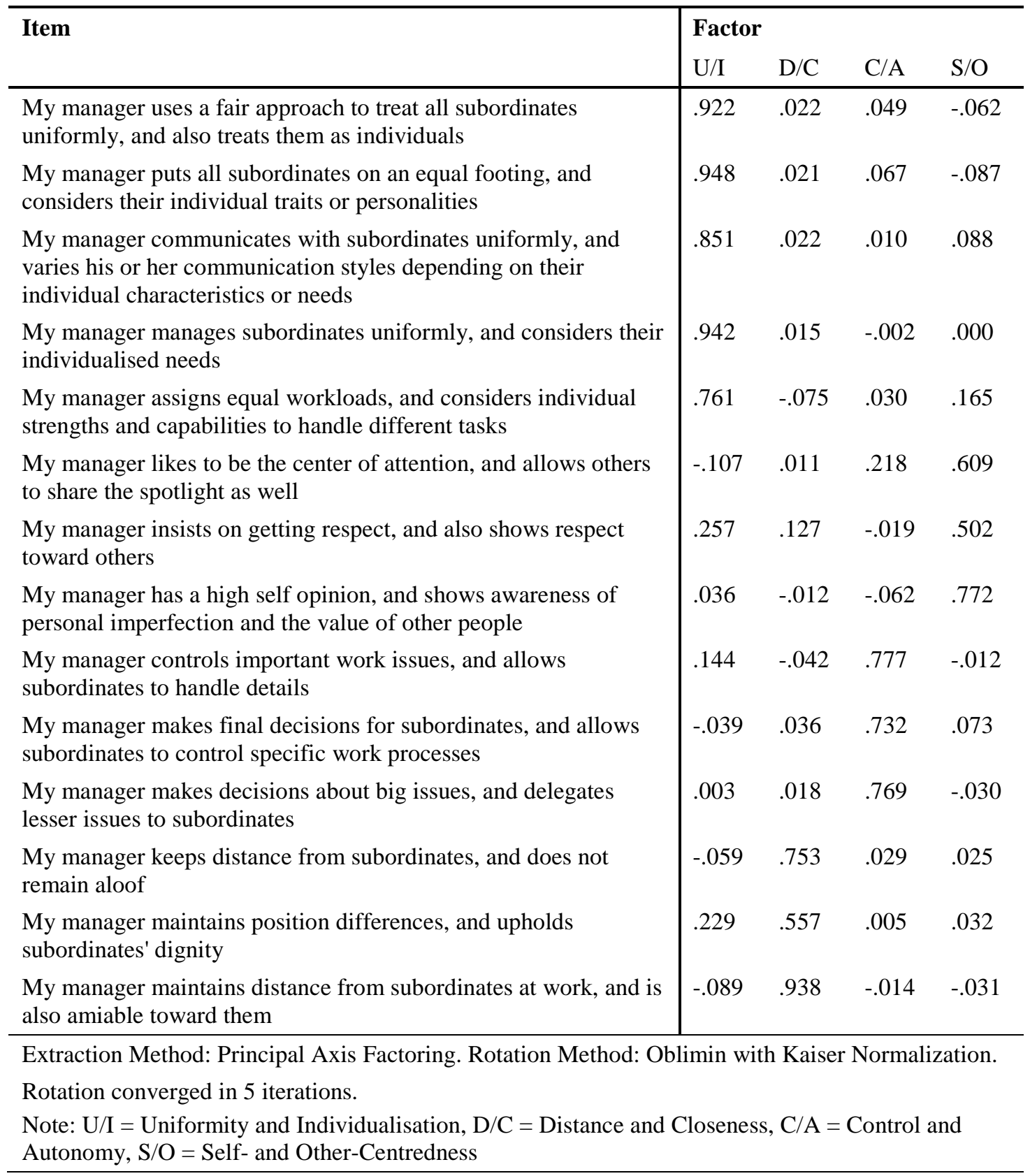




\section{APPENDIX D: INTERVIEW GUIDES (PHASES 2 \& 3)}

\section{D.1: Interview Guide (Phase 2)}

Thanks for meeting with me today, this interview should only last about half an hour, if it goes over we can cut it short or keep going depending on how it goes...

I take it you already know a bit about the study from the information sheet but to clarify - I am mostly interested in what managers and organisations can do to help people grow and remain resilient at work.

Do you have any questions before we get started?

So, the body of the interview will be structured around challenges and experienced by you and those you manage. I want to know what you, as a manager (or employee), think makes teams and employees better manage these challenges, as that is a core part of being resilient.

But I thought it would be good to start with some general questions about the work you do.

1. What do you do at [name of organisation]?

- How long have you been here?

- Could you tell me a bit about what you like/dislike about working in the public sector?

2. Interested to know about the nature of challenges you face in your work, so what are some of the typical day to day challenges like?

- Could you tell me a bit about the nature of less frequent, but perhaps more serious challenges?

3. CIT: Can you tell me about a significant challenge or crisis that required you/your employees to respond in an adaptive and resilient way?

4. Part of what I want to understand is the response in the context of this challenge or crisis, so starting with you, how did you respond - what kind of action or support was required? Did collaboration help?

- How did your team/those you manage respond?

o Did they seek your help/support?

- What did you learn from this incident?

- What would have improved the overall response to this incident, if anything?

0 Leadership generally?

- Based on your experience, what kind of things make it harder to respond effectively to challenge?

5. Leadership in context of incident:

- What kind of role did your own manager play in your response to this situation?

o What helped?

o Was there anything your manager did during this experience that made it even more challenging and difficult?

o Why/how was this behaviour unhelpful? 


\section{D.2: Interview Guide (Phase 3)}

Thanks for meeting with me today, this interview should only last about half an hour, if it goes over we can cut it short or keep going depending on how it goes...

I take it you already know a bit about the study from the information sheet but to clarify - I am mostly interested in what managers and organisations can do to help people grow and remain resilient at work.

I thought it would be good to start with some general questions about the work you do.

1. What do you do at [name of organisation]?

a. How long have you been here?

b. Could you tell me a bit about what you like/dislike about working in the public sector?

I would like you to answer the following main questions like you would a questionnaire, with your response ranging from 'Not at all' to 'To a large extent'. After each main question, a series of probing questions will follow.

1.

a. To what extent does your manager foster collaboration in your workgroup?

b. Why? (if yes, why do you think this occurs?; if no, why does this not occur?)

c. How? (How do they/How don't they do this?)

2.

d. What impact does this have on you?

a. To what extent does your manager enable self-management?

b. Why? (if yes, why do you think this occurs?; if no, why does this not occur?)

c. How? (How do they/How don't they do this?)

d. What impact does this have on you?

3.

a. To what extent does your manager facilitate career and growth opportunities?

b. Why? (if yes, why do you think this occurs?; if no, why does this not occur?)

c. How? (How do they/How don't they do this?)

d. What impact does this have on you?

4.

a. To what extent does your manager foster an environment in which learning is encouraged?

b. Why? (if yes, why do you think this occurs?; if no, why does this not occur?)

c. How? (How do they/How don't they do this?)

d. What impact does this have on you?

5.

a. To what extent do you feel supported by your manager?

b. Why? (if yes, why do you think this occurs?; if no, why does this not occur?)

c. How? (How do they/How don't they do this?)

d. What impact does this have on you?

6.

a. To what extent does your manager recognize your individual needs and contributions?

b. Why? (if yes, why do you think this occurs?; if no, why does this not occur?)

c. How? (How do they/How don't they do this?)

d. What impact does this have on you? 


\section{APPENDIX E: ETHICS DOCUMENTS (PHASE 4)}

\section{E.1: Participant information sheet (Phase 4: Focus Groups)}

\section{Building employee resilience in the public sector Focus group and interview information sheet}

My name is Esme Franken, and I am conducting research as part of a $\mathrm{PhD}$ thesis in Management. I am studying what public sector managers and organisations can do to help employees grow and develop in their jobs.

I am asking a number of people with expertise in public sector work and leadership to comment and give feedback on a set of supervisory behaviours I have developed that may help or hinder growth and development. Anyone who is working in the public policy sphere, studying HR management or leadership, or an academic in a related field is welcome to participate.

This stage of the project involves a meeting that should not exceed more than an hour. It will be undertaken at a meeting room in VUW and will be recorded. A summary will be available on request and you can give comments and feedback if you wish.

All material collected will be kept confidential, and will be viewed only by myself and my supervisors. The project is based at Victoria University of Wellington, and is being conducted as part of a $\mathrm{PhD}$ in the School of Management.

Should you participate, your identity will be kept confidential. In addition to this, the name of your employer will not be made open to the public. I will not use any quotations where participants or their employer can be identified. Should you wish to withdraw from the project, you may do so up until commencement of the focus group discussion by emailing esme.franken@vuw.ac.nz. If you withdraw during the focus group, any comments made by you will not be able to be withdrawn from the study. All data collected from participants will be kept in a password protected file and will be destroyed within 5 years after the completion of the project.

To participate in this research, you must agree that the identity and comments made by others are kept private and confidential outside of the focus group session. After the focus groups and other data are analysed the findings may be used for academic publications, conference presentations, and public reports. The findings of this research will be used for a $\mathrm{PhD}$ thesis that is publically available. The thesis will be submitted for marking to the School of Management, and subsequently deposited in the University Library.

This research has been approved by the Victoria University Human Ethics Committee with approval number (0000025909). Should you have any ethics queries, you are welcome to contact HEC Convener Dr Judith Loveridge (judith.loveridge@vuw.ac.nz; 04 4636028).

Please do not hesitate to contact the researcher or primary supervisor (details below) if you have any questions.

\author{
Researcher: \\ Esme Cleave, School of Management, Victoria \\ University of Wellington \\ esme.cleave@vuw.ac.nz
}

\section{Primary Supervisor:}

Dr Geoff Plimmer, School of Management, Victoria University of Wellington, 463-5700, geoff.plimmer@vuw.ac.nz 


\title{
E.2: Participant consent form (Phase 4: Focus Groups)
}

\author{
Building employee resilience in the public sector \\ Participant Consent Form - Focus groups and interviews
}

I have read the Information Sheet and the project has been explained to me. My questions have been answered to my satisfaction. I understand that I can ask further questions at any time.

I understand that:

- I may withdraw from this study up until commencement of the focus group discussion.

- If I withdraw during the focus group discussion, any comments I have made will not be able to be withdrawn from the research.

- The information I provide will be destroyed within 5 years after the research is finished.

- Any information I provide will be kept confidential to the researcher and the supervisors.

- Collected data will be secured in password protected files.

- The results will be used for a PhD thesis and a summary of the results may be used in academic reports and/or presented at conferences.

- My name will not be used in reports, nor will any information that would identify me.

I agree:

- To take part in an audio recorded focus group session

- That I may be identified by occupational category (job type) only

- To keep the identity and comments of other participants private.

I would like a summary of the focus group and have added my email address below

Yes $\square$ No

Signature of participant:

Name of participant:

Date:

Email address (optional):

Researcher:
Esme Cleave, School of Management, Victoria
University of Wellington
esme.cleave@vuw.ac.nz

Primary Supervisor:

Dr Geoff Plimmer, School of Management, Victoria University of Wellington, 463-5700, geoff.plimmer@vuw.ac.nz 


\section{APPENDIX F: PHASE 4 CONTENT}

\section{F.1: Information for Participants (Phase 4: Focus Groups and Interviews)}

The purpose of this meeting is to discuss, confirm and contrast my findings to date. So far, I have identified a set of supervisory behaviours that seem to enable resilient behaviours in employees (see Table C and D below). I will ask your thoughts on the supervisory behaviours (Table D) that I've identified, including what you think they look like in practice (i.e. do the current examples make sense to you?), whether they need to be worded differently or changed, and whether you have any other specific examples that relate to any of the identified behaviours.

Table C: Resilient employee behaviours

\begin{tabular}{|c|c|}
\hline $\begin{array}{l}\text { Resilient } \\
\text { behaviour }\end{array}$ & Behavioural examples \\
\hline \multirow{5}{*}{$\begin{array}{l}\text { Network } \\
\text { leveraging } \\
\text { ability }\end{array}$} & Collaborating internally with peers, managers and teams \\
\hline & Collaborating with people and teams in other organisations \\
\hline & Seeking support from managers when required \\
\hline & Exchanging resources with peers and managers \\
\hline & Seeking resources from peers \\
\hline \multirow[t]{2}{*}{ Learning } & Using mistakes as learning opportunities \\
\hline & $\begin{array}{l}\text { Re-evaluating performance on a continuous basis to improve own work } \\
\text { Using feedback, including negative feedback, for learning and } \\
\text { improvement of own work }\end{array}$ \\
\hline \multirow[t]{3}{*}{ Adaptability } & $\begin{array}{l}\text { Managing resources effectively in order to cope with high workloads } \\
\text { when needed }\end{array}$ \\
\hline & Engaging in crisis management effectively \\
\hline & Using change as an opportunity for growth \\
\hline
\end{tabular}

Adapted from Näswall, Kuntz, Hodliffe, \& Malinen (2015) and Kuntz et al. (2017). 


\section{F.1 cont.: Information for Participants (Phase 4: Focus Groups and Interviews)}

\section{Table D: Resilience-enabling supervisory behaviours identified through initial survey and interviews}

\begin{tabular}{l|l}
\hline $\begin{array}{l}\text { Supervisory } \\
\text { behaviour }\end{array}$ & \multicolumn{2}{l}{ Examples (Items) } \\
\hline $\begin{array}{l}\text { Fostering } \\
\text { collaboration }\end{array}$ & $\begin{array}{l}\text { My manager encourages our team to work collectively when } \\
\text { appropriate } \\
\text { My manager expects me to collaborate with others when necessary } \\
\text { My manager involves themselves in collaboration with the team } \\
\text { My manager sets tasks which require us to work together }\end{array}$ \\
\hline $\begin{array}{l}\text { Enabling self- } \\
\text { management }\end{array}$ & $\begin{array}{l}\text { My managers gives guidance that is focused on outcomes, rather than } \\
\text { processes } \\
\text { My manager trusts me to achieve outcomes } \\
\text { My manager supports me when I need it } \\
\text { My manager knows what I am capable of } \\
\text { My manager lets me get on with my work } \\
\text { My manager does not micromanage }\end{array}$ \\
\hline $\begin{array}{l}\text { Fostering an } \\
\text { learnironment for }\end{array}$ & $\begin{array}{l}\text { My manager values the knowledge I bring to the team } \\
\text { When I make a mistake, my manager stays calm } \\
\text { When I make a mistake, my manager helps me to learn from it } \\
\text { My manager shows a general openness toward learning }\end{array}$ \\
\hline $\begin{array}{l}\text { Facilitating } \\
\text { growth and } \\
\text { opportunities }\end{array}$ & $\begin{array}{l}\text { I have open conversations with my manager about my future career } \\
\text { plans } \\
\text { My manager supports me to seek out opportunities for training and } \\
\text { development } \\
\text { My manager supports me to go on courses for training and } \\
\text { development }\end{array}$ \\
\hline $\begin{array}{l}\text { Providing support } \\
\text { individual needs } \\
\text { and contributions }\end{array}$ & $\begin{array}{l}\text { My manager backs the work decisions I make } \\
\text { My manager supports my personal needs } \\
\text { I feel comfortable talking honestly with my manager when I need } \\
\text { their advice } \\
\text { I feel comfortable seeking help from my manager } \\
\text { contributions provides recognition that is specific to my real } \\
\text { My manager trusts me to do my own work well } \\
\text { Where possible, my manager is good at providing me with } \\
\text { meaningful non-monetary rewards }\end{array}$ \\
\hline
\end{tabular}




\section{F.3: Consultation document (Phase 4: Written Feedback)}

\section{Introduction}

Thank you for agreeing to provide expert commentary on the development of the "Resilience-enabling leadership scale". The aim of this thesis project is to identify items. Your commentary on the following would be greatly appreciated:

1. The draft items and dimensions for the scale (Table 1) in terms of readability and content validity.

2. Any additional comments in the proposed quantitative survey design (Phase 5), including comparative leadership constructs

\section{Background}

This thesis is comprised of four key phases of research. The research purpose is to develop a scale measuring resilience-enabling leadership. In other words, it seeks to identify leadership behaviours which help employees to behave resiliently in their jobs. Employee resilience has been defined as "the capacity of employees to utilise resources to continually adapt and flourish at work, even when faced with challenging circumstances" (Kuntz, Näswall, \& Malinen, 2016, p. 460). This is a capacity that is developable by factors, such as leadership, that exist in one's work context.

The descriptions below outline the processes used in the development of this scale. I am aware of a number of comparable leadership scales and constructs, but not of any which logically appear to foster resilience in employees

\section{Phase 1 - Quantitative survey on paradoxical leadership and resilience}

Phase 1 consisted of a quantitative survey administered in a large public sector organisation in New Zealand. This phase quant-tested the relationships between leadership behaviours and employee resilience. Although valuable insights were gained in this phase, such as the effect of paradoxical leadership on employee resilience, this deductive model did not sufficiently explain the wider phenomenon of resilience-enabling leadership. Thus, qualitative inquiry was seen as necessary to further identify, refine, and explain this concept of resilience-enabling leadership and whether or not it really is paradoxical in nature.

Phase 2 - Qualitative interviews on resilience enhancing leadership

Phase 2 involved 10 interviews with both employees and managers. This explored the nature of resilience-enabling leadership behaviours in the public sector context using the critical incident technique. Informed by both Phase 1 findings and emergent responses from Phase 2 participants, a taxonomy of six key resilience-enabling leader behaviours was developed. The behavioural dimensions of this taxonomy consist of managers: managing the whole team, managing stretch goals and safe failures, supporting personal growth and wellbeing, enabling self-management, and recognising individual needs and contributions.

Phase 3 - Further interviews with employees on causal mechanisms

In Phase 3, 10 more interviews were carried out to explore the mechanisms behind these behaviours, and in what ways they might impact resilient employee behaviours. It sought to identify leadership behaviours from employees' point of view. Perceptions regarding how they experienced such behaviours, if they did indeed experience them, were of particular interest, as well as perceptions of the outcomes these behaviours had on their own resilience. An explanatory framework of resilience-enabling leadership was developed 
out of the initial behavioural taxonomy. This explanatory framework comprised the mechanisms by which the behaviours were experienced by participants.

\section{Phase 4 - Focus group and interviews on item validity}

Phase 4 comprised of 2 focus groups and 6 individual interviews with managers or reports $(n=13)$. Its primary aim was to confirm, modify, and help validate the explanatory framework for scale development (DeVellis, 2017). 29 items resulted from this phase of inquiry, which represented mechanisms behind the identified leadership behaviours. These are shown in the table below.

Table 1: Resilience-enabling leadership behaviours: Dimensions and items

\begin{tabular}{l|l}
\hline Leadership behaviour & Examples (Items) \\
\hline $\begin{array}{l}\text { Managing the whole } \\
\text { team }\end{array}$ & $\begin{array}{l}\text { helps to create an environment where I want to collaborate } \\
\text { encourages our team to work collectively } \\
\text { expects me to work with others } \\
\text { involves themselves in collaboration with the team } \\
\text { sets tasks which encourage us to work together } \\
\text { is good at managing conflict within the team } \\
\text { assists me in developing broader networks }\end{array}$ \\
\hline $\begin{array}{l}\text { Enabling self- } \\
\text { management }\end{array}$ & $\begin{array}{l}\text { gives guidance that is focused on outcomes, rather than processes } \\
\text { trusts me to achieve outcomes } \\
\text { knows what I am capable of } \\
\text { lets me get on with my work } \\
\text { does not micromanage }\end{array}$ \\
\hline $\begin{array}{l}\text { Managing stretch } \\
\text { goals and safe failures }\end{array}$ & $\begin{array}{l}\text { values the knowledge I bring to the team } \\
\text { stays calm when I make a mistake } \\
\text { helps me to learn from mistakes I make } \\
\text { shows a general openness toward learning }\end{array}$ \\
\hline $\begin{array}{l}\text { Supporting personal } \\
\text { growth }\end{array}$ & $\begin{array}{l}\text { has open conversations with me about my future career plans } \\
\text { encourages me to seek out opportunities for my development } \\
\text { looks out for new opportunities for me to be exposed to } \\
\text { values my career aspirations }\end{array}$ \\
\hline $\begin{array}{l}\text { Recognising } \\
\text { individual needs and } \\
\text { contributions }\end{array}$ & $\begin{array}{l}\text { backs the work decisions I make } \\
\text { supports my personal needs } \\
\text { I feel comfortable talking honestly with my manager when I need } \\
\text { it } \\
\text { I feel comfortable seeking help from my manager }\end{array}$ \\
\hline $\begin{array}{l}\text { cares about me as a person } \\
\text { palues my differences } \\
\text { provides me with individualised feedback } \\
\text { is govides recognition that is specific to my real contributions } \\
\text { where possible }\end{array}$ \\
\hline
\end{tabular}




\section{Phase 5}

The next phase is a quantitative validation study of the resilience-enabling leadership scale, and an analysis of its consequences.

This particular phase is informed by the steps in scale development suggested by De Vellis (2017), Step 5 of which is having the initial item pool reviewed by experts. Following this, the items will be administered in a pilot survey to a development sample (De Vellis, 2017).

\section{Expert commentary sought}

In relation to the information given above, can you please provide comments on:

1. The draft items and dimensions for the scale (Table 1) in terms of readability and content validity.

2. Any additional comments in the proposed quantitative survey design (Phase 5), including comparative leadership constructs

Your help and consideration is greatly appreciated. Please let me know if you have any questions or further comments,

Esme Franken

Esme.Franken@vuw.ac.nz 


\section{APPENDIX G: ETHICS DOCUMENTS AND CONTENT (PHASE 5)}

\section{G.1: Pilot survey email}

\section{Dear [name/member of affiliation]}

Victoria University is researching what challenges public sector organisations and their employees face, and what organisations can do to help employees grow and develop in their jobs.

This survey should not take any longer than 15 minutes to complete (probably less). Your participation would be much appreciated - please have your say.

- If a question is not relevant to you -- please move on to the next question.

- You can close the survey tab or window at any time and return to it later. Your answers will be saved (to reload your survey, simply access the link sent to you in the invitation email).

- When you have completed the survey, you will be presented with a message thanking you for your participation.

This survey of present and former public servants is anonymous: Your name will not be attached to survey results. Data will be secured in a password protected file. Only summary information about patterns and trends across the organisation will be reported. Summary results will be reported to [name of network].

Please click the following link if you would like to participate in the survey: [link]

After the survey responses are analysed the findings may also be used for academic publications, conference presentations, and public reports. The findings of this research will be used for a $\mathrm{PhD}$ thesis that is publicly available. All data collected from participants will be kept in a password protected file and will be destroyed within 5 years after the completion of the project.

Your answers to this survey will be anonymous. Your participation in this survey is taken as consent.

This research has been approved by the Victoria University Human Ethics Committee with approval number (0000025909). Should you have any ethics queries, you are welcome to contact HEC Convener Dr Judith Loveridge (judith.loveridge@vuw.ac.nz; 04 4636028).

Please do not hesitate to contact Esme Franken or Dr Geoff Plimmer (details below) if you have any further questions:

Esme Franken, School of Management, Victoria University of Wellington esme.franken@vuw.ac.nz

Dr Geoff Plimmer, School of Management, Victoria University of Wellington geoff.plimmer@vuw.ac.nz 


\section{G.2: Final survey email}

Dear [member of network],

Victoria University is researching challenges facing public sector organisations and their employees, and what organisations can do to help employees grow and develop in their jobs

This survey should not take any longer than 15 minutes to complete. Your participation would be much appreciated - please have your say.

- Try to answer as many questions as possible. There are no right or wrong answers, we are interested in your perception.

- If a question is not relevant to you -- please move on to the next question.

- You can close the survey tab or window at any time and return to it later. Your answers will be saved (to reload your survey, simply access the link sent to you in the invitation email).

- When you have completed the survey, you will be presented with a message thanking you for your participation.

This survey of present and former public servants is anonymous: Your name will not be attached to survey results. Data will be secured in a password protected file. Only summary information about patterns and trends across the organisation will be reported. Summary results will be reported to [name of network]. Your participation in this survey is taken as consent.

Please click the following link if you would like to participate in the survey: http://vuw.qualtrics.com/jfe/form/SV 8d0cjl566Yf1DlH

After the survey responses are analysed the findings may also be used for academic publications, conference presentations, and public reports. The findings of this research will be used for a $\mathrm{PhD}$ thesis that is publicly available. All data collected from participants will be kept in a password protected file and will be destroyed within 5 years after the completion of the project. This research has been approved by the Victoria University Human Ethics Committee with approval number (0000025909). Should you have any ethics queries, you are welcome to contact HEC Convener Dr Judith Loveridge (judith.loveridge@vuw.ac.nz; 04 4636028).

Please do not hesitate to contact Esme Franken or Dr Geoff Plimmer (details below) if you have any further questions:

Esme Franken, School of Management, Victoria University of Wellington esme.franken@vuw.ac.nz

Dr Geoff Plimmer, School of Management, Victoria University of Wellington geoff.plimmer@vuw.ac.nz 


\section{APPENDIX H: PILOT STATISTICS}

Table E: Descriptive statistics for resilience-enabling leadership

\begin{tabular}{|c|c|c|c|c|c|}
\hline The manager I report to ... & $\mathbf{N}$ & Min & Max & Mean & $\begin{array}{l}\text { Std. } \\
\text { Deviation }\end{array}$ \\
\hline acts calm when I make a mistake & 30 & 2 & 7 & 5.51 & 1.10 \\
\hline helps me to learn from mistakes I make & 30 & 4 & 7 & 5.91 & .52 \\
\hline shows a general openness toward learning & 30 & 5 & 7 & 6.09 & .61 \\
\hline gives guidance that is focused on outcomes & 30 & 3 & 7 & 5.49 & .96 \\
\hline trusts me to achieve outcomes & 30 & 3 & 7 & 6.07 & .79 \\
\hline knows what I am capable of & 30 & 2 & 7 & 5.56 & 1.22 \\
\hline lets me get on with my work & 30 & 3 & 7 & 5.99 & 1.08 \\
\hline does not micromanage & 30 & 3 & 7 & 6.00 & 1.01 \\
\hline expects me to work with others & 30 & 6 & 7 & 6.40 & .46 \\
\hline $\begin{array}{l}\text { helps to create an environment where I want to } \\
\text { collaborate }\end{array}$ & 30 & 4 & 7 & 5.97 & .72 \\
\hline encourages our team to work collectively & 30 & 4 & 7 & 6.05 & .77 \\
\hline involves themselves in collaboration with the team & 30 & 3 & 7 & 5.61 & .98 \\
\hline sets tasks which encourage us to work together & 30 & 2 & 7 & 5.19 & 1.08 \\
\hline manages conflict within the team & 30 & 2 & 7 & 4.79 & 1.29 \\
\hline assists me in developing broader networks & 30 & 1 & 6 & 4.29 & 1.31 \\
\hline $\begin{array}{l}\text { has open conversations with me about my future } \\
\text { career plans }\end{array}$ & 30 & 2 & 7 & 5.44 & 1.24 \\
\hline $\begin{array}{l}\text { encourages me to seek out opportunities for my } \\
\text { development }\end{array}$ & 30 & 1 & 7 & 5.41 & 1.44 \\
\hline $\begin{array}{l}\text { looks out for new opportunities for me to be exposed } \\
\text { to }\end{array}$ & 30 & 1 & 7 & 4.82 & 1.48 \\
\hline values my career aspirations & 30 & 1 & 7 & 5.07 & 1.44 \\
\hline backs the work decisions I make & 30 & 2 & 7 & 5.75 & 1.09 \\
\hline supports my personal needs & 30 & 2 & 7 & 5.89 & 1.10 \\
\hline makes me feel comfortable talking honestly to them & 30 & 4 & 7 & 5.96 & .72 \\
\hline makes me feel comfortable seeking help from them & 30 & 4 & 7 & 6.01 & .65 \\
\hline cares about me as a person & 30 & 2 & 7 & 5.90 & 1.16 \\
\hline values my differences & 30 & 3 & 7 & 5.83 & .86 \\
\hline provides me with individualised feedback & 30 & 2 & 7 & 5.70 & .89 \\
\hline $\begin{array}{l}\text { provides recognition that is specific to my real } \\
\text { contributions }\end{array}$ & 30 & 2 & 7 & 5.63 & 1.17 \\
\hline $\begin{array}{l}\text { is good at providing me with meaningful non- } \\
\text { monetary rewards where possible }\end{array}$ & 30 & 1 & 7 & 5.08 & 1.26 \\
\hline
\end{tabular}




\section{APPENDIX I: MODIFICATION INDICES, CFA MODEL COMPARISON}

Table F: Model comparisons

\begin{tabular}{lccccc}
\hline Model & $\chi^{2} / \mathbf{d f}$ & CFI & GFI & RMSEA & RMR \\
\hline Three-Factor 15-item EFA Model & $602.87 / 87$ & .92 & .85 & .12 & .14 \\
\hline Checking error covariances & & & & & \\
\hline Covary E1 and E2 & $577.47 / 86$ & .92 & .85 & .11 & .13 \\
Covary E2 and E3 & $559.82 / 85$ & .92 & .86 & .11 & .13 \\
Covary E4 and E5 & $531.40 / 84$ & .93 & .86 & .11 & .12 \\
Covary E7 and E8 & $506.68 / 83$ & .93 & .87 & .11 & .13 \\
Covary E8 and E9 & $482.34 / 82$ & .94 & .88 & .11 & .12 \\
Covary E8 and E11 & $458.77 / 81$ & .94 & .89 & .10 & .13 \\
Covary E9 and E11 & $400.63 / 80$ & .95 & .90 & .10 & .11 \\
Covary E9 and E10 & $359.19 / 79$ & .95 & .91 & .09 & .11 \\
Covary E11 and E13 & $339.89 / 78$ & .96 & .91 & .09 & .10 \\
Covary E16 and E17 & $326.76 / 77$ & .96 & .92 & .09 & .10 \\
Covary E9 and E13 & $300.58 / 76$ & .96 & .92 & .08 & .09 \\
\hline Final model & & & & & \\
\hline Three-Factor 15-item CFA Model & $300.58 / 76$ & .96 & .92 & .08 & .09 \\
\hline Comparing to alternative model & & & & & \\
\hline Single-Factor 15-item CFA Model & $1666.54 / 90$ & .74 & .58 & .20 & .18 \\
\hline
\end{tabular}

